Portland State University

PDXScholar

$11-1-1996$

\title{
The Constraints of a Typological Implicational Universal for Interrogatives on Second Language Acquisition
}

Dee Anne Bess

Portland State University

Follow this and additional works at: https://pdxscholar.library.pdx.edu/open_access_etds

Part of the Bilingual, Multilingual, and Multicultural Education Commons Let us know how access to this document benefits you.

Recommended Citation

Bess, Dee Anne, "The Constraints of a Typological Implicational Universal for Interrogatives on Second Language Acquisition" (1996). Dissertations and Theses. Paper 5086.

https://doi.org/10.15760/etd.6962

This Thesis is brought to you for free and open access. It has been accepted for inclusion in Dissertations and Theses by an authorized administrator of PDXScholar. Please contact us if we can make this document more accessible: pdxscholar@pdx.edu. 


\section{THESIS APPROVAL}

The abstract and thesis of Dee Anne Bess for the Master of Arts in TESOL were presented November 1, 1996, and accepted by the thesis committee and the department.

COMMITTEE APPROVALS:
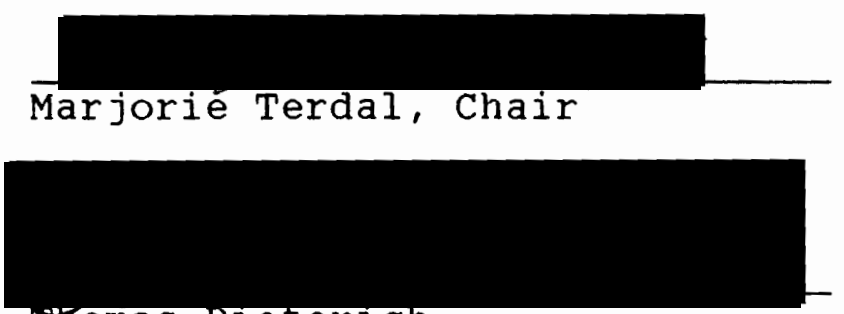

Homas Dieterich

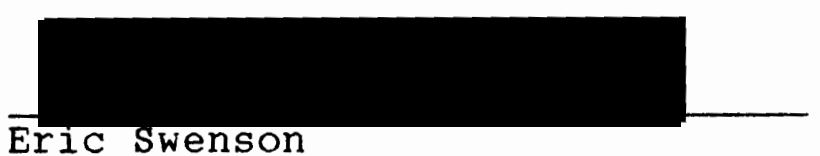
Representative of the office of Graduate studies

DEPARTMENT APPROVAL:

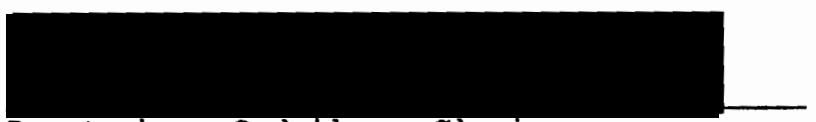

Beatrice Oshika, Chair

Department of Applied Linguistics

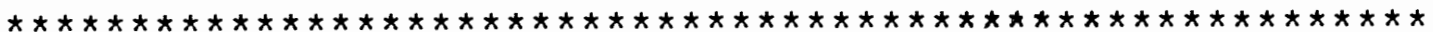

ACCEPTED FOR PORTLAND STATE UNIVERSITY BY THE LIBRARY

by

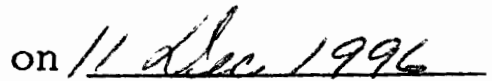




\begin{abstract}
An abstract of the thesis of Dee Anne Bess for the Master of Arts in TESOL presented November 1, 1996.

Title: The Constraints of a Typological Implicational Universal for Interrogatives on second Language Acquisition
\end{abstract}

A typological implicational universal based on a diverse sample of the world's languages describes a hierarchy for interrogatives. The universal hierarchy states that in any given language, inversion in Yes-No questions (YNQS) implies inversion in information questions (WHQs in English), which, in turns implies the fronting of the information word pronoun to sentenceinitial position.

Several researchers have proposed that typological implicational universals such as this one for interrogatives may constrain not only the primary languages on which they are based, but also the interlanguages of second language learners. 
This study, a partial replication of one by Eckman, Moravcsik, and wirth (1989), examined second language acquisition data to determine whether constraints of the interrogative universal were evident in the interlanguages of learners of English as a second language. It was hypothesized that learners' control of WH-word fronting would exceed their control of WHQ inversion, which, in turn, would exceed their control of YNQ inversion.

Data were elicited in oral interviews with 32 Japanese-speaking learners of English. The task of the subjects during the interviews was to ask questions in order to discover the story partially told by a grid of puzzle-like drawings. The interviews were tape-recorded, the recordings transcribed, and the transcribed interrogative forms analyzed. Two methods of data analysis showed strong support for the hypothesis. A third method of analysis revealed that seven subjects produced patterns of interrogatives not predicted by the universal; six of the exceptions could be resolved using an argument also used by Eckman et al. (1989) in explaining their exceptions. 
THE CONSTRAINTS OF A TYPOLOGICAL IMPLICATIONAL UNIVERSAL FOR INTERROGATIVES ON SECOND LANGUAGE ACQUISITION

by

DEE ANNE BESS

A thesis submitted in partial fulfillment of the requirements for the degree of

\author{
MASTER OF ARTS \\ in \\ TESOL
}

\author{
Portland state University \\ 1996
}




\section{DEDICATION}

This thesis, about universals,

is dedicated to God

Who, in the sovereign systematicity

of His creative order,

designed them. 


\section{ACKNOWLEDGEMENTS}

To the following people, who gave of themselves to help me with this project, I offer my deepest appreciation and sincere thanks:

Michael $W$. Bess, my loving and long-suffering husband and chief research assistant. I'm afraid there do not exist words apt enough to express my thanks to you, my Bear. Thank you for the blessings of your support, sacrifice, encouragement, and agape love. You're my treasure.

My Mom, Doris Senn, for her prayers and encouragement and her painstaking proof-reading (any remaining errors are mine).

MY Dad, Earle Senn, for his prayers and encouragement, checking the reference list against the text, making the poster for my defense meeting, and for springing into action to possibly replace the ailing computer.

Dad and Mom Bess for their encouragement and prayers.

Dr. Marge Terdal, my advisor and teacher par excellence.

Dr. Thomas Dieterich and Dr. Eric Swenson, my patient, instructive, and highly-appreciated thesis committee members.

Dr. Satyanarayan, Tom Pettey, and Bruce Thomas for their help in God's ongoing healing of my body and brain after the car accident which delayed the completion of this project for a year.

Mike and Barbie, Bill and Norma, Dan and Calvina, Alexandra, and Mieko for their prayers and encouragement.

Toyoko and steve Roberts for translating the Consent Form, and for their encouragement and prayers.

Yakentim Ibrahim for his suggestions that finally cured the ailing computer. I still owe him some guava sauce. 
Mari Balke for interviewing several subjects, as well as for her bilingual and bi-cultural expertise used in encouraging the spring Break study program teachers to allow their students to participate and in translating during the practice session.

Kenichi Mizutani and Kikue Yoda for the video-taped practice session.

Masa for the vocabulary cards.

Informants who shared information about their native languages: Suwako Watanabe, Dr. Sbait, Monika Emmi, Sergei Polozov, Tuyen (thanks to Ruth Chapin!), Mieko Takagi, and Xue-Qing Peng.

Patty schlimpert for allowing me to include her spring Break study Program students in my study.

Randy Bush for tracking down all those ILL books.

Harry witt for providing the recording and AV equipment.

Mickie Bush for scheduling the necessary rooms.

Don Crites for his encouraging prayer and help during the computer crisis.

Jay Peterson for finding the teacher's edition of story squares without which I never could have figured out the stories.

Jane Dresser for suggesting that I contact Jay and proposing possible alternate elicitation tools.

Susan Gelder and Marjo Philips for arranging my meeting with one of my pilot study participants.

My three pilot study participants, 32 subjects, and the other two who would have been had the tape-recorder worked.

The teachers of the spring Break study Program for allowing their students to participate.

All family members, friends, and colleagues who provided emotional support, encouragement, and prayers along the way.

Thank you, all. I couldn't have done it without you! 
TABLE OF CONTENTS

PAGE

ACKNOWLEDGEMENTS . . . . . . . . . . . . . . iii

LIST OF TABLES . . . . . . . . . . . . . . . . iX

LIST OF FIGURES . . . . . . . . . . . . . . . xiii

CHAPTER

I INTRODUCTION . . . . . . . . . . . . . 1

Opening summary . . . . . . . . . . 1 .

Background . . . . . . . . . . . 2

The Role of Universals in SLA

Typological Implicational

This Study

Definition of Terms . . . . . . . . . 9

Statement of Hypothesis........ 11

II REVIEW OF THE LITERATURE . . . . . . . . . 13

Introduction . . . . . . . . . . 13

Universals . . . . . . . . . . 13

Process Universals

Chomskyan Universals

Typological Universals

The Basis for Application of

TIUS to SLA

Studies of TIUS And SLA . . . . . . . 24

The Accessibility Hierarchy

TIU for Relative Clauses

SLA Studies Involving other TIUs 


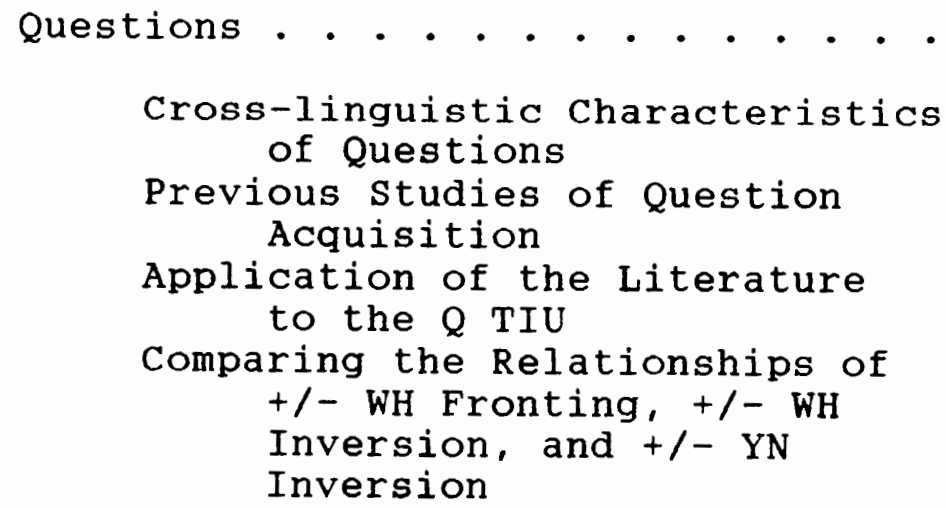


Restatement of the Hypothesis . . . . 167

Analysis of the Data . . . . . . . 170

Introduction

Percentage of WH Fronting

Percentage of $W H$ Inversion

Percentage of YN Inversion

Counts and Percentages of $\mathrm{WH}$

Fronting and WH Inversion

Counts and Percentages of WH

Inversion and $\mathrm{YN}$ Inversion

The status of the Hypothesis:

Introduction

The status of the Hypothesis:

Absolute Existence

Interpretation

The status of the Hypothesis:

Relative Existence

Interpretation

The status of the Hypothesis:

A Whole Group Approach

The status of the Hypothesis:

Another Type of Exception

to the TIU

The status of the Hypothesis:

A Summary

Incidental Findings: Introduction

Summary . . . . . . . . . . . 239

V SUMMARY AND CONCLUSIONS . . . . . . . . . 241

Introduction . . . . . . . . . . 241

Limitations . . . . . . . . . . 241

Limitations Due to Characteristics

of the Subjects

Limitations Due to the Type and

Quantity of Data obtained

Limitations Due to Methods and

Techniques of the Study

Limitation to the Target structure

Implications . . . . . . . . 265

Implications for Linguistic Theory

Implications for SLA Research

Implications for Teaching ESL 
Avenues for Further Research . . . . . 271

Further Research to Reconfirm

the $Q$ TIU

Further Research on Question

Acquisition in General

Further Research on other TIUs

Summary of the Project . . . . . . . 277

REFERENCES • • • • • • • • • • • • • • • • 281

APPENDIXES

A Acronyms Used in this Thesis... . . 293

B Summary of Category Names and

Definitions........... 296

C Story Squares: Basic Information, Complete stories, and Picture Grids . . . . . . . . . . 298

D Story Square Instructions . . . . . . . . 315

E The 64 Original "Problem" Categories and their Final Classifications . . . 319

F Transcript Conventions and sample

Transcript . . . . . . . . . 328 
$\square$ 


\section{LIST OF TABLES}

TABLE

PAGE

1 Stages of Question Acquisition as

Presented by Larsen-Freeman

\& Long . . . . . . . . . . . 48

2 Stages of Question Acquisition as

Presented by Pienemann \&

Johnston. . . . . . . . . . 48

3 Stages of Question Acquisition as

Presented by Wode . . . . . . . 49

4 SLA Stages Inferred from the Q TIU . . . . 56

5 Sample of the Original 64 Category

Types and Corresponding Utterances . 114

6 Absolute Number of Utterances in each

Category, by subject . . . . . . 169

7 Percentage of Frontedness and Total

Number of WHQs Used in Determining

Percentage of Frontedness with

Categories of Origin, by subject . • 175 
8 Percentage of WH Inversion and Total

Number of WHQS Used in Determining

Percentage of WH Inversion,

by subject . . . . . . . . . . . 177

9 Percentage of YN Inversion and Total

Number of YNQS Used in Determining

Percentage of YN Inversion,

by subject . . . . . . . . . 178

10 Utterance Counts and Percentages

of WH Fronting and WH Inversion . . 180

11 Utterance Counts and Percentages

of YN Inversion and WH Inversion . . 181

12 Absolute Existence Interpretation

status of Hypothesis 1a: WH

Inversion Implies WH Fronting . . . 185

13 Absolute Existence Interpretation

Status of Hypothesis 1b: YN

Inversion Implies WH Inversion . . . 188

14 Implicational scaling of all Three

structures of the TIU, ordered

by WH Fronting . . . . . . . . 190

15 Relative Existence Interpretation

Status of Hypothesis 1a: WH

Inversion Implies WH Fronting . . . 194 
16 Relative Existence Interpretation

status of Hypothesis 1b: YN

Inversion Implies WH Inversion . . . 196

17 Resolution of the Exceptions to the

Relative Existence Interpretation

of the TIU by the Addition or

subtraction of one "Insignificant,"

Hypothetical Data Item . . . . . . 198

18 Total TIU Analyzable Utterance Counts

for all Subjects $(n=32)$. . . . 209

19 Number, Type, and Total of UNAQs,

by subject . . . . . . . . . . . 224

20 Decreasing Average Number of UNAQ 1

Utterances for each More Advanced

stage of the TIU . . . . . . . . 226

21 Total Number of TIU and UNAQ

Utterances, with Percentage

of UNAQ Utterances . . . . . . . 228

22 Lower Percentage of UNAQ Utterances

for each More Advanced stage

of the TIU . . . . . . . . . . . 229

23 Type and Distribution of UNAQ 5

Utterances . . . . . . . . . . 233 
24 Number of Subjects Producing specific

Ranges of YNQs and WHQs

(Subjects $n=32$ ) . . . . . . . 246

25 Conforming Cases Changed to Exceptions

by the Addition or subtraction

of One Hypothetical Data Item . . . 252

26 Eckman et al. (1989): Conforming

Cases Changed to Exceptions by the

Addition or Subtraction of one

Hypothetical Data Item . . . . . . 255 


\section{LIST OF FIGURES}

FIGURE

PAGE

1. Underlying structure for questions such as "What is that object?"

(From Celce-Murcia\&

Larsen-Freeman, 1983) • . . . . 156

2. Break down of data into all categories,

with aggregate number of tokens

in each category . . . . . . . 168

3. Percentages of correct YN inversion,

WH inversion, and WH fronting for

all subjects combined $(n=32)$. . . 210 
CHAPTER I

\section{INTRODUCTION}

\section{OPENING SUMMARY}

This research project sought to determine whether or not a typological implicational universal for interrogatives that limits the variations of primary languages also constrains the interlanguages of second language learners. For this purpose, data rich in interrogative forms were needed. The data were elicited from students of English as a Second Language (ESL) by using story squares, grids of drawings that incompletely represent a mystery story. In individual, tape-recorded interviews, the subjects attempted to solve the mystery and discover the story by asking questions of the researcher. The taped sessions were then transcribed, and the subjects' transcribed questions were analyzed for their conformity to the universal. Another elicitation tool, a Grammaticality Judgement Test, was also administered but was not analyzed and is not reported on in this paper.

This investigation begins with a brief discussion, in this chapter, of the possible role of typological 
implication universals (TIUs) in second language acquisition (SLA). The review of the literature extends that discussion and, because the TIU considered in this project concerns interrogatives, provides information on the acquisition of question forms by second language learners. Following the review is a discussion that describes the instrument and materials employed in this study, records the procedures used for eliciting data from the subjects, and presents the rules and categories necessary for analyzing the data. Next, the results of the data analysis are reported and discussed. The paper concludes with a discussion of the limitations of this study: its implications for linguistic theory, SLA research, and for teaching ESL; suggestions for further research; and a summary of the entire investigation.

\section{BACKGROUND}

\section{The Role of Universals in SLA}

"The ultimate goal of second language acquisition research", says Gregg (1989, p. 15), "is the development of a theory of second language acquisition." An ideal theory would not only describe and explain the process of SLA, but would also be able to predict order of acquisition, areas of difficulty for learners, and errors. Thus SLA research, in hope of one day being able 
to predict SLA, focuses on describing and explaining second language (L2) data, or interlanguage (IL), the name given by Selinker $(1969,1972)$ to learner languages. However, even the tasks of describing and explaining are enormous. IL is so changeable, variable, and instable that Tarone (1979) calls it a chameleon. As we attempt to describe it, it changes color and squirms away before our very eyes. Is there systematicity in IL? Are there constraining factors in IL? L2 learners appear to have acquired a certain structure one moment and the next they "backslide" and do not correctly produce it. How can the tangle of L2 data be predicted or even described and explained?

\section{History}

In the early days of SLA theory, attempts at describing and explaining IL data involved the use of the Contrastive Analysis (CA) hypothesis (Lado, 1957). Wardhaugh (1974) distinguishes two versions of CA, the strong version and the weak version. The strong version involves contrasting the native language (NL) with the target language (TL) for the purpose of predicting areas of difficulty for the L2 learner, with the assumption that points of difference between the NL and the TL will cause difficulty for the learner. Language transfer, that is, transferring $\mathrm{NL}$ patterns into IL production, 
causes the learner to make errors where the NL and TL differ and assists the learner in learning the TL where the two languages are the same (Ellis, 1986; Flynn \& O'Neil, 1988; Lado, 1957). The weak version, on the other hand, does not claim any predictive powers, but rather uses the NL/TL differences simply as a way of explaining whatever difficulty the L2 learner experiences. The value of the weak version of $C A$ is scientifically limited since it is not falsifiable.

As researchers sought to confirm CA predictions through the examination of IL data, problems with the hypothesis became evident. Many of the errors that L2 learners made were not predicted by $C A$ and could not be attributed to transfer from their NLs. Likewise, many of the errors that CA predicted were not found in IL data at all Eckman, 1977, 1985; Oller \& Ziahosseiny, 1970; Whitman \& Jackson, 1972). As a result of these problems and the decline of the Behaviorism theory upon which CA was based, many language researchers abandoned the CA hypothesis entirely (Ellis, 1986; Gass, 1984; Wardhaugh, $1974)$ and new explanations for ILs were sought.

Dulay and Burt (1973) and Bailey, Madden, and Krashen (1974) offer evidence that L2 learners of English follow the same order of acquisition despite different NL backgrounds. This suggests that it is the structure of 
the TL and a universal degree of difficulty, rather than transfer from the NL, that determines L2 learners' errors in IL (Eckman, 1977). It also suggests that strategies and "creative construction" on the part of L2 learners influences IL production (Flynn \& O'Neil, 1988). However, Flynn (1987) points out that this creative Construction hypothesis cannot account for data in which transfer from the $N L$ is evident and that it does not specify what kind of principles govern the apparent order of L2 acquisition.

Although both the $C A$ and creative Construction hypotheses contributed to the solving of the SLA puzzle-$\mathrm{CA}$ through transfer and Creative construction through natural order and learner strategies--neither of these hypotheses could fully account for IL phenomenon. In the last decade or so, a third factor has become the most frequently mentioned explanation for ILs: language universals (Rutherford, 1984a).

\section{Typological Implicational Universals}

Typological language universals, the type of universal involved in this study, are based on studying the surface structures of many different primary languages (Comrie, 1989) and observing patterns that emerge across the languages. Many such universals are 
also implicational, that is, whenever structure $P$ is found in languages, that implies that structure $Q$ will also be in those languages. This is typically written as, if $P$, then $Q$ (Comrie, 1989, p. 17). The implied structure, $Q$, is more fundamental, easier, than the more marked, difficult structure, $P$, that implies it. Thus a hierarchy of the relative difficulty of the structures $P$ and $Q$ can be established.

\section{Studies of TIUs in SLA}

Previous research in SLA indicates that a TIU governing the possible types of relative clauses (RCs) in primary languages, the Accessibility Hierarchy for Relative Clauses (AH) (Keenan \& Comrie, 1977), also seems to constrain ILs and determine order of acquisition (Eckman, Bell, \& Nelson, 1988; Gass, 1979; Hansen, 1986; Pavesi, 1986). Therefore, the $A H$ may be seen as an explanation for relative clause data in ILs. A few similar studies further suggest that other syntactic universals and some phonological universals that restrict primary languages also apply to ILs (Eckman, 1977, 1984, 1991; Eckman, Moravcsik, \& Wirth, 1989; Schmidt, 1980).

This type of research, which attempts to demonstrate that the TIUs that constrain primary languages also constrain ILs, has several purposes. First, it seeks to confirm that ILs are indeed natural languages in the same 
way that primary languages are (Schmidt, 1980). In addition, it essays to provide additional support for the idea that universals are indeed universal, not merely over-exaggerated findings from a few languages (Eckman et al., 1989). It also seeks to contribute to an explanation for and a way of predicting SLA data (Eckman, 1984; Gass, 1984; Hawkins, 1987; Hyltenstam, 1990). Another purpose of this type of research is to establish the field of SLA as one that has valuable contributions to make to the discipline of theoretical linguistics (Eckman, 1993; Gass \& Ard, 1980; Rutherford, 1993).

\section{This study}

The present inquiry endeavors to further these purposes by partially replicating a 1989 study by Eckman, Moravcsik, and wirth that explores the relationship between a TIU for interrogatives ( $Q$ TIU) and IL data. According to the $Q$ TIU, the presence of subject-verb inversion in Yes-No questions (YNQS) in a language implies the presence of subject-verb inversion in information questions in that same language, which, in turn, implies the presence of the fronting of the information question pronoun. This relationship can be represented in the English language, in which information questions are WH-questions (WHQs) and information 
question pronouns are WH-words (such as who, what, and which), by the following notation:

$$
\text { WH fronting > WH inversion > YN inversion }
$$

(where > means "is implied by," wH fronting means the fronting of the wHQ pronoun to sentence-initial position, WH inversion means subject-verb inversion in wHQs, and $Y N$ inversion means subject-verb inversion in YNQs).

\section{The Question}

The question, then, is whether the IL data elicited in this study exhibit the constraints of the Q TIU. In other words, does the subjects' control of wh fronting imply their control of $\mathrm{WH}$ inversion, and does their control of wh inversion imply their control of $\mathrm{YN}$ inversion?

This question is of interest to the field of SLA because of its possibility of contributing to the largescale effort to find factors with predictive and explanatory power for ILs, as mentioned above. It is also of interest, of course, on the very specific level of determining the nature of the acquisition of interrogative structures. This is made even more interesting because, in contrast to the results of the study by Eckman et al. (1989) that indicate that the $Q$ TIU does constrain ILs, several researchers, including Pienemann and Johnston (1987), Chen (1986), and Tang 
(1991), claim that YN inversion is acquired before $W H$ inversion in English SLA, which is opposite of the order predicted by the TIU. Thus, the question remains open, and this study attempts to contribute to its answer.

\section{DEFINITION OF TERMS}

The following definitions explain the meanings of terms relevant to this paper. In addition, Appendix A contains a list of acronyms commonly used in this paper, along with their meanings.

Accessibility Hierarchy $(\mathrm{AH}):$ a universal order, established cross-linguistically by Keenan and Comrie (1977), that describes the order of the relativizability of Noun Phrase (NP) positions in primary languages. The highest, most readily relativized NPs are those in subject position. Therefore, subject relativization occurs most frequently across languages and within any given language; and thus, subject relativization is the least marked of the six possible relativizable positions existing in the $\mathrm{AH}$. The lowest, least relativized $\mathrm{NP}$ is the object of comparison, which is, therefore, the most marked. The four positions in between subject and object of comparison are progressively lower on the $\mathrm{AH}$, less readily 
relativized, less frequent, and more marked. Evidence exists that indicates that the $\mathrm{AH}$ order is also the order of acquisition for L2 learners. The order is commonly presented in the form, $S>S O>I O$ $>O O>$ GEN > OCOMP. (These symbols are further explained in the review of the literature.)

Interlanguage (IL): the highly variable, yet apparently systematic language of a second language learner. Typological implicational universal (TIU): a typological universal that contains a sequence of structures that are related in such a way that the presence of a structure later in the sequence implies tho presence of all the structures earlier in the sequence.

Typological Universals (Greenbergian universals): patterns that emerge across all languages or most languages when the surface structures of many different primary languages are compared. They constrain the possible variations of languages.

Universal: a pattern held in common that emerges crosslinguistically; a language universal in the typological or Greenbergian paradigm, i.e., not a Chomskyan, transformational, or "Universal Grammar" universal. 
WH fronting:

the sentence-initial/clause-initial. position of the question pronoun in wH questions.

WH inversion: the inversion of the subject and verb in a WHQ so that the question order is verb-subject instead of the subject-verb order of a declarative sentence.

Yes-No inversion (YN inversion): the inversion of the subject and verb in a YNQ so that the question order is verb-subject instead of the subject-verb order of a declarative sentence.

\section{STATEMENT OF HYPOTHESIS}

The general question explored by this study was whether the TIUs that constrain primary languages also constrain ILs. Since the scope of such a question is obviously too broad for a single study to answer, a more specific question involving only one particular TIU, the Q TIU, was addressed. The hypothesis proposed is as follows :

1. The interrogative TIU,

WH fronting > WH inversion > YN inversion, which constrains primary languages, will also constrain learners' ILs.

1a. Subjects' control of WH inversion will imply their control of wH fronting. 
1b. Subjects' control of YN inversion will imply their control of $\mathrm{WH}$ inversion.

The following chapter will detail further theoretical and empirical information necessary for understanding this study. 


\section{CHAPTER II}

\section{REVIEW OF THE LITERATURE}

\section{INTRODUCTION}

This chapter presents a review of the literature relevant to the current study, beginning with a look at the place of linguistic universals in general in SLA theory. The focus is then narrowed to an examination of TIUs, the type of universal considered in this study. Next the discussion focuses on studies that have explored the influence of TIUs on SLA data, as this study does. Finally, since the TIU in question pertains to interrogatives, information about question acquisition is presented.

\section{UNTVERSALS}

Discussion of three types of language universals may be found in the literature: process universals, Chomskyan universals, and typological universals. Hyltenstam (1987) suggests that due to the varying interpretations of the term "language universals," many studies of universals in SLA may be unclear since the particular genre of universals in question may not be specified by 
the researcher. In order to avoid lack of clarity, distinctions among the three types are briefly drawn below, followed by a more detailed account of TIUs in particular.

\section{Process Universals}

Process universals seem to find their roots in the Creative Construction hypothesis; central to each is that the L2 learner is actively involved in psychologically doing something, mostly subconsciously, with the language to be learned. In other words, language learning involves the use of strategies on the part of the learner. The process universals approach maintains that these strategies, being psychologically based, are the same, or universal, for all learners. While the strategies used by language learners must, indeed, play a role in learning a second language, such psychological processes are not able to be directly observed. This makes it very difficult for researchers to agree on a standard model, or even on what factors should be included in such a model. Seliger (1984) distinguishes between "communication strategies" and the strategies involving process universals and between universal processing strategies and "tactics" that differ from learner to learner and from time to time. Gass (1989) 
describes the Competition Model, basic to which are the notions of form and function and the idea that speakers of different languages use different cues from the form of the sentence to determine meaning. Process universals may deal with concepts such as hypothesis testing; overgeneralization; simplification; cognitive style (Seliger, 1984); or morphological, word order, and animacy cues (Gass, 1989). Although such processes and strategies are certainly important in SLA, it seems that there is little consensus on which processes merit the status of "universal" and which do not.

\section{Chomskyan Universals}

Chomskyan universals, on the other hand, seem to be more standard. They stem from a generative theory of language which claims that surface structure, observable linguistic data, is far different from the corresponding deep structure syntactic representations, which are very abstract (Comrie, 1989). The theory of Universal Grammar explains that, thanks to an innate Universal Grammar (UG) which contains the abstract principles and parameters of generative grammar, children learn their first language with ease and in a much shorter time than the abstractness would otherwise permit even though the language input they receive is "degenerate" (Mazurkewich, 
1984). These UG principles are the same in every child and will, therefore, work for any language; they are "abstract and linguistically significant principles that underlie all natural languages" (Flynn, 1987, p. 5). Thus, whatever principles are innately available to children are universal properties of all languages. Since these universals are so abstract, a language must be studied in great depth in order to determine just what the universals are. This leads to a methodological preference for analyzing a few languages in detail rather. than analyzing many languages in less depth. Therefore, these universals have been based primarily on abstract analyses of English syntax (Comrie, 1989), although, in recent years, the study has extended to a few other languages as well (Hawkins, 1983).

\section{Typological Universals}

Typological universals are also called Greenbergian universals because they are derived from a typology of languages initiated by Greenberg (1963a). Such universals, as explained in Chapter $I$, are based on studying the surface structures of many different primary languages that are, ideally, representative of all the types of languages in the world (Comrie, 1989). When 
languages are thus compared, cross-linguistic patterns, or universals, may appear.

It is possible that the three types of universals are actually interrelated. Intuitively, it seems reasonable to assume that deep structure universals and cross-linguistic universals must both be based on psychologically real processing limitations. Furthermore, it may be that Chomskyan and typological universals are compatible or two sides of the same coin, as pointed out by Rutherford (1984a). However, typologists prefer Greenbergian universals and have reservations about some of the methodological and theoretical bases for Chomskyan universals.

\section{More Detail on Typological Universals}

Since this paper is based on a typological approach to universals, further detail about TIUs, including a brief history, follows.

Hyltenstam (1987) and Greenberg (1969) attest that the idea of language universals has intrigued linguists for a very long time. Western Greco-Roman grammatical tradition held that its categories of grammar were universal, that all languages could be described using that same grammar. Eventually, however, it became apparent that not all languages could be forced into one mold. As a result, structural approaches arose, which 
emphasized the importance of describing each language individually, without imposing any outside categories upon it. Thus, structuralists looked at differences, not universals, mainly because universals seemed impossible to find. Beginning in the late 1950s, however, interest in universals revived, due, Greenberg (1969) says, to their importance in generative grammar. In addition, since previous endeavors to establish language universals, involving attempts to link universals with language families, had not been successful, a new typology of languages based on empirically-generated categories was proposed by Greenberg (1963a). His typology offered hope to the search for universals.

Greenberg's typology (1963a), based on word order, examined in languages "the relative order of subject, verb, and object in declarative sentences with nominal subject and object" (Greenberg, 1963a, p. 76), the presence of prepositions or postpositions, and the position of adjectives relative to the noun. Of the six logical possible orderings of subject, verb, and object (svo, sov, VSO, Vos, OSV, ovs), Greenberg found that only three (SVO, soV, VSO) commonly occurred in his comparison of 30 languages. Although it is now recognized that all six possibilities are represented in the world's languages (Dryer, 1988; Comrie, 1989), Greenberg's three 
patterns are clearly dominant. Greenberg also found that, based upon the categories that languages fell into regarding svo order, pre- and postpositions, and adjective position, predictions could be made regarding other characteristics of the languages. These constituted typological universals and are formulated thus: (for example) "Universal 3: Languages with dominant Vso order are always prepositional", and "Universal 14: In conditional statements, the conditional clause precedes the conclusion as the normal order in all languages" (Greenberg, 1963a, pp. $311 \& 315$ ). Given all the logically possible combinations of features that languages could conceivably employ, "it becomes rather more impressive that natural languages, while they do not: all have the same system, are confined to [certain patterns]" (Greenberg, 1969, p. 475).

As briefly mentioned in Chapter I, many typological universals (either absolute or tendencies) are also implicational, that is, whenever structure $P$ is found in a language, that implies that structure $Q$ will also be in that language. This is typically written as, if $P$, then $Q$ (Comrie, 1989; Greenberg, 1963a). An example of a TIU is "If a language has inversion of statement order in wH questions so that verb precedes subject $[P]$, then that language also places the question word sentence-initially 
[Q]" (Greenberg, 1963a; Eckman, 1989). The implied structure, then, is more fundamental--in plain terms, easier--than the structure that implies it, so that it can be said that the implied structure, $Q$, is preferred to the harder structure, $P$ (Greenberg, 1969). The implicational relationship provides a definition of typological markedness: in a TIU, the item that is implied $(Q)$ is less marked than the item $(P)$ that implies it. $Q$ is not called less marked because of some circular or subjective argument about difficulty which, according to many typologists, seems to form the basis for Chomskyan markedness (Hyltenstam, 1987). Rather, $Q$ is called more marked because empirically it has been established that item $Q$ is a prerequisite for item $P$ in any language and also because item $Q$ occurs in more of the world's languages than does item $P$ (Hyltenstam, 1987). This implicational relationship of markedness allows the establishment of a hierarchy of difficulty for the structures $P$ and $Q$ (Greenberg, 1969) (and $R, S$, and $T$ if there happen to be more than two members in the structure's set that are implicationally related). This hierarchy establishes an order of "panhuman . . preferences" (Greenberg, 1969, p. 476). In other words, TIU patterns across languages show that all human beings 
consider some structures to be more difficult than others.

\section{The Basis for Application of TIUs to SLA}

TIUs exhibit rules that constrain all natural primary languages, since the rules are based on straightforward data from those languages. Because these universals reveal human preferences regarding difficulty, it stands to reason that these same preferences would be evident in nonprimary natural languages such as first language acquisition. The first person to relate TIUs to nonprimary languages was Jakobson (1968). He attempted to predict relative orderings in first language acquisition based on typological universals.

It seems that TIUs may also be applied to other nonprimary languages, such as ILs. Adjemian (1976, pp. 298, 299) contends, and later researchers concur, that

ILs are natural languages. . . If ILs are not linguistic systems in this sense, then learner speech is beyond the grasp of linguistic science and its analytic procedures. Moreover, given modern beliefs in linguistics and psychology that human languages form a definable set, it would be curious if learner languages should turn out to not fit into the set of possible human languages.

This being the case, ILs should also be constrained by TIUs. Recently, scholars have begun investigating this 
idea by testing TIUs against SLA data (Hawkins, 1987). The hypothesis is, essentially,

if there are features of language that are common to all languages and conversely, if there are universal constraints on the formation of language, then it stands to reason that these same constraints and/or commonalties would hold true for second-language grammars. (Gass, 1989, pp. 512, 513)

or, more succinctly, "The universal generalizations that hold for the primary languages hold also for interlanguages" (Eckman, 1991).

\section{Two Cautions}

In exploring the application of universals to SLA, two matters must be kept in mind. The first, pointed out by Hawkins (1987), is the fact that this application does not claim to predict that in SLA a certain item will be acquired first, followed by the next on the TIU hierarchy, followed by the next on the hierarchy, and so on. Rather, the claim made by the TIUs is that the second, more marked item of a hierarchy will not be present without the first, less marked item being present. This does not preclude the possibility that they may both appear at the same time. In other words, if the universal is "if $P$, then $Q, " Q$ may appear first in an IL, followed by $P$, but it would be just as possible 
for $Q$ and $P$ to appear at the same time. However, based on the TIU, $P$ will never appear in an IL alone.

The second consideration is addressed most definitively by Bley-Vroman (1983) who argues that Selinker's (1969) definition of IL implies that ILs should be studied on their own terms, rather than in terms of the TL. Linguists have been caught in the "comparative fallacy," comparing the IL with the TL and attempting to classify IL errors as omission, substitution, and so on, which necessarily means that the IL is being compared with the TL. Bley-Vroman contends that the comparative fallacy can severely distort descriptions of IL. He demonstrates that, with regard to the systematicity of ILs, the comparative fallacy may lead linguists to 1 abel as unsystematic characteristics of an IL that do not conform to the TL when, in fact, those characteristics are systematic within the IL even though rules differing from the TL are employed. Eckman et al. (1989) offer an example of avoiding the comparative fallacy in deciding what criteria to employ in judging the grammaticality or ungrammaticality of $L 2$ learners' questions. They accept questions such as what is reading Mary now? as exemplifying subject-verb inversion even though they are ungrammatical when compared with the TL, English. 


\section{STUDIES OF TIUS AND SLA}

A consideration of the various studies that have explored the influence of TIUs on SLA data appears in the following sections.

\section{The Accessibility Hierarchy TIU for Relative Clauses}

The preponderance of SLA studies involving hierarchies resulting from TIUs investigate the $\mathrm{AH}$ for relative clauses (RCs). These studies are based on an investigation by Keenan and Comrie (1977) of the possibilities for $R C$ formation in about 50 primary languages of the world. Keenan and Comrie observe that languages differ as to which NP positions may be relativized and that there is a universal hierarchy that governs how relativization can take place. This TIU hierarchy may be represented as the following:

$$
\mathrm{SU}>\mathrm{DO}>\mathrm{IO}>\underset{(\mathrm{OPREP})}{\mathrm{OBL}}>\mathrm{GEN}>\mathrm{OCOMP}^{1}
$$

(where > means "is more accessible to relativization than," SU means subject, DO means direct object, IO meanss indirect object, $O B L$ means oblique object lobject of

\footnotetext{
${ }^{1}$ Examples of relative clause types:

SU The man who saw the cat...

Do The man that the cat saw...

Io The man that I gave the book to...

OPREP The table that he is standing on...

GEN The man whose book I borrowed...

OCOMP The man that he is taller than...
} 
preposition), GEN means genitive, and OCOMP means object of comparison.)

This means that if a language can relativize a NP in any given position of the $\mathrm{AH}$, then it can also relativize the NPs for any position higher (more accessible, easier, to the left) on the AH. (Keenan and Comrie, 1977, p. 69, qualify this statement by adding that this relativization may be done "either directly or by promoting [the NP] to a position that can itself be relativized".) However, since not all languages allow relativization of all NP positions, relativization may or may not be allowed for NP positions lower on the AH (less accessible, harder, to the right).

Languages differ on the lowest relativizable position. For example, if language A can relativize the NP in the IO position, then it can also relativize NPs in the DO and SU positions. That is, IO relativization implies DO and SU relativization. However, if $I O$ is the lowest position that language $A$ can relativize, then none of the positions lower than (to the right of) Io may be relativized. That is, Io relativization does not imply OBL, GEN, or OCOMP relativization. An additional constraint is that relativization occurs on continuously connected positions; a position may not be "skipped." According to the $\mathrm{AH}$, it is impossible for language $A$, in 
addition to relativizing positions IO, DO, and SU, to skip OBL and GEN and to be able to relativize OCOMP.

Keenan and Comrie also assert that all languages allow relativization out of the sU position (Keenan \& Comrie, 1977, p. 67). Furthermore, they suggest that the AH mirrors psychological reality regarding the ease of relativizability. In other words, in a given language, it is more difficult to relativize and more difficult to comprehend the relativizations of the lower positions that are relativizable in that language (Keenan \& Comrie, 1977, pp. 88, 931. Therefore, the AH is intralinguistically valid as well as universally valid.

If, as Keenan and Comrie (1977) claim, the $\mathrm{AH}$ applies universally to all languages, it seems reasonable to posit that it would also constrain ILs, nonprimary languages, but natural languages all the same. Gass (1979, 1980) explores this possibility in an analysis of data from 17 ESL students based on elicitation tasks of grammaticality judgement, free composition, and sentence combination. Though the students were of typologically diverse language backgrounds, Gass finds that

The ease or difficulty of relativization on a given position. . seems to correspond to a universal hierarchy rather than to the particular facts of a learner's [native] language. (Gass, 1980, p. 138) 
Her subjects follow the constraints of the AH with the exception of one position. The relativization that is second most accessible to the subjects is GEN instead of the expected DO. Gass suggests that since whose of the GEN has no variations such as that or which, as the other positions do, GEN is, in English, an easier relative marker to learn. She also hypothesizes that, had the GEN examples on her tests contained the for whom construction, GEN would have been more difficult to relativize, as predicted. Thus, she proposes that although TIUs are the main force governing IL data, specific facts about the NL and about the TL also come into play. In her words, "the $A H$ may represent a natural. path of least resistance to learning" (Gass, 1980, p. 140), but it is not a rigid law, unaffected by other factors such as NL and TL.

A similar study by Tarallo and Myhill (1983) also concludes that TIUs constrain ILs; their subjects' difficulty in relativizing reflects the $\mathrm{AH}$ order except in the case of IO, which is more difficult for the subjects than the $A H$ predicts. Tarallo and Myhill propose an explanation for this oddity based on Keenan and Comrie's (1977) observation that the boundary between IO and OBL is "fuzzy." This being the case, it is reasonable that the Io is more difficult to relativize 
for L2 learners because it is not clear which relativization strategy should be used for it. Research on four NP positions of the AH by Ioup and Kruse (1977) also partially supports the hypothesis that the AH's universal constraints apply to SLA.

That Gass (1979, 1980) and Tarallo and Myhill (1983) discover two distinct deviations from the pattern predicted by the $A H$ in their $L 2$ data may seem to bode poorly for the hypothesis that TIUs constrain ILs. Their results may seem to call into question the validity of the hypothesis or the accuracy of the AH. However, it seems that the fact that each study shows evidence for a different deviation could be explained in terms of sample size. Rollins (1988), below, with a much larger sample size, finds both deviations in her study. The explanation she gives seems plausible and follows arguments similar to those of Gass and Tarallo and Myhi11.

Further inquiries into the relationship of the AH to SLA data have proceeded in similar fashion, but with several additional features of interest to SLA research.

\section{Varied Learning Environments}

Pavesi's (1986) research explores one such dimension in addition to studying the relationship of the $A H$ to SLA. She is interested in the possible effect of 
learning context on RC formation and studies two groups of learners of Italian as a second language, one formally studying the language, the other learning it informally. The results from both groups are consistent with the order predicted by the $\mathrm{AH}$. In addition, the formal learners more able to relativize the more marked positions on the $\mathrm{AH}$ than the informal learners. This Pavesi attributes to the greater amount of planned, written, and formal input received by the formal learners as compared with the informal learners.

A later study by Rollins (1988), patterned after Pavesi's and involving ESL students, finds that GEN is more easily relativized than predicted by the $\mathrm{AH}$, coinciding with Gass' studies $(1979,1980)$ and that Io is more difficult than the AH predicts, concurring with the results in Tarallo and Myhill (1983). However, unlike Pavesi's study, Rollins' shows that formal and informal learners are closer together in the production of marked relativizations than in the production of unmarked relativizations. Although Rollins' formal learners do produce more marked structures than her informal learners, the difference is not as great as it was in Pavesi's results.

Hansen's (1986) inquiry concerning universals in $\mathrm{RC}$ acquisition involves child and adult learners of Hindi- 
Urdu, both as a first language (L1) and as a L2. He discovers that the L1 data support the AH predictions. The L2 data, however, do not support the AH. Regarding this deviation from the universal pattern, Hansen observes that the $L 2$ results would support the $A H$ if the lowest level L2 learners were not included among the subjects. He hypothesizes that wild guessing on the part of the least proficient L2 learners skew the results. Thus he draws the following conclusion:

For complex linguistic structures. d the
application of universal processing strategies
to a comprehension task depends on a
prerequisite level of competence [italics
added] in the language. (Hansen, 1986, p. 155)

\section{Pedagogical Considerations}

In a 1982 study, Gass points out that theoretical SLA research inquiries such as those involving the $\mathrm{AH}$ above are very seldom applied to L2 teaching, and she endeavors to reconcile theory with pedagogy. She notes that most language textbooks present easy structures first, followed by more difficult ones. However, if certain structures are typologically and implicationally related, she proposes that teaching the more difficult structure first will result not only in the students' acquisition of that more marked structure, but also in their use of generalization to acquire the structures less marked, without their receiving instruction 
specifically addressing the less marked structures. This would theoretically be possible since a TIU states that it is impossible for a natural language to contain a more marked structure without also containing the implicationally related structures that are less marked.

Gass tests this possibility on two low-intermediate groups of ESL students. A pre-test determines the groups' baseline recognition and production of relative clauses and establishes that the differences in overall performance are nonsignificant between groups. Then the control group $(n=5)$ receives instruction on relative clauses based on their textbook which, typically, presents relativization of SU and DO first, with very little emphasis on IO and GEN. The experimental group $(n=13)$ receives instruction only on OPREP (OBL) relativization. Gass finds that for the control group, learning is limited to the relativizations of instruction whereas the experimental group's improvement is not limited to OPREP, but also applies to all lower positions on the AH. Based on these results, Gass suggests that an efficient syllabus would, given the presence of an implicational relationship between structures, take advantage of the learners' natural abilities to generalize from marked structures to less marked ones. 
In a similar but more elaborate study, Eckman, Bell, and Nelson (1988; see also Eckman, 1985) improve on Gass' (1982) methodology by having the same number of subjects-nine--in each of four groups, which receive more varied instruction than did Gass' groups. In Eckman et al. (1988), one group is instructed in su relativization, another in object relativization, another in OPREP relativization, and the fourth group receives instruction that has nothing at all to do with $\mathrm{RCs}$. Their results are consistent with Gass'. Each group improves on the structure focused on in instruction, and the group that shows the most generalization to other positions on the $\mathrm{AH}$ is the group that was instructed in OPREP relativization. The group instructed in object relativization generalizes less, but still more than the group instructed in SU relativization, which does not significantly generalize to other positions at all. The performance of the control group is the same on the posttest as on the pre-test.

Eckman et al. (1988) place two qualifications on the results of their study. First, unlike Gass (1982), they caution that the results do not necessarily imply that the most marked structure of a hierarchy should always be taught. Their reasoning is that the most marked structure may occur so infrequently in the language as to 
limit its usefulness to someone learning that language as an L2. Thus, they say it would be "unwise" to teach relativization of the OCOMP position in English because sentences such as There is the man that I am taller than are very rare.

Secondly, they point out that their results do not necessarily mean that it is more time efficient to teach only the more marked structure. All groups received an hour of instruction on their RC type whether they needed all that time or not. In other words, the group instructed in $\mathrm{SU}$ relativization might have been able to learn relativization of $\mathrm{SU}$ in a few minutes and then been able to proceed to object relativization and OPREP relativization all within the same hour. In that case, they would have had post-test results similar to the group that received instruction only on OPREP relativization without any additional instructional time.

\section{SLA Studies Involving other TIUS}

As stated earlier, the bulk of research regarding TIUs and SLA has been concentrated on various investigations of the $\mathrm{AH}$ for relative clauses. Perhaps this is because that particular implicational relationship has been established in great detail by Keenan and Comrie (1977). There have been far fewer 
studies that have explored universals of phonology or other universals of syntax.

\section{Phonological TIUs}

In the area of phonological TIUs and SLA, Eckman (1984) tests the TIU (taken from Greenberg, 1963a) which states that word-initial or word-final consonant sequences of length $n$ imply at least one continuous subsequence of length $n-1$ in that same position. In other words, if a language has, for example, the cluster /spr/ word-initially (e.g. spring), that implies that the language also has a cluster /sp/ (e.g. spot) or /pr/ (e.g. pretty) or both $/ s p /$ and $/ p r /$. To represent this TIU in a way that is schematically consistent with the other TIUs above, an example needs to be used:

$$
\text { \#/sp/ and \#/pr/ OR \#/sp/ or \#/pr/>\#/spr/ }
$$

Eckman (1991) tests this same TIU and an additional one which states, "If a language has a least one final consonant sequence consisting of stop + stop, it also ha: a least one final sequence consisting of fricative + stop" (Eckman, 1991, p. 24). For example, /ft/\#, /sp/\#, /st/\#, and/or/sk/\#>/pt/\#,/kt/\# In both TIUs, as usual, what is to the right of > implies the presence of what is to the left of $>$; what is to the right of > cannot be present in a language without the presence of what is to the left of $>$. However what is to 
the left of > may be present in a language without the presence of the items to the right of $>$. Eckman's studies (1984, 1991) examine L2 data to see if the universals which are based on primary languages also apply to ILs. His 1984 study finds that they do: Subjects either produce both three-letter and related two-letter consonant clusters, or they produce only twoletter clusters.

The 1991 study is based on data gathered from list reading, elicitation using pictures, the reading of four 500-word essays, and a set of eight conversations. It results in only five nonconformities for the first TIU, which were produced by three subjects. In those cases, the three subjects produced three-letter clusters without producing sufficient numbers of the related two-letter clusters. One of these counter-examples is explainable because the subject produces allophonic variations of the two-letter clusters, that is, although he produces /skr/, $/ s k /$ is produced with a palatalized $/ k /$ and $/ k r /$ is produced as $/ \mathrm{kl} /$. For the other two counter-examples to the first TIU, Eckman has no explanation. In addition, two counter-examples to the second TIU are present in the results, but Eckman says that these are the result of the subjects not attempting enough of the fricative-stop clusters in their conversation (a minimum of five tokens 
was the criterion for assuming that the cluster was a real part of the subject's IL). Eckman concludes that the total of five exceptions out of 524 possibilities is nonsignificant and that his findings do, therefore, support the hypothesis that ILs also conform to TIUs.

\section{other syntactic TIUs}

Negation. Regarding other syntactic universals, Hyltenstam (1977) examines negation in the ILs of learners of Swedish as a second language. He first establishes the problem areas in negation based on free composition and taped conversations, then builds this knowledge into a cloze test that is administered to 160 subjects. He finds a common and implicational route of acquisition of negation for the subjects that is not affected by variables such as length of education, knowledge of other languages, or NL. However, his findings are not compared with any TIUs that might exist for negation. And although Dryer (1988) presents universals of negation based on his study of 345 languages, he makes no observations about possible implicational relationships and no reference to SLA.

Complements. Dryer's study $(1980$, as cited in Frawley, 1981) establishes a TIU for sentential complements that states that there are cross-linguistic 
preferences for the position of sentential complements that may be represented thus:

$$
\text { clause-final >clause-initial > clause-internal }
$$

(where > means "is implied by"; clause-final means the complement is in final position [Jim knows that Peter made the explosion]; clause-initial means the complement is in initial position [That Tom went to Palm springs upset Sue]; and clause-internal means the complement is internal in the sentence, a position not possible in English, but possible in some languages such as Hopi, Lakota, and Tamil, according to Frawley, 1981, p. 3). Frawley (1981) compares this complement TIU with L1 and L2 data produced by adult subjects whose task it was to construct sentences using a pack of cards, half of which contained a verb, and the other half of which contained a sentential complement. Frawley reports that both native speakers (NSS) and non-native speakers (NNSS) produced many more clause-final complements than they did clauseinitial complements; no subjects produced clause-internal complements. Furthermore, Frawley finds that as English proficiency increases, production of the lower (more difficult) structure does also. Thus, he concludes that the complement TIU constrains L1 and L2 data.

Interrogation. A TIU of interrogative structures is compared with L2 data in Eckman (1984) and Eckman et al. 
(1989). The TIU tested (taken from Greenberg, 1963a), when applied to English, may be represented as:

WH fronting > WH inversion > YN inversion

(where > means "more accessible than," wH fronting means the question pronoun in WHQs is sentence-initial [Where are you going?] instead of non-sentence-initial [You are going where?], $W H$ inversion means the verb and subject are inverted as compared with a declarative sentence so that the question order is verb-subject [Where are you going?] instead of subject-verb [Where you are going?], and $Y N$ inversion means that the inverted order, verbsubject, is used in YNQS [Are you going home?] instead of an uninverted order [You are going home?]).

Eckman's study (1984) is based on data gathered from one subject using pictures about which the subject is instructed to ask questions. The study by Eckman et al. (1989) displays a bit more authenticity in that subjects are shown a series of pictures and are asked to discover the story by asking questions, starting with YNQs and followed by WHQs. The results of Eckman et al. also seein more dependable since 13 subjects are tested, from three different NLs. In neither of the studies do the NLs exhibit any of the three question-forming strategies involved in the TIU, thus eliminating the possibility of transfer as an influence and augmenting the possibility 
that the $Q$ TIU is solely responsible for the IL order. Both studies conclude that the data support the hypothesis that ILs follow the TIU.

\section{QUESTIONS}

Since this study investigates the constraints of the Q TIU on ILs, this final division of Chapter II presents information about questions and question acquisition. In this first section, an overview of cross-linguistic categories of question types provides background for the upcoming discussion on previous studies of interrogative acquisition .

\section{Cross-linguistic Characteristics of Questions}

Sadock and Zwicky (1985) identify seven types of questions, listed and described here with an accompanying example from English, when possible. YNQs are used to determine the truth or falsity of a proposition (Is Peter Tina's boyfriend?). Alternative questions provide a list of two or more suggested possibilities from which the respondent can choose the correct answer (Did Jim cause the explosion, or did Peter?). Information or questionword questions are open-ended and seek further information on a topic incompletely known, with the question word or particle substituting for the unknown 
portion (Why did the bad guys kidnap Patty?). Biased questions are those for which the questioner expects a certain answer and are used to gain confirmation of that expectation (Sue didn't go to Los Angeles, did she? Tina is married, isn't she?). Confirmative questions are "statements that carry with them the demand that the addressee express his agreement or disagreement" (Sadock \& Zwicky, 1985, p. 82) and, in some languages, are similar to or even indistinguishable from biased questions. Many languages form such questions by adding a tag, such as n'est ce pas in French or nicht wahr in German, to a declarative. English confirmative questions differ from biased questions only in intonation; the former have falling intonation, while the latter have rising intonation (Peter is a bad man, isn't he?). Rhetorical questions are used for rhetorical purposes when both the speaker and the listener know the answer (English does not have a special form for this question type). And finally, dependent or embedded questions are dependent clauses with some or all of the formal properties of information questions or YNQs ( $I$ want to know why Peter made the explosion).

While languages differ on the number of question types they possess, most languages mark their interrogatives with certain syntactic or phonological 
characteristics such as distinctive intonation; permuted word order; or segmental elements, including interrogative particles, interrogative words, or tags (Ultan, 1978). These and other less frequent formal aspects combine with different question types to form the various questions in the world's languages. The next three paragraphs describe the combinations prevalent in YNQs and information questions, which are the types relevant to this paper and are also the two most basic types in the languages of the world (Greenberg, 1963a).

\section{YNQS Cross-linguistically}

The most widely distributed question type in the languages of the world is the YNQ (Sadock \& Zwicky, 1985). Virtually all languages (exceptions include Greenlandic [Sadock \& Zwicky, 1985] and Finnish [Wode, 1983]) can convert declarative sentences into YNQs simply by marking them with rising (or other specially contoured) intonation (Ultan, 1978; see also sadock \& Zwicky, 1985). For some languages, this rising intonation is the only means of marking YNQs, but most languages use other forms in conjunction with or as alternates to intonation. Sadock and Zwicky and Ultan all attest that the next most common way for languages to mark YNQS is with the use of question particles and that marking YNQs via word order permutation, such as with the 
subject-verb inversion in English and several other European languages, is rare, as the Q TIU asserts. Ultan finds that only about 18 percent of the languages he evaluated invert YNQs. Some languages mark YNQs with a combination of the formal devices.

\section{Information Questions Cross-linguistically}

Information questions occur in nearly all languages, although a few, such as Hopi, may not have an information question form at all, relying instead on indefinite statements or YNQS to request information (Sadock \& Zwicky, 1985, pp. 179, 182). Cross-linguistically there exists no single, distinctive intonation pattern for information questions as there does for YNQs; falling intonation characterizes information questions in about half of the world's languages, and the other half employ rising intonation (Ultan, 1978, p. 221). Information questions are formed, in some cases, with particles but more frequently with interrogative proforms, which the next paragraph discusses in further detail. In keeping with the $Q$ TIU, word order changes are more pervasive in information questions than in YNQs; about 70 percent of the languages assessed by Ultan employ inversion in information questions. Like YNQs, information questions may also be marked with a combination of the formal instruments. 
The interrogative proform typically used in an information question replaces the questioned constituent of the sentence. Thus, in the question, where does Tina live?, the interrogative word, where, substitutes for an unknown phrase that identifies location. Basic English interrogative words substitute for noun phrases (who, what, which) and for phrases expressing time (when), location (where), purpose (why), and manner (how) (Thompson \& Martinet, 1991, pp. 71-74). The number of question words in other languages ranges from only three to more than 12, and common to all but two or three languages (Lithuanian, Khasi, and perhaps Sango according to Sadock \& Zwicky, 1985, p. 182; Ultan, 1978, p. 229]) is a distinction between personal and impersonal interrogative words (who and what in English). Ultan and Sadock and Zwicky all confirm the predominant tendency for languages to place the question word (or particle) sentence-initially, noting that that position is also typically the "focus" or "topic" position. Ultan goes on to specify two more facts of interrogative word placement. First, he notes that languages with a basic SOV word order (such as Japanese) are significantly less likely to front the question word. Only about 57 percent of such languages locate the question word in initial position as opposed to about 74 percent of languages with 
other basic word orders (Ultan, 1978, p. 223). Secondly, he reveals that while question word fronting occurs in about 74 percent of languages, in almost all of the remaining languages, the question word remains in place in the sentence, that is, the question word occupies the same syntactic slot as would the phrase for which it is substituting (p. 229).

\section{Previous Studies of Question Acquisition}

The interrogative has been one of the most widely investigated structures in language acquisition (Ellis, 1988, p. 32). Because interrogative studies abound in both first language acquisition (FLA) and SLA, an exhaustive review of the literature would be prohibitively lengthy. Therefore, the following sections discuss first two foundational FLA studies, after which appears an overview of the diversity of foci found in SLA interrogative studies. Following that, the studies are reviewed according to the ways in which their assumptions, methodologies, or findings may relate specifically to the $Q$ TIU.

\section{FLA Studies}

Two FLA studies of interrogatives, those by $R$. Brown (1968) and Klima and Bellugi (1966), have served as cornerstones and points of comparison for the majority of: 
SLA interrogative studies to date. The two studies actually report on the same data, collected in a longitudinal study of the naturalistic acquisition of English as a native language by three now-famous children, Adam, Eve, and Sarah. R. Brown reports in depth on the development of WHQs in the children's speech, while Klima and Bellugi give a broader picture of question acquisition in general.

R. Brown (1968) focuses on an attempt to discover evidence in the data to support the psychological reality of two proposed underlying structures posited by transformational grammar. He hypothesizes that WHQs may initially appear in transformational grammar's "base" form, without WH fronting and without inversion, that the next stage may yield WHQs that have undergone a single transformation resulting in questions with fronted wH words but still without inversion, and that WHQs in the final stage may have undergone both a fronting and an inversion transformation, resulting in WHQs that are in accord with those produced by adults' grammar. His findings partially support his hypotheses in that while no WHQs of base form are observed, the children do produce fronted, uninverted WHQs before reaching a stage of adult-like production. R. Brown also mentions several other phenomena that he observes in the data: the 
occurrence of whole WHQs apparently learned as rote, unanalyzed formulae; the absence of most function words considered obligatory in adult grammar; the shaping influence of the WHQ input that at least one child, Adam, received from his environment; and the fact that although the children did not produce unfronted, uninverted WHQs, they were more often able to respond appropriately to such questions than to fronted, inverted WHQs. $R$. Brown's findings are consistent with the $Q$ TIU. Although he reports no base form WHQs, neither does the $Q$ TIU require the presence of such: As long as WH words are fronted by the time WH inversion is acquired, the TIU is upheld.

The findings of Klima and Bellugi (1966) result in their description of three periods of question acquisition. In Period 1, YNQs are marked by intonation only, containing no inversion, no auxiliaries, and no do.. support. WHQs in this period are formulaic routines only, according to Klima and Bellugi, and include such structures as What's that?, Where NP (go)?, and what NP doing? The WHQs display no productive inversion or dosupport. YNQs in Period 2 are the same as in Period 1. WHQS become productive, rather than just routine, and many include verbs; however, they remain uninverted. Period 3 (also known as "stage C"), Klima and Bellugi 
state, is characterized by YNQs with inversion and WHQs without inversion. Like R. Brown, Klima and Bellugi also make note of other observations: They notice that their subjects' questions, especially at the outset, are missing function words and even nouns or verbs necessary in adult speech; and they discuss their subjects' use of unanalyzed formulae. Although some of the results that Klima and Bellugi report are consistent with the $Q$ TIU (such as the observation that uninverted YNQs precede inverted YNQS), their Period 3 represents evidence that is disconfirming of the TIU. The existence of Period 3 is, however, a matter of debate in the literature, an issue that is discussed more thoroughly in later sections.

\section{SLA Studies}

As did the FLA studies by R. Brown (1968) and Klima and Bellugi (1966), SLA studies of interrogatives (some of which examine the interrogative exclusively, others of: which include the interrogative as one of several key structures investigated), as well as compilations of such studies, typically result in lists of stages of question acquisition. The degree of detail in the stages ranges from very little, as in Larsen-Freeman and Long (1991), to moderate, as in Pienemann and Johnston (1987), to a 
great deal, as in Wode (1978), as illustrated in Tables 1. to 3 , below.

\section{Table 1}

$$
\begin{gathered}
\text { Stages of Question Acquisition as Presented } \\
\text { by Larsen-Freeman \& Long }
\end{gathered}
$$

\begin{tabular}{ll}
\hline Stage & Example \\
\hline $\begin{array}{l}\text { 1. Rising intonation } \\
\begin{array}{l}\text { 2. Uninverted wH } \\
(+/- \text { Aux. })\end{array}\end{array}$ & He work today? \\
$\begin{array}{l}\text { 3. "Overinversion" } \\
\text { 4. Differentiation }\end{array}$ & Do you know where is it? \\
\hline
\end{tabular}

Table 2

$$
\begin{gathered}
\text { stages of Question Acquisition as Presented } \\
\text { by Pienemann \& Johnston }
\end{gathered}
$$

\begin{tabular}{ll}
\hline Stage & Example \\
\hline 1. Single words, formulae & How are you? \\
2. Svo? & The tea is hot? \\
3. Do fronting & Do he work? \\
WH fronting & (no example) \\
4. Pseudo-inversion & Where is my purse? \\
Yes/No inversion & Have he seen it? \\
5. Aux 2nd & Where has he seen you? \\
6. Q-tag & It's expensive, isn't it? \\
\hline (Note: Examples from Pienemann, Johnston, and Brindley, \\
1988.)
\end{tabular}


Table 3

stages of Question Acquisition as

Presented by Wode

stage

Example

YNQS :

1. uninverted, intonation only
a) non-sentence
b) can
Right?
c) V
You can see that?
You see my little ball?

2. inversion with
a) copula
b) can
c) full verbs

It's (= is) my fishing

pole in the water?

Can I have a drink?

Catch Johnny fish today?

3. do support with full verbs Did you catch anything?

4. do support with
a) copula
B) can
Do it is good?
Do the crickets can fly?

5. target-like inversion and do support

WHQS :

1. WH- copula

What is it fishing pole?

2. WH- in full verb questions without do support
a) WH- Subj Ving
b) WH- Subj
c) WH V Subj
d) WH $\mathrm{BE}$ Subj Ving

3. uninverted copula \& can
a) $W H-$ Subj $B E\left|\begin{array}{l}\text { Ving } \\ \mathrm{X}\end{array}\right|$
b) WH- Subj can
c) WH- can subj

What you doing, Craig?

What you want it (= how do you want the pitch?) Where have you your ball? What are you doing, airplane man?

4. do support with V

5. do support with Ving

How far we are going?

Why we are so slow?

What socks I can take?

What else can I take out?

How do you clean them?

What do we doing, Johnny? What do you was doing? 
The various lists of question acquisition orders sometimes do, but most often do not, present the information in a manner that allows the claims of the $Q$ TIU to be compared directly to the results of the studies. Instead, question acquisition studies commonly focus on factors other than those addressed by the Q TIU. Furthermore, even when issues pertaining to the TIU (WH fronting, WH inversion, and YN inversion) are considered, most interrogative studies "slice the pie" differently than along the lines of the $Q$ TIU. While most of the slicing patterns are not mutually exclusive--in fact, one study can combine several--typically, the assertions of the TIU cannot be or simply are not adequately delineated. The following paragraphs present some of the prevalent foci and data-slicing patterns.

The Various Foci of SLA Studies of Interrogatives. Perhaps the most common way of slicing the data is to examine the order in which the various auxiliaries are acquired and inverted in interrogatives. Some of these studies make distinctions between the various allomorphs of certain auxiliaries (am, are, is, for example), while others consider the allomorphs together. Research that places a major emphasis on the issue of auxiliary order includes that by Cazden et al. (1975, see especially p. 26 and pp. 35a-351), Bailey, Eisenstein, and Madden 
(1976), Adams (1978), Wode (1978), and Syamala (1991). Many other studies include auxiliary order as one of several research questions: Gillis and Weber (1976), Pienemann and Johnston (1987), and Shimada (1987) are examples. Numerous other works make mention of at least one auxiliary that seems to appear or to be inverted before others, including Ravem (1974a), Ravem (1978), Huang and Hatch (1978), Ellis (1988), Lindholm (1986), and, with Swedish as the TL, Hyltenstam (1981).

Another very popular focus concerns the question, "Does question acquisition in English as a second language mirror question acquisition in English as a first language?" (the "L1 = L2" hypothesis). These investigations seek to determine whether learning strategies, developmental stages, and errors are the same for second language learners as they are for first language learners. Gillis and weber (1976), Raven (1974a, 1978), Sobin (1977), Felix (1981), Chen (1986), Shimada (1987), and syamala (1991) are among the ones who answer this question in the affirmative. While most of these concede that differences between L1 acquisition and L2 acquisition do exist, wode (1978) focuses primarily on the differences, as does Felix (1976).

Approaching the $\mathrm{L} 1=\mathrm{L} 2$ matter from the opposite direction generates the question, "Is there evidence of 
L1 transfer in the L2 data?" The researchers above who espouse the L1 = L2 theory generally answer this question in the negative. However, Kwan-Terry (1986) attributes an entire stage of interrogative formation to influence of her subject's L1, and Adams (1978), Butterworth and Hatch (1978), and Tang (1991) each report one interrogative pattern stemming from NL influence. In addition, cazden et al. use transfer as a way of explaining certain of their results (1975, p. 36).

Another approach taken in SLA studies on interrogatives is to analyze the subject's speech production with regard to the input available to the subject. Wagner-Gough (1978) and Huang and Hatch (1978), for example, argue that a substantial number of their subjects' question utterances and even entire acquisition stages can be attributed to a strategy whereby the subjects incorporate into their own interrogatives patterns that they imitate from the speech input in their environments. While focusing mainly on other points, Ravem (1974a), Cazden et al. (1975), and shimada (1987) still make much extensive use of the input issue to account for several patterns in their subjects' speech. Input also figures largely in Felix's (1981) study of classroom ESL, but from a different perspective. He 
claims that input cannot override "principles of naturalistic acquisition" (p. 87).

Most studies at least mention a matter related to input: the presence of unanalyzed, memorized routines, or formulae, in subjects' speech. These are "chunks" of speech that learners hear frequently in their language input and adopt as a whole to be used in relevant situations. However, the TL rules of grammar that govern the chunked structures remain unanalyzed by the subjects, that is, the subjects are not producing these formulae by means of their own internal grammar rules, but by virtue of simply having memorized the phrases or structures intact. Wode (1978) points out that L2 learners "may differ drastically as to the extent to which they rely on such [formulae]" (p. 41). And, presumably reflecting their subjects' penchants for employing such routines, some studies attribute significant portions of the data to (and may exclude from analysis) memorized chunks (Cazden et al., 1975; Gillis \& Weber, 1976; Kwan-Terry, 1986), while others make limited mention of formulae (Adams, 1978; Ellis, 1992a; Wode, 1978).

Beyond these major emphases in evaluating the data, there are also other trends that dominate the literature to a lesser degree. A few studies examine SLA interrogative data with the purpose of finding support 
for one of several aspects of transformational grammar. Ravem (1974a), Sobin (1977), and Wagner-Gough (1978) devote much discussion to this end; Cazden et al. (1975) also address it, but more briefly. Some inquiries center primarily around the effect of instruction (Ellis, 1992a; Felix, 1981) or the effects of different learning environments (Brines, 1990; Felix, 1981; Tang, 1991) on the acquisition of interrogatives. Others give extensive consideration to the effects that different elicitation tasks might have on the type of data produced (Adams, 1978; Bailey et al., 1976; Brines, 1990; Syamala, 1991; and Tang, 1991). Felix (1976), Shimada (1987), and Tang, (1991) address the comprehension/production issue, inquiring as to whether subjects' ability to comprehend a given structure might exceed their ability to produce the structure or vice versa. The order in which the WH word:3 themselves are acquired is the main focus for Felix (1976), one of several main points for both wode (1978) and Ellis (1992a), and an item mentioned by Ravem (1974a, 1978), Huang and Hatch (1978), Butterworth and Hatch (1978), and shimada (1987). In terms of question type, WHQs are the most commonly studied, and YNQs are next. Embedded and alternate questions are examined infrequent $1 Y$. 


\section{Application of the Literature to the $Q$ TIU}

None of these various foci shed light on the claims of the $Q$ TIU as a whole. On the other hand, most SLA studies of interrogatives do offer comments on some portions of the $Q$ TIU. Before considering the TIUrelated information that can be gleaned from the literature, a more detailed look at the $Q$ TIU itself is necessary.

The TIU,

WH fronting > WH inversion > YN inversion,

when describing cross-linguistic patterns of question formation, states (from right to left) that if a given language inverts YNQs, it must necessarily also invert information questions (WHQs in English) and front the question word (WH words in English). If YNQs are uninverted in a language, WHQs may be either uninverted or inverted. If WHQs are inverted, the wH word must be fronted. If WHQs are uninverted in the language, WH words may be either fronted or unfronted. In short, the presence of any given structure to the right necessarily implies the presence of all structures to the left of that given structure, and structures may not be omitted. However, the implications do not travel in the opposite direction, from left to right. 
When applied to SLA data, the Q TIU claims are similar but involve the additional consideration of developmental stages. Since English interrogatives employ all the structures of the $Q$ TIU, it might be deduced that ESL learners begin their acquisition of interrogatives at the left side of the hierarchy and progress to the right side. Logically, four stages of SLA may be inferred from the $Q$ TIU, named in Table 4 according to the most advanced structure of the $Q$ TIU characteristic of the stage.

\section{Tab1e 4}

SLA Stages Inferred from the $Q T I U$

\begin{tabular}{ll}
\hline Stage Name & Characteristic Question Types \\
\hline - WH fronting & $\begin{array}{l}\text { unfronted WHQS } \\
\text { uninverted WHQs } \\
\text { uninverted YNQS }\end{array}$ \\
+ WH fronting & fronted WHQs \\
& uninverted WHQs \\
& uninverted YNQS \\
+ WH inversion & fronted WHQS \\
& inverted WHQS \\
& uninverted YNQs \\
& fronted WHQS \\
+ YN inversion & inverted WHQs \\
& inverted YNQS
\end{tabular}

Presenting these inferred stages does not constitute a claim that ESL learners must progress through each of 
them. On the contrary, the claims of the $Q$ TIU would be satisfied if language learners acquired WH fronting and WH inversion simultaneously, followed by YN inversion; if they acquired $W H$ fronting first followed by the simultaneous acquisition of WH inversion and YN inversion; or if they acquired all three structures at the same time. However, for the purposes of this paper, the six structures of each of the possible stages are considered in order to examine all possible aspects of the TIU in light of the related literature. Subsequent mention in this paper of the stages of the $Q$ TIU refers to these implied stages.

\section{\pm 1 - WH Fronting}

While the literature customarily does not specifically address the issue of frontedness or unfrontedness, it is clear that most researchers (about 80 percent of those whose works were consulted for this review) assume that fronting is a characteristic feature of learners initial ILs, with no prior stage characterized by unfronted WHQs. Most others simply make no mention of the issue (which may, in itself, imply the same assumption). Several scholars, however, explicitly state that WHQs first appear in the L2 learner's speech with the WH word already fronted. For example, Wode's (1978) stage I, based on his primary research, asserts 
that "The wh-pronouns are placed initially from their first occurrence" (p. 51). Similarly, in their compilation of various studies, Dulay et al. (1982) write, "STEP 1: wh-words appear before the rest of the statement form of the utterances, which is otherwise left unchanged" (p. 128). Hatch (1974) and Wagner-Gough (1978) make similar statements. That the most oft-cited studies include this assumption is reflected in the fact that none of the compilations of the stages of WHQ acquisition list unfrontedness as a characteristic of a stage or even as an isolated phenomenon (Dulay et al., 1982; Ellis, 1986, 1988; Hatch, 1974; Hatch \& WagnerGough, 1976; Larsen-Freeman \& Long, 1991; Lightbown \& Spada, 1993)

However, as R. Brown (1968) did in FLA research, a few SLA researchers, including Ravem (1974a) and Eckman et al. (1989), suggest that unfronted WHQs are a possibility, although they find no occurrence of them in their data. Several works, most of them less familiar, include evidence for the existence of unfronted WHQs. Gillis and Weber (1976) mention the presence of unfronted WHQs in their data from Japanese subjects but do not discuss it. Butterworth and Hatch (1978) only briefly discuss unfronted WHQs produced by their spanish-speaking subject. Chen (1986) and Tang (1991) also briefly 
discuss such utterances produced by their chinese subjects. Sobin (1977) and Kwan-Terry (1986) alone discuss the matter at length; their findings are detailed in a later section entitled, "The Case of Unfronted WHQS."

\section{$\pm 1-$ WH Inversion}

As mentioned above, an acquisition stage in which WHQs are not inverted is not necessary to the $Q$ TIU. However, if a stage typified by unfronted WHQs does exist, any WHQs asked during that stage must also be uninverted, according to the requirements of the TIU. In this case, a stage in which WHQs are uninverted becomes an inferred necessity to the TIU.

That second language learners progress through a stage in which WHQs are uninverted is a fact widelysupported in the literature. About 80 percent of the sources consulted discuss the phenomenon of uninverted WHQs (see, for example, Butterworth \& Hatch, 1978, p. 240; Cazden et al., 1975; Felix, 1981, p. 100; Pienemann \& Johnston, 1987; Ravem, 1974b, p. 129); those that do not typically either imply the presence of such questions or have an alternate focus.

After discussing the stage in which WHQs are uninverted, most primary studies and all of the compilations consulted go on to claim or at least imply 
that a stage featuring inverted wHQs follows later. For example, in Ellis' compilation (1988, p. 33), stage 4 states, "WH pronouns are used productively with a declarative nucleus" while stage 5 maintains "Inversion now occurs in both yes/no and wH questions." similarly, Shimada (1987) writes that her subject's stage II was characterized by no inversion in either YNQs or WHQS, while in stage III, both YNQs and WHQs began to be inverted. Others with comparable assertions include Adams (1978), Lindholm (1986), Dulay et al. (1982), and Larsen-Freeman and Long (1991).

only two of the studies consulted, Cazden et al. (1975) and wode (1978), indicate that uninverted WHQs may not necessarily precede inverted wHQs. While both of these studies verify the existence of uninverted WHQs, each of them finds prior or concurrent evidence of inverted WHQs. In both cases, however, the problematic, early inversion of these WHQs may possibly be explained by the subjects' use of formulae; they appear to consist of such popular formulaic expressions as what's $X$ or what is it?

\section{$\pm 1-$ YN Inversion}

Again, as with wHQs, a stage in which YNQS are uninverted is not necessary to the $Q$ TIU. Language learners could acquire $W H$ inversion and $Y N$ inversion 
together. However, because the literature cited above indicates that a stage characterized by uninverted WHQs does exist, the $Q$ TIU would predict that any YNQs produced during that stage would also need to be uninverted. Therefore, a stage including uninverted YNQs becomes an implied necessity for the $Q$ TIU.

As with uninverted WHQs, support for the existence of uninverted YNQS is abundant in the literature. Of the 27 sources consulted that address YNQs in SLA, 24 confirm the presence of uninverted YNQs (see, for example, Brines, 1990; Cazden et al., 1975; Eckman et al., 1989; Felix, 1981; Pienemann \& Johnston, 1987; Tang, 1991; Wode, 1978). Of the three remaining studies, Hyltenstam (1981) does not mention uninverted YNQs because the focus of his research is on comparing inversion in simple YNQs with non-inversion in embedded YNQs, a comparison where the status of uninverted YNQs is irrelevant; Wagner-Gough (1978) makes no comment on the presence or absence of uninverted YNQS, mentioning only that her subject's YNQS of the form, Is it bicycle is Judy? are produced by juxtaposing a formulaic is it with a declarative sentence; and Ravem (1974a, 1974b), while not explicitly denying the presence of uninverted YNQS in his data, typifies one of his subject's early YNQs as inverting the main verb with the subject (for example, Like you food?), 
a strategy he attributes to transfer from his subject's NL, Norwegian.

The vast majority of the research confirming the presence of uninverted YNQs also specifies that Ianguage learners regularly mark such questions with rising intonation. only shimada (1987) explicitly reports occasional absences of rising intonation in YNQs; she ascribes this to transfer from her subject's NL, Japanese, which, she indicates, does not always mark YNQs in this manner.

Another point of consensus among the researchers is that acquisition proceeds from uninverted YNQs to inverted YNQs. For example, Cazden et al. (1975) report, "Uninverted $y / n$ questions consistently appear prior to inverted $y / n$ questions" (p. 35). In the same vein, Felix (1981) writes that after a period characterized by uninverted YNQs, "intonation-marked questions ceased to appear and were replaced by structures which show the regular inversion pattern" (p. 100). In addition, all the compilations consulted list a stage characterized by YN inversion following the stage in which YNQs are uninverted, as Ellis (1986, p. 60) does: "The first productive questions are intonation questions, i.e. utterances with declarative word order but spoken with a rising intonation", and "Somewhat later, inversion occur:s 
in yes/no questions" (p. 61). Nineteen of the 23 studies reporting uninverted YNQs clearly confirm this sequence. of the four remaining studies, three cease before their subjects reach the stage that includes inverted YNQs (Butterworth \& Hatch, 1978; Kwan-Terry, 1986; and Lindholm, 1986), and one (Tang, 1991) implies the same sequence.

\section{Comparing the Relationships of $+1-$ WH Fronting $+1-$ WH}

\section{Inversion, and $+1-$ YN Inversion}

Now that the Iiterature has been examined for the presence of the various components of the $Q$ TIU that are or may be necessary to account for SLA interrogative data, the next step is to examine the relationships of each of these phenomenon to the others by asking the basic questions inherent in the $Q$ TIU: Does $W H$ inversion imply WH fronting? And, does $Y N$ inversion imply WH inversion?

\section{Does WH Inversion Imply WH Fronting?}

This question concerning the two highest (easiest) positions on the $Q$ TIU can be answered in the affirmative if studies show either that WH fronting is acquired before WH inversion or that WH fronting and WH inversion are acquired simultaneously. As discussed above, most of the literature assumes that WH fronting is present at the 
outset of WHQ production (for example, see again Dulay et a1., 1982; Larsen-Freeman \& Long, 1991; wagner-Gough, 1978; and wode, 1978). Furthermore, as Felix (1981), Pienemann and Johnston (1987), Ellis (1988), and others report, language learners go through a stage in which they produce uninverted WHQs before reaching a stage in which their WHQs are inverted, and even in this stage of uninverted WHQs, fronting is present. By the time learners enter the later stage featuring inverted WHQs, fronting has been long established. Thus, the stages through which learners progress seem to support this first claim of the Q TIU.

Whether WH inversion implies WH fronting can also be examined on the level of individual utterances found in SLA data. In fact, inverted WHQs apparently do not occur unfronted, as noted by Eckman (1984) and discussed at length by Sobin (1977). Eckman (1984) presents the question, Are you going where? (p. 100) as a hypothetical. example of a question that violates the $Q$ TIU because, although the WH word is not fronted, the subject and verb are inverted. Prior to giving this example, Eckman has already asserted that ILs characterized by such questions do not exist, "since no data have ever been presented in support of such an IL" (p. 99). Likewise, although Sobin's (1977) data contain unfronted WHQs; fronted, 
uninverted WHQs; and fronted, inverted WHQs, he states, "Neither in this work, nor in any other work on the acquisition of English as a second language is there any indication of the production by learners of a form like *Did Max have to do what yesterday?" (p. 10). These observations also substantiate the assertion of the $Q$ TIU's first claim.

The case of Unfronted WHQs. Implicit in the Q TIU's claim that $W H$ inversion implies $W H$ fronting is the underlying criterion that if fronting is absent, WH inversion must also be absent, that is, WHQs must be uninverted. From this point of view, an examination of the literature that mentions the existence of unfronted WHQS may also lend support to the claims of the Q TIU.

Gillis and weber (1976) report that, in the first 12 sessions of data collection, the utterances produced by one of their subjects, Akio, "lacked evidence for those transformations essential to the adult grammar of question formation: WH-preposing and Subj-Aux inversion" (pp. 87, 88). Following that period of both unfronted and uninverted WHQs, however, the researchers note that their subject's utterances "were marked by the word orders requiring both these transformations..." (p. 88). From these comments, it appears that the subject may have acquired $W H$ fronting and $W H$ inversion concurrently, 
consistent with the first claim of the TIU. (The other subject in their study was at a lower level, and the $Q$ TIU cannot be applied to his data.)

The subject in the inquiry by Butterworth and Hatch (1978) produced a few unfronted, uninverted WHQs (for example, You watch in television what? and $H e$ is who?) and a few WHQs with the main verb inverted (such as what city like you more?). However, Butterworth and Hatch report that most of the subject's wHQs are fronted and uninverted. That all three of these structures, unfronted, uninverted WHQs; fronted, inverted WHQS; and fronted, uninverted WHQs, apparently occur during the same time period reveals the variability of ILs mentioned in Chapter I. Given that language learners do not typically transition from one stage to the next in a clear-cut manner, the fact that the subject's IL is characterized by the fronted, uninverted WHQs suggests that he is solidly in the + WH fronting stage of the $Q$ TIU. The few unfronted WHQs may signify a strategy of occasionally reverting back to a lower developmental stage, while the few inverted wHQs may foreshadow an approaching stage typified by wH inversion. Under this interpretation, these data also appear to be consistent with the Q TIU. 
This same interpretation may apply to Chen's (1986) data, gathered from 139 subjects. In a written exercise requiring the rapid translation of Cantonese questions into English, Chen reports that most of his subjects' errors in WHQs were due to lack of inversion, while only three or four errors related to unfronted wH words (pp. 126, 128). It thus appears that his subjects who were producing both inverted and uninverted wHQs had already mastered wH fronting.

Although Tang (1991) reports no corresponding numbers or percentages, her examination of the results of several research tools completed by her 135 Cantonese subjects reveals the presence of some unfronted wHQs. Whether these questions seem characteristic of an actual stage of acquisition for the learners or whether the unfronted questions are merely uncharacteristic, isolated instances is not specified. However, with each group of subjects and for each elicitation tool, wH fronting is consistently at the easy end of her scale, and wH inversion is toward the difficult end. In terms of overall stages of the groups of subjects, then, it appears that WH inversion implies wH fronting.

Sobin's (1977) study involves university classes of Spanish-speaking learners of ESL whose task it was to transform written English statements with indefinite 
pronouns into written English wHQs. The subjects produced questions with unfronted wH words such as Max had to do what yesterday? as well as fronted, uninverted WHQs and fronted, inverted WHQs. However, as mentioned above, Sobin points out that his subjects never produced unfronted, inverted WHQs and, from his data, concludes that WH fronting is acquired before WH inversion and that WH inversion does not occur without a fronted WH word. While sobin attributes the presence of unfronted wH words in the unfronted, uninverted wHQs to the influence of the base form of the sentence in transformational grammar and uses his data primarily to support certain arguments related to transformational grammar, his conclusion: support the first claim of the $Q$ TIU, as he himself acknowledges.

Kwan-Terry's (1986) investigation is a longitudinal study of a young Cantonese-speaking boy learning English. In the subject's native language, the question word is not fronted as it is in English, but is left in the same syntactic position that its corresponding phrase occupies in a declarative sentence. A question such as older sister when go school? displays normative interrogative word order in Cantonese. Kwan-Terry finds that her subject initially fronts his wH words only in formulaic utterances, leaving them in place in his productive 
utterances. The pattern of unfronted WHQs, which KwanTerry attributes to transfer from the NL, characterizes a developmental stage that persists in the subject's speech for about nine months. Although Kwan-Terry does not specifically make this connection, a comparison of the ages at which her subject produces certain typical utterances leads to the observation that his productive fronting of wH words appears to be well established before he begins to acquire wH inversion. Hence, these data, too, support the first claim of the $Q$ TIU.

Regardless of the source of the reported unfronted WHQs, whether from L1 transfer as Kwan-Terry (1986) proposes or from the transformational base form as Sobin (1977) suggests, the first claim of the Q TIU is upheld if production of unfronted wHQs has ceased or become very rare by the onset of WH inversion. And such is apparently the case in all the above studies. Thus, it appears that the TIU's claim that WH inversion implies Wil fronting is strongly supported in the literature.

\section{Does YN Inversion Imply WH Inversion?}

There is no such consensus to report for the second claim of the $Q$ TIU, regarding the relationship of YN inversion to $\mathrm{wH}$ inversion. Moreover, it is in the context of this relationship that the various data- 
slicing patterns discussed above add further ambiguity. In terms of acquisition order, an affirmative answer to the question, "Does YN inversion imply WH inversion?" would obtain if WH inversion is acquired prior to or simultaneously with $Y N$ inversion. The following paragraphs examine from this perspective the literature that has already been partially reviewed above. However, some of the studies mentioned above cannot be included in this section because they have a focus that does not reveal the relative order of the acquisition of wH inversion and YN inversion. This includes those studies that examine only WHQs (Bailey, Eisenstein, and Madden, 1976; Ellis, 1992a; Felix, 1976; and Ravem, 1974a), those that deal with YNQs only (Brines, 1990; Hyltenstam, 1981), and the one by wagner-Gough (1978) that focuses on input. The investigations that can be brought to bear on the question concerning the chronological relationship of the acquisition of $\mathrm{WH}$ inversion and $\mathrm{YN}$ inversion $\mathrm{fall}$ into four groups. First, there is research that considers both WHQS and YNQS but that is inconclusive regarding the order in which inversion is acquired in each question type. Secondly, there are studies that place the acquisition of inversion in WHQs and the acquisition of inversion in YNQs together in the same stage. There are also studies that answer the present 
question affirmatively, concluding that $\mathrm{WH}$ inversion is acquired prior to YN inversion. And finally, there are investigations that conclude just the opposite--that YN inversion precedes WH inversion.

Does YN Inversion Imply WH Inversion? Inconclusive Evidence. The following works are plainly inconclusive regarding the acquisition order of WH inversion versus $Y N$ inversion either because inversion is addressed but relevant question types--WHQS and YNQs--are not specified or because data concerning inversion in WHQs and YNQs are presented in two separate, non-intersecting groups.

Three of the seven compilations consulted are inconclusive with regard to the relative ordering of the acquisition of $\mathrm{WH}$ inversion and $\mathrm{YN}$ inversion. In both Hatch (1974) and Hatch and wagner-Gough (1976), stages are presented in terms of "inversion" in general, without specifying whether the stages apply equally to WHQs and YNQs. The focus is actually on the order in which auxiliaries are inverted. Ellis (1988), on the other hand, does separate WHQs and YNQs but still does not speak conclusively as to the order of inversion. In stage 4 he states, "WH pronouns are used productively with a declarative nucleus . . . More-or-less concurrently, inversion occurs in yes/no questions with modals but this may also be formulaic" (p 33). In stage 
5 he says, "Inversion now occurs in both yes/no and wH questions" (p. 33). Because formulaic questions introduce an element of doubt into the picture, it is not clear whether YNQs are actually inverted prior to WHQs or whether both types undergo inversion during the same stage.

Also inconclusive is Adams' (1978) study. As noted in a previous section, Adams' focus was mainly on the order of appearance of and inversion of various auxiliaries. Her method of grouping the data does not allow a chronological comparison of the development of $\mathrm{YN}$ inversion versus wH inversion, except in reference to one specific auxiliary about which she reports, "The dosupport appeared in yes/no questions first. Shortly after its appearance there, it began to emerge in $Q$-wh" (p. 287). Beyond that, she makes no comparison between YNQS and WHQS, presenting instead separate lists of acquisition order for each type.

Kwan-Terry's (1986) study is also inconclusive because she essentially does not compare the timing of WH inversion with the timing of $Y N$ inversion. From the beginning of her study, her subject produces inverted and uninverted forms of both YNQs and WHQs. Kwan-Terry argues that all of the apparently inverted forms are merely formulaic and supports her analysis with evidence 
that they all contain a limited number of patterns, namely, What's $X$, Where's $X$, Is it, Can + pronoun, Are you, and Did + pronoun. The only reference she makes specifically concerning the chronology of the development of inversion in YNQS relative to WHQs is when she notes that did-support develops first in YNQs for her subject and only much later in WHQs (p. 31). This need not be interpreted as evidence contrary to the $Q$ TIU, however, because Kwan-Terry maintains that all the questions involved are formulaic.

The studies appearing in the next paragraphs also are inconclusive because the researchers make no claims about which type of inversion is acquired first due to their focusing on other issues. However, as it happens, in each of these cases, the researchers provide enough examples or datia that some reanalysis can be applied, with the result that the data may be interpreted to partially confirm the hypothesis that YN inversion implies WH inversion.

The report by Butterworth and Hatch (1978) implies that their subject's question-forming strategies remain constant throughout the duration of their observation. His YNQs are uninverted and marked by rising intonation, and most of his WHQs are fronted and uninverted. However, Butterworth and Hatch also present a few 
examples in which WHQs exhibit an inverted main verb. In contrast, they present no examples of inverted YNQs. This may possibly indicate that their subject is preparing to enter a new stage in which wHQs, but not YNQs, are inverted, the + WH inversion stage of the $Q$ TIU.

Lindholm (1986) does examine WHQs and YNQS for inversion, but she does not attempt to interpret her results in terms of the chronology of their acquisition. However, in her Table 2, she displays, among other items, the percentages of inversion for both WHQs and YNQs for her four subjects. Because she includes percentages for two different observations of each subject, performed a year apart, a total of eight comparisons of wH inversion with YN inversion can be made. Seven of these eight comparisons reveal that WHQs are inverted at a higher rate than are YNQs. Thus, under this reanalysis, Lindholm's data may be interpreted to support the $Q$ TIU to a large degree.

Likewise, although Syamala (1991) examines WHQs and YNQs separately, his focus is not at all on the issue of the relative order of inversion of the two question types. Instead, he considers only the percentage of correctly and incorrectly formed questions, focusing on the types of errors present in those incorrectly formed. 
However, he does offer data in his Table I that is amenable to some analysis in terms of the $Q$ TIU. For each of three levels of students he supplies the number of questions correctly formed, unattempted, and erroneously formed for YNQs and for WHQs. If the unattempted questions are disregarded, the number of correctly formed questions can be compared to the total number of questions produced, for each group. The resultant percentages indicate that his two lower groups of subjects produce slightly more correctly inverted WHQs than YNQs, a finding that seems to substantiate the $Q$ TIU. However, Syamala's highest group of students produces more correctly inverted YNQs than they do WHQs, a result that contradicts the TIU. A confounding factor is that syamala apparently requires NS-like tense and number agreement to be present in subjects' questions before he considers them to be correct. In other words, in his study, inversion is confounded with tense and number issues. Were this not the case, his results may more stongly support the Q TIU.

Does YN Inversion Imply WH Inversion? Consistent Evidence. Several sources place WH inversion and YN inversion together in the same developmental stage. It is not always clear whether the researchers do so because they view the acquisition of $\mathrm{YN}$ and $\mathrm{WH}$ inversion as 
occurring simultaneously or because they find no definitive answer as to which is acquired first. However, the fact that they are placed into the same stage may be construed as evidence consistent with the $Q$ TIU. A few of these studies also contain additional comments or data that may be seen as evidence that actually confirms the hypothesis that $Y N$ inversion implies WH inversion.

Three of the seven compilations consulted group WH inversion and $Y N$ inversion together in the same stage. Larsen-Freeman and Long (1991) describe their stage 3 as a time when inversion "is applied correctly to yes/no and WH-questions" (p. 93). Similarly, Ellis (1986) first describes both uninverted WHQs and uninverted YNQs and then writes, "Somewhat later, inversion occurs in yes/no questions and in WH-questions" (p. 61). Lightbown and spada (1993) present the same view when they say that stage 4 consists of "Inversion in wh- and 'yes/no' questions" (p. 63). These pairings of WH inversion and YN inversion into the same stage may reflect the constraints of the $Q$ TIU.

In primary research, Gillis and weber (1976) do not make any clear-cut claims about which type of question is inverted first. However, whereas their first period is characterized by an absence of productive inversion in 
either type of question, they indicate that inversion is frequent in both WHQs and YNQs by the second period. Since they give no further detail, a definitive answer on the order of acquisition of $\mathrm{WH}$ inversion versus $\mathrm{YN}$ inversion is impossible, although the researchers seem to suggest that both are acquired during the same stage. A complicating factor, possibly one that prevents them from making a stronger statement regarding acquisition order, is that their most advanced subject, on whose data they base most of their discussion, tended to employ many formulaic question forms.

The study by Cazden et al. (1975) does specifically investigate the relative acquisition order of WH inversion versus YN inversion. They ask, "Does Klima ani Bellugi's "Stage C" [where YNQs are inverted but WHQs are not] exist for our second language learners?" and, "Is there a stage for our second language learners which is the exact opposite of "Stage $C, "$ i.e., where wh-question:s are inverted and $y / n$ questions are not?" (p. 35). Their answer is that there is not a stage in which YNQs are inverted while WHQs are not, but neither is there a stage in which WHQs are inverted while YNQs are not; "Inverted $\mathrm{y} / \mathrm{n}$ questions do not precede inverted wH-questions or vice versa" (p. 35). Despite their conclusion, a reanalysis that calculates percentages of inverted WHQs 
and YNQS from their data tables reveals that subjects consistently invert a higher percentage of wHQs than YNQS. However, this may not be sufficient evidence to conclude that control of WH inversion precedes control of YN inversion because the numbers in the tables apparently include what Cazden et al. consider to be formulaic utterances as well as utterances that the researchers consider to be productive and, therefore, truly inverted by the subjects. Cazden et al. make this distinction in utterance types in their text and hesitate to give subjects credit for inversion in formulae. However, their data tables seem to report both formulaic and productive utterance types together, undifferentiated.

Shimada (1987) also explicitly states that Klima and Bellugi's stage in which YNQs are inverted but WHQs are not is not evidenced in her data. Instead, she suggests that her subject acquired $\mathrm{YN}$ inversion and $\mathrm{WH}$ inversion simultaneously in stage III, which she describes as a stage in which "Both Yes-No and wh-questions were sometimes inverted and sometimes not" (p. 4). In addition, although shimada does not interpret it as such, her data may actually be viewed as support for the sequence of $\mathrm{WH}$ inversion before $\mathrm{YN}$ inversion because she indicates that the proportion of inverted WHQs is higher than that of YNQs (p. 5). 
All of these studies which group WH inversion and YN inversion into the same developmental stage may be interpreted as providing evidence that is consistent with the second claim of the $Q$ TIU because the requirements of the TIU are met if acquisition of $\mathrm{WH}$ inversion and of $\mathrm{YN}$ inversion occur simultaneously.

Does YN Inversion Imply WH Inversion? Confirming Evidence. A few inquiries supply evidence that specifically confirms the second claim of the $Q$ TIU. As discussed in a previous section, Eckman et al. (1989) specifically seek to test the $Q$ TIU against SLA data. After evaluating their data by establishing a 90 percent accuracy rate as the criterion for control and by comparing each subject's relative rates of $\mathrm{WH}$ and $\mathrm{YN}$ inversion, they conclude that inversion in YNQs implies inversion in WHQs.

Wode (1978) reaches the same conclusion in his longitudinal study of four German children, ages $3 ; 11$ to 8;11, learning English. In exposing the differences between the L1 and the L2 acquisition of interrogatives, he points out that, in contrast to Klima and Bellugi's stage $C$ in FLA in which YNQs are inverted but wHQs are not, the SLA data contains no such stage. In fact, he maintains that the opposite pattern emerges: "in the L2 
data inversion first occurs in copula wh-Q. Furthermore, do-support is earlier in wh-Q than in JNQ [YNQ]" (p. 53). Partial support for the hypothesis that YN inversion implies $\mathrm{WH}$ inversion may also come from the study by Huang and Hatch (1978). Although their subject does not control inversion in either WHQs or YNQs requiring do throughout the duration of their investigation, it is clear that he does acquire a productive inversion of $\mathrm{WH}$ copula questions well before such inversion appears in YNQs. This pattern of development in Huang and Hatch's subject is also cited by wode (1978) as further L2 evidence in support of his own findings, described in the previous paragraph.

Does YN Inversion Imply WH Inversion? Disconfirming Evidence. In contrast to the sources above that are consistent with or confirming of the claim of the $Q$ TIU that YN inversion implies WH inversion, there are several. studies that reach the opposite conclusion, namely that YN inversion precedes $\mathrm{WH}$ inversion. However, in every case, this conclusion may be disputed, and, in most cases, some kind of possible explanation can be found to account for the pattern that deviates from the $Q$ TIU. Summaries of the disconfirming works appear in the paragraphs below along with remarks addressing their possible limitations. 
Only one of the compilations consulted stated that YN inversion is acquired prior to WH inversion, and that statement is given rather tentatively. Dulay et al. (1982) say,

From the available data, scanty though they are, it appears that for some subjects at least, the auxiliary inversion rule is applied to yes/no questions somewhat before it is applied to wh-questions. Likewise, the doinsertion rule seems to begin operating on yes/no questions before it operates regularly in the wh-questions. (p. 132)

Ravem (1974a, 1974b), as mentioned in a section above, finds that one of his subjects, Rune, produces uninverted WHQs while, during the same period, he typically forms YNQs by inverting the main verb with the subject. And although his other subject, Reidun, goes through a stage in which she uses both uninverted WHQs and uninverted YNQs, Ravem (1974b) reports that she acquires inversion first in YNQS. Thus it appears that, for these subjects, YN inversion precedes WH inversion, violating the Q TIU. However, Ravem does make a point of mentioning that his subjects' NL, Norwegian, employs inversion in both WHQs and YNQs, and he suggests that it is possible that the subjects are transferring questionforming strategies from their L1. That the L1 transfer assists only in YN inversion may be due to the fact that 
such questions are syntactically simpler than wHQs (see Eckman et al., 1989, for a similar argument).

Although Sobin's (1977) exploration involves WHQs exclusively, in a discussion attempting to further the implications of his findings, he mentions, unsupported by references or data, his assumption that ESL students "apply inversion in yes/no questions earlier than they do in wh-question" (p. 26). This is the extent of his comment on the issue.

Felix (1981) also seems to find that $Y N$ inversion precedes WH inversion. Although he does not explicitly make such a statement, that conclusion may be inferred from his study. He finds that, in the first two weeks of: instruction, his German ESL students produce 21 percent of their YNQS without inversion. Later he remarks,

While the students learned fairly soon to
correctly apply the inversion transformation to
yes/no questions, the earliest instances of wh-
questions lack the NP/Aux inversion. In this
case the percentage of uninverted structures,
calculated for a period of two and a half
weeks, is even higher than in the case of
yes/no questions, namely 43\%. (p. 100)

Thus, it seems that his subjects show greater control of YN inversion than of WH inversion. It is possible that this violation of the $Q$ TIU may be due to a high degree of monitoring, however. Felix states that in English class, the subjects were required to "strictly conform to 
the type of pattern presented by the teacher. Errors were immediately and consistently corrected" (p. 90). In addition, the teacher blocked any attempted utterances that did not follow the intended pattern. This type of learning environment may have caused the subjects to monitor their utterances heavily, and the monitoring may have been more successful in the case of the syntactically simpler YNQs.

Chen's (1986) data also appear to contradict the $Q$ TIU. He divides YNQs and WHQS according to the auxiliaries they require in NS English and finds the following stages in his subjects' route of acquisition: 1) YNQs with copula or main verb have, 2) YNQs with an aspect auxiliary, 3) YNQs and WHQs with do, and 4) WHQs with copula. Based on this sequence, he claims that YN inversion is acquired prior to WH inversion. However, reviewing his methods used in arriving at this conclusion reveals two possible problems. First, in his elicitation task, he tests four different YNQ structures (copula, have, aspect auxiliary, and do) but only two WHQ structures (do and copula). Since the task is a translation task, he could have more evenly distributed the target structures types among the YNQs and WHQs. Had he done so, different results may have been obtained. Also, in judging whether or not his subjects' utterances 
demonstrate inversion, Chen uses a point system in which NS-like questions are given full credit, while questions with the wrong auxiliary or with tense, number, or both that do not accord are given only partial credit, even though they are inverted. The significance of this is that, in Chen's results, as in syamala's (1991) above, inversion is confounded with tense and number agreement. If it were not, the results could have possibly been much different.

The results of Pienemann and Johnston (1987) and Pienemann et al. (1988) do not readily fit into the dimensions of the $Q$ TIU because they also "slice the pie" differently. They divide both YNQs and WHQs into two groups and contend that acquisition proceeds from "Dofronting" YNQS to "Pseudo-inversion" WHQs to "Yes/Noinversion" to "AUX-2nd" WHQs. Nevertheless, it seems that they, also, are claiming that YN inversion precedes WH inversion, and Cook (1993, p. 101) endorses this interpretation of their work. Their claim is subject to the limitation of their definition of inversion, however. "Do-fronting" and "Yes/No-inversion" are both descriptions of YNQ types. Presumably the fact that a distinction is made between the two types implies that questions with a "fronted" do word are not inverted (a notion subscribed to by several investigators who view do 
as a formulaic question marker because it of ten appears question-initially, unmarked for tense or person). This would mean that there is no YN inversion before a stage of "Pseudo-inversion" in WHQs. Pienemann et al. define "Pseudo-inversion" WHQs as WHQs with copula $B E$ as a verb. The label "Pseudo-inversion" implies that such wHQs are not inverted; however, the $+/-$ inversion status of WHQs with copula is a matter of debate, and an argument in Chapter III contends that such WHQs are, indeed, inverted. If this is the case, and "Do-fronting" YNQs are actually formulaic, then WH inversion precedes YN inversion even in the framework of Pienemann et al.

A final dissenter to the TIU's claim that wH inversion precedes $\mathrm{YN}$ inversion is Tang (1991). She elicits data on the acquisition of English interrogatives from three groups of Cantonese-speakers by means of five elicitation tasks: a timed oral production task in which the subjects construct dialogs based on a set of cue cards; an untimed, written dialog completion task; a timed, written grammaticality judgement task; and untimed error correction and grammatical explanation tasks. She finds that for all groups of students on all measures, YN inversion is easier than (or, for one group on one task, equally as easy as) WH inversion. In the description of her methodology and in her discussion of the results, 
there is no limiting factor apparent that may account for this contradiction of the $Q$ TIU. However, since she makes no mention of her criteria for determining the presence or absence of inversion, this may be the explanation. If Tang required tense and number to also be correct as did chen (1986), whose work she cites, and Syamala (1991), her study may also confound inversion with other issues. However, there is no evidence that this is the case.

Tang's study presents an additional challenge to the Q TIU. As reported in a previous section, her results show support for the claim of the Q TIU that WH inversion implies WH fronting. However, the segment of the TIU that claims that $\mathrm{YN}$ inversion implies $\mathrm{WH}$ inversion also actually contains the entailment that YN inversion also implies wH fronting. For no other study consulted is this claim a problem. For Tang's, it is. Tang's results not only show that $Y N$ inversion is easier than $W H$ inversion, but they also show that, for eight out of 15 student group/task type combinations, YN inversion is easier than WH fronting and that, for one other student group/task type combination, YN inversion and WH fronting are equally difficult. In other words, Tang's data support an acquisition order that proceeds from YN inversion to wH fronting to $\mathrm{WH}$ inversion. However, her 
data that indicate, contrary to the TIU, that YN inversion precedes WH fronting may possibly be explained in terms of task type. This is because the data show that YN inversion is demonstrated to be easier than WH fronting almost exclusively in timed tasks but not in untimed tasks. As to why this should be the case, Tang offers no explanation.

The fact that the above portion of the literature review reveals no consensus as to the relative order of the acquisition of WH inversion versus $Y N$ inversion indicates, at the least, that the assertion that YN inversion precedes $\mathrm{WH}$ inversion is a question still open for discussion. At the most, it may signify that the TIU is inaccurate for predicting SLA data. The present study aims to join the debate.

\section{SUMMARY}

This chapter discussed SLA studies that indicate that cross-linguistically established TIUs may constrain language learners' ILs. If the constraints of TIUs extend to ILs, then the application of TIUs to SLA may prove to be a more accurate source of explanation and prediction for SLA data than was the previous theory of Contrastive Analysis. In addition if, as Gass (1980) suggests, a multifactor approach is taken, including TIUs 
as the dominant force in SLA, but also considering specific facts of the NL and TL, then the TIUs' application to SLA may also account for those instances when transfer from the NL is evident, instances for which the theory of Creative Construction hypothesis could not account.

Although the results in the studies cited above generally, and at times overwhelmingly, support the hypothesis that TIUs constrain ILs, it seems that more investigation is needed to confirm the hypothesis. To date, the results of the application of TIUs to SLA are limited because relevant studies either have focused on a single TIU, the $\mathrm{AH}$, or, when considering other TIUs, have involved a very small number of subjects. Although the few studies involving different structures also seem to confirm this hypothesis, more research needs to be conducted with TIUs other than the $\mathrm{AH}$, including replication studies of the structures already examined, such as interrogatives and complements, as well as studies of as yet unexplored TIUs. The next chapter describes the design and procedures of this study, which seeks to contribute to the ongoing efforts to explain and predict SLA data by investigating the relationship between the TIU for interrogatives and language learners' ILS. 
CHAPTER III

\section{METHODOLOGY}

\section{INTRODUCTION}

This study consisted of an empirical investigation that sought to confirm the hypothesis by comparing the presence of each interrogative structure as predicted by the TIU with the actual presence of each in the IL of learners of ESL. The IL data were elicited by means of an individual interview in which subjects looked at story square pictures and had to discover the underlying story by asking questions of the interviewer. The data elicitation sessions were tape-recorded, the tapes transcribed, and the transcribed interrogatives categorized and analyzed. (A listing of all categories employed is given in Appendix B.)

\section{SUBJECTS}

The 32 subjects for this study were drawn from two groups. The first group of subjects $(n=12)$ were female high school students in a spring Break study Program at a local college. They had come as a group from their high school in Japan to the American college for a week of 
intensive ESL conversation/American culture classes, as well as classes in art, crafts, fashion, science, computers, drama, and sports. The high schoolers also participated in field trips and other activities and stayed with American host families. The schedule planned for these students' short time here was very busy, resulting in the fact that their time available to participate in this study was limited to 30 minutes during either lunch or snack breaks. In actuality, this time could often be stretched to about forty minutes, but sometimes had to be reduced to slightly fewer than 30 minutes.

The second group of subjects $(n=20)$ were college students, both men and women, currently or formerly enrolled in academic-track ESL classes at the same local college. These students participated in the study either during their free time or during teacher-approved release time from classes. Each of them signed up for a 30minute session, but since their schedules were not as full as the high school students', this time often stretched to about 40 minutes, or, in a few cases, to 45 minutes.

The subjects were between the ages of 16 and 23 and had studied English as a foreign language for four to eight years. Generally, the older students were also 
those who had studied English longer. Their time studying ESL in the United States ranged from two days to one-and-a-half years: only two to five days for the high school group (the Spring Break Study Program was five days long), five to 19 days for 14 of the college students (they had just arrived), and six months to a year-and-a-half for the others.

The subjects' English proficiency levels ranged from Very Low Beginning to Advanced. Although for the 12 high schoolers no standardized measure of ability level was available, their teachers, the program administrator, and the researcher subjectively classified nearly all of them as being at the very Low Beginning to High Beginning level of an American academic-track college-level ESL program. The college ESL students had been placed in their levels of academic-track ESL classes according to their scores on the Michigan English Placement Test and ranged from Very Low Beginning to Advanced. Six of these college-level subjects were classified as Very Low Beginning to High Beginning; there were eight subjects of Low Intermediate to High Intermediate level; of the remaining six, three were at an Advanced level in ESL classes, one was taking a combination of ESL and regular academic classes, and two had finished the ESL program 
and were taking only regular academic classes at the college.

All subjects were volunteers, and all except the three post-ESL students were from five intact classes. with the exception of one class, all members of each class participated in the study. In that one class, four of eight possible subjects participated.

The native language of the subjects was an important consideration. Eckman et al. (1989) selected subjects whose native languages were Japanese, Korean, and Turkish specifically because these languages do not use the question strategies employed in English (or in the TIU). This was necessary so that if the TIU order were evidenced in the data, it would clearly be as the result of the influence of the universal and not as the result of transfer from the native language. Similarly, the present study needed participants whose native languages do not employ the question strategies used in English for in the TIU). For this reason, the researcher investigated the native languages of various ESL student populations available within the geographic area, in order to determine their appropriateness for this study. The examination of Chinese, Russian, Arabic, Vietnamese, and Japanese found that either there was insufficient evidence available for the language's suitability or that 
the language used some or all of the question strategies that English uses, except in the case of Japanese. Japanese alone could be demonstrated to meet the criterion. Therefore, by design, the native language of all subjects was Japanese.

\section{INSTRUMENTS AND MATERIALS}

All the participants completed a subject Information Form and a story squares interview. In addition, some further materials were needed to model for the subjects what their task was to be. All these materials are described below.

\section{Subject Information Form}

Each subject completed a form requesting demographic information including the subject's native language, age, number of years studying English, length of study in the USA, and other languages studied. This information is reported in the "SUBJECTS" section, above.

\section{Story Squares}

\section{Selecting the Elicitation Tool}

The story square pictures were chosen as the elicitation tool because they uniquely met two important criteria. First, the story squares could elicit data 
with a very high density of questions, both YNQs and WHQS, with various auxiliaries and various wH words. In addition, the story squares provided a quite authentic communicative context and purpose that allowed the elicited data to be as natural, spontaneous, and authentic as possible. The subjects' task with the story Squares could be structured so that the subjects remained unaware of the purpose of the task, or, at least, so that their focus was on the structure under inquiry to the least extent possible. This was important so that the data would be produced spontaneously instead of by meticulously consulting known grammar rules.

\section{The Story Squares Themselves}

Story squares, taken from an ESL textbook entitled Story squares: Fluency in English as a Second Language (Knowles \& Sasaki, 1980), were used to elicit speech from the subjects. The story square pictures used in this study were unaltered from the originals except that the textbook directions were deleted and the names of some characters were changed. A story square consists of a three-by-three or four-by-four grid of line-drawn pictures that partially tell a story and that relate to at least three or four different characters depicted at various times and in different settings. Each picture is a hint about the story, but all the pictures taken 
together as a whole are not sufficient to reveal the story. In fact, in most cases, the pictures even appear to be rather unrelated. The subjects' task, after receiving some basic information about the pictures, was to discover the story and solve the mystery by asking questions about the pictures.

The puzzle-like nature of the story squares and the knowledge that they work together to solve the mystery presented in the pictures make a story square very intriguing. The amount of interest that the story Squares roused in the subjects was intended to take the focus off of the forms being produced and place it on to the desire to solve the mystery. This objective seemed to be reasonably fulfilled; subjects seemed to think that the purpose of the study was to determine how quickly they could discover the story. The data thus elicited is, therefore, presumed to be relatively natural and spontaneous since it was focused mainly on an authentic communicative purpose, an important consideration in SLA research (Larsen-Freeman \& Long, 1991; Tarone, 1988).

Five story Squares were available, each listed here by its title used for this project, followed by its original title in parentheses: "Patty and Tom" (The Ru Lou Square), "Tina and Peter" (Baltimore Blues), "Professor Brown" (The Boris Affair), "Mr. Puff" (The 
Downfall of J. B. McBribe), and "Jimmy Chang" (Murder on the Amtrak Express). Since the "Patty and Tom" and "Tina and Peter" stories required primarily commonly-known vocabulary, dealt with everyday relationships, and included concepts probably within the realm of at least vicarious experience for most subjects, these two stories were judged "easiest" and chosen as the primary elicitation tools. Of the remaining stories, "Mr. Puff" and "Jimmy Chang" seemed to be somewhat more difficult, and "Professor Brown" was the most difficult because of its esoteric concepts. They were used as examples, backup elicitation tools, or both. Appendix $\mathrm{C}$ contains the "basic information" for each story, the complete stories, and the five picture grids.

\section{Vocabulary Cards}

To assist low level subjects, two sets of vocabulary cards were made to accompany the story square interviews. A Japanese man, bilingual in Japanese and English and familiar with the stories represented by the story Squares, made the cards, which each had a difficult English word or phrase written at the top, with the Japanese translation written below. The first set of cards consisted of words and phrases necessary for instructions given to the subjects: mystery, puzzle, discover, solve the mystery, hint, something is still 
missing, and There's more to the story are examples. The second set of vocabulary cards consisted of words necessary for understanding the stories, including kidnap, ransom money, steal, headache, factory, motorcycle gang, fired, and explosion. Different stories required different numbers of vocabulary cards.

\section{"WH Card"}

A card with the words who, what, which, when, where, why, and how written on it was available if subjects needed it.

\section{Materials for a Model story square Session}

A story Square that was not used to elicit data from subjects was prepared as an example, to demonstrate to the subjects exactly what their task was to be. For the high schoolers, this model session was a live, participatory meeting, requiring only an overhead transparency, multiple copies of the story square "Mr. Puff," and an interpreter. For the college group, however, an interpreter was not available, so a model session using the "Professor Brown" story square was videotaped and used to acquaint the subjects with their task. 


\section{PROCEDURES}

\section{Pilot study}

A pilot study was carried out with three participants. As a result of the pilot study, it was decided that 1) two story squares were necessary in order to elicit sufficient data, 2) certain essential vocabulary needed to be provided via vocabulary cards, 3) a model session was necessary in order to acquaint subjects with their task and reduce the amount of time required for each individual session, and 4) instructions specifying allowable question types should not be given. This fourth point represents a deviation from the methods used by Eckman et al. (1989). Those researchers first instructed subjects to ask only YNQs and later allowed WHQs also. Similar instruction given to the first pilot study participant resulted in an average $Y N$ inversion rate of 82 percent when only YNQs were permitted. That rate fell to only 4.5 percent as soon as restrictions on question type were lifted. Clearly, the instructions placing restrictions on the type of questions allowed were resulting in highly monitored utterances instead of the hoped for spontaneous utterances. Since spontaneity was considered more necessary even than type of questions elicited, all instructions restricting question type were 
eliminated after the first pilot subject. Data elicited from the two remaining pilot subjects appeared to be free of unusually heavy monitoring. The data elicited from the pilot study participants were used only for informing procedures for the main study and are not reported on in this paper.

\section{The Study}

\section{Introduction}

Most subjects first encountered this study when the researcher presented the project to their class, asked for volunteers, modelled a story square session either live or via.video-cassette, and collected consent forms. subjects then signed up for 30 minute individual interviews during which they would attempt to solve two Story Square mysteries. Because of busy schedules and other time constraints, eight of the high schoolers met with one of two research assistants, and four of the college subjects met with one of the research assistants. Two college subjects who had already finished ESL classes did not have a class presentation; they were individually asked to participate. They then watched the videotaped model session and completed their interviews in one sitting each. More specific procedures are detailed in the following paragraphs. 


\section{story Squares Model Session}

During the initial presentation of the project, classes were shown a model story square session. For the high schoolers, who were the first to participate in the study, this session consisted of a live, participatory practice session with the researcher and a facilitating interpreter. The researcher had wanted to use the "Professor Brown" Story square as the model because it was the hardest and its difficulty could limit the amount of data produced if it became necessary to use it in individual interviews with subjects. However, the interpreter deemed the "Mr. Puff" story more likely to be approved by the chaperones who had accompanied the high schoolers from Japan. Thus, "Mr. Puff" was chosen for the model.

The "Mr. Puff" story square picture grid was projected on a screen, the basic information was given in English and interpreted into Japanese, copies of the story square were distributed to pairs of subjects, and finally, the subjects were instructed to solve the mystery by asking as many questions as possible. The researcher and the interpreter circulated separately among the subjects, answering questions whether in English or Japanese, but not many questions were forthcoming. Instead, subjects shared whatever 
information they had gleaned, as well as speculations, between pairs and gradually discovered the story without asking many questions. This unexpected turn of events had the felicitous effect of ensuring that the session in no way instructed the subjects on the question formation strategies of English, while at the same time providing the subjects practice with the format of the story squares. Story square interviews with individual subjects commenced the next day and continued for four days.

The model session took a different form for the college subjects. Initially it was thought that since students in even the lowest level of the college's ESL program generally have a higher English proficiency than those in the spring Break study Program, it would not be necessary to show them an example story square at all. However, after two of the first three subjects needed an example (provided to them by telling them the "Professor Brown" story), it was decided that all future subjects should see a model session in their intact classes before participating in their individual sessions. Because the interpreter who had helped with the high schoolers was no longer available and because several more model sessions would be necessary, the decision was made to use a videotaped model session rather than a live, 
participatory session. Two Japanese-English bilinguals volunteered to be taped. Before the taping, one volunteer was briefed on the "Professor Brown" story. On the video, she then played the role of researcher, while the other, who did not know the story, played the role of subject, asking questions until he discovered the story and solved the mystery. The videotape was produced in Japanese. It was subsequently shown to all the groups of college-level subjects before their individual story Square interviews.

Although the two types of model session were quite different from each other, it is doubtful that any confounding variables were introduced by the two formats. Certainly the video, because it was in Japanese, could have had no effect on the subjects' English speech production, regardless of how little time elapsed between the viewing of the video and the eliciting of the speech. Concerning the live model format, even if the participatory session could be construed as being an unintentional teaching tool or an opportunity for some subjects to practice question formation in English, the benefits of this extremely limited instruction or practice must surely have worn off before the first individual story square interviews were conducted the day following the live model session. In addition, since all 
subjects had studied English for years, they had all undoubtedly received much formal instruction in English question formation prior to participating in this study, and a few minutes of further "instruction" would not be likely to suddenly change their ability levels. Furthermore, in the improbable event that the participatory model session could have improved subjects' question formation abilities, however slightly, that would have had the effect of simply moving them up to the next level on the hierarchy of the universal rather than producing some sort of qualitative change in their question strategies. Subjects who participated in the live model session and those who viewed the video seemed equally confident about the format of the story squares and their task when they came to the individual interview sessions, so both forms of model session accomplished the goal of acquainting subjects with their task.

\section{Story Squares Interviews}

Subjects met individually with either the researcher or an assistant to attempt to solve the mystery for two Story squares. These individual interview sessions took place in quiet rooms free of distractions and lasted about 30 minutes. The sessions were tape-recorded. Since tape-recorders have an inhibiting effect on most ESL students, the tape-recorder was hidden from view, and 
the subject could see only two small microphones on the table, one for the subject and one for the interviewer.

As an ice-breaker and in order to elicit some declarative statements from the subject, an objective not always reached, the interviewer asked the subject lusing declaratives, not questions) to tell about his or her hobbies, American host family, or family in Japan. The subject was then presented with the first story square for data elicitation. In all but five cases this was the "Tina and Peter" story square. (The five atypical cases are explained below in the discussion of interviewing problems.) The subject was reminded of the format of the Story Squares; was given the basic information about the story including the characters' names, a partial explanation of each of the pictures, and some indication as to the time when the events depicted occurred, along with necessary vocabulary cards; and then was asked to be a detective and to try to solve the mystery by asking as many questions as possible. No restrictions on question type were given; in fact, no mention of question type was made at all because of the results of the pilot test. The instructions that the interviewers gave to the subjects and a listing of procedures for the interviewers are included in Appendix D. 
As the subject asked questions, the interviewer supplied answers, and, when necessary, hints. Hints were usually either in the form of information about missing bits of the story or in the form of vocabulary cards. Sometimes, when the subject seemed unable to think of further questions, the interviewer reviewed the alreadydiscovered facts of the story as a hint. Occasionally, when it seemed to the interviewer that the subject was producing few if any wHQs, the interviewer would present the subject with the WH Card along with the hint, "Maybe these words can help you." However, the presentation of the WH Card rarely had the effect of eliciting more WHQs from the subject. If subjects so desired, they were allowed to use their bilingual dictionaries to look up unfamiliar words not supplied by the vocabulary cards. In each case, the interviewer also looked at the dictionary entry to make sure that subjects were not reading entire questions from the dictionary. In nearly all instances, the dictionary entry provided only single words. When entire questions were supplied, the interviewer made a note of this and such questions were not admitted to the analyzable data. When the story was discovered, the subject was asked to summarize it, in another not-always-fulfilled attempt to elicit declaratives (see Eckman et al., 1989, p. 204), and was 
then presented with a second story square, usually the "Patty and Tom" story. After completing as much of both story squares as possible in the given time, the subject was advised that the stories were a secret, not to be discussed with other students.

Several problems arose concerning the procedure, two of them unanticipated. The first problem involved the worry that interviewers might ask questions of the subjects, thereby modelling the target constructions for the subject and possibly having the undesirable effect of instructing or correcting the subjects' own production of questions in a way that would skew the data. Therefore, throughout each session, the interviewers tried to refrain from producing utterances interrogative in form, but this was not always possible. However, even when interrogatives were unavoidably produced, there seemed to be no effect on the form of the subjects' questions because subjects continued to produce uninverted forms.

The second problem was that, due to the lack of directions prescribing that either only YNQs or only WHQs be produced at certain points during the interview, very few WHQs were produced by some subjects. This type of problem had been anticipated; however, because of the implications of the directions that Eckman et al. (1989) gave to their subjects, it had been anticipated that 
YNQS, not WHQS, would be scarcer in the data. Because of this expectation, an effort was made in the pilot study to augment the number of YNQs produced by initially giving the subject "YNQs only" instructions. However, a:s noted above, these instructions resulted in the subject's paying so much attention to form that the quality of datia was greatly altered. Since spontaneous, unmonitored data was considered more important than having the "correct" proportion of YNQS to WHQS, instructions restricting question type were discarded after the first pilot study participant. The result was that 11 of the subjects produced fewer than ten WHQs.

Another complication involved the fact that, occasionally, the subject seemed to be already somewhat familiar with the first story square, presumably from hearing about it from another subject whose interview had already been completed. The problem with this familiarity was not that the authentic communicative value of the story square was voided; the subject never had complete knowledge about the story, so there were always at least a few new things for the subject to ask about. Rather, the problem with such familiarity was that the story could be discovered much more quickly, with fewer questions necessary, thereby reducing the amount of data gleaned. In such cases, the second story 
Square presented was one that had not yet been used with any of the subject's classmates, and a more difficult one, either "Professor Brown" or "Mr. Puff" (depending on which had been used in the subject's model session) or "Jimmy Chang." This invariably resulted in the session continuing for the full 30 minutes. (In the case of the last high schooler interviewed, where it seemed that the stories had become the talk of the class, the first story Square presented was "Professor Brown.")

The first unanticipated problem was that some subjects tried to guess the story instead of asking questions, which meant that these subjects produced more declaratives and fewer questions than hoped for. Probably all subjects guessed in this manner from time to time, but for some subjects this became a problem that needed to be dealt with. In the cases of thoso persistent guessers, the interviewer tried to change the subject's strategy by saying things such as "Oh, don't tell me the story! Ask a question!" However, this technique did not always result in more questions on the subject's part. In addition, when a subject was very shy and hesitant this technique could not be used without running the risk of silencing the subject altogether. Also, such direction, especially if given too frequently, might have interrupted the flow of spontaneous speech. 
The other unanticipated problem was that, for six of the college subjects, the tape-recorder failed to work. Two of these subjects, in spite of the fact that they were in the college-level ESL program, had such low level English abilities that the story squares had been extremely hard for them, and most of their utterances had consisted of only one word each. Rather than ask them to endure another interview, these two were culled entirely from the study. The remaining four subjects graciously agreed to complete another interview. Since their model session had used the "Professor Brown" story, the subjects did the "Mr. Puff" and "Jimmy Chang" stories for the second interview, with the exception of one subject who, because of an exceptionally long day, was too tired to continue after finishing the "Mr. puff" story, but who still produced enough questions with that single story square. Although these subjects' first interviews could arguably have given them practice forming English questions that the other subjects did not receive, the effect of that practice would not have made these subjects' data qualitatively different from that of the other subjects. If the practice gained in the first interview had any effect at all, it would have been only to push the subjects up to the next level on the 
hierarchy of the universal, in which case the resulting data would still be admissible for this study.

\section{Subject Information Form}

After all subjects from a given class had completed their story square interviews, the subject Information Form was distributed to the class as a whole. With the help of an overhead transparency, the researcher guided the subjects in completing the form.

\section{METHODS OF DATA CATEGORIZATION}

\section{Overview}

The tape-recorded interview sessions were transcribed using standard orthography, supplemented with phonetic transcription where necessary; both the interviewers' and the subjects' utterances werc transcribed. The subjects' utterances were then categorized based on an analysis of their surface structure, in conjunction with a discourse analysis. In general, subjects' utterances were one of three types: 1) non-question utterances, 2) questions that were not analyzable according to the TIU because they did not contain both subject and verb (referred to as "UNAQ" utterances, UNAQ standing for "unanalyzable question") and 3) questions that were analyzable according to the 
TIU (referred to as TIU QS; Appendix B contains a list of all UNAQ and TIU $Q$ categories, along with a brief description of each.) Ultimately, as described in Chapter IV, utterances of the third type were analyzed according to the TIU: as in Eckman et al. (1989), the total number of WHQs and of YNQs for each subject was counted, and the percentages of fronted WHQs, inverted WHQS, and inverted YNQS were calculated.

Although this study attempted to partially replicate the study by Eckman et al. (1989), their report included very little mention of the rules they used for counting utterances and categorizing questions. Consequently, the present paper necessarily employs many rules that may or may not be the same as those used by Eckman et al. Whatever rules were specified by Eckman et al. are, of course, adhered to in this study. The following sections delineate the processes and rules used to categorize utterances.

\section{Non-question Utterances}

Identifying non-question utterances was not always a straight-forward task, and no mention of this was made by Eckman et al. (1989). The difficulty arose when trying to distinguish simple declaratives from uninverted YNQs: both types of utterance have exactly the same structure. 
In many cases, intonation could be relied on to make the distinction. However, the subjects by no means consistently used NS-like intonation, a tendency that may have been transferred from their NL; shimada (1987) suggests that Japanese does not regularly use rising intonation in YNQS. In many of the initially unclear cases, discourse analysis provided the distinction. of particular use was noting whether the utterance in question contained information about the story that the subject had already discovered: if it did, the utterance could usually be concluded to be a declarative; if it did not, the utterance was concluded to be a question. In some cases, however, particularly when a subject tried to guess parts of the story instead of asking questions to discover the story, even the aforementioned attention to discourse details was of no use. In absence of any evidence that an utterance was, indeed, a question, it was counted as a non-question utterance. Once nonquestion utterances were identified as such, no further analysis was applied to them. 


\section{Question Utterances in General: Unanalyzable and Analyzable}

\section{"Problem" Questions}

With only question utterances remaining, an attempt was made to evaluate each question to determine whether or not it could be analyzed according to the TIU. As a result of this attempted evaluation, it became clear that many utterances did not neatly fit into the categories defined by the TIU. such "problem" utterances were categorized according to the problem they posed, syntactically, lexically, or, sometimes, functionally and fell into 64 different descriptive categories. A sample of the types of categories along with an example utterance is given in Table 5, and the complete listing of the 64 categories may be found in Appendix $E$.

With the problem questions grouped by characteristics, patterns became more readily observable. Fourteen of the 64 categories were instrumental in defining some of the 26 Rules of data analysis; 31 of the categories were eventually consolidated into nine larger UNAQ categories, broad enough to adequately describe all unanalyzable questions; and utterances in 22 of the original categories were eventually recategorized as TIU Qs. (Fourteen, 31, and 22 added together equal 67. This is because three of the original 64 categories initially 
Table 5 Sample of the Original 64 Category Types
and Corresponding Utterances

\begin{tabular}{|c|c|}
\hline Category description & Example utterances \\
\hline YNQ: Noun only & Person? \\
\hline YNQ: Echo & $\begin{array}{l}\text { Angry? } \\
\text { Trying to kill? }\end{array}$ \\
\hline YNQ: But + uninverted $Q$ & But she is married John? \\
\hline YNQ: missing verb only & This letter from Cindy? \\
\hline $\begin{array}{l}\text { WHQ: Aux. inverted } \underline{\alpha} \text { left in } \\
\text { place. }\end{array}$ & $\begin{array}{l}\text { In the past, is Jim is } \\
\text { good boy? }\end{array}$ \\
\hline WHQ: One word (WH word) only & Why? \\
\hline $\begin{aligned} \text { WHQ: } & \text { unfronted, following } \\
& \text { because clause }\end{aligned}$ & Because of what? \\
\hline $\begin{array}{l}\text { Second person pronouns mixed } \\
\text { inappropriately into question }\end{array}$ & $\begin{array}{l}\text { How old are you? } \\
\text { [Gloss: How old is Tina?] }\end{array}$ \\
\hline
\end{tabular}

had two different functions each. For example, original category 16 contained some utterances that were eventually placed into UNAQ categories and others that were eventually categorized as TIU QS.) Appendix E also indicates the final classification of each of the initial. categories.

\section{What Makes a Question?}

Before any of the questions, unanalyzable or analyzable, could be sorted and categorized, decisions also had to be made about what constitutes a single 
question. Because of their spontaneous nature, the data were replete with false starts, hesitations, selfcorrections, paraphrases, clarifications, and the like, which made it very difficult to determine exactly what should be counted as a separate question. Consider several examples, presented below, after the next paragraph, which explains necessary transcription and descriptive conventions.

As in all examples from the data, those below are numbered, and separate instances of each example are lettered if there are more than one; hyphenated numbers at the left of each example represent subject number and utterance number; interviewers' utterances are those enclosed in parentheses; and interview or transcription notes are enclosed in brackets. Category codes, which are included with most examples after the current section, appear to the left of the hyphenated subjectutterance number. For a full explanation of transcription conventions and a sample transcription, see Appendix F. Note also that in describing example utterances, categories, or rules, the term "complete" (or "incomplete") refers to the presence of all (or absence of some) basic grammatical elements (that is, both a subject and a verb), though a "complete" utterance is not necessarily grammatical according to NS rules. A 
"finished" utterance, on the other hand, is one that a subject finished speaking whether it was grammatically complete or not, while an "unfinished" utterance is one that was interrupted, either by the subject or by the interviewer.

EXAMPLES $1 \& 2$ :

These two subjects utter a question, then quickly selfcorrect perceived mistakes. Should both the uncorrected and the corrected utterances be counted? Should only the initial, more spontaneous utterances be counted? or should only the final best effort be counted?

EXAMPLE 1:

$$
\text { 005-069 } \mathrm{ff} \text {. He is rich? Ah- Is he rich? }
$$

EXAMPLE 2:

$$
\begin{aligned}
& \text { 021-067 ff. Patty Tom friend? Patty and Tom is } \\
& \text { friend? }
\end{aligned}
$$

EXAMPLES $3 \& 4$ :

These two subjects each produce a question and then quickly append another thought, the underlined part, to clarify the question. Should the appendages be counted as separate questions, or should the subjects be considered to have uttered only one question each? should only the appendage that is also a new idea (usually) be counted as a separate question while the appendage that is a repetition (after that) be considered part of the initial question?

EXAMPLE 3:

a) 005-075

Oh. She, she father rich man? usually?

EXAMPLE 4:

b) $\quad 025-042$

And mmm - why umm, eh? Why, whafter that, he, what umm . what is he doing? um after that? 
EXAMPLE 5:

In the following example, the subject interrupts her initial underlined question with a second italicized question and then slightly rephrases the initial question at the end. Does this example contain one, two, or three questions?

$$
\begin{aligned}
& \text { 014-069 ff. Why she's mmm ing what's say? } \\
& \begin{array}{l}
\text { (stealing?) stealing? Why she } \\
\text { stealing now? }
\end{array}
\end{aligned}
$$

EXAMPLE 6:

Here, two grammatically complete questions of the sequence Why + she + Verb Phrase (VP) can be identified, but the lack of a significant pause between the two and the addition of the negative in the second sequence may indicate that the first sequence is not, in fact, finished but is rather a false start. Should one or two questions be counted?

014-067 Why, why, she working, why she EXAMPLES $7 \& 8:$

The two subjects in this last example produce questions of identical or very similar structures in very close proximity to each other. The similarly structured questions of the first subject are, in fact, within the same utterance and have the same meaning (that is, here refers to factory). Those of the second subject occur within 15 very short lines of each other and, in fact, the last two are identical except in terms of their referents. Should such structuraliy similar questions be counted separately, or should it be considered that the subject is actually just plugging a variety of words into a single sentence so they should all be counted as only one question?

EXAMPLE 7:

020-012 Where is here? Where is factory?

EXAMPLE 8:
$022-073$
Where is this, here?
$022-075$
Where is this college?
$022-081$
Where is here? California? 


$$
\begin{aligned}
& 022-087 \\
& 022-088
\end{aligned}
$$

Where is this? [asking about the restroom picture]

Train??! Where is this? [asking about the counting sheep picture]

The quandary precipitated by the ambiguity of the data necessitated the creation of 26 rules for question analysis. Some of these rules apply equally to TIU QS and to UNAQ utterances; others apply only to TIU Qs. These rules are enumerated in the pages to come in the following order: First listed are Rules 1 through 14 , which apply to both TIU Qs and UNAQs. This is followed by a discussion of the nine categories for UNAQ utterances. Issues relating to only TIU Qs are then introduced, and Rules 15 through 26, for determining the presence or absence of inversion, are presented. Some of the rules specify TIU or UNAQ categories to which certain types of utterance belong. These categories will be explained later in the sections entitled "Questions Unanalyzable According to the TIU" or "Questions Analyzable According to the TIU" .

Rules Applicable to Both Unanalyzable and Analyzable Questions

Rules for Determining How Many Questions to Count. The following are rules for determining how many questions to count in a given segment of data. 
RULE 1. Count every question separately unless it is verbatim, adjacent, and has the same meaning (as evidenced by discourse analysis) as a previous question. (The "verbatim" criterion disregards repetition or stuttering internal in the question, that is, two questions identical except for repetition or stuttering are considered verbatim and are counted as one question. "Adjacent" means the subject's first or second utterance following the utterance under consideration, regardless of intervening utterances by the interviewer.)

EXAMPLE 9:

These are counted as two separate questions even though they differ only by one lexical item:

TIU A 014-076. Sue is Tom's wife?

TIU A 014-077 OK. Sue is Tom's girlfriend?

EXAMPLE 10 :

Here, two separate questions are counted even though their meaning is the same and the words are very similar:

TIU A 017-002 This happen, this happen. Ithis happen 1 . when this happen, Peter go Washington? (Ah-) Before?

TIU A 017-003 This happen before Peter goed to washington?

EXAMPLE 11:

These are counted as two separate questions even though they are adjacent and identical because the meaning of each is different. He has a different referent in each:

TIU D 001-052 Who is he? (He is bad guy. Ok, some bad guy kidnapped Patty.)

TIU D 001-053 Who is he? (She is sue.) 
EXAMPLE 12:

Because these two questions are verbatim and adjacent with the same meaning, they are counted as only one question:

5 004-174 Uhh? Hmm. ... where do you job? (Hm?) Where do you job? (Um, sue is a student.)

EXAMPLE 13:

In this example, the two questions she is keep him, keep him? and she is keep him? are counted as only one question since they are verbatim except for internal repetition:

TIU A 001-041 /whe/ they give .. (mm-hm) mm. ah, they, he is, ah, she is keep him, keep him? (mm-hmm) She is keep him? $(\mathrm{mm}-\mathrm{hmm})$ before-

Background for Rules 2, 3, and 4. False starts are utterances that the subject interrupts before they are finished and, after the interruption, the subject then starts over or tries another approach.

False starts are to be distinguished from selfcorrections in that, in a self-correction, an utterance is actually finished but then is repeated by the subject in either slightly- or greatly-modified form, in order to correct a perceived mistake in the initial utterance.

Utterances are determined to be finished or unfinished on the basis of a discourse analysis that takes into account context, meaning, intonation, and pauses. 
RULE 2. In case of a false start series, do not count any unfinished utterances/questions, even if the segment under analysis has a subject and verb or auxiliary. Count only the finished question that the subject settles on.

\section{EXAMPLE 14:}

Because it is an unfinished false start, the underlined When did Jim is not considered a question to be counted even though it has a subject and auxiliary:

TIU D 023-009

When did Jim, When did Jim know, meet Peter? know Peter?

EXAMPLE 15:

Why peter is not considered a question to be counted because it is a false start:

TIU D 026-016 Why Peter . . Why did Peter. stop the work? stop the work this factory?

EXAMPLE 16:

Because the why question was never finished, only the YNQ is counted as a question to be analyzed:

TIU A 021-008 Umm, why does she- ah - she . um house, housewife. she um she. she was housewife in the past? (Yes.)

RULE 3. In case of self-corrections, even within a false start series, where the subject tries out two or more grammatically complete utterances, count each complete, non-verbatim question separately, not only the final one settled on.

EXAMPLES $17 \& 18$ :

In the false start series by the following two subjects, the underlined questions are counted as a separate 
questions in addition to the versions finally settled upon, because they are grammatically complete utterances:

EXAMPLE 17 :

TIU A 027-069 Oh! Are these guys.. These guys

TIU A 027-070 Ah, Tom and these bad guys are friends?

EXAMPLE 18:

TIU D 023-035 ….. Last year, what . what Pewhat did Peter do?, no, um, occupa-

TIU D

$023-036$ what what did Pe- what did Peter, what did, what was Peter's job?

EXAMPLE 19:

All three of the following questions are counted separately even though the second and third are selfcorrections :

TIU A 014-162 And she find it?

TIU B 014-163 Does she find it?

TIU B 014-164 Did she find it?

RULE 4. Where a self-correction corrects a previously grammatically incomplete question (for example, one missing a verb or one that consisted of only one word) which was, nevertheless, a finished utterance, count the initial incomplete utterance, and place it into the appropriate UNAQ category.

EXAMPLE 20:

The Patty Tom friend? part of the following turn is placed into UNAQ 4, while the Patty and Tom is friend? part is analyzed according to the universal as TIU A.

$\begin{array}{lll}4 & 021-067 & \text { Patty Tom friend? } \\ \text { TIU A } & 021-068 & \text { Patty and Tom is friend? }\end{array}$


RULE 5. When a subject's question is finished or interrupted by interviewer or dictionary input, the following apply:

5a. Count as one any question which is started before the input and finished after the input.

EXAMPLE 21:

TIU A

$017-065$

mmm Peter . Peter's higher officoffic- offic- offic- offic- (Office. Official?) official is John?

EXAMPLE 22:

TIU A

$$
\begin{aligned}
& \text { 012-055 } \mathrm{He} \text { is } \ldots \mathrm{mm} \mathrm{mm} \quad \ldots \quad \mathrm{mm}\{\mathrm{J}\} \\
& \text { (Dictionary?) Yeah. (That's ok, } \\
& \text { that's ok.) [Subject looks in }
\end{aligned}
$$

5b. Count as one any question which was started but not finished before the input and then repeated and finished after the input (this is similar to Rule 2).

EXAMPLE 23:

TIU B 013-010 Uu. Is she, is she now ahh?-(Housewife?) Yes. Is she housewife now?

5c. Count separately any finished questions before and after the input which are not verbatim repetitions.

EXAMPLE 24:

TIU B 012-076 Hm...mm This meeting. (mm-hm) /ga/ /mto/ is he doing? (Mmm, I didn't understand. Try again, once more.)

TIU B [She's asking about Boris.] . mmm This meeting at this time $(\mathrm{mm}-\mathrm{hm})$ is he doing? 
5d. EXCEPTION: If the interviewer inadvertently supplied either the subject or verb of the question, the resulting question must not be analyzed according to the universal. Instead, place it into UNAQ 7.

EXAMPLE 25:

017-008 .. Jim . . Why, why Jim [pointing at motorcycle gang picture] (Joined?) joined?

5e. Place into UNAQ 7 any question that is interrupted by the interviewer before the presence or absence of inversion $(+/$ - inversion) or the presence or absence of WH fronting $(+/-$ WH fronting) can be determined and that the subject never finished.

NON-EXAMPLE 26:

Even though the interviewer interrupted before the subject finished her question, this is still counted as an uninverted YNQ because enough of the utterance was completed to determine $+/$ - inversion:

TIU D 025-016 I see. Next. Why mm, mmm did Puff's company go out of $-\mathrm{mm}$ ? go out? No? $\mathrm{mm}$ ? (Loosing money?)

OK 025-017 Yes.

EXAMPLE 27:

7 006-121 Where. three years agoooo../tokode/ where Tina and Peter uh (Meet.) uh.

EXAMPLE 28:

7

020-098 l? Tom Patty and bad guys in
Palm Springs, so um (No, only Tom is
in Palm Springs.)

RULE 6. When a question is finished with a gesture or non-lexical sound, the following apply: 
6a. Analyze the question according to the TIU if it contains a subject and verb.

EXAMPLE 29:

TIU A 018-019 John stay at [Subject points to hospital.]? (Yes, yeah.)

6b. Analyze the question according to the TIU if the gesture or sound is substituted for the subject or verb of the question, and the substitution is unmistakenly identifiable, and the resulting meaning of the question is definitely clear according to discourse analysis, transcription notes, or both.

EXAMPLE 30:

TIU B 028-025 Did he, did, did she [Subject gestures "separate" by moving joined hands apart.] (Separate?) separate? (No, not really; he's in the hospital.)

6c. Otherwise, place that question into an appropriate UNAQ category for questions that cannot be analyzed according to the TIU.

EXAMPLE 31:

8

015-076 mmm ... Suuuue [Subject points and points at the picture of the car going to Los Angeles.] [laugh] (Good question! No, Sue's not in the car!)

RULE 7. Do not count Mmmm?, Ahh?, Uhh?, or other nonlexical sounds as questions. Rationale: Although some of these are definitely used as word- or phrase-substitutes, 
others are used only for filler. Distinguishing between substitutes and fillers becomes subjective in many cases. EXAMPLE 32 :

Here, the Mmm? is definitely substituting for a word.

(No, Tina is not fired. She has job and she has a boyfriend. Another person was fired.)

OK

$015-027$

Mmm? [A word substitute for "Peter". subject was pointing at Peter.] (Question?)

1

$015-028$

Peter? - (Yes, Peter was fired, etc.)

EXAMPLE 33:

Here, the Mmm and um's are clearly just fillers:

TIU B 021-077 Mmm . um . Do, does she know, um Tom and bad . bad man acquaintance?

RULE 8. At times, subjects begin a question, then interrupt it with another question (usually to ask for pronunciation help or to ask about something they forgot) after which they finish the original question without starting it over again. In these cases of "nested" questions, count both questions.

EXAMPLE 34:

Lines 068 and 069 represent the same utterance, but the distinct underlined parts each need to be counted under different categories.
TIU C
$014-068$
A lot of money.
Why she's mmm. What's say? [Subject points to picture of Patty stealing money in the bank.] (stealing?) stealing? A lot of money.
Why she's mmm. What's say? [Subject points to picture of patty stealing money in the bank.) (Stealing?) stealing? 
RULE 9. If part of an utterance is not clear on the tape, apply the following rules:

$9 a$. Count the utterance as a question to be classified according to the TIU only if the unclear part does not interfere with determining $+/-$ inversion or $+/-$ wH fronting.

EXAMPLE 35:

TIU A

$$
020-025
$$

OK. mm . . um, Peter and John . mm . already go to Tina's /wur?/? [I'm not sure what that last word was.]

9b. Place the utterance in UNAQ 7 if the unclear part would affect $+/$ - inversion or $+/$ - wH fronting. EXAMPLE 36:

$\mathrm{mm}$ Is [?] [I'm not sure if it's really "is" or if it's just a little squeaky sound his mother's name Tina?

9c. Count the utterance as a question to be classified into one of the UNAQ categories, other than UNAQ 7, only if the unclear part does not interfere with determining which other UNAQ category it should be placed into. (There do not happen to be utterances of this type in the data.)

9d. Place the utterance into UNAQ 7 if the unclear part makes it impossible to accurately place it into any other UNAQ category. 
EXAMPLE 37 :

7

$018-067$

Peter /mmm bif/ John /ste ha/? [Transcriptions are best guesses only; not clear on tape.] (Yes, explosion hurt John, yes.)

RULE 10. If an embedded question is not inverted, place it into UNAQ 6 because, according to NS English rules, it, should not be inverted (Example 38). If the embedded question is inverted, categorize it as TIU B or TIU D (both of which are correctly inverted) even though this is an overgeneralization of NS English rules (Example 39). Rationale: The universal does not address languagespecific rules such as the English rule for embedded questions, and this rule is similar to Rule 22, later, which was based on a rule used by Eckman et al. (1989). EXAMPLE 38:

6

032-039 I don't understand why sue is involved with this story.

EXAMPLE 39:

TIU D 028-090 I'm wondering why did guys get money from her father?

RULE 11. When subjects interrupt their own questions before they are finished and before $+/$ - inversion can be determined, count only the next finished utterances, not interrupted parts. 
EXAMPLE 40 :

The Five years ago? part is counted as a UNAQ 1 utterance, but the why she- portion is not counted at all.

1 025-106 Why she - five years ago?!

RULE 12. When a subject finishes a question and then guesses at an answer, the guessed-at answer should be counted as a separate question if it is intended as a question (usually determinable by intonation). Question:3 such as these usually fall into UNAQ 1 or UNAQ 2 (Example 41). However, when a question is finished and then followed by a repetition of something in the question (as for clarification) or by a different word or phrase intended to make the original question more clear or precise, that little repeated or additional segment is not a separate question; it is more like a "false end" and is not counted as a separate question (Example 42 \& 43).

EXAMPLE 41 :

In addition to the two longer questions that fall into TIU categories, the underlined utterance that is a guessed-at answer is counted as a separate question.

Peter?

EXAMPLES $42 \& 43:$

Here, the main questions would be counted as TIU D and TIU B, but the underlined parts would not be counted as separate questions. 
EXAMPLE 42 :

TIU D 025-042 Mm-hm. And mmm . \{?\} Why umm, eh? Why, wh- after that, he, what umm. what is he doing? Um after that?

EXAMPLE 43:

TIU B 006-150a Patty mm Patty is/u/ is Patty two man kidnap? Not die, not killed? (Right, she's not kilied.)

RULE 13. When the subject repeats part of the interviewer's answer with question intonation lan echo question), count it as a question (always as a UNAQ), usually either in UNAQ 1 or UNAQ 9 (Examples 44 \& 45). Without question intonation, do not count it as a question at all (Example 46).

EXAMPLE 44:

TIU D 022-073 Where is this, here? (on the train.) 1 022-074 Train? (Mmm-hm.)

EXAMPLE 45:

9 003-029 (Yeah, but Jim hates-)

EXAMPLE 46 :

The code "OK" means that the utterance on that particular line is a non-question utterance.

OK

(He was talking to Mr. Puff.)

025-031 Puff, Puff, Puff. I see.

\section{Discourse Analysis Rule.}

RULE 14. Before categorizing any question, apply a discourse analysis that considers such details as the interviewers' answers and the subjects' prior discoveries 
about the story, surrounding utterances, and responses to the interviewers' answers. This is necessary in order to help inform the categorization process because, without considering the surrounding discourse, an utterance may appear to belong to one category when, in actuality, it belongs to another.

EXAMPLE 47 :

Without considering the surrounding dialog, the underlined question might be thought to be a fronted, inverted WHQ (TIU D) about the location of Washington DC, countable, even though the subject abandoned it for another question, because of Rules 3 and 11, above. In taking the absence of significant pause and the rest of the dialog into consideration, however, it becomes apparent that the subject is not asking the location of anything. She is, in fact, asking the reason that Peter went to washington DC, having mistakenly substituted the word where for why. The result is that the underlined part is a false start, not counted at all, and the where - go to washington part is counted as a UNAQ 3.

\begin{tabular}{|c|c|c|}
\hline $\begin{array}{l}\text { TIU D } \\
3\end{array}$ & $\begin{array}{l}004-058 \\
004-059\end{array}$ & $\begin{array}{l}\text { Where is this? (Washington DC.) } \\
\text { Washington. Where is Washing- where } \\
\text { go to Washington? (Where?) where? } \\
\text { AH-Why? (Because he had to find a } \\
\text { new job. His new job [pointing at } \\
\text { taxi], etc.) }\end{array}$ \\
\hline
\end{tabular}

EXAMPLE 48 :

At first, the underlined question in line 005 appears to be a YNQ consisting only of a NP with the meaning "Was anger the reason he joined the motorcycle gang?", and this interpretation is further supported by the interviewer's response, "Mm-hm." A question such as this would be categorized as UNAQ 1. However, the next two lines show that this is not the interpretation intended by the subject; she meant, What reason was he angry? (line 007). Thus, the initial question in line 005 is not actually a YNQ at all, but is rather a WHQ in intent, missing its wH word. As such, it correctly belongs in UNAQ 9. Its lack of a WH word misleads the interviewer, who mistakenly continues to answer "Mm-hm" until the 
following sections describe how both UNAQs and TIU Qs were categorized.

\section{Questions Unanalyzable According to the TIU (UNAQS)}

Of the 2316 questions produced by all subjects, 926 , or 40 percent, were UNAQ utterance, not analyzable according to the TIU because they did not contain both a subject and a verb. (Actually, "UNAQ" is somewhat of a misnomer for the utterances in UNAQ 3 and some of the utterances in UNAQS $2,6,7$, and 8 because these utterances were "analyzed" in the sense that they did contribute to the calculation of one of the relevant percentages--Wh fronting. In addition, a small number of: WHQs that did not contain both a subject and verb are not included among the 926 UNAQs because they were unfronted WHQs and so could be placed into the TIU category for unfronted wHQs since that portion of the hierarchy does not address $+/$ - inversion. For further information on both of these points, refer to the section entitled "Percentage of WH Fronting", in Chapter IV.)

Although UNAQs are not even mentioned by Eckman et al. (1989), it seems that such utterances merit some attention, since they comprise so large a percentage of the raw data. Admittedly, analyzing such questions and 
subject finally succeeds at wording her question in a more NS-like fashion.

\begin{tabular}{|c|c|c|}
\hline TIU D & $026-003$ & $\begin{array}{l}\text { Why he, why did he want to } \\
\text { motorcycle gang? }\end{array}$ \\
\hline TIU D & $026-004$ & $\begin{array}{l}\text { Why did he want? (Because he is } \\
\text { angry!) }\end{array}$ \\
\hline $\begin{array}{l}9 \\
9\end{array}$ & $\begin{array}{l}026-005 \\
026-006\end{array}$ & The reason? ( $\mathrm{Mm}-\mathrm{hm}$.) \\
\hline IU $D$ & $026-007$ & $\begin{array}{l}\text { What reason was he angry? (Good } \\
\text { question. Because he saw Tina and } \\
\text { Tina's boyfriend together, and he is } \\
\text { angry about that.) }\end{array}$ \\
\hline
\end{tabular}

EXAMPLE 49:

Considering only the surface structure, it appears that the underlined question in 040 is an uninverted WHQ with John as the subject and doesn't like as the verb phrase, with the meaning, "Why doesn't John like someone?" Such a question would be categorized as TIU C. However, considering the interviewer's hint in 037 and answer in 040, it seems that 040 could be a grammatically incomplete question with non-standard word order and a missing subject, with the meaning, "Why doesn't someone like John?" Such a question would be categorized as UNAQ 3 . Since structure and surrounding discourse indicate different codings and neither interpretation seems more justifiable than the other, the utterance was placed into UNAQ 8 , a category for ambiguous utterances.

\begin{tabular}{|c|c|c|}
\hline $\begin{array}{l}1 \\
\text { OK } \\
1\end{array}$ & $\begin{array}{l}008-037 \\
008-038 \\
008-039\end{array}$ & $\begin{array}{l}\text { Angry? (Someone doesn't like John.) } \\
\text { Hmmm. (Question.) } \\
\text { Question? Eh! Why - ah, question, } \\
\text { ok? (mm-hm) }\end{array}$ \\
\hline 8 & $008-040$ & $\begin{array}{l}\text { Why John doesn't like? (Ah, Tina's } \\
\text { boyfriend doesn't like John. Tina's } \\
\text { boyfriend said, } \\
\text { explosion, maybe I will kill make } \\
\text { then I can marry Tina.") }\end{array}$ \\
\hline
\end{tabular}

Once the problem questions were dealt with and Rules 1 through 14 were applied to utterances, separate questions could be identified and evaluated to determine whether or not they could be analyzed according to the TIU. The 
their patterns of occurrence will have no bearing on the answers to the research questions asked by this study, but such examination will undoubtedly contribute to the larger study of interrogatives in general. In order to accurately represent the data elicited in this study, some consideration of the 926 UNAQs is necessary.

\section{The Nine UNAQ Categories}

The nine UNAQ categories, the criteria for placing utterances into them, other explanations, and examples for each category are described below.

UNAQ 1. YNQS: Single words, isolated phrases

NPs, Prepositional Phrases (PPs), VPs, others; two or more such phrases juxtaposed. Included are questions that the subject utters as finished questions but may later try to correct, and echoes. Not included are cases where 1) these phrases are parts of false start sequences, 2) simply inserting a verb or subject would make a grammatically complete question, though not necessarily grammatical according to NS rules (those belong in UNAQ 4), and 3) the one-word question is a WHQ in intent (those belong in UNAQ 9).

EXAMPLE 50 :

1 004-112 Know? (Mm-hm, I think so.) [Subject is asking whether peter knows that $\mathrm{Jim}$ is in the motorcycle gang.] 
EXAMPLE 51:

$1 \quad 022-074 \quad \begin{aligned} & \text { (On the train.) } \\ & \text { Train? }\end{aligned}$

EXAMPLE 52:

1 008-007 Tina mmm son /mto/ mother children?

EXAMPLE 53:

$\begin{array}{lll}1 & 010-079 & \text { Steal? } \\ 3 & 010-080 & \text { Ah-why stole? }\end{array}$

UNAQ 2. WHQS: WH word only, WH word + Single word, WH word + isolated phrase

WH word optionally followed by NPs, PPs, VPs, others, or two or more such phrases juxtaposed. Included are questions that the subject utters as finished questions but may later try to correct. Not included are cases where 1) these phrases are parts of false start sequences, 2) inserting a verb between the wH word and the single word or isolated phrase, or inserting a subject would make a grammatically complete question, though not necessarily grammatical according to Ns rules (those belong in UNAQ 3), and 3) one word questions without a WH word that are, nevertheless, WHQs in intent (those belong in UNAQ 9).

EXAMPLE 54:

2 003-003 What?

EXAMPLE 55:

2 004-093 oh. Why this dress? 
EXAMPLE 56:

2 004-169 Why yesterday two bottles wine?

UNAQ 3. WHQs without Verb or without subject

Verb or subject is missing from a question that is otherwise grammatically complete, though it may not necessarily be grammatical according to Ns rules.

EXAMPLE 57 :

3 001-017 Why .. (mm-hmm) gave money?

EXAMPLE 58:

3 004-018 Where.. live, live?

EXAMPLE 59:

3 005-016 Mmm? Why Tina. this job?

EXAMPLE 60:

3 005-039 Oh. Why Peter . Washington DC?

EXAMPLE 61:

3 005-072 Why Tom long. Iong road driver?

UNAQ 4. YNQS without Verb or without subject

Verb or subject is missing from a question that is otherwise grammatically complete, though it may not: necessarily be grammatical according to NS rules.

EXAMPLE 62:

4

004-001 Here and here .. same factory?

EXAMPLE 63:

4

004-202 But lived in San Francisco? 
EXAMPLE 64:

4

$010-096$

... Two, two people ki ki kidnap (Mmhm.) eh sue connection? (No.) [Gloss: Do the two people who kidnapped have connections with sue?]

EXAMPLE 65:

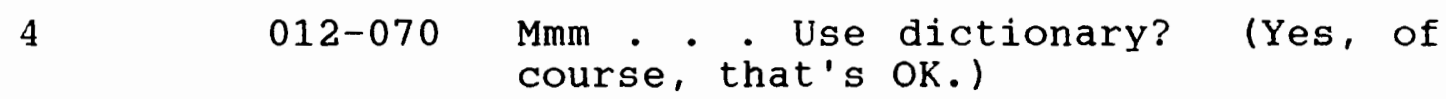
EXAMPLE 66:

4 015-120 Don't go home? (Right. She wants to go home, but the bad men are keeping her.)

UNAQ 5. Inappropriate first or second person pronouns mixed in

Although in many cases these questions are grammatically complete and well-formed, the presence of inappropriate pronouns suggests that these questions were, for the subject, unanalyzed, memorized chunks. These questions are, therefore, counted as unanalyzable.

EXAMPLE 67 :

5 004-017 Oh. .. Tina issss, Tina . where .. do you live? (Mm?)

EXAMPLE 68:

5 004-047 mmm? Jim is . how old /i/ how old
are you? (Jim?)

EXAMPLE 69:

5 004-050 How old are you? Yes, Tina. (Um, probably 47) 
EXAMPLE 70:

5

010-037 Oh... Tina, (mm-hm) do you like him?

(Yes, Tina likes her boyfriend.)

EXAMPLE 71:

5 016-203 Tom. I don't know . steal? (Pardon me?)

UNAQ 6. Grammatically complete questions, unanalyzable due to English-specific rules

Although many of these are uninverted questions, they are correctly uninverted, that is, NS rules require that they remain uninverted. In counting TIU Qs, these cannot be counted as inverted (because they are not), nor can they be counted as uninverted (because they cannot correctly be inverted). Hence, they are unanalyzable. Tags in tay questions, although inverted, appeared to be memorized chunks.

6a. Uninverted WHQs that are about the subject of the sentence should not be classified as uninverted according to the TIU but should be placed into UNAQ 6 because, in English, this type of WH question should not be inverted; nor can they be counted as inverted, because they are not, even though they are well-formed. (Also see Rule 21.)

EXAMPLE 72 :

6 004-152 Which ah, in the-, with-, go to LA? (The bad guys and Patty in the bag, I think.) 
EXAMPLE 73:

6

013-088 Oh! mm . Tom . mm . Who, who, who is, who is go, go, who is go to LA with Tom?

EXAMPLE 74:

6

019-011 And who did call him?

EXAMPLE 75:

6

024-005 So, who, who gave a information to John?

6b. Uninverted YNQS following the word Because should not be classified as uninverted according to the TIU but should be placed into UNAQ 6 because, in English, this type of YNQ should not be inverted. Furthermore, this type of YNQ was produced almost exclusively by higher level subjects.

EXAMPLE 76 :

6

028-066 Because he likes Tina?

\section{EXAMPLE 77:}

6 030-112 Huh? Because they want more money? 6c. Uninverted questions followed by a tag should not be classified as uninverted according to the TIU but should be placed into UNAQ 6 because, in English, this type of question should not be inverted. If the tag is in the form of an inverted question, it was not counted as a TIU $Q$ because all such tags in the data appeared to be memorized formulae. 
EXAMPLE 78 :

6

029-068 Ah, but he is still taxi driver, right?

EXAMPLE 79:

6 021-086 Umm, she stole, she is steal a lot of money, isn't it, isn't she?

6d. Certain unfronted WHQs that cannot be correctly fronted in English or that are optionally unfronted are placed into UNAQ 6 .

EXAMPLE 80 :

6

030-097 Because of what?

EXAMPLE 81:

6

030-067 For what?

6e. Embedded questions, correctly uninverted, also fall into UNAQ 6 (see Rule 10).

EXAMPLE 82 :

6 032-039 I don't understand why sue is involved with this story.

UNAQ 7. Unanalyzable because of interviewing problems various interviewing problems prevented the analysis of some utterances. The main types are described below. 7a. The recording was not clear, thus yielding an inaccurate transcription in a place that would probably affect $+/$ - inversion or $+/$ - fronting. 
EXAMPLE 83:

7

007-052 So he ... \{?J?\} [Actually, it must have been English since the interviewer answered, but it is much too quiet to hear.] (Yes, that's why he joined the motorcycle gang.)

7b. The subject reads a whole question from the dictionary.

EXAMPLE 84:

7 010-028 Peter ehh, accident day, what have you been doing all this while? [subject read whole question from dictionary.]

7c. The interviewer inadvertently supplies a subject or verb, which could affect +/- inversion.

EXAMPLE 85:

7 006-121 Where - three years agoooo../tokode/ where Tina and Peter uh (meet) uh. (At a party.)

7d. The interviewer inadvertently cuts off a subject's question before $+/$ - inversion can be determined, and the question is never finished.

EXAMPLE 86:

7

025-144 Ah, she there /arivay/-ah, did she. /say-/ (Well, day before yesterday, she was teaching class as usual, etc.)

UNAQ 8. Miscellaneous unanalyzable

For various reasons, these questions do not fall into any other category and do not seem to deserve separate categories of their own. Placement into any other 
category could vary from rater to rater because they are not at all clear cut.

8a. No readily identifiable meaning is possible to distinguish, or the meaning is unclear, due to factors such as gestures, Japanese words, or non-lexical sounds; consequently, the question cannot be accurately categorized or could be interpreted in various ways, each resulting in a different categorization (see Rule 6).

EXAMPLE 87 :

The meaning and correct interpretation of this question is obscured by unclear sounds, some of them possibly Japanese words, making accurate categorization uncertain, so the utterance is classed as UNAQ 8.

8

$016-215$

Money nothing /gu/ [pointing sounds] Patty /ni hoies/? (Mm-hm, mm-hm. Do you know why they kidnapped Patty?)

EXAMPLE 88:

The correct categorization of this utterance is a toss-up between TIU A (because of the Tom car don't know, part) and UNAQ 5 (because of the inappropriate first person pronoun in $I$ don't, don't know Tom). Since the utterance cannot be placed in one of these two categories over the other, it is placed in UNAQ 8.

8

$$
016-204
$$

Tom. Tom car /de/ (mm)/hara/ don't know, I don't, don't know Tom. (Ah, yes, Tom doesn't know about kidnap and Tom doesn't know about stealing. Tom thinks just customers.)

EXAMPLE 89:

It is not clear whether the subject intended the first part of the utterance to be background with only the but Washington segment as a question (which would result in a UNAQ 1 classification), or whether the whole utterance was intended to be a question (which would result in a TIU A classification). 
004-081 Tina is meet to Peter (Mm-hm.) but washington? (I think it's close, next city, not far away from Baltimore, I think.)

EXAMPLE 90 :

Though the surface structure of this example seems to be an inverted WHQ (TIU D), analysis of the discourse shows that the subject meant "who was he killed by" or "who killed him?", which makes the placement of this utterance into TIU D dubious.

8

025-121 Oh, who is, who . did . he kill?

8b. So much false starting makes an actual question impossible to decipher even though the subject has finished--not abandoned--the attempt, and the interviewer may have succeeded at answering the subject.

EXAMPLE 91:

8

$$
011-014
$$

$$
\begin{aligned}
& \text { - John } \mathrm{mm} \text { job } \mathrm{mm} \text {. John's factory } \\
& \mathrm{mm} \text { Peter's office } \mathrm{mm} \text {. Ah, Peter, } \\
& \text { Peter mmm . mm . ex, explosion mm } \\
& \mathrm{mm} \text { this factory mm, re, re, reason mm } \\
& \text { - (Do you want to say again?) }
\end{aligned}
$$

8c. A Japanese word or phrase affects +/- inversion, so the question cannot be analyzed according to the TIU. EXAMPLE 92 :

8

007-041 Ha. In the past (mm-hm?) \{J\} (OK, ask me in English.)

8d. The subject abandons the question before $+/-$ inversion can be determined. (These differ from UNAQ 1 utterances because these were not finished, whereas UNAQ 1 utterances are finished questions. They also differ 
from false starts because false starts eventually ask the same question, though perhaps in a different way.)

EXAMPLE 93:

8

$003-026$

Eh? Boyfriend, Tina's boyfriend . . her $m m$ ? $\{\mathrm{J}\}$.

EXAMPLE 94:

8

$017-019$

So mmm This happen . . mmm . (explosion?) eh, this factory worker - mmm? (Dictionary?)

EXAMPLE 95:

8

$$
\text { 004-196 oh. Sue and Tom ...ah- no, ah- }
$$

EXAMPLE 96 :

8

$$
\text { 006-051 Where } i \text { - where is-/ore/? }
$$

EXAMPLE 97 :

8

$013-030$

mmm.... Who, who i-, who is./wa/, eh, /wakanai/. . (Do you have a dictionary?)

NON-EXAMPLE 98 :

Even though the subject interrupts herself, this question is not a UNAQ 8 because +/- inversion can already be established:

TIU C 008-091 mmm, Why, . mmmm wh- Patty's father - don't give ehhh?

8e. Non-standard word order or seemingly randomly-strung words makes the question impossible to categorize.

EXAMPLE 99:

8

$016-238$

Ah, ah, ah, ah, Patty, Patty father rich man (mmm.) bad bo- ah, bad mans ransom money but San Francisco Los Angeles /de/ money nothing, force? 
EXAMPLE 100:

8

009-026

Mmm, In restaurant /su/ in restaurant work to his?

EXAMPLE 101:

8

015-020 Factory (Mm-hm.) work Peter?

UNAQ 9. WH question in intent, but without a WH word, including echoes

These questions typically appear to be UNAQ 1 utterances at first glance. However, analysis of the discourse reveals that they are not YNQs, but rather WHQs lacking a WH word.

EXAMPLE 102:

1 006-034 OK. . Tina Jim /wa//ki-/ ah-Tina's children? (It's a good question; try to make a longer question.)

9 006-035 Longer question? (Mm-hm. "Tina's children" only two words. Try to

EXAMPLE 103: make a longer question.)

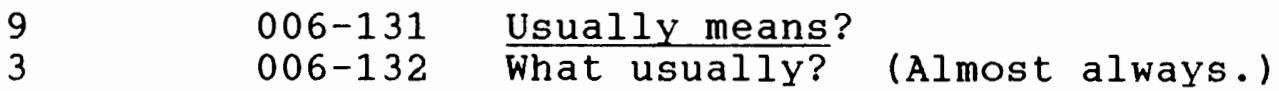

EXAMPLE $104:$

9

$$
\text { 008-026 Hurt-o? (Hurt. /itay/. Someone }
$$

EXAMPLE 105:

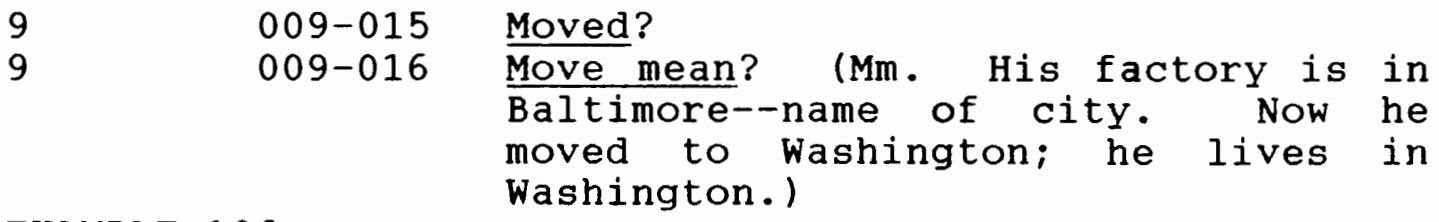

EXAMPLE 106: Washington.)

/Mæt/? ("Hello, how are you, glad to meet you," etc.) 
Throughout this paper, each category is referred to simply by its UNAQ number. For ease of reference, a summary table giving the names of UNAQ (and TIU) categories, along with a brief definition of each, is located in Appendix B.

\section{Questions Analyzable According to the TIU (TIU Qs)}

Questions analyzable according to the TIU fell into one of six categories: YN uninverted (TIU A); YN inverted (TIU B); WH fronted, uninverted (TIU C); WH fronted, inverted (TIU D); WH complete but unfronted (TIU E); or WH unfronted with subject or verb missing (TIU F). The following divisions discuss issues considered in classifying utterances into these TIU categories and are concluded with a set of example utterances from each category.

\section{Unfronted WH Utterances}

The most accessible end of the universal deals with WH fronting. Any WHQ that was not an abandoned question or part of false start series was assessed with respect to the placement of the WH word. All questions in which the $\mathrm{WH}$ word was not clause-initial were classified as unfronted. In addition, any wHQ that was a finished utterance and in which the wH word was not fronted could 
be analyzed according to the TIU even if it was not complete with both a subject and a verb. Fronting alone, independent of inversion, comprises the first portion of the TIU, so although many of the unfronted wHQs did contain both subject and verb, these elements were not necessary in order to determine whether or not the $\mathrm{WH}$ word was fronted.

\section{Identifying Inversion in YNQs and WHQs}

Any complete YNQ or WHQ with both a subject and a verb could be analyzed for inversion according to the TIU and so placed into one of the last four TIU categories above, except in cases where the meaning was ambiguous (the two different readings would result in placement into different categories) or unidentifiable. (In these cases, the utterance was placed into UNAQ 8, described above.) However, again because of the nature of the data, determining whether a given utterance was inverted or uninverted was no simple task, and rules were developed for making the distinctions. These rules are stated in the following section.

\section{Rules for Determining $+/$ - Inversion.}

RULE 15. Count uninverted YNQs as uninverted even though the context is such that a NS might also leave the question uninverted, as in a confirmation or following But (used for objecting) or so (used for concluding). 
Rationale: Dividing NS-like uninverted confirmation questions from non-NS-like uninverted questions is an subjective process. In addition, Eckman et al. (1989) followed this rule, after establishing that NNSs produce a much higher percentage of such uninverted YNQs than do NSs .

EXAMPLE 107:

OK 027-003 She was. (And she is married.)

TIU A 027-004 Oh, but does she. (Yeah-) She has. new boyfriend?

EXAMPLE 108:

TIU A 023-039 So Peter changed a job?

EXAMPLE 109:

TIU A 021-014 Now he is . motorcycle gang, /ke/? $(\mathrm{Mm}-\mathrm{hm}$.$) [Subject had already been$ told that Jim joined a motorcycle gang, so this could be a confirmation question.]

RULE 16. Although this rule actually instructs that affected questions be placed in UNAQ 6 , it is included here in the rules for determining inversion because the pertinent questions at first appear as if they should be classified as either inverted or uninverted. This is not the case, however, and so the following rules apply: Count as a UNAQ any uninverted question followed by the tag right? Rationale: The form Uninverted question + right? is a perfectly well-formed question according to NS rules even though it is not inverted. Such questions 
fall into UNAQ 6. Likewise, questions of the form Uninverted stem + inverted tag should be counted as unanalyzable according to the TIU even though the tag is inverted. Inverted tags in the data appeared to be memorized question markers.

EXAMPLE 110 :

6

029-068 Ah, but he is still taxi driver, right?

EXAMPLE 111:

6

021-086 Umm, she stole, she is steal a lot of money, isn't it, isn't she?

RULE 17. Count as uninverted any question in which the auxiliary is both inverted and left in place. Rationale: Although this form exhibits type of inversion, acquisition of inversion is still not complete. Although these questions could arguably have been counted as inverted because they do exhibit a type of inversion, their classification in this analysis is as uninverted. There were eight such utterances in the data. EXAMPLE 112:

TIU A 023-001 . . Is this factory is same Peter's factory?

EXAMPLE 113:

TIU A 001-004 But she ... is she is housewife? EXAMPLE 114:

TIU A 007-043 Does Peter don't like John? 
RULE 18. Count as uninverted any question in which the subject initially inverts in a false start series but then goes on to settle on an uninverted form (see Rule 2). However, if the initially inverted form is a finished utterance which is then "self-corrected" to an uninverted form, count both questions (see Rule 3). EXAMPLE 115:

TIU C 025-147 . . Why did, why . this picture need EXAMPLE 116: this story?

TIU C 030-114 . Why did not they, they did not do by themselves?

RULE 19. Count as uninverted all questions in which subjects use the pattern, subject $+B E+$ rest of the sentence $+M V$.

EXAMPLE 117:

TIU A 003-070 Oh. . . mm Tina.. Tina is him love? EXAMPLE 118 :

TIU A 005-049 Jim is Tina and Peter together saw? [Gloss: Did Jim see Tina and Peter together?]

EXAMPLE 119:

TIU A 006-061 John and Peter is. together work?

RULE 20. Count as inverted any WH question in which, initially, the subject of the sentence directly follows the WH word (as it would in an uninverted question) but then is self-corrected by the subject so that the 
auxiliary precedes the subject of the sentence (inversion), even though the WH word is not repeated. EXAMPLE 120:

TIU D 025-095 $\mathrm{mmm}$, where $\mathrm{mm}, \mathrm{mm}$. where got, this train, where this train. . where. this did this train go?

EXAMPLE 121:

TIU D 030-031 Baltimore. mmmm . $\mathrm{mm}$ Where Tina - did Tina meet her boyfriend?

RULE 21. In some cases, subjects insert an auxiliary after the wH word in WHQs about the subject of a sentence, a position where NSs use an auxiliary only in marked cases. The added auxiliary does not affect inversion, however, and the question is still correctly uninverted. These uninverted WHQs constitute a special case because of English specific rules, and all such utterances should be classified as UNAQ 6 . EXAMPLE 122 :

6 019-011 And who did call him?

EXAMPLE 123 :

6 025-104 Oh! Who, who did die?

RULE 22. Count as inverted any question in which the main verb or the main verb and the auxiliary are inverted, even though only the auxiliary should be inverted according to NS rules. Rationale: The TIU does not specify the inversion of an auxiliary only and, in fact, governs languages, such as French, where the main 
verb is regularly inverted. In addition, Eckman et al. (1989) followed this rule.

EXAMPLE 124:

TIU D 006-143 What does means bad mans?

EXAMPLE 125:

TIU D 024-010 Ohh. Why, ah, now, so, why. $\mathrm{mmm}$ come - ah, policeman to ah, Mr. Puff's company?

EXAMPLE 126:

TIU D 024-042 Oh. Why, why, ah . where, where called Tony?

RULE 23. Count as inverted any question that has an inverted auxiliary, whether or not it is the correct auxiliary or form. Rationale: The TIU addresses inversion, not issues such as agreement, tense, or choice of auxiliary. In addition, this rule was followed by Eckman et al. (1989).

EXAMPLE $127:$

TIU B 020-088 And is, is Tom know Patty?

EXAMPLE 128:

TIU B 021-085 She issss, um, is she a lot of money, stole a lot of money? oK?

EXAMPLE 129:

TIU D 004-026 Where is he live?

EXAMPLE 130:

TIU D 013-048 Mm why, \{why\} .. why did. Jim angry? angry his mother? 
RULE 24. Count as inverted any question in which the auxiliary is inverted but which lacks a main verb.

EXAMPLE 131:

TIU D 019-045 Why, why did he lots of money?

EXAMPLE 132:

TIU D 022-077 Why Jimmy, ah, why di-does Jimmy. late. late airplane?

RULE 25. In some cases, Noun + 's could be interpreted either as Noun + contracted $B E$ or Noun + possessive, the former being part of a TIU $Q$, the latter being part of a UNAQ if no other verb was present. In such questionable cases, count the 's as Noun + contracted BE (and therefore analyzable) only if the subject uses a contracted form of $B E$ elsewhere in the transcription. EXAMPLE 133:

mmm . Tina's Jim, John's family? [No other contracted copula present; count this as a possessive.]

EXAMPLE 134:

1

004-080 But father, ah, father's hospital? [No other contracted copula.]

EXAMPLE 135:

TIU D 006-021 In the past. What's past means? [There are several other utterances that could be interpreted as having contracted copula also. Since there are several, it is considered that other contractions are present and this one is counted as inverted.] 
EXAMPLE 136:

TIU A

$009-049$

Ah. Jim father's John? contracted copula present.]

lother

RULE 26. Count as inverted any wHQ with copula $B E$ of the form WH word + copula $B E+$ rest of the sentence (Example:s 137-139) and as uninverted any wHQ in which copula follows the subject of the sentence (Examples 140-142). For this rule, the rationale is rather lengthy because it encompasses an area debate, as the paragraphs following the examples indicate.

EXAMPLE 137:

TIU D 010-083 Oh .. eh . mmm ... Which $(\mathrm{mm}-\mathrm{hm}$.$) is$ EXAMPLE 138:

TIU D 025-005 Yes. Who is mmm Sam's boss?

EXAMPLE 139:

TIU D 031-001 Who is Tina's boyfriend?

EXAMPLE 140:

TIU C 003-024 Why she is waitress?

EXAMPLE 141:

TIU C 006-073 Ohhh. mmm. Why Peter is .. taxi driver?

EXAMPLE 142:

TIU C 009-019 This is ah-what this is?

The syntactic form of WHQs with copula $B E$ is not entirely clear. It is well-known that, with verbs other than $B E$, WHQs that focus on the subject of the sentence 
are definitely not inverted (Azar 1992, p. 128; CelceMurcia \& Larsen-Freeman, 1983, p. 149; Frank, 1972, p. 92); in the following example, the question and the answer both have the same, uninverted svo order: EXAMPLE 143:

Who made the explosion?

Peter made the explosion.

Therefore, when subjects produced WHQs similar to this example, such questions could not be counted as inverted and were placed into UNAQ 6 .

However, Celce-Murcia and Larsen-Freeman (1983) contend that WHQs that appear to have the same structure as the example above but that are constructed with copula $B E$ as the verb are actually inverted. Their example and argument is as follows:

EXAMPLE 144: What is that object?

The question in Example 144 is related to the underlying statement a., not b.:

a. That object is a stethoscope.

b. A stethoscope is that object.

Since it is the predicate NP, not the subject NP being questioned, the basic structure for this question is as shown in Figure 1.

This means that the formation of the question, what is that object?, requires not only that the wH word be fronted, but also that the subject of the sentence and $B E$ be inverted. The difference, then, between non-inversion 


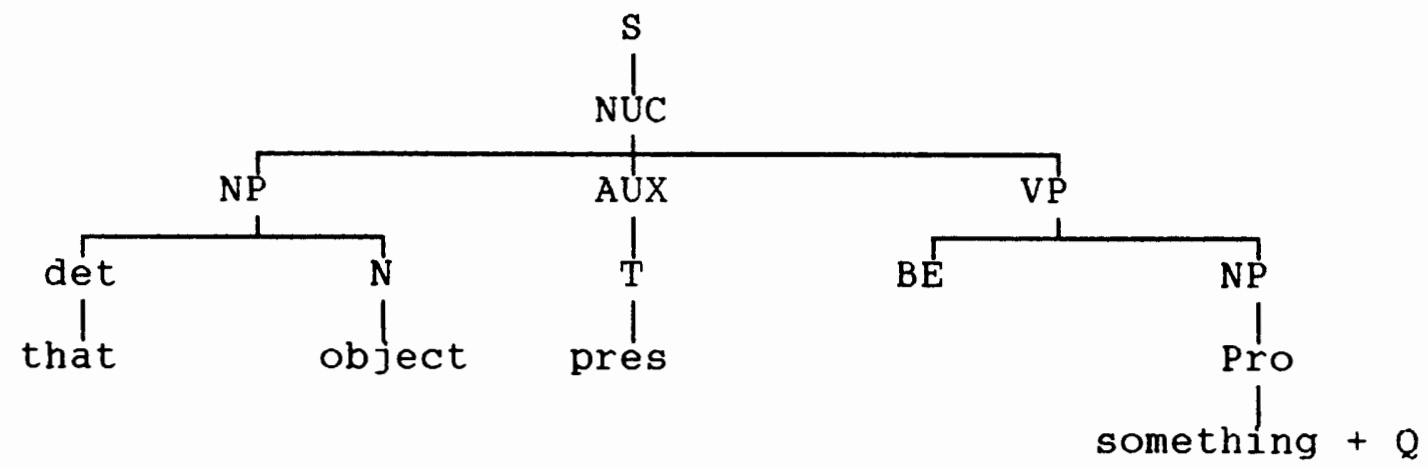

Figure 1. Underlying structure for questions such as "What is that object?" (From CelceMurcia \& Larsen-Freeman, 1983)

in who made the explosion? and inversion in what is that object? is, Celce-Murcia and Larsen-Freeman (1983) imply, that the verb in the latter question is copula $B E$.

However, the "underlying statement" basis of their argument, when applied to some questions from the data, does not seem so satisfactory. Below are some examples produced by subjects in this study, along with the two possible related underlying statements:

EXAMPLE 145: Who is Tina's boyfriend?

$$
\text { a. Tina's boyfriend is Peter. }
$$

b. Peter is Tina's boyfriend.

EXAMPLE 146: Who is Sam's boss?
a. Sam's boss is Tony.
b. Tony is Sam's boss.

EXAMPLE 147: Which is Tom?
a. Tom is the guy in the taxi.
b. The guy in the taxi is Tom.

In each of these examples, both possibilities for related underlying statement seem almost equally 
plausible. If it is the case that either statement could be considered the underlying related statement, then the argument of Celce-Murcia and Larsen-Freeman (1983) does not provide the answer as to whether such questions are inverted or not. Such questions would have to be regarded as ambiguous and placed into UNAQ 6. If nothing conclusive regarding the status of inversion in these kinds of question can be said on formal grounds, then the dilemma becomes a psycholinguistic question about how English speakers treat such questions on a behavioral basis as they process them, a question beyond the scope of this paper.

Searching other readily available sources that offer syntactic descriptions of WHQs (Frank, 1972; Quirk \& Greenbaum, 1973; Quirk, Greenbaum, Leech \& svartvik, 1985; and Radford, 1981) does not yield a definitive answer on the status of inversion in these problematic types of questions. In fact, only Quirk et al. (1985) address the issue, noting only that such questions display "ambiguity" (p. 819). However, Dieterich and Vasbinder (in press) offer two arguments in favor of the + inversion interpretation. The first involves considering a question very much like who is Tina's boyfriend? above, except using the empty pronoun, it: EXAMPLE 148 : Who is it? 
The answer would invariable be, It is Peter, not Peter is it. The conclusion then, is that questions such as who is it? are inverted.

More compelling evidence for the + inversion interpretation is an argument involving embedded questions (Dieterich \& Vasbinder, in press; Bolinger, 1957, also offers this argument). Embedding who is Tina's boyfriend? inside a larger sentence results in two possibilities, the second of rather untenable grammaticality (when not considered to be a direct quotation):

EXAMPLE 149: John asked who Tina's boyfriend is. *John asked who is Tina's boyfriend.

Since the first sentence is definitely grammatical, with the subject NP Tina preceding the copula $B E$, this is evidence that questions such as who is Tina's boyfriend? are, indeed, inverted.

The argument put forth by Celce-Murcia and LarsenFreeman (1983), and especially the evidence offered by Dieterich and Vasbinder (in press) led to the decision to count these types of questions as inverted.

Additional Considerations Concerning Analyzable Questions

As some of the above rules suggest, the TIU Qs were not required to be grammatical according to Ns rules. Issues of agreement, form, tense, choice or presence of 
auxiliary, and even word order (when it did not interfere with meaning or $+/$ - inversion) were not judged. In fact, in several cases, subjects used adjectives or nouns as verbs, as in the utterance, why does she sad? (021-044). This occurred primarily with words that were new to the subjects such as explosion, acquaintance, discovery, and fired--words with which the subjects had had no prior experience that had allowed them to discover the syntactic class to which the words belonged. However, subjects also occasionally used as verbs more common, well-known non-verb words such as sad, angry, and late-words which, in the researcher's experience in teaching Japanese students, are frequently used as verbs. In both cases, the adjective/noun-used-as-a-verb was considered a verb, and these utterances were analyzed according to the TIU. All these seemingly "lenient" interpretations of acceptable questions are based on Bley-Vroman's warning (1983), as Eckman et al. say, "against analyzing interlanguages from the target language's angle rather than on their own terms" (1989, p. 203.) The TIU addresses only the presence or absence of inversion and WH fronting; the data were examined in this light.

\section{Examples of Each TIU Category}

To conclude this chapter, examples of each TIU utterance type are presented in this final section. 
EXAMPLE 150: YN uninverted (TIU A)
a) TIU A 001-015 John is mmm . mmm. his, his father?
b) TIU A 002-037 Tom and . . Patty became Tom's girlfriend?
c) TIU A 004-089 Mmm. mm? He going, he going to . this house? go to?
d) TIU A 007-013 He . (mm-hmm) mmm is he . he know Peter?
e) TIU A 007-018 . . . This factory explosion?
f) TIU A 012-041 OK. mmm! . mm This idea mm she knows? [indicating discovery and Cindy]
g) TIU A 014-009a Mm, I think. Mom is other man, she find another man and other mmm.. other mmm.. and other people marry? She other peop- other man? or fall in love?

EXAMPLE 151: YN inverted (TIU B)
a) TIU B 001-008 Was she husband? (Mm-hmm.)
b) TIU B 005-009 Ah! Is this the washington DC?
c) TIU B 006-150a Patty mmm Patty is/u/ is Patty two [Gloss: Was patty only kidnapped by the two men, not killed?] (Right, she's not killed.)
d) TIU B 007-035 ...mm Does, does he know... does he know /fam/ Ti-Tina and Peter? (mm- $\mathrm{hm})$ together?
e) TIU B 011-033 Mmm . Does Cindy this important mmm. (Discovery?) discovery $\mathrm{mm}$ know?
f) TIU B 021-010 Money. Um, she had. ah, did she have husband?


EXAMPLE 152: WH fronted, uninverted (TIU C)
a) TIU C 001-055
Why mmm • • why • they, why mm why they kidnap her?
b) TIU C 002-024
Mm. Why Patty became a rob a bank?
c) TIU C 002-039
They $\mathrm{mm}, \mathrm{mm}$, . what they . . kidnap nap her? (Because Patty's father is a very rich man, etc.)
d) TIU C 004-002 When this factory explosion?
e) TIU C 005-004 Why, why Jim study math?
f) TIU C 008-091 Mmm, Why, mmmm wh- Patty's father - don't give ehhh? (Ah, Patty's father thinks maybe the bad guys killed Patty, etc.)
g) TIU C 017-018 Why, why Peter goed washington DC?
h) TIU C 022-072 Ah, why di- why did he did see Indian?

EXAMPLE 153: WH fronted, inverted (TIU D)
a) TIU D 003-009 what . does "in the past" mean?
b) TIU D 004-026 where is he live?

C) TIU D 006-109

Ahh? When? /ore/ It it's when is Tina and Peter knew? /ore/

d) TIU D 011-040 Where is last week Boris?

e) TIU D 013-081 Mmm why, why . did Tom . go to go to /sem ses/ [meaning unclear] with Sue?

f) TIU D 019-015 What what is . What is know.. Why he, why did he . . uumm did he go to TV news?

g) TIU D 019-042 Wha-which projecting he $\mathrm{mmm}$ do? does he, did he?

h) TIU D 022-124 Ah! But what is /habuje/? (What does she teach?) 
EXAMPLE 154: WH unfronted (TIU E)
a) TIU Ea 004-200 $\begin{aligned} & \text { Patty . . mm. how, how much . bank } \\ & \text { steal? }\end{aligned}$
b) TIU Ea 006-029 Tina, um why change?
C) TIU Ea 006-052 mm Peter at, at first is where?
d) TIU Ea 010-033 Mm. . . mm? . mmm . . This accident umm, what caused? Eh.... Oh-

EXAMPLE 156: WH unfronted with subject or verb missing (TIU F)
a) TIU F 006-042 Mmm. Change/u/ mm why?
b) TIU F 010-082 Tom why vacation?
c) TIU F 012-008 This letter mmm . where from?
d) TIU F 012-018 Mm. $\mathrm{mm}$. This hand who? [Subject was pointing to a picture.]

Throughout this paper, each category is referred to simply by its TIU letter. For ease of reference, a summary table giving the names of TIU (and UNAQ) categories, along with a brief definition of each, is located in Appendix B.

\section{SUMMARY}

This chapter's two main purposes were to describe the instrument and procedures used for data elicitation in this study and to describe the methods employed for placing the data into relevant categories. Data were collected from the 32 high school- and college-aged 
participants through the use of story square pictures about which the subjects had to discover the story by asking questions. The data obtained were transcribed and the utterances categorized.

Utterances were of three types: non-question utterances, question utterances that could not be analyzed according to the TIU, and question utterances that could be analyzed according to the TIU. Nonquestion utterances were merely identified and put aside. For both the unanalyzable questions and the analyzable questions, rules had to be formulated to determine how many separate questions there were in a given section of data, rife as it was with false starts, self-corrections, repetitions and other phenomena likewise as inaccessible to straightforward tallying. Once questions could be separated and counted, they could be categorized. Questions that were not analyzable according to the TIU because they lacked a subject or verb were placed into one of nine descriptive UNAQ categories. Questions analyzable according to the TIU were placed into one of six TIU categories. Since placement into the first four TIU categories depended on the presence or absence of inversion, rules clarifying what constitutes inversion were developed. The six TIU categories were as follows: YN uninverted (TIU A); YN inverted (TIU B); WH fronted, 
uninverted (TIU C); WH fronted, inverted (TIU D); WH unfronted (TIU E); and WH unfronted with subject or verb missing (TIU F). Sample utterances from each TIU category were presented in the last part of this chapter. whether subjects' data show the constraints of the TIU depend on their percentages of $\mathrm{WH}$ fronting, $\mathrm{WH}$ inversion, and YN inversion. The method of calculating these percentages and the results of these calculations are presented in Chapter IV. 
CHAPTER IV

\section{RESULTS AND DISCUSSION}

\section{INTRODUCTION}

This chapter reports the results of the analysis of the data into TIU categories and categories for questions unanalyzable according to the TIU (UNAQ categories). The results are examined under several different perspectives, and woven throughout the reporting is a discussion of the meaning of the results and of how they compare to other related studies.

A review of the hypothesis proposed in chapter I begins the chapter. The ensuing analysis details how the data relate to the hypothesis.

After the initial counts and percentages for each structure of the TIU--WH fronting, WH inversion, and YN inversion--are presented, the status of the hypothesis is assessed under three interpretations of the data: an "Absolute Existence Interpretation," a "Relative Existence Interpretation," and a whole group approach.

In the final section of the chapter, several incidental findings, relating both to the TIU and to UNAQ utterances, are discussed. 


\section{An Overview of the Data}

Transcribing the story square interview sessions with individual subjects resulted in a written record of the subjects' utterances, both non-questions and questions. Non-question utterances were merely identified and then disregarded, not counted or categorized.

The data, then, consisted of subjects' question utterances. Together all subjects produced 2311 questions, an average of just over 72 per subject.

Forty percent of these, 926 questions, an average of almost 29 per subject, were not analyzable according to the TIU because they did not contain both a subject and a verb. These unanalyzable questions were categorized into nine descriptive groups (the UNAQ categories), with a range of 26 to 435 tokens in each of the nine groups.

The remaining 1385 questions, an average of 42 per subject, were complete with subject and verb and could be analyzed according to the universal. (Actually, 14 of the 1385 questions, those in TIU category F, did not have both subject and verb. They were, nevertheless, included with questions analyzable according to the TIU because they were unfronted WHQs. In the portion of the TIU dealing with +/- frontedness, inversion is irrelevant, so 
these 14 questions could be analyzed into a TIU category characterized by unfrontedness despite the fact that they were missing either a subject or verb so that $+1-$ inversion could not be determined.) of the 1385 questions analyzable according to the TIU, 35, an average of about one per subject, were unfronted WHQs; 479, an average of nearly 15 per subject, were fronted WHQs; and 871, an average of about 27 per subject, were YNQs.

Figure 2 illustrates the preceding break down of the data and indicates further divisions of the YNQs and fronted WHQs into inverted and uninverted groups and of the unfronted WHQs into complete (with both verb and subject) and incomplete (lacking either subject or verb) groups. The number of utterances in each group is given, along with the groups' category names (for example, TIU A). Table 6 shows the absolute number of utterances in each category for each subject.

\section{RESTATEMENT OF THE HYPOTHESIS}

As stated in chapter $I$, the general question explored by this study was whether the TIUs that constrain primary languages also constrain ILs. Since the scope of such a question is obviously too broad for a single study to answer, a more specific question 
All subject utterances

(subjects $n=32$ )

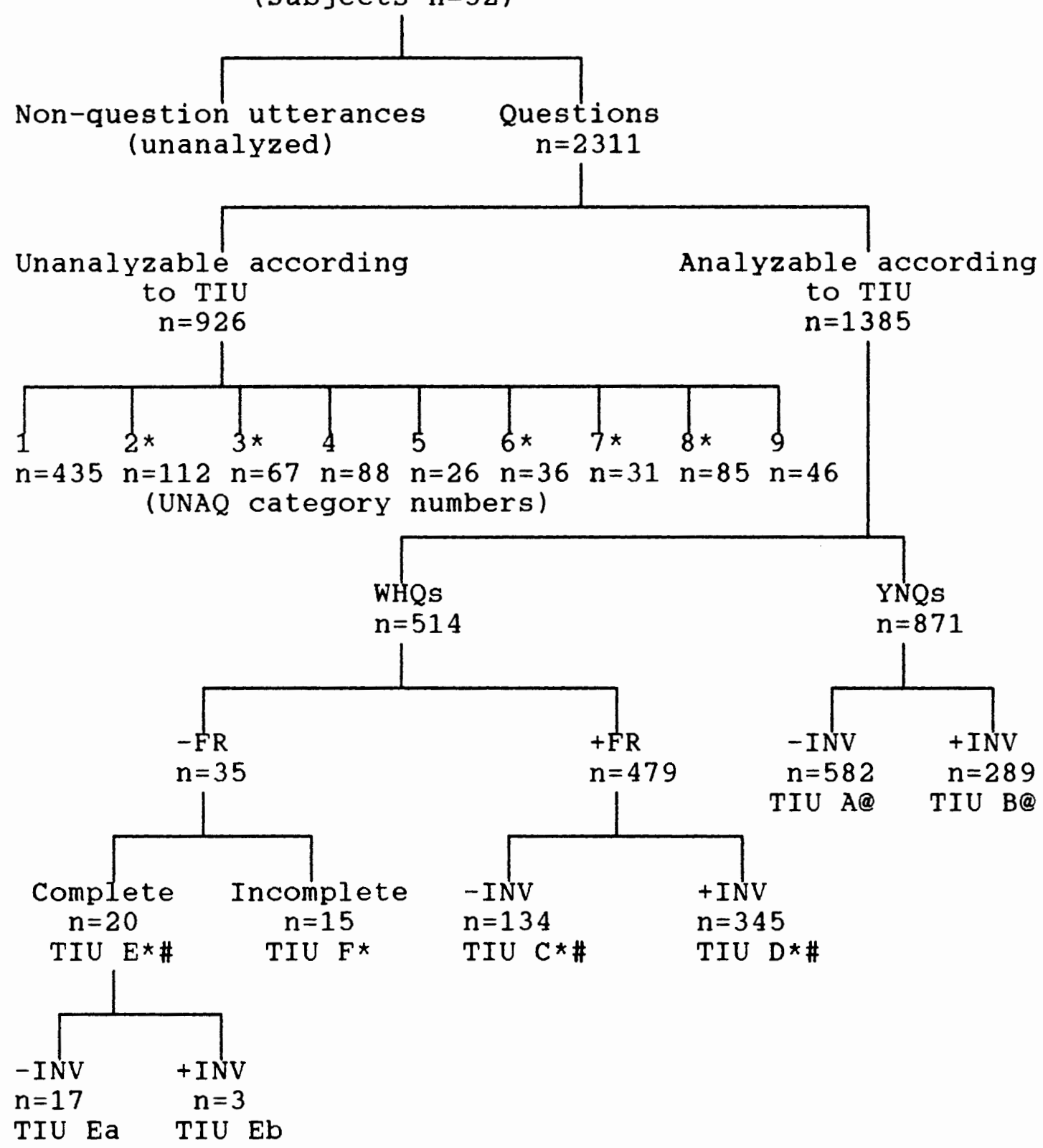

Figure 2. Break down of data into all categories, with aggregate number of tokens in each category.

* Some or all of the utterances in these categories were considered in determining $+/-$ wH fronting.

\# All utterances in these categories were considered in determining $+/-$ wH inversion.

@ All utterances in these categories were considered in determining $+/$ - YN inversion. 
Table 6

Absolute Number of Utterances in each Category, by Subject

\begin{tabular}{|c|c|c|c|c|c|c|c|c|c|c|c|c|c|c|c|c|}
\hline & 2 & 3 & 4 & 5 & 6 & 7 & 8 & 9 & 10 & 11 & 12 & 13 & 12 & 15 & 16 & 17 \\
\hline & & C & $\mathrm{A}$ & $E$ & G & $\mathbf{R}$ & $Y$ & $\mathrm{~N}$ & $\mathrm{UM}$ & & $\mathrm{R} /$ & & & & & \\
\hline & 1 & 2 & 3 & 4 & 5 & 6 & 7 & 12 & 13 & A & B & C & D & $E$ & $\mathrm{~F}$ & $\mathrm{OK}$ \\
\hline & 9 & 3 & 1 & 2 & 0 & & 0 & 2 & & 13 & 19 & & 10 & & 0 & 8 \\
\hline & 5 & 0 & 0 & 0 & 0 & & & 0 & ( & & 2 & 9 & 1 & & & \\
\hline & 7 & 5 & 2 & 0 & 0 & ( & 0 & 3 & 3 & 14 & 0 & 5 & 1 & & 1 & 35 \\
\hline & 33 & 16 & 5 & 4 & 18 & 1 & 0 & 7 & 1 & & 0 & 9 & 10 & & & \\
\hline & 13 & 1 & 8 & 4 & 0 & $c$ & 1 & 1 & 4 & 19 & 2 & 13 & & 1 & 0 & 10 \\
\hline & 1 & 6 & 2 & 4 & 0 & 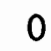 & 2 & 14 & 13 & & 1 & 12 & 10 & & & 41 \\
\hline & & 0 & 0 & 2 & 0 & 0 & 1 & 2 & 1 & 16 & 7 & 2 & 3 & & & \\
\hline & 28 & 7 & 3 & 3 & 0 & 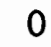 & & & 2 & & ( & & 0 & & & \\
\hline & & 1 & 3 & 3 & 0 & 1 & 0 & 4 & 4 & 49 & 0 & 2 & 3 & & & 1. \\
\hline & 14 & 3 & 3 & 3 & 4 & 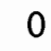 & & c & $c$ & & 4 & & 5 & & 2 & 13 \\
\hline & 1 & 0 & 2 & 4 & 0 & 0 & 1 & 3 & 0 & 8 & 2 & 1 & 1 & & & \\
\hline & 2 & 4 & 5 & 2 & 0 & $c$ & 1 & 0 & 1 & 16 & 11 & 2 & 2 & & 2 & 17 \\
\hline & 7 & 2 & 2 & 0 & C & 2 & 1 & 4 & 0 & 1 & 7 & 0 & 16 & & 1 & \\
\hline & 27 & & 6 & 13 & & 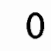 & 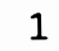 & 1 & 0 & & 9 & 4 & 6 & & 0 & 64 \\
\hline & 3 & 3 & 4 & 5 & & $c$ & 2 & 6 & 0 & & & 3 & 0 & & & 13 \\
\hline & 57 & & 5 & 16 & 2 & ( & 6 & 15 & 3 & & & 4 & 2 & & & \\
\hline & 9 & 9 & 0 & 5 & ( & $c$ & 1 & 4 & 5 & 40 & 0 & 8 & 4 & 1 & & 18 \\
\hline & 16 & 3 & c & 6 & & ( & 3 & & & & 1 & c & 2 & & & 26 \\
\hline & 3 & 0 & 1 & 0 & & 1 & & 2 & ( & & 5 & 2 & 10 & & & \\
\hline & 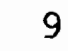 & & $c$ & 1 & & 2 & & & & & 4 & & 24 & & & \\
\hline & 13 & 0 & 1 & 4 & 2 & 4 & & 2 & $c$ & 17 & 14 & C & 8 & & & 17 \\
\hline & & & & 1 & & 1 & & & & & & & & & & 38 \\
\hline & 13 & 1 & 0 & 0 & ( & 1 & & 1 & 1 & & 25 & 0 & 11 & & & \\
\hline & 5 & 4 & 1 & 1 & & 3 & & & & & 2 & & & & & 20 \\
\hline & 9 & 1 & $\epsilon$ & 1 & ( & 3 & & 2 & 1 & 7 & 17 & 21 & 35 & 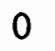 & & 35 \\
\hline & 3 & 4 & 1 & & & & & & & & & 1 & 17 & & & \\
\hline & 8 & 5 & ( & 2 & ( & 2 & & 1 & c & 14 & & 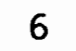 & 8 & & & 12 \\
\hline & 15 & 10 & 2 & 0 & & & & & & & & & & & & 29 \\
\hline & & 1 & C & 1 & ( & 2 & & ( & 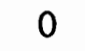 & 5 & & 1 & 2 & & 0 & 8 \\
\hline & 21 & 5 & & 1 & & 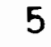 & & & c & 27 & & 7 & & & & 17 \\
\hline & 1 & ( & C & 0 & C & C & & 0 & 0 & 0 & & ( & 3 & & $c$ & \\
\hline & 6 & 0 & 0 & 0 & & 3 & & 0 & 0 & 4 & 16 & 2 & 19 & 0 & & \\
\hline
\end{tabular}

involving only one particular TIU, the $Q$ TIU, was addressed. The hypothesis proposed was as follows: 
1. The interrogative TIU,

WH fronting > WH inversion > YN inversion,

which constrains primary languages, will also constrain learners' ILs.

1a. Subjects' control of wh inversion will imply their control of wh fronting.

1b. Subjects' control of YN inversion will imply their control of wh inversion.

The following discussion attempts to relate the results of the data analysis to this hypothesis.

\section{ANALYSIS OF THE DATA}

\section{Introduction}

Since the present study is a partial replication of the study by Eckman et al. (1989), much of the presentation, analysis, and discussion of the data in this section follows the same format that their study follows. However, whereas Eckman et al. provide extensive argument and documentation defending their choices of presentation and analysis, these are generally only summarized here. other differences in format between their study and this arise because the present study contains some different types of data than did the study of Eckman et al. (for example, their data did not include unfronted WHQs), because this study gives a more 
detailed report of the data (for instance, it reports on UNAQ utterances whereas theirs did not), and because the data are examined from some angles not considered in Eckman et al.

Because the TIU has to do with WH fronting, inversion in WHQS, and inversion in YNQs, subjects' utterances were examined for evidence of these constructions, according to the rules enumerated in Chapter III, and then placed into suitable categories, also described in Chapter III.

The current division presents the percentages of $\mathrm{WH}$ fronting, WH inversion, and $\mathrm{YN}$ inversion and compares those percentages among themselves to determine whether the hypothesis was confirmed. These comparisons reveal the status of the hypothesis: whether $\mathrm{WH}$ inversion implies $\mathrm{WH}$ fronting in the data, the first claim of the $Q$ TIU; and whether YN inversion implies $\mathrm{WH}$ inversion in the data, the second claim of the TIU. These comparisons are first made using an "Absolute Existence Interpretation" (AEI) of the TIU, as did Eckman et al. (1989). In addition, unlike Eckman et al., this study includes an implicational scaling, comparing all three percentages. Next, the results of a "Relative Existence Interpretation" (REI) of the TIU are compared with the results of the AEI, as in Eckman et al. The REI yields 
seven exceptions to the TIU, which are then discussed. The final comparison, made from a perspective not investigated by Eckman et al., is a whole group approach that compares the three percentages for all subjects together. At the end of this section, another type of exception, which did not appear in any of the general tendencies, is discussed.

After conclusions are reached regarding the status of the hypothesis, the final section of this chapter reports various incidental findings.

Throughout this chapter reference is made to various category names such as "TIU A" and "UNAQ 6". Succinct definitions of each of these categories can be found in Appendix B .

\section{Percentage of WH Fronting}

Figuring the percentage of WH fronting was the most complex calculation because utterances had to be drawn from both TIU and UNAQ categories in order to find the total number of WH utterances. In determining the percentage of WH fronting, any WH question of two words or longer required consideration unless the utterance was part of a false start series (see Rules 1 and 2, in Chapter III) or part of an utterance where $+/$ - fronting could not be readily determined (many of the utterances 
in UNAQ 7 and 8 ). In other words, as mentioned briefly before, WH questions were not required to be complete with both subject and verb in order to be considered to exhibit wH frontedness or unfrontedness.

Hence, in determining the overall percentage of $\mathrm{WH}$ fronting for any given subject, all utterances from the TIU categories C, D, E, and F were considered as were all pertinent utterances from the UNAQ categories $2,3,6,7$, and 8. While every utterance from each of the TIU categories and from UNAQ 3 was counted in determining + /frontedness, this is not the case for the other UNAQ categories: UNAQ 2 includes utterances that consist of only one word, a WH word, which could not properly be said to be fronted; UNAQ 6 contains questions such as YN tag questions that could not be counted; UNAQ 7 contained some questions that were not acoustically clear enough to analyze at all; and some of the questions containing WH words in UNAQ 8 were too ambiguous to determine whether the WH word was fronted or not. However, it was necessary to include those utterances from the UNAQ categories that clearly did have fronted wH words because considering only utterances from the TIU categories would result in an inaccurately inflated percentage of unfronted WH questions. 
The sum of all wHQs from all the categories mentioned in the paragraph above equals the total number of WHQs. This number, less the number of unfronted WHQs (those in questions in TIU $E$ and $F$ ), divided by the total number of WHQs yields the percentage of fronted $\mathrm{WH}$ questions, the first structure of the TIU. Table 7 shows the total number of WHQs used in determining frontedness, the categories from which the said WHQs originated, and, in column 16, the percentage of fronting for each subject.

\section{Percentage of WH Inversion}

Determining the percentage of $\mathrm{WH}$ inversion was a simpler matter, involving utterances from only three categories: TIU C, D, and E. At first glance, it may appear that only utterances from TIU C (complete, uninverted WHQs) and TIU D (complete, inverted WHQs) need be considered for determining the percentage of $\mathrm{WH}$ inversion. However, in actuality, those categorie:s represent only part of the +/- wH inversion picture. There are, in the data, other wHQs that can be classified as either inverted or uninverted, namely, those questions complete with both subject and verb that also happen to contain an unfronted WH word. These questions are found in TIU E. The questions in TIU $E$ were considered in 
Table 7

Percentage of Frontedness and Total Number of WHQs Used in Determining Percentage of Frontedness with Categories of Origin, by subject

\begin{tabular}{|c|c|c|c|c|c|c|c|c|c|c|c|c|c|c|c|}
\hline $\begin{array}{l}S \\
U \\
B\end{array}$ & 2 & $\begin{array}{l}\mathrm{C} \\
\text { WH }\end{array}$ & $\begin{array}{r}4 \\
\text { UN } \\
\text { ATEC }\end{array}$ & $\begin{array}{l}5 \\
\text { AQ } \\
\text { DR IE }\end{array}$ & $\begin{array}{r}6 \\
\mathrm{SS}\end{array}$ & 7 & $\begin{array}{c}8 \\
\mathrm{CA} \\
\mathrm{Fr}\end{array}$ & $\begin{array}{r}9 \\
\text { TI } \\
\text { TEG } \\
\text { ont }\end{array}$ & $\begin{array}{l}10 \\
\text { JRIES } \\
\text { OQS }\end{array}$ & $\begin{array}{l}\text { Tot } \\
+ \text { FR }\end{array}$ & $\begin{array}{l}12 \\
\mathrm{~T} \\
\mathrm{CA} \\
\text { Un }\end{array}$ & $\begin{array}{l}13 \\
U \\
\text { GR. } \\
\text { rnt }\end{array}$ & $\begin{array}{l}\text { Tot } \\
\text {-FR }\end{array}$ & $\begin{array}{l}\text { A11 } \\
\text { WHQ }\end{array}$ & 16 \\
\hline 1 & 3 & 1 & 0 & 0 & 0 & 4 & 2 & 10 & 12 & 16 & 0 & 0 & 0 & 16 & 100 \\
\hline 2 & 0 & 0 & 0 & 0 & 0 & 0 & 9 & 1 & 10 & 10 & 0 & 0 & 0 & 10 & 100 \\
\hline 3 & 3 & 2 & 0 & 0 & 0 & 5 & 5 & 1 & 6 & 11 & 0 & 1 & 1 & 12 & 92 \\
\hline 4 & 4 & 5 & 1 & 0 & 0 & 10 & 9 & 10 & 19 & 29 & 2 & 0 & 2 & 31 & $y$ \\
\hline 5 & 1 & 8 & 0 & 0 & 0 & 9 & 13 & 4 & 17 & 26 & 1 & 0 & 1 & 27 & 96 \\
\hline 6 & 0 & 2 & 0 & 1 & 1 & 4 & 12 & 10 & 22 & 26 & 2 & 2 & 4 & 30 & 87 \\
\hline 7 & 0 & 0 & 0 & 0 & 0 & 0 & 2 & 3 & 5 & 5 & 0 & 0 & 0 & 5 & 100 \\
\hline 8 & 0 & 3 & 0 & 0 & 1 & 4 & 4 & 0 & 4 & 8 & 0 & 0 & 0 & 8 & 100 \\
\hline 9 & 1 & 3 & 0 & 0 & 1 & 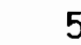 & 2 & 3 & 5 & 10 & 0 & 0 & 0 & 10 & 100 \\
\hline 10 & 1 & 3 & 0 & 0 & 0 & $\leq$ & 3 & 5 & 8 & 12 & 7 & 2 & 9 & 21 & 57 \\
\hline 11 & 0 & 2 & 0 & 0 & 0 & & 1 & 1 & 2 & 4 & 0 & 1 & 1 & 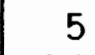 & 80 \\
\hline 12 & 3 & 5 & 0 & 0 & 0 & 8 & 2 & 2 & 4 & 12 & 0 & 2 & 2 & 14 & 86 \\
\hline 13 & 0 & 2 & 2 & 0 & 0 & 4 & 0 & 16 & 16 & 20 & 0 & 1 & 1 & 21 & 95 \\
\hline 14 & 0 & 6 & 0 & 0 & 0 & $\epsilon$ & 4 & 6 & 10 & 16 & 0 & 0 & 0 & 16 & 100 \\
\hline 15 & 2 & 4 & 0 & 0 & 6 & $\epsilon$ & 3 & 0 & 3 & 9 & 0 & 0 & 0 & 9 & 100 \\
\hline 16 & 1 & 5 & 0 & 0 & 1 & 7 & 4 & 2 & 6 & 13 & 1 & 1 & 2 & 15 & 87 \\
\hline 17 & 0 & 0 & 0 & 1 & 0 & 1 & 8 & 4 & 12 & 13 & 1 & 0 & 1 & 14 & 93 \\
\hline 18 & 0 & 0 & 0 & 0 & 0 & & 0 & 2 & 2 & 2 & 1 & 2 & 3 & 5 & 40 \\
\hline 19 & 0 & 1 & 1 & 0 & 0 & 2 & 2 & 10 & 12 & 14 & 0 & 0 & 0 & 14 & 100 \\
\hline 20 & 1 & 0 & 2 & 0 & 0 & 3 & 6 & 24 & 30 & 33 & 0 & 0 & 0 & 33 & 100 \\
\hline 21 & 0 & 1 & 1 & 0 & 0 & 2 & 0 & 8 & 8 & 10 & 1 & 1 & 2 & 12 & 83 \\
\hline 22 & 1 & 3 & 1 & 0 & 1 & 6 & 3 & 35 & 38 & 44 & 1 & 0 & 1 & 45 & 98 \\
\hline 23 & 1 & 0 & 1 & 0 & 1 & 3 & 0 & 11 & 11 & 14 & 0 & 0 & 0 & 14 & 100 \\
\hline 24 & 3 & 1 & 2 & 0 & 0 & 6 & 2 & 8 & 10 & 16 & 4 & 1 & 5 & 21 & 76 \\
\hline 25 & 0 & 6 & 3 & 0 & 1 & 10 & 21 & 35 & 56 & 66 & 0 & 0 & 0 & 66 & 100 \\
\hline 26 & 1 & 1 & 0 & 0 & 0 & 2 & 1 & 17 & 18 & 20 & 0 & 0 & 0 & 20 & 100 \\
\hline 27 & 1 & 0 & 1 & 0 & 0 & 2 & 6 & 8 & 14 & 16 & 0 & 0 & 0 & 16 & 100 \\
\hline 28 & 3 & 2 & 1 & 0 & 0 & 6 & 0 & 24 & 24 & 30 & 0 & 0 & 0 & 30 & 100 \\
\hline 29 & 0 & 0 & 1 & 0 & 0 & $\perp$ & 1 & 22 & 23 & 24 & 0 & 0 & 0 & 24 & 100 \\
\hline 30 & 2 & 0 & 0 & 0 & 0 & 2 & 7 & 14 & 21 & 23 & 0 & 0 & 0 & 23 & 100 \\
\hline 31 & 1 & 0 & 0 & 0 & 0 & 1 & 0 & 30 & 30 & 31 & 0 & 0 & 0 & 31 & 100 \\
\hline 32 & 0 & 0 & 2 & 0 & 0 & 2 & 2 & 19 & 21 & 23 & 0 & 0 & 0 & 23 & 100 \\
\hline
\end{tabular}


determining $+/-$ WH fronting, above, but they must also bo considered in determining $+/-$ wH inversion since they are WHQs complete with subject and verb. In considering the utterances from TIU $E$ used in determining $+/-$ WH inversion, the uninverted utterances from TIU $E$ (classified as TIU Ea) must be added to the uninverted WHQs in TIU C, while the inverted utterances from TIU E (classified as TIU Eb) must be added to the inverted WHQS in TIU D. Table 8, below, shows the raw numbers and, in column 6, the percentage of wH inversion for each subject.

\section{Percentage of YN Inversion}

Finding the percentage of YN inversion for each subject was the simplest calculation. First, for each subject, all the utterances from TIU A (that is, the uninverted YNQS) were counted, as were those from TIU B (the inverted YNQS). The number of utterances from theso two categories together comprised the total number of grammatically complete YNQs to be considered for calculating the percentage of $Y N$ inversion. Then the number of TIU B utterances was divided by the total number of complete YNQs, yielding the percentage of $Y N$ inversion, which is shown in column 5 of Table 9. 
Table 8

Percentage of WH Inversion and Total Number of WHQS Used in Determining Percentage of

WH Inversion, by Subject

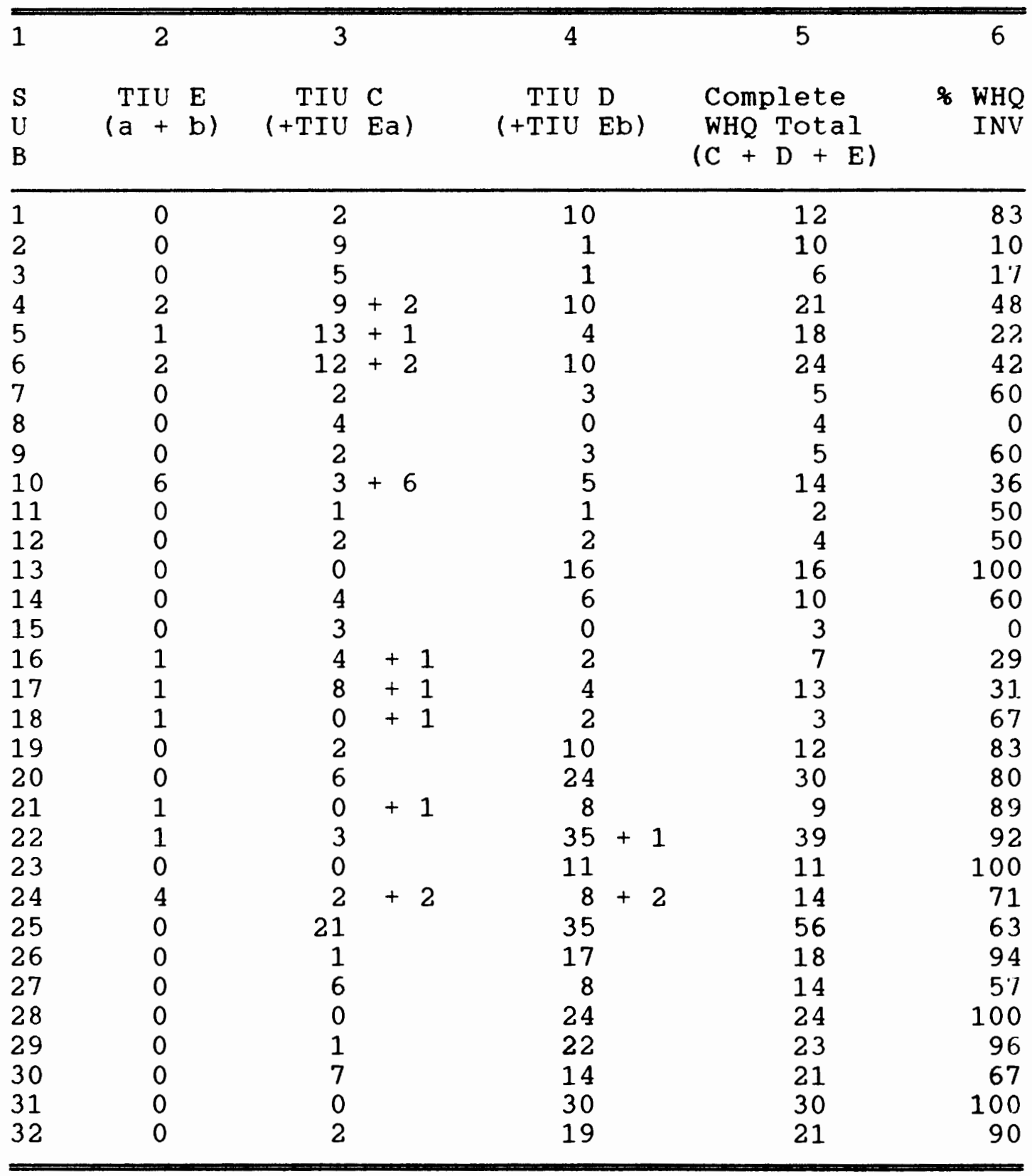


Table 9

Percentage of YN Inversion and Total Number of YNQS Used in Determining Percentage of YN Inversion, by subject

\begin{tabular}{|c|c|c|c|c|}
\hline 1 & 2 & 3 & 4 & 5 \\
\hline Subj. & TIU A & TIU B & $\begin{array}{c}\text { YNQ Total } \\
(\mathrm{A}+\mathrm{B})\end{array}$ & $\begin{array}{l}\text { \% YN } \\
\text { INV }\end{array}$ \\
\hline 1 & 13 & 19 & 32 & 59 \\
\hline 2 & 16 & 2 & 18 & 11 \\
\hline 3 & 14 & 0 & 14 & 0 \\
\hline 4 & 51 & 0 & 51 & 0 \\
\hline 5 & 19 & 2 & 21 & 10 \\
\hline 6 & 25 & 1 & 26 & 4 \\
\hline 7 & 16 & 7 & 23 & 30 \\
\hline 8 & 13 & 0 & 13 & 0 \\
\hline 9 & 49 & 0 & 49 & 0 \\
\hline 10 & 6 & 4 & 10 & 40 \\
\hline 11 & 8 & 2 & 10 & 20 \\
\hline 12 & 16 & 11 & 27 & 41 \\
\hline 13 & 10 & 7 & 17 & 41. \\
\hline 14 & 35 & 9 & 44 & 20 \\
\hline 15 & 25 & 0 & 25 & 0 \\
\hline 16 & 39 & 0 & 39 & 0 \\
\hline 17 & 40 & 0 & 40 & 0 \\
\hline 18 & 29 & 1 & 30 & 3 \\
\hline 19 & 12 & 5 & 17 & 29 \\
\hline 20 & 22 & 4 & 26 & 15 \\
\hline 21 & 17 & 14 & 31 & 45 \\
\hline 22 & 3 & 13 & 16 & 81 \\
\hline 23 & 8 & 25 & 33 & 76 \\
\hline 24 & 33 & 2 & 35 & 6 \\
\hline 25 & 7 & 17 & 24 & 71. \\
\hline 26 & 4 & 12 & 16 & 75 \\
\hline 27 & 14 & 24 & 38 & 63 \\
\hline 28 & 2 & 32 & 34 & 94 \\
\hline 29 & 5 & 18 & 23 & 78 \\
\hline 30 & 27 & 24 & 51 & 47 \\
\hline 31 & 0 & 18 & 18 & 100 \\
\hline 32 & 4 & 16 & 20 & 80 \\
\hline
\end{tabular}




\section{Counts and Percentages of WH Fronting and}

\section{WH Inversion}

Table 10 compares the counts and percentages of wH fronting and $\mathrm{WH}$ inversion. Table 10 is similar to Table 3 in Eckman et al. (1989) except that Table 10 includes an additional column, column 5 "Total All WHQs," used for calculating the percentage of fronting. The numbers in column 5 differ from the numbers in column 2, "Total Complete wHQs," because, as explained above, both grammatically complete and grammatically incomplete but finished WHQs were considered in figuring the percentage of WH fronting while only grammatically complete wHQs could be used in figuring the percentage of wH inversion. Table 3 in Eckman et al. did not require a counterpart to column 5 because no unfronted WHQs were obtained in that study. Subjects are ordered in Table 10 according to percentage of WH fronting, and, where that is 100 percent, according to percentage of wH inversion.

\section{Counts and Percentages of WH Inversion and}

\section{YN Inversion}

A table similar to Table 10 but showing the number of tokens displaying $\mathrm{YN}$ inversion and $\mathrm{WH}$ inversion and their percentages for each subject is presented below. This table, Table 11, is similar to table 4 in Eckman 
et al. (1989). Columns 2 through 4 of Table 11 concern inversion in YNQs, while columns 5 through 7 deal with

Table 10

Utterance Counts and Percentages of WH Fronting and WH Inversion

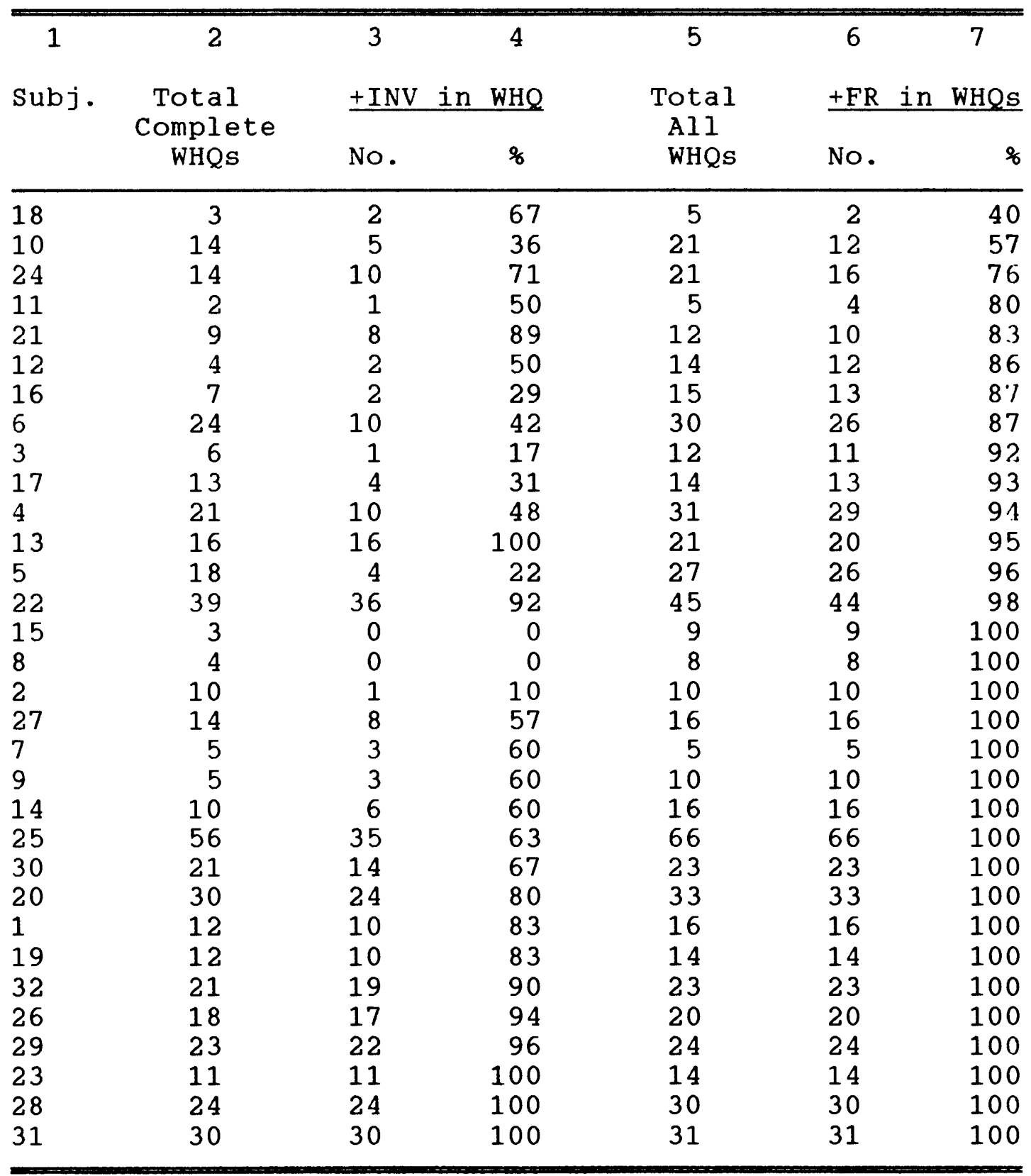


Table 11

Utterance Counts and Percentages of YN Inversion and WH Inversion

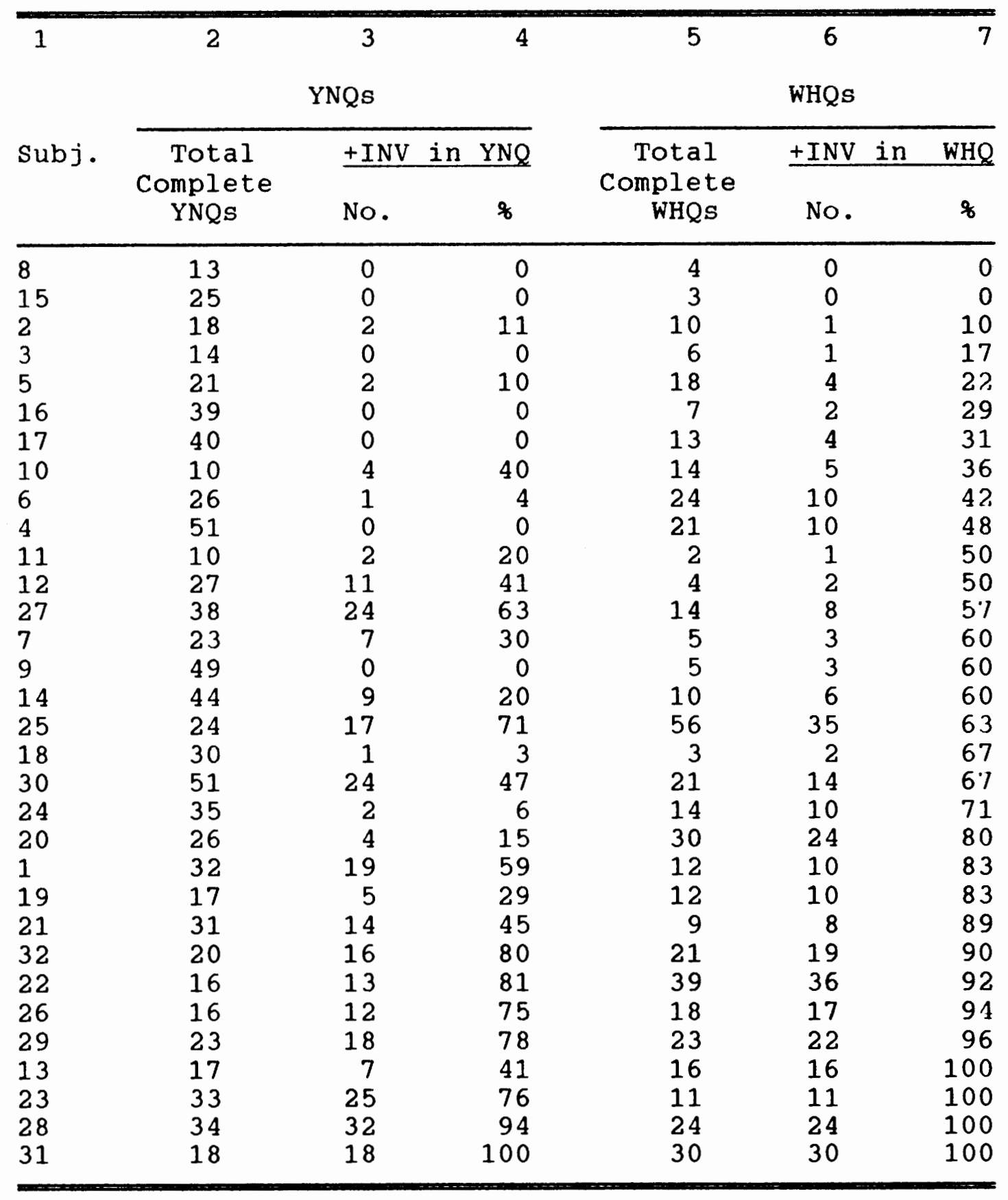


information about inversion in wHQs. As can readily be seen, columns 5 through 7 of Table 11 contain information identical to the information displayed in columns 2 through 4 of Table 10, above, although in a different order. The information is repeated because both claims of the TIU, "WH inversion implies WH fronting" and "YN inversion implies wH inversion", deal with wH inversion. In Table 11, subjects are arranged according to percentage of $W H$ inversion, and, where that is 100 percent, according to percentage of YN inversion.

\section{The Status of the Hypothesis: Introduction}

With the counts and percentages of wH fronting, wH inversion, and YN inversion established above, these may now be compared in various ways in order to determine whether or not the data support the hypothesis. Comparisons are made below from the perspectives of an AEI and of a REI, as in Eckman et al. (1989). Exceptions under the latter interpretation are discussed, and the last perspective considered is a whole group approach. The final section discusses a type of exception that did not alter the results of any of the comparisons overall, but which are, nevertheless, exceptions to the TIU. 
The Status of the Hypothesis:

\section{Absolute Existence Interpretation}

Comparisons for the two claims of the universal are made separately below, on two tables, as they were by Eckman et al. (1989). Following that, all three structures of the universal are considered together on an implicational scaling.

Making comparisons using the traditional approach of SLA researchers that Eckman et al. (1989) call an AEI of the data involves setting as an absolute criterion a percentage of correct occurrence at or above which it is said that the subject has control of a certain construction, or that the construction is a manifestation of a general rule of the subject's IL. Occurrence of the construction below the chosen percentage criterion indicates that the subject does not control the construction, that the rule for forming such constructions is not a general rule of the IL.

As Eckman et al. (1989) observe, the choice of the particular percentage to be used as the absolute criterion is arbitrary. Language acquisition researchers generally select rather high percentages in order to avoid classifying as a general rule of the IL constructions that appear in a subject's speech only rarely or haphazardly. The percentage criterion chosen 
for this study is 90 percent because that is the criterion used by Eckman et al.

In the tables below, a value of "+" for a construction indicates that the given subject is deemed to possess control of that construction by virtue of having produced the construction correctly in at least 90 percent of relevant utterances. A value of "-" for a construction means that a subject does not control the construction, as determined by a correct production rate lower than 90 percent.

\section{Does WH Inversion Imply WH Fronting?}

Comparing subjects' control of wH inversion with their control of wH fronting reveals the status of part 1a. of the hypothesis, repeated here for convenience:

1a. Subjects' control of wH inversion will imply their control of WH fronting.

The comparison of control of wH inversion with control of WH fronting is made by means of Table 12, below. This table is similar to Table 5 in Eckman et al. (1989), differing only in that their table gives two additional "control" criteria, 80 percent and 100 percent. subjects are ordered in Table 12 according to percentage of $\mathrm{WH}$ fronting, with the exceptions of subjects 13 and 22 , who appear lower in the list than their percentage of wH fronting would allow, in order to preserve the pattern of 
Table 12

Absolute Existence Interpretation status of Hypothesis 1a: WH Inversion Implies

WH Fronting

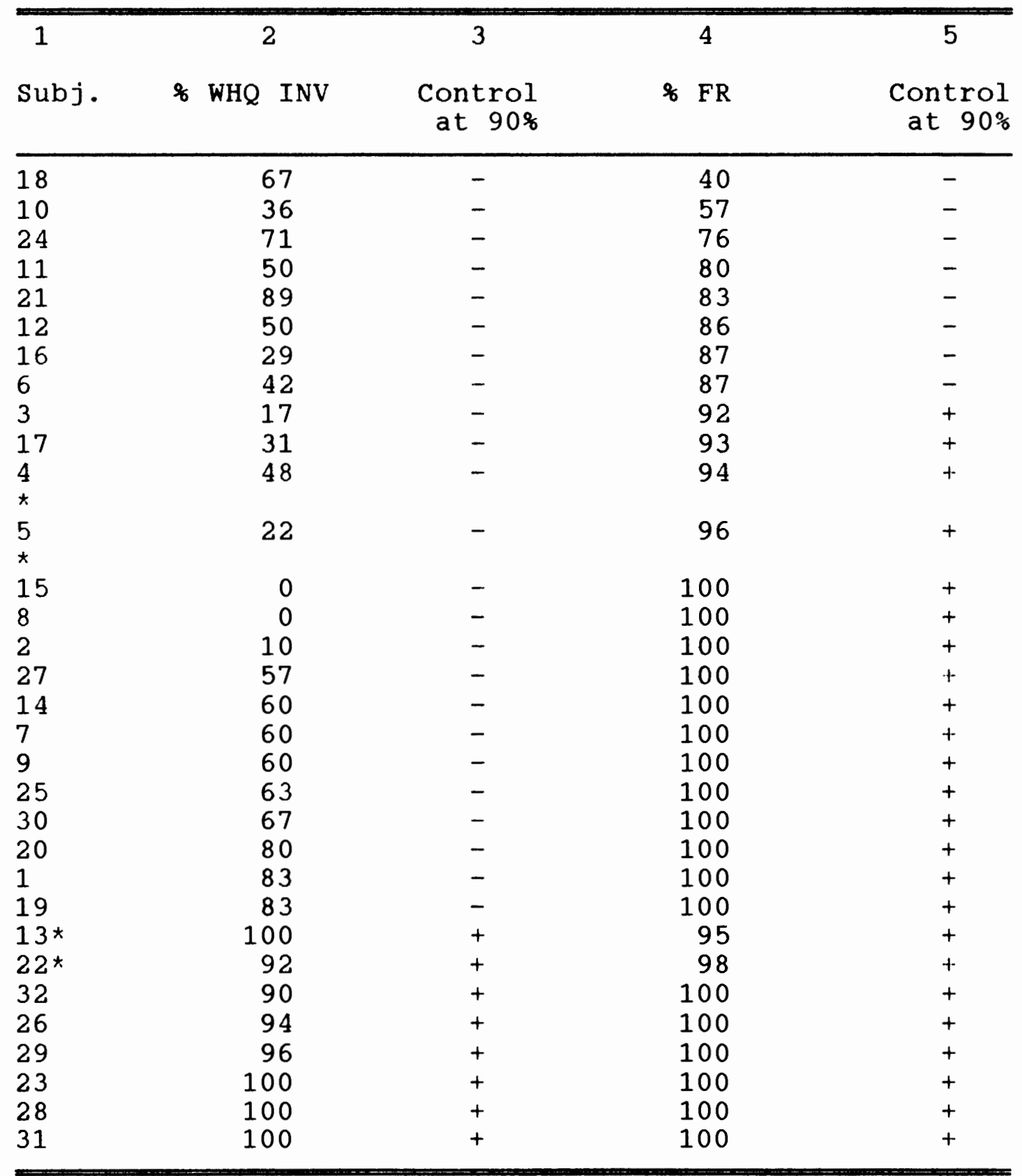


"+'s" and "-'s". Their original positions, according to percentage of wH fronting, are marked with an asterisk.

In Table 12, three patterns of pluses and minuses signify a confirmation of the part of the universal under consideration: $(-,-)$, which indicates control of neither WH fronting nor WH inversion, $(-,+)$, which indicates control of WH fronting but not of WH inversion, and ${ }^{+}$, $+)$, which indicates control of both wH fronting and WH inversion. The pattern, $(+,-)$, however, indicating control of WH inversion without control of WH fronting, violates the universal. Examination of the patterns of pluses and minuses in Table 12 reveals no exceptions to this part of the universal at a 90 percent absolute criterion. The data of all subjects uphold this claim of the universal, including data from subjects 13 and 22 who, though their slightly lower percentage of WH fronting made it necessary to move them down on the table to preserve the pattern of pluses and minuses, still meet the 90 percent absolute criteria for both wH fronting and WH inversion.

\section{Does YN Inversion Imply WH Inversion?}

Subjects' control of YN inversion compared with their control of $\mathrm{WH}$ inversion reveals the status of part 1b. of the hypothesis, repeated here for convenience: 
1b. Subjects control of YN inversion will

imply their control of $\mathrm{WH}$ inversion.

Table 13, below, compares subjects' control of YN inversion with their control of wH inversion. As above, control of a structure is indicated by a plus sign on the table, while lack of control is indicated by a minus sign. Table 13 is similar to Table 6 in Eckman et al. (1989), and, accordingly, subjects are ordered by percentage of YN inversion.

Again, as in Table 12, three patterns of pluses and minuses, $(-,-),(-,+)$, and $(+,+)$ are consistent with the predictions of the TIU, while the pattern $(+,-)$ indicates a violation of the TIU. Inspecting Table 13 shows that the patterns for all subjects are of the first three types. That is, at a 90 percent absolute criterion, all subjects confirm the portion of the hypothesis that claims that YN inversion implies $\mathrm{WH}$ inversion.

\section{Implicational scale of the Three structures of the TIU}

Although Eckman et al. (1989) did not do so, the data from Tables 12 and 13 may be combined into an implicational scaling that shows the relationship of all three structures of the TIU in one table. Implicational scales are often used to depict variation in SLA data (Ellis, 1986). Across the top of the scale are the 
Table 13

Absolute Existence Interpretation status of Hypothesis 1b: YN Inversion Implies

WH Inversion

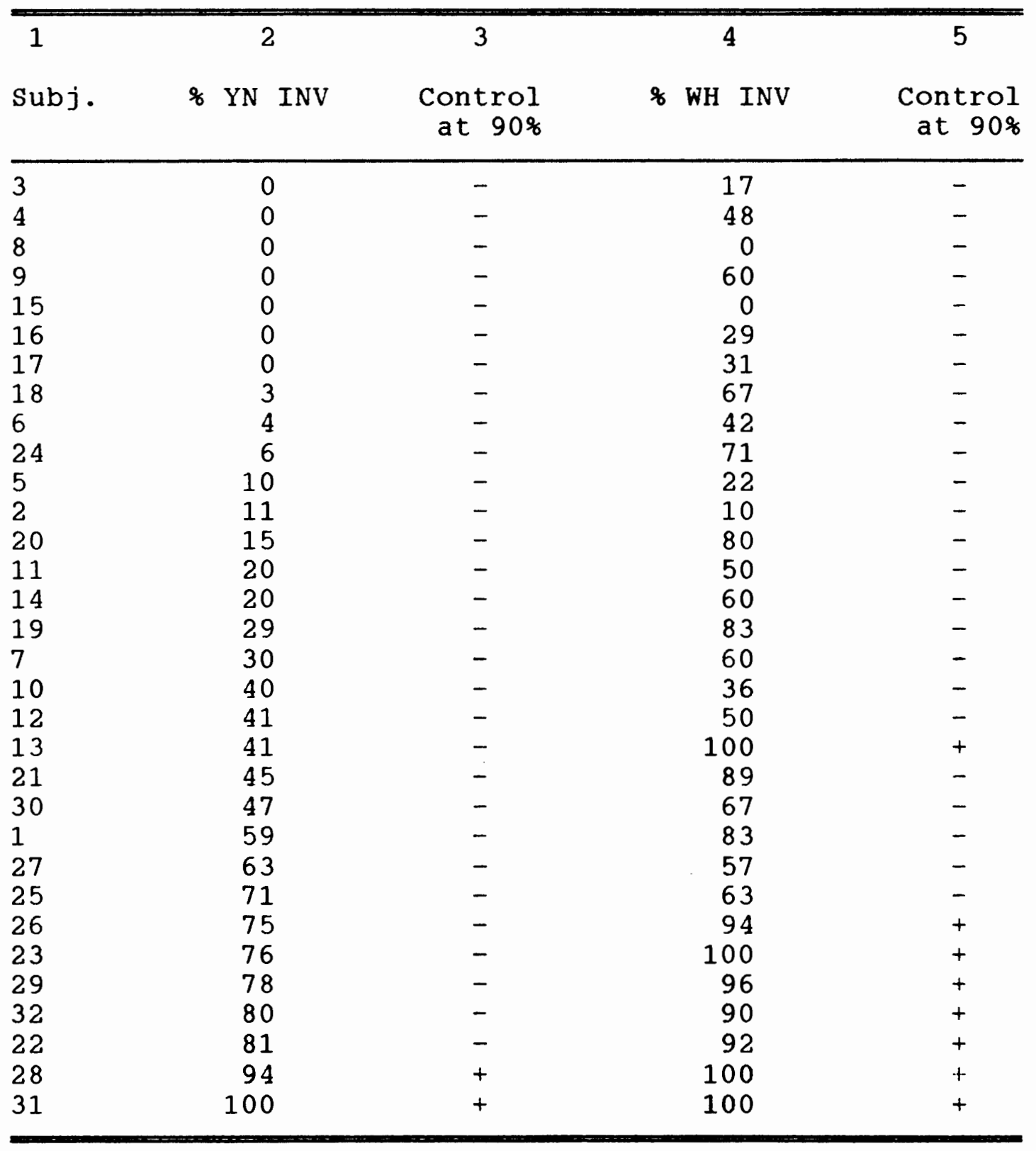

structures under consideration, arranged in the order of frequency of occurrence in the data. subjects are 
arranged vertically according to the number of structures that they control such that subjects who control the fewest of the structures are listed first, and those who control all or most of the structures appear last. Pluses are placed in the columns of the structures each subject controls, and minuses in any column indicate a subject's lack of control for the particular structure. If there is an implicational relationship between the structures, this is reflected in the way that, in any given row, all pluses appear to the right of all minuses (Hyltenstam, 1977).

The implicational scaling below, in Table 14, is modified to also include the percentages of correct production of each structure from which the pluses or minuses were derived. Table 14 shows that the data fall into the "stair-step" pattern typical of implicational scales, signifying that, under the AEI at a 90 percent criterion, all subjects confirm the hypothesis.

\section{The Status of the Hypothesis:}

\section{Relative Existence Interpretation}

Jakobson (1968), Hawkins (1987), and Eckman et al. (1989) describe what the latter call the REI, which can be used for examining data in instances of implicational relationships such as exist in the $Q T I U$. In contrast to 
Table 14

Implicational scaling of all Three structures of the TIU, ordered by WH Fronting

\begin{tabular}{|c|c|c|c|c|c|c|}
\hline 1 & 2 & 3 & 4 & 5 & 6 & 7 \\
\hline subj. & $\begin{array}{l}\% \text { YN } \\
\text { INV }\end{array}$ & $\begin{array}{c}\text { Control } \\
\text { at } 908\end{array}$ & $\begin{array}{l}\text { \% WH } \\
\text { INV }\end{array}$ & $\begin{array}{c}\text { Control } \\
\text { at } 908\end{array}$ & of FR & $\begin{array}{c}\text { Control } \\
\text { at } 908\end{array}$ \\
\hline 18 & 3 & - & 67 & - & 40 & - \\
\hline 10 & 40 & - & 36 & - & 57 & - \\
\hline 24 & 6 & - & 71 & - & 76 & - \\
\hline 11 & 20 & - & 50 & - & 80 & - \\
\hline 21 & 45 & - & 89 & - & 83 & - \\
\hline 12 & 41 & - & 50 & - & 86 & - \\
\hline 16 & 0 & - & 29 & - & 87 & - \\
\hline 6 & 4 & - & 42 & - & 87 & - \\
\hline 3 & 0 & - & 17 & - & 92 & + \\
\hline 17 & 0 & - & 31 & - & 93 & + \\
\hline 4 & 0 & - & 48 & - & 94 & + \\
\hline ๙ & & & & & & \\
\hline 5 & 10 & - & 22 & - & 96 & + \\
\hline$\star$ & & & & & & \\
\hline 15 & 0 & - & 0 & - & 100 & + \\
\hline 8 & 0 & - & 0 & - & 100 & + \\
\hline 2 & 11 & - & 10 & - & 100 & + \\
\hline 27 & 63 & - & 57 & - & 100 & + \\
\hline 14 & 20 & - & 60 & - & 100 & + \\
\hline 7 & 30 & - & 60 & - & 100 & + \\
\hline 9 & 0 & - & 60 & - & 100 & + \\
\hline 25 & 71 & - & 63 & - & 100 & + \\
\hline 30 & 47 & - & 67 & - & 100 & + \\
\hline 20 & 15 & - & 80 & - & 100 & + \\
\hline 1 & 59 & - & 83 & - & 100 & + \\
\hline 19 & 29 & - & 83 & - & 100 & + \\
\hline $13 *$ & 41 & - & 100 & + & 95 & + \\
\hline $22 \star$ & 81 & - & 92 & + & 98 & + \\
\hline 32 & 80 & - & 90 & + & 100 & + \\
\hline 26 & 75 & - & 94 & + & 100 & + \\
\hline 29 & 78 & - & 96 & + & 100 & + \\
\hline 23 & 76 & - & 100 & + & 100 & + \\
\hline 28 & 94 & + & 100 & + & 100 & + \\
\hline 31 & 100 & + & 100 & + & 100 & + \\
\hline
\end{tabular}


the AEI, which uses a criterion of a certain absolute percentage of occurrence to signify a subject's control of a construction, the REI examines the frequency of the implied structure of a TIU relative to the frequency of the implying structure of the TIU in order to determine whether a subject's IL is constrained by the implicational universal. If the relationship is such that the rate of correct production of an implierl structure (such as WH fronting) is equal to or greater than the rate of correct production of an implying structure (such as wH inversion), the IL rules are considered to exhibit the constraints of the TIU. With a TIU, such as the $Q$ TIU, that involves more than two structures, the REI would demand that each succeeding lower (more difficult) structure of the TIU should occur with less frequency than the previous higher (less difficult) structure just above.

Under an REI approach to the data in this study, parts $1 \mathrm{a}$. and $1 \mathrm{~b}$. of the hypothesis would be reworded to more specifically reflect the assumptions of the REI, as follows :

REI 1a. Subjects' frequency rate of WH inversion will not be greater than their frequency rate of WH fronting.

REI 1b. Subjects' frequency rate of YN inversion will not be greater than their frequency rate of $\mathrm{WH}$ inversion. 
Eckman et al. (1989) state that the REI has two advantages over the AEI. First, the REI, because it deals with relative frequency, eliminates the arbitrary choice of percentage criterion associated with the AEI. Secondly, the claims made by the REI are stronger than those made by the AEI; that is, some data that are deemed to conform to a TIU under the AEI will be evaluated as nonconforming under the REI. For example, subject 25 , in Table 13, above, had rates of 71 percent for $Y N$ inversion and 63 percent for WH inversion. Under the AEI, subject 25 was considered to lack control of either construction at a 90 percent accuracy criterion and was given a value of "-" for each of them. This pattern where neither structure was controlled by the subject was concluded to be in conformity with the TIU under the AEI. However, subject 25 had a higher frequency of $\mathrm{YN}$ inversion than of WH inversion, which would be interpreted to be inconsistent with the TIU under the REI.

In Tables 15 and 16, following, the data are reexamined from the point of view of the REI.

\section{Does WH Inversion Imply WH Fronting?}

Under the REI method of evaluating the data, the frequency rate of $\mathrm{WH}$ fronting must always be equal to or greater than the rate of WH inversion. Table 15, below, is similar to Table 7 in Eckman et al. (1989) and 
examines the percentages of $\mathrm{WH}$ fronting and wH inversion for each subject. Column 4 of Table 15 presents a summary of the AEI information from Tables 12 and 13 , above while column 5 specifies conformity or nonconformity to the portion of the TIU under consideration, according to the REI method. In both columns 4 and 5, a $Y$ signifies that the implicational relationship, "WH inversion implies wH fronting," is upheld by the relevant interpretation, while an $N$ indicates that that portion of the TIU is not upheld. In addition, subjects that do not uphold this portion of the TIU under the REI are marked with an asterisk. As in Eckman et al. (1989), subjects are arranged on the table according to their percentages of $\mathrm{WH}$ inversion.

Table 15 shows that although the claim of the TIU that "WH inversion implies WH fronting" holds without exception under the AEI approach, there are three exceptions under the REI method, namely, subjects 13, 18, and 21. They are judged to be exceptions because their rates of $\mathrm{WH}$ inversion are higher than their rates of $\mathrm{WH}$ fronting, which, in the REI perspective, signifies a contradiction of the TIU. These three exceptions are discussed in a later section. 
Table 15

Relative Existence Interpretation status of Hypothesis 1a: WH Inversion Implies

WH Fronting

\begin{tabular}{|c|c|c|c|c|}
\hline 1 & 2 & 3 & 4 & 5 \\
\hline Subj. & $\begin{array}{l}\text { * WHQ } \\
\text { INV }\end{array}$ & $\&$ FR & $\begin{array}{c}\text { AEI } \\
(90 \%)\end{array}$ & REI \\
\hline 8 & 0 & 100 & $+1 Y$ & $\mathrm{Y}$ \\
\hline 15 & 0 & 100 & $(-\quad+) Y$ & $\mathrm{Y}$ \\
\hline 2 & 10 & 100 & $(-\quad+) Y$ & $\mathrm{Y}$ \\
\hline 3 & 17 & 92 & $+) Y$ & $Y$ \\
\hline 5 & 22 & 96 & $(-\quad+) Y$ & $Y$ \\
\hline 16 & 29 & 87 & $(-\quad-) Y$ & $\mathrm{Y}$ \\
\hline 17 & 31 & 93 & $+1 Y$ & $\mathrm{Y}$ \\
\hline 10 & 36 & 57 & $-) Y$ & $\mathrm{Y}$ \\
\hline 6 & 42 & 87 & $-1 Y$ & $\mathrm{Y}$ \\
\hline 4 & 48 & 94 & $+1 Y$ & $Y$ \\
\hline 11 & 50 & 80 & $-1 Y$ & $Y$ \\
\hline 12 & 50 & 86 & $-1 Y$ & $Y$ \\
\hline 27 & 57 & 100 & $+Y Y$ & $\mathrm{Y}$ \\
\hline 7 & 60 & 100 & $+1 Y$ & $Y$ \\
\hline 9 & 60 & 100 & $+I Y$ & $\mathrm{Y}$ \\
\hline 14 & 60 & 100 & $+1 Y$ & $\mathrm{Y}$ \\
\hline 25 & 63 & 100 & $+1 Y$ & $Y$ \\
\hline$\star 18$ & 67 & 40 & $-I Y$ & $\mathrm{~N}$ \\
\hline 30 & 67 & 100 & $+1 Y$ & $Y$ \\
\hline 24 & 71 & 76 & $-j Y$ & $\mathrm{Y}$ \\
\hline 20 & 80 & 100 & $+1 Y$ & $\mathrm{Y}$ \\
\hline 1 & 83 & 100 & $+1 Y$ & $Y$ \\
\hline 19 & 83 & 100 & $+1 Y$ & $\mathrm{Y}$ \\
\hline$\star 21$ & 89 & 83 & $-1 Y$ & $N$ \\
\hline 32 & 90 & 100 & $+1 Y$ & $Y$ \\
\hline 22 & 92 & 98 & $+1 Y$ & $\mathrm{Y}$ \\
\hline 26 & 94 & 100 & $+1 Y$ & $\mathrm{Y}$ \\
\hline 29 & 96 & 100 & $+1 Y$ & $\mathrm{Y}$ \\
\hline$\star 13$ & 100 & 95 & +) $Y$ & $\mathrm{~N}$ \\
\hline 23 & 100 & 100 & $+1 Y$ & $\mathrm{Y}$ \\
\hline 28 & 100 & 100 & $+1 Y$ & $\mathrm{Y}$ \\
\hline 31 & 100 & 100 & $+1 Y$ & $\mathrm{Y}$ \\
\hline
\end{tabular}




\section{Does YN Inversion Imply WH Inversion?}

The second part of the hypothesis is examined in light of the REI, below, in Table 16, which is similar to Table 8 in Eckman et al. (1989). Again, a $Y$ in columns 4 and 5 indicates conformity to part $1 \mathrm{~b}$. of the hypothesis while a $N$ denotes inconsistency, and exceptions under the REI are marked with an asterisk.

Inspecting Table 16 reveals that while all subjects are considered to conform to the second claim of the TIU, "YN inversion implies $\mathrm{WH}$ inversion," under the AEI, subjects $2,10,25$, and 27 constitute exceptions to the TIU according to the REI. They are considered exceptions because their rates of YN inversion are higher than their rates of wH inversion. These exceptions are discussed below.

The Status of the Hypothesis: The Seven Exceptions Under the REI

While there are no exceptions to the TIU under the AEI approach, seven exceptions emerge under the REI approach. Three of these are exceptions to the first claim of the TIU, "WH inversion implies WH fronting," and four are exceptions to the second claim, "YN inversion implies WH inversion."

In their study, Eckman et al. (1989) find exceptions

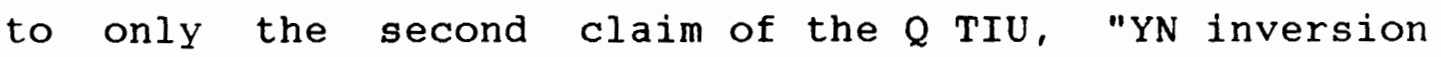


Table 16

\section{Relative Existence Interpretation status of Hypothesis 1b: YN Inversion Implies \\ WH Inversion}

\begin{tabular}{|c|c|c|c|c|}
\hline 1 & 2 & 3 & 4 & 5 \\
\hline subj. & $\begin{array}{l}\% \text { YN } \\
\text { INV }\end{array}$ & $\begin{array}{l}\text { \& WH } \\
\text { INV }\end{array}$ & $\begin{array}{c}\text { AEI } \\
(90 \%)\end{array}$ & REI \\
\hline 3 & 0 & 17 & $-1 Y$ & Y \\
\hline 4 & 0 & 48 & $-) Y$ & $Y$ \\
\hline 8 & 0 & 0 & $-\mid Y$ & $Y$ \\
\hline 9 & 0 & 60 & $-) Y$ & $Y$ \\
\hline 15 & 0 & 0 & $-1 Y$ & $Y$ \\
\hline 16 & 0 & 29 & $-1 Y$ & $Y$ \\
\hline 17 & 0 & 31 & $-1 Y$ & $\mathrm{Y}$ \\
\hline 18 & 3 & 67 & $-) Y$ & $Y$ \\
\hline 6 & 4 & 42 & $-) Y$ & $Y$ \\
\hline 24 & 6 & 71 & $-j Y$ & $Y$ \\
\hline 5 & 10 & 22 & $-1 Y$ & $\mathrm{Y}$ \\
\hline$\star 2$ & 11 & 10 & $-I Y$ & $N$ \\
\hline 20 & 15 & 80 & $-\mid Y$ & $Y$ \\
\hline 11 & 20 & 50 & $-\mid Y$ & $Y$ \\
\hline 14 & 20 & 60 & $-) Y$ & $\mathrm{Y}$ \\
\hline 19 & 29 & 83 & $-1 Y$ & $\mathrm{Y}$ \\
\hline 7 & 30 & 60 & $-) Y$ & $\mathrm{Y}$ \\
\hline$\star 10$ & 40 & 36 & $-) Y$ & $\mathrm{~N}$ \\
\hline 12 & 41 & 50 & $-J Y$ & $Y$ \\
\hline 13 & 41 & 100 & $+I Y$ & $\mathrm{Y}$ \\
\hline 21 & 45 & 89 & $-) Y$ & $Y$ \\
\hline 30 & 47 & 67 & $-1 Y$ & $Y$ \\
\hline 1 & 59 & 83 & $-I Y$ & $Y$ \\
\hline$\star 27$ & 63 & 57 & $-I Y$ & $\mathrm{~N}$ \\
\hline$\star 25$ & 71 & 63 & $-\mid Y$ & $\mathrm{~N}$ \\
\hline 26 & 75 & 94 & $+Y$ & $Y$ \\
\hline 23 & 76 & 100 & $+1 Y$ & $Y$ \\
\hline 29 & 78 & 96 & $+1 \mathrm{Y}$ & $\mathrm{Y}$ \\
\hline 32 & 80 & 90 & t) $Y$ & $\mathrm{Y}$ \\
\hline 22 & 81 & 92 & $+) Y$ & $\mathrm{Y}$ \\
\hline 28 & 94 & 100 & $(+\quad+) Y$ & $Y$ \\
\hline 31 & 100 & 100 & $(+\quad+) Y$ & $Y$ \\
\hline
\end{tabular}

implies WH inversion." Under the AEI, they find only one exception to this claim; under the REI, they find two 
additional exceptions. Of the three, Eckman et al. contend that only one is significant. They base this contention on the fact that for two of the exceptions, while the rate of YN inversion does exceed the rate of $\mathrm{WH}$ inversion, the differences in the percentage rates are attributable to a difference of only one utterance. They then conclude that a difference of one utterance is not, in their view, significant. For example, their subject, "SI," had a YN inversion rate of 100 percent, while that subject's wH inversion rate was only 95 percent, constituting a violation of the REI view of the TIU. However, the 95 percent wH inversion rate represented 18 inversions out of a possible 19 inversions. In other words, had subject SI inverted just one more time, both rates would have been 100 percent and the second part of the TIU would have been upheld.

Six Exceptions Resolved. The same argument can be used to absolve six of the seven exceptions in this study of their violation of the TIU. The argument for each subject is presented in Table 17, below. The first subject in the table, SI, the exception in Eckman et al. (1989) whose case is explained in the previous paragraph, is presented as an example. The next group of subjects, separated between dotted lines, are subjects 13, 18, and 21, who are exceptions to the first claim of the TIU, "WH 
inversion implies WH fronting." The last group, subjects 2, 10, and 27, are exceptions to the TIU's second claim, "YN inversion implies WH inversion."

\section{Table 17}

Resolution of the Exceptions to the Relative Existence Interpretation of the TIU by the Addition or subtraction of One "Insignificant," Hypothetical Data Item

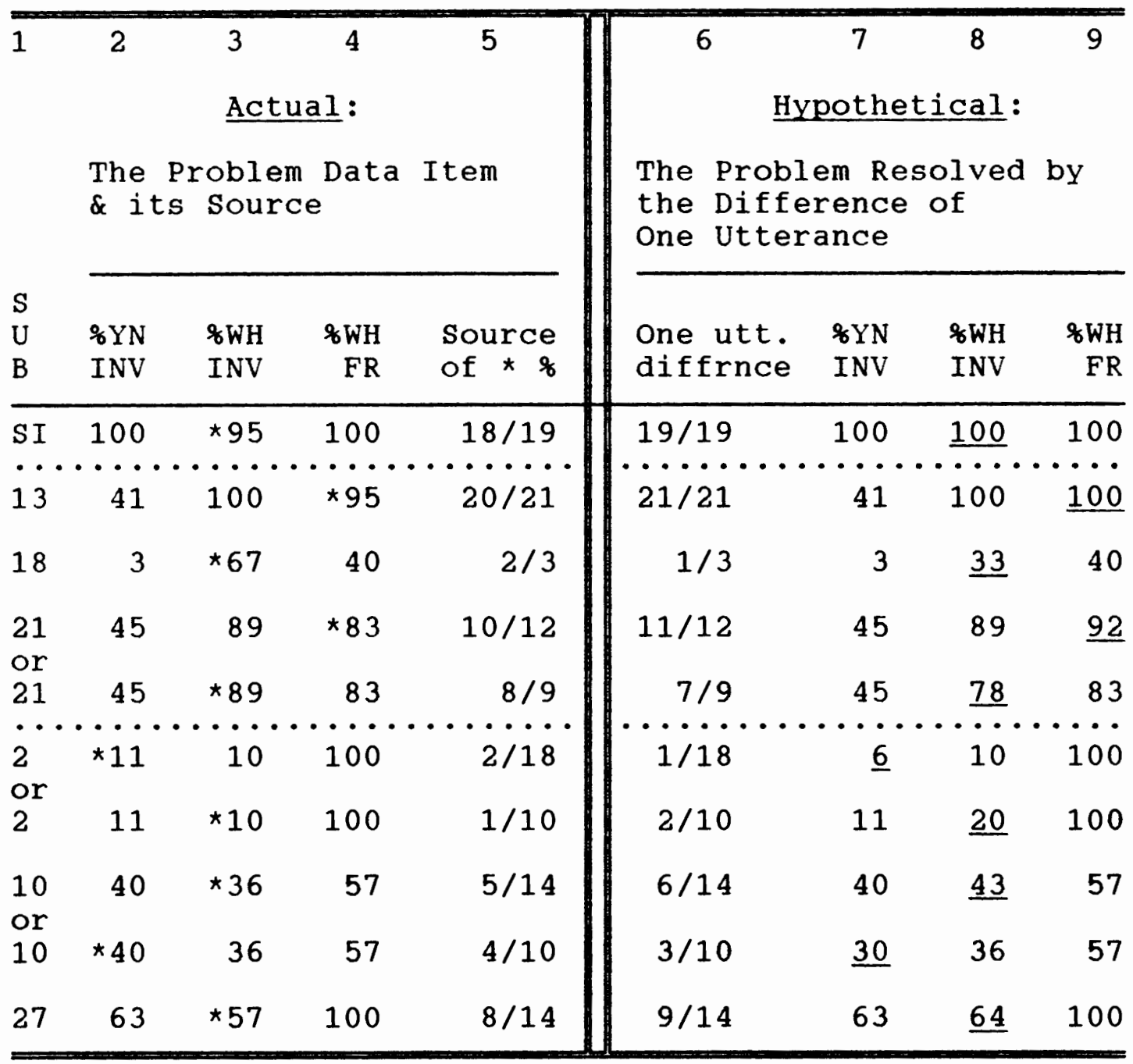


These subjects and their real data that violate the TIU under the REI are presented in the left half of Table 17. For each subject, the anomalous percentage which violates the TIU pattern of relative frequency is marked with an asterisk in any of columns 2 through 4 . Column 5 gives the ratio of correctly produced utterances out of total number of relevant utterances which produced the percentage in the category that was marked with the asterisk.

The right side of Table 17 presents a hypothetical situation in which the violation of the TIU is shown to be resolved according to the method used by Eckman et al. (1989), by the difference of only one utterance. Column 6 presents the ratio from column 5, with the addition or subtraction of a single, hypothetical, correctly produced utterance. This represents the "difference of one data item" that Eckman et al. consider to be insignificant (1989, p. 191). Columns 7 through 9 repeat the rates of YN inversion, WH inversion, and WH fronting from columns 2 through 4 except that the aberrant percentage that was marked with an asterisk in columns 2 through 4 has been changed to reflect the difference of the single, hypothetical data item added or subtracted. The resulting patterns of percentages in columns 7 through 9 are all consistent with the TIU, demonstrating that the 
difference of only one "insignificant" item of data would correct the violations of the TIU under the REI.

Subject 13 serves as an example to illustrate Table 17. Subject 13 has a YN inversion rate of 41 percent (column 2), a WH inversion rate of 100 percent (column 3), and a wH fronting rate of 95 percent (column 4). This constitutes a violation of the TIU under the REI because the $\mathrm{WH}$ inversion rate exceeds the $\mathrm{WH}$ fronting rate. Therefore, the 95 percent wH fronting rate is marked with an asterisk in column 4 to indicate its deviancy from the TIU under the REI. The number of utterances that are the source of the deviant percentage are given in column 5. Column 5 indicates that subject 13 produced 21 wHQs, 20 of which were fronted. Column 6 shows that if subject 13 had fronted just one more of her utterances--21 fronted out of 21 wHQs--the percentage of fronting would have been 100 percent as shown in column 9. In that case, subject 13 would have had a YN inversion rate of 41 percent (column 7 ), a wH inversion rate of 100 percent (column 8), and a wH fronting rate of 100 percent (column 9), and the TIU would have been confirmed. The percentage shown for subject 13 in column 9 is underlined to indicate that that was the value that originally deviated from the TIU and that is 
hypothetically resolved by a difference of just one utterance.

It should be pointed out that subjects 21,2 , and 10 deviate from the predicted REI pattern in such a way that adding or subtracting only one correctly produced utterance at either of two points on the TIU results in a pattern of percentages that conforms to the TIU. For each of these subjects, both methods of resolution are presented in the table.

Table 17 shows that the exceptions to the TIU represented by subjects $2,10,13,18,21$, and 27 can be traced to the difference of just one data item. In other words, if each of the subjects in Table 17 had correctly formed just one more of their incorrectly formed tokens of the relevant construction, or had incorrectly formed just one more of their correctly formed tokens of the relevant construction, all the subjects would have upheld the TIU instead of constituting exceptions to the TIU. Eckman et al. (1989) maintain that a difference of just one data item is not significant. If this is so, the conclusion of the matter is that the aforementioned six subjects may not be true disconfirming cases, and this view is further supported by the fact that none of them disconfirms the TIU under the AEI approach. 
A further argument for the unimportance of the deviation from the predicted pattern by subject 10 is the fact that three out of her four inverted YNQs may be inverted only because they include unanalyzed, memorized chunks. The three all follow the pattern, Is it NP? in which the Is it could be functioning as an unanalyzed, memorized question marker. Two instances of these utterances are underlined in the exchanges below:

EXAMPLE 1:

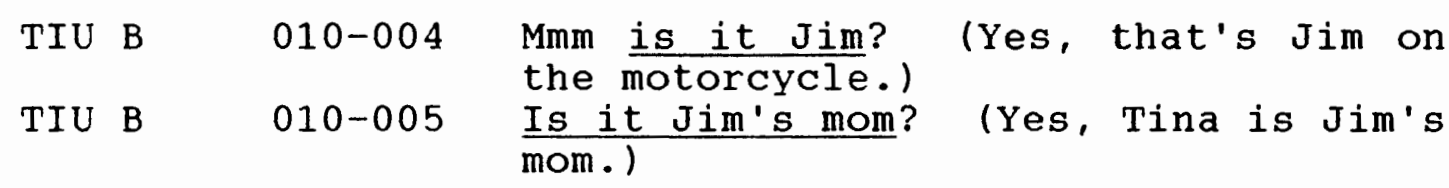
One Remaining Exception. There remains, however, one exception to the TIU, namely, subject 25. She inverted her YNQS at a rate of 71 percent (based on 17 inversions out of a possible 24), while her wH inversion rate was only 63 percent (based on 35 inversions out of a possible 56) thus violating the second claim of the TIU, "YN inversion implies WH inversion," under the REI. (Her rate of wH fronting was not a problem, at 100 percent.)

Interestingly, the two resolved exceptions and the one actual exception in the study by Eckman et al. (1989) also violate this claim of the universal. Eckman et al. endeavor to explain the unexpectedly high rate of $Y N$ inversion in their one true exception in terms of the amount of effort necessary to produce an English YNQ 
relative to the effort required to produce a WHQ. They point out that while producing a YNQ involves only the single syntactic step of inverting the subject and verb, producing a WHQ involves two steps, wH fronting and inversion. Thus, they reason, if a subject were to violate the TIU, the violation would be apt to take the form it did, that of a higher than expected rate of YN inversion (because that is relatively "easier") and of a lower than expected rate of $\mathrm{WH}$ inversion (because that is relatively "harder"). However, Eckman et al. conclude that argument by admitting that if such an explanation of: the exception were valid, it would seem that there should have been more than only one exception. In the end, they say, "we have so far no explanation for the one exception to the 'Yes/No Inversion implies Wh Inversion' universal" (Eckman et al., 1989, p. 194).

Another possible explanation for an unexpectedly high percentage of $\mathrm{YN}$ or $\mathrm{WH}$ inversion is that the high rate could be due to over-monitoring by the subject. This explanation may be related to the previous one because simpler structures are presumably easier to monitor than more complex structures. In the case of subject 25, perhaps her aberrantly high rate of YN inversion occurred because she monitored heavily, that is, because, although her YNQs may have been initially 
uttered without inversion, she may have self-corrected them before they were finished (false starts), and, in the self-corrected version, they were inverted. An example of such self-correction is

EXAMPLE 2:

TIU B 019-031 She had, she had, did $h$ - she have a lot of money?

Such a question, under the system of coding employed in this study and described in Chapter III, would have been counted as one inverted $Y N Q$ in spite of the fact that its initial formulation began as an uninverted question. Although such a situation would have great explanatory powers, such was not the case with subject 25 . Of her 17 inverted YNQS, only one could possibly be classified as a self-correction in this sense.

Yet another possible explanation exists for exceptions to a general pattern such as the TIU: individual variables. Gass and selinker (1994) mention the influence of such individual variables as attitude, motivation, and attentiveness in their discussion of the constraints of universals on SLA (p. 117). At greater length, Ellis (1986) discusses such individual variables as personality, motivation, and attitude. He notes that whether such factors affect only the rate of acquisition or also have the potential to affect the order of acquisition is controversial. This leaves open the 
possibility that individual variables could influence the order of acquisition and so constitute an explanation for the exceptional order exhibited by subject 25 . That individual variables may explain the data of subject 25 seems quite plausible. Subject 25 was personally known to the researcher and seemed to be an exceptional ESL student in many ways. She seemed to be a highly motivated, attentive, and adept student who put much effort into everything she did and who was very focused on communication with NSs during her one-year total stay in the United States. Evidence of these traits can be seen in these examples: She determined never to speak her $\mathrm{NL}$ in the United States until after she passed the Test Of English as a Foreign Language; she involved herself, on a long-term basis, in a local community organization providing support to grieving children; she was wellknown for her motto, "I don't like to do things the easy way." Given these personal characteristics of subject 25 and the discussion of individual variables in Ellis (1986), two possible explanations for her exceptional performance may be speculated upon.

First, perhaps the intense effort subject 25 typically applied to any challenge was more easily applied to the syntactically simpler YNQs and so effected some improvement over the rate of inversion that would 
have occurred in them had the TIU met with ordinary circumstances--a student of only average motivation. At the same time, perhaps all her effort could not surmount the more complex WHQs so that their inversion rate remained lower, at the normal, TIU-controlled level or just slightly higher, instead of equalling or exceeding the $\mathrm{YN}$ inversion rate. If this was the case, it would have been interesting to interview subject 25 at a later date to see if WH inversion had surpassed YN inversion, which could have been interpreted as the TIU reasserting its control after the subject's acquisition level had reached the place where her efforts could have also improved her wh inversion rate.

The other possible explanation that the concept of individual variation has to offer concerns discourse needs. As mentioned above, subject 25 was very focused on communication with NSs of English. Perhaps in the course of her extensive communication she had intuitively learned that while wHQs have only one function, to find further information about a presupposed proposition (Sadock \& Zwicky, 1985), YNQs have two: inverted YNQs serve the purpose of discovering the truth or falsity of what is questioned, while uninverted YNQs usually serve to confirm something already believed to be true (Vander Brook, Schlue, \& Campbell, 1977; Williams, 1989). 
Perhaps in her desire to communicate clearly with Americans, subject 25 had learned to disambiguate the two purposes of YNQs in the same way NSs do, by paying attention to the form chosen, whether inverted or uninverted. In forming WHQs, on the other hand, the subject might not have felt a communicative need to pay attention to the correct form because a wHQ, whether inverted or not, can have only one purpose.

The way that individual variables affect SLA is very difficult to define or measure even when such considerations are the sole focus of an investigation. In a study such as this, which made no formal attempt at all to correlate individual variables with the production of the grammatical constructions of interest, the effects of such variables are even less clear. However, it is quite certain that such variables do play a role in SLA and could even occasionally alter patterns constrained by forces such as the $Q$ TIU. The possible explanations offered above for the exceptional pattern produced by subject 25 could be modified or exchanged for any number of similar explanations involving individual variables, enough to account for any number of exceptions including those six that were resolved in Table 17, above. However, as of yet, none of these explanations of individual variables are definitive answers to the 
problem of exceptions to the Q TIU. Thus, in the end, it must be concluded that there is no incontrovertible explanation for the exception to the TIU represented by subject 25 .

\section{The Status of the Hypothesis:}

\section{A Whole Group Approach}

In addition to looking at each subject's data individually under the AEI or REI as did Eckman et al. (1989), there is an alternate approach that considers all the data together, as a whole group. This method is used by several researchers including Gass (1979), Gass and Ard (1984), Hansen (1986), and Rollins (1988). Although Hansen and Rollins had subject pools much larger than the present study, the use of this whole group approach is not limited to large groups because the studies reported by Gass and Gass and Ard had only 17 subjects. This approach is presented here in order to obtain an overall view of the patterns formed by the data.

To examine the data for all subjects as a whole, totals for all subjects of each type of TIU $Q$ were tallied. The total number of YNQs consisted of all questions from TIU A and TIU B. The total number of grammatically complete WHQs used for calculating WII inversion comprised all questions from TIU C, D, and E. 
To figure the total number of WHQs, both grammatically complete and incomplete, considered in determining $\mathrm{WH}$ fronting, all questions from TIU categories C, D, E, and F as well as all relevant questions from UNAQ categories $2,3,6,7$, and 8 were tallied. The total for each TIU category and the total for each structure of the TIU (WH fronting, WH inversion, and YN inversion) are presented below in Table 18. The corresponding percentages are displayed in graph form in Figure 3.

Table 18

Total TIU Analyzable Utterance Counts for all subjects $(n=32)$

\begin{tabular}{|c|c|c|c|c|c|c|c|}
\hline 1 & 2 & 3 & 4 & 5 & 6 & 7 & 8 \\
\hline $\begin{array}{l}\text { Cate- } \\
\text { gory }\end{array}$ & TIU A & TIU B & TIU C & TIU D & TIU E & TIU F & $\begin{array}{l}\text { WH } \\
\text { UNAQS }\end{array}$ \\
\hline $\begin{array}{l}\text { Sub- } \\
\text { total }\end{array}$ & 582 & 289 & 134 & 345 & 20 & 15 & 127 \\
\hline \multirow[t]{2}{*}{ Totals } & & & \multicolumn{5}{|c|}{641 all WHQs } \\
\hline & 871 & YNQS & 499 & mplete & WHQS & & \\
\hline
\end{tabular}

When considered from a criterion threshold perspective, such as the AEI at 90 percent as described above, Figure 3 shows only that subjects, overall, have acquired wH fronting and have not acquired either wH inversion or $Y N$ inversion, since neither of those have reached the 90 percent criterion. This could bo 


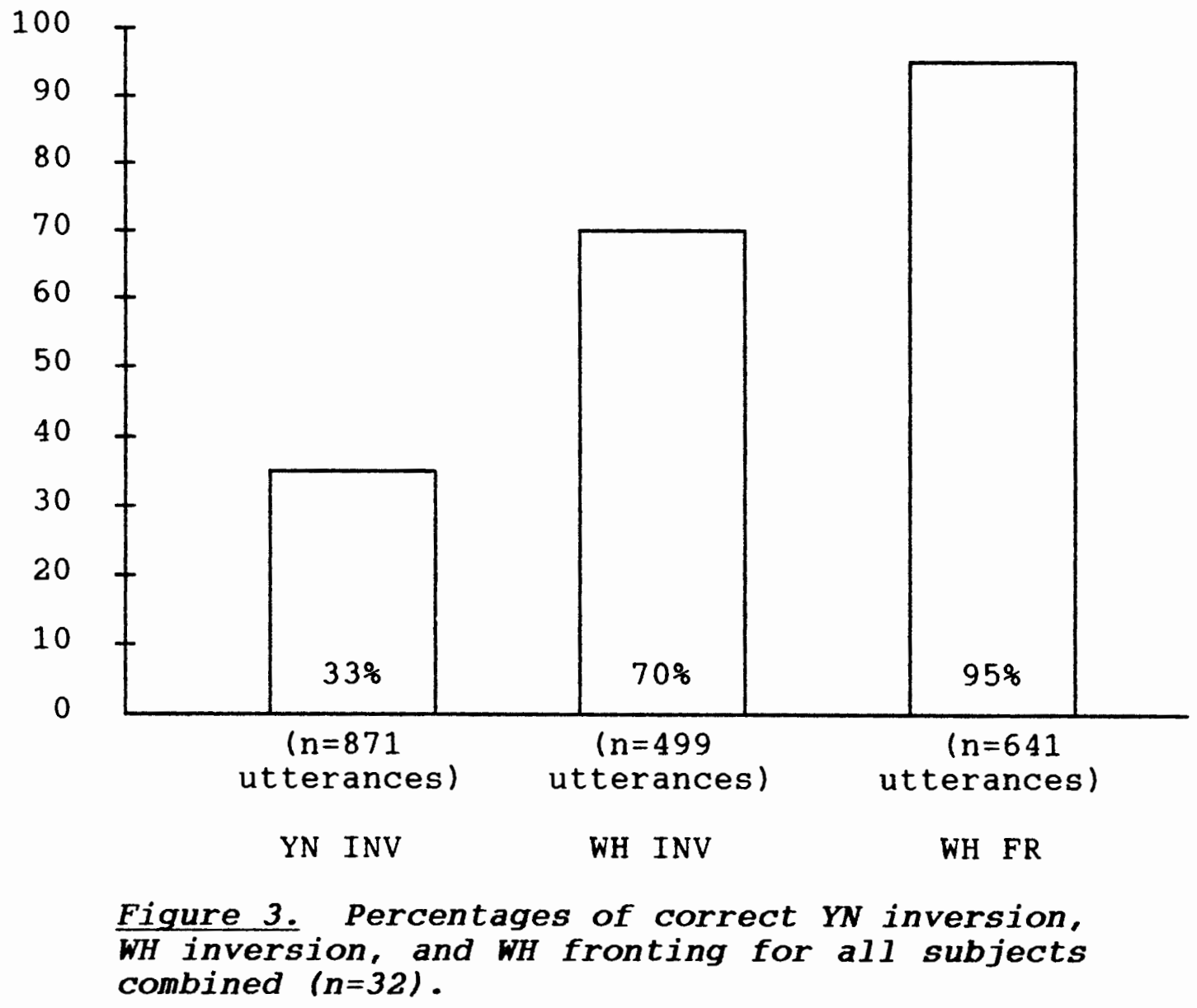

interpreted further to indicate that of the three structures, wH fronting is the structure acquired first. This is consistent with the TIU, but such a finding can neither confirm nor disconfirm the hypothesis because the hypothesis deals with the implicational relationships among the three structures, two of which, under this perspective, have not yet been acquired. However, in assessing Figure 3 in terms of the relative frequency of the structures as does the REI, above, the hypothesis is 
confirmed in that the rate of WH fronting exceeds that of WH inversion, which in turn exceeds that of YN inversion. Another issue can be addressed in light of the information in Table 18 and Figure 3. Chapter II reported that some researchers, most notably Pienemann and Johnston (1987), hold that the acquisition of $Y N$ inversion precedes the acquisition of WH inversion. However, the results of this study and the one by Eckman et al. (1989) indicate that WH inversion precedes $Y N$ inversion. Perhaps the opposing orders of acquisition could be explained if it were known that the separate groups of researchers used widely different rules for categorizing their subjects' utterances, resulting in qualitatively different outcomes. However, if such a reconciliation of the order of acquisition of $Y N$ inversion versus $\mathrm{WH}$ inversion is impossible, it remains that the conclusion reached by Pienemann and Johnston (1987) stands in opposition to the evidence in Eckman et al. and in this paper that WH inversion precedes $Y N$ inversion. Further strengthening the claim that WH inversion precedes $Y N$ inversion is an argument related to the raw numbers of utterances obtained in this study. As shown in Table 18, at 871 tokens YNQs were, by far, the most numerous in the data. With so many tokens, subjects had abundant opportunity to demonstrate whether they had 
acquired YN inversion, yet their overall YN inversion rate was very low. At the same time, all subjects produced far fewer wHQs--499--so they had relatively little chance to demonstrate whether they had acquired wil inversion. Yet, overall, as shown in Figure 3, they inverted WHQs at a rate of 70 percent, much higher than their rate of 33 percent for YN inversion. This lends credence to the conclusion that WH inversion precedes YN inversion.

\section{The Status of the Hypothesis: Another Type of Exception to the TIU}

There are, in the data, utterances that constitute another type of exception to the TIU but that did not affect any of the above analyses because their infrequent occurrences were not sufficient enough to alter the general tendencies. These utterances are unfronted, inverted WHQs, classified as TIU Eb utterances. Eckman (1984) makes reference to these types of questions as "hypothetical" (p. 101) and presumes that Ils containing such questions "do not exist, since no data have ever been presented in support of such an IL" (p. 99). According to Eckman (1984), the existence of such questions would seem to bode poorly for the claim that TIUs constrain ILs as well as primary languages. Yet, 
though the present data strongly support the $Q$ TIU, it cannot be denied that unfronted, inverted wHQs were produced. Granted their number was very small; there were only three such utterances, produced by only two subjects, out of the 499 grammatically complete wHQs that could be analyzed for $+/$ - inversion. Nevertheless, the TIU would specifically claim that such questions could not exist, and their existence constitutes counterevidence to the TIU's influence on ILs. The three utterances, produced by subjects 22 and 24 , are cited in Examples 3 to 5 .

EXAMPLE 3:

TIU Eb 022-039 Who- this, this, Is this important information from who, who?

EXAMPLE 4:

TIU Eb 024-033 So last month Tony, ah, what about, ummm . . what about ah . mmm, mmmm . Did he spoke, speak what about?

EXAMPLE 5:

TIU Eb 024-039 Mmmm, what ah . Did Sam tell to John, what about thing?

In spite of the problem that these three utterances pose for the TIU, it is possible to neutralize their counter-evidence in several ways. First of all, it may be explained in terms of the rules of classification. Under the rules employed in this study, listed in Chapter III, these three utterances were determined to be 
unfronted and inverted. However, perhaps under different rules these utterances may have classified differently. In each occurrence, a WH word does appear near the beginning of the utterance but, under the rules of this study, was considered a false start and so did not constitute a case of WH fronting (see Rules 2 and 3 , Chapter III). The rules specified that only a finished, settled-upon question could be counted as fronted or unfronted. Different rules, however, might dictate that the elements termed "false starts" here be given more significance.

Assuming, though, that their present classification is correct, other explanations for the counter-evidence exist. Introduction of the concept of individual variables may help explain the anomalies, just as it shed light on the exception of subject 25 , above. Subject 24 was personally known by the researcher. She was struggling in her acquisition of English, and this struggle was made worse by the fact that she was misplaced into several classes too difficult for her true level of proficiency. In these classes she was undoubtedly exposed to teaching concerning correct interrogative forms, but that teaching could conceivably have been beyond her true level of ability in terms of the TIU (at the 90 percent criterion, she had mastered 
none of the TIU constructions), resulting in some confusion and, finally, in the two aberrant utterances obtained.

Subject 22 was also personally known to the researcher, but no unusual circumstances were involved in her case. However, perhaps some explanation can be sought in the form of her particular question. Under the AEI, subject 22 controls WH fronting at 98 percent and $W H$ inversion at 92 percent. Her aberrant utterance, cited above, is her only unfronted utterance and also her only WHQ that involves an object of the preposition. It seems, intuitively, that there is something more difficult about questions involving an object of the preposition because they have two possible forms (who is this important information from? and From whom is this important information?), and perhaps this difficulty caused subject 22 enough confusion that she backslid to an unfronted position for the wH word (which is characteristic of her NL) but still managed to maintain her customary inversion. The result was her nonconforming question.

Another way of reconciling these three nonconforming utterances to the claims of the TIU may simply be to recognize the fact that these three utterances do not represent major patterns in the ILs of the subjects who 
produced them nor in the ILs of the group as a whole. Even Eckman (1984), in the above mentioned article where he calls such deviant utterances a "serious threat", implies that it would be necessary for such questions to typify the IL before they could be considered an actual problem. Subject 24 produced only two unfronted, inverted WHQS out of a total of ten grammatically complete WHQs evaluated in terms of inversion, a rate of only 20 percent. The deviant utterance by subject 22 was one out of a total of 36 , a rate of just 2.7 percent. Considered in the context of all subjects, the three aberrant utterances represent only 0.6 percent of the total 499 complete WHQs. Clearly such a small number does not reflect a typicality or major pattern in any of the subject's ILs but seems more likely to be just a chance, haphazard anomaly.

If even such a small percentage of aberrant utterances are perceived as a problem for the SLA claims of the TIU, then an argument proposed by Gass and Selinker (1994) may resolve the difficulty. Referring specifically to the exception to the $Q$ TIU pattern in the study by Eckman et al. (1989), Gass and Selinker (p. 117) ask, "How is this to be interpreted? Does it suggest that the universal is not valid for second language 
data?" They object to this rigid interpretation and propose, instead, another:

Are there extenuating circumstances that might mitigate against the strength of this universal? Because there are so many competing factors in second language acquisition (including NL, TL, pragmatics, processing limitations, attitudes, motivations, attentiveness), it is unlikely that predictions can be made in an absolute fashion. It is only when the exceptions seem to outweigh the predictions of universals that we can begin to invalidate the claims. In other words, the most we can hope for with second language predictions are tendencies or probabilistic predictions. (Gass \& Selinker, p. 117, 1994)

In this view, then, it seems that the fact that three utterances directly contradict a claim of the $Q$ TIU does not nullify the explanatory or predicting force of the TIU for SLA subjects in general. That these three exceptional utterances exist is noteworthy but does not force rejection of the hypothesis.

\section{The Status of the Hypothesis: A Summary}

The status of the hypothesis has been examined under two interpretations of the data that deal with each subject individually, an Absolute Existence Interpretation and a Relative Existence Interpretation. A whole group approach to the data was also considered.

Under the AEI at the level of individual subjects, there were no exceptions to either part of the $Q$ TIU. 
Thus, the hypothesis was upheld under this interpretation of the data.

Under the stricter REI there were three exceptions to the claim that "WH inversion implies WH fronting" and four exceptions to the claim that "YN inversion implies WH inversion." However, all but one of these exceptions could arguably be considered only marginally exceptional. The remaining exception could possibly, but not irrefutably, be explained as a manifestation of certain individual variables. With 25 of 32 subjects exhibiting the constraints of the TIU, six additional subjects considered to vary from the TIU only unimportantly, and only one true exception, it was concluded that, under the REI approach to the data, also, the results of this study upheld the TIU.

The whole group evaluation of the data further supports this conclusion by showing that, with all subjects' data combined, the overall percentage of $Y N$ inversion was less than the percentage of WH inversion, which, in turn, was less than that of wH fronting, findings confirming of the $Q$ TIU.

Three utterances that were unfronted, inverted WHQs constituted an additional exception to the TIU. However, in the end, they were concluded to be too few in number to be considered very important. 
The various exceptions, though noteworthy, do not seem to be enough to induce abandonment of the hypothesis. Sufficient positive results were obtained to conclude that, overall, the hypothesis was upheld.

\section{Incidental Findings: Introduction}

The results of the analysis of the data suggested several incidental findings stemming from utterances in the TIU categories, utterances in the UNAQ categories, and interactions between the two groups of questions. Some of the findings have a direct bearing on the claims of the TIU; others have to do with the acquisition of questions in general. These findings are discussed below.

\section{Incidental Findings: Unfronted WHQs}

One of the findings that had to do with the TIU involved the unfronted wHQs in the data. In order for the constraints of the TIU to be exhibited in SLA data, it is not necessary that second language learners ever produce unfronted WHQs. The TIU does not claim that there is a stage that includes unfronted wHQs through which learners must pass. The universal specifies only that WH fronting is implied by WH inversion. When the structures of the TIU are interpreted as also representing acquisition order, it may be natural to 
suppose that subjects will first learn wH fronting, which concept presupposes that there may have been a time prior to learning $W H$ fronting when subjects did not know fronting, that is, a time when they produced unfronted wHQs. Although this situation would be consistent with the TIU, it is not demanded by the TIU. Theoretically, WHQs could be learned with fronting intact at the outset. Whether this is the case or not is a matter that can be established by empirical evidence.

In the literature, there is no consensus. The TIU implies that unfronted WHQs are a possibility, and Eckman et al. (1989) assume that they are possible because they attribute the lack of unfronted WHQs in their data to the fact that their subjects were at too high a level to produce unfronted questions. R. Brown (1968) and Ravem (1974a) propose that unfronted wHQs are possible, and even probable, because of assumed fronting transformations involved in forming a wHQ from deep structure. However, they find no instances of such questions in their data. Several scholars (Hatch, 1974; Wagner-Gough, 1978; and Wode, 1978, for example) assert that WHQs are learned with fronting in place, which signifies that there is no stage where WHQs are unfronted. Most seem to assume that this is so (Dulay et al., 1982; Ellis, 1986, 1988; Hatch, 1974; Larsen-Freeman 
\& Long, 1991, are examples). Only a few studies report the presence of unfronted wHQs, and only sobin (1977) and Kwan-Terry (1986) offer more than a passing mention of such utterances.

The results of this study shed some light on this disagreement. All together, there were 641 WHQs that could be evaluated as to $+/-$ frontedness, and analysis verified that there were, indeed, some unfronted WHQs spontaneously produced. Although there were only 35 instances of unfrontedness out of 641 WHQs, a very low 5.46 percent, nevertheless, 14 of the 32 subjects produced at least one unfronted wHQ.

It may be concluded, then, that unfronted WHQs do exist. The uncertainty regarding their existence, which is portrayed in the literature, may be due to two different factors. First, studies with subjects at higher levels, such as the study by Eckman et al. (1989) may never obtain unfronted WHQs in their data because the high levels of the subjects preclude the production of unfronted WHQs. In addition, even studies with low level subjects may not obtain sufficient data to detect unfronted WHQs because, like wode (1978) and Wagner-Gough (1978), they may have too few subjects. 
Incidental Findings: Non-TIU Dynamics of Question Acquisition

Findings that had to do with the interaction of UNAQ utterances and TIU utterances are discussed in this section. Although the $Q$ TIU does not necessarily demand an acquisitional stage in which wHQs are unfronted, the existence of unfronted WHQs in the data suggests that all together four stages of question acquisition may correspond to the TIU, as discussed in chapter II. (See the section entitled, "Application of the Literature to the Q TIU".) However, the TIU, even when interpreted to apply to SLA, does not claim to represent the whole picture of the acquisition of interrogatives, and the stages that are implied by the TIU are not necessarily a sufficient statement of interrogative acquisition. Other studies on the acquisition of questions tend to focus on the issue of inversion, either from the perspective of $Y N$ inversion versus $\mathrm{WH}_{\mathrm{H}}$ inversion (such as cazden et al., 1975; and Tang, 1991) or with the purpose of determining the order in which certain auxiliaries are inverted (such as Adams, 1978, and Syamala, 1991). Few if any studies seem to consider other aspects of question acquisition, some of which may take place before the stages involving WH fronting and WH inversion are entered. Although a few researchers do refer to phenomena such as one-word 
questions (Pienemann \& Johnston, 1987; Wode, 1978), WHQs without the WH word (Wode, 1978), and questions without necessary verbs (Bailey, Eisenstein, \& Madden, 1976; Brines, 1990; Ellis, 1992a) or subjects (Adams, 1978), these types of questions are mentioned only in passing and do not constitute a major focus.

It cannot be assumed that fronting and inversion constitute the initial stages of acquisition or that fronting and inversion are the only dynamics involved in the early stages of question acquisition. In fact, utterances placed into most of the UNAQ categories in this study suggest that there may be other factors and patterns involved, especially in the early stages of question acquisition. Just the fact that there were recurring UNAQ patterns, some of them quite common, suggests that something regular was occurring even before WH fronting and WH inversion were established.

In order to examine two of these patterns more closely, Table 19, below, gives the numbers of utterances in all UNAQ categories except UNAQ 6 and 7. (UNAQ 6 and 7 utterances are not included because UNAQ 6 utterances were all grammatically complete sentences and because UNAQ 7 utterances were so classified because problems in the interviewing/taping process prevented them from being heard; thus neither of these types could be considered 
Table 19

Number, Type, and Total of UNAQs, by Subject

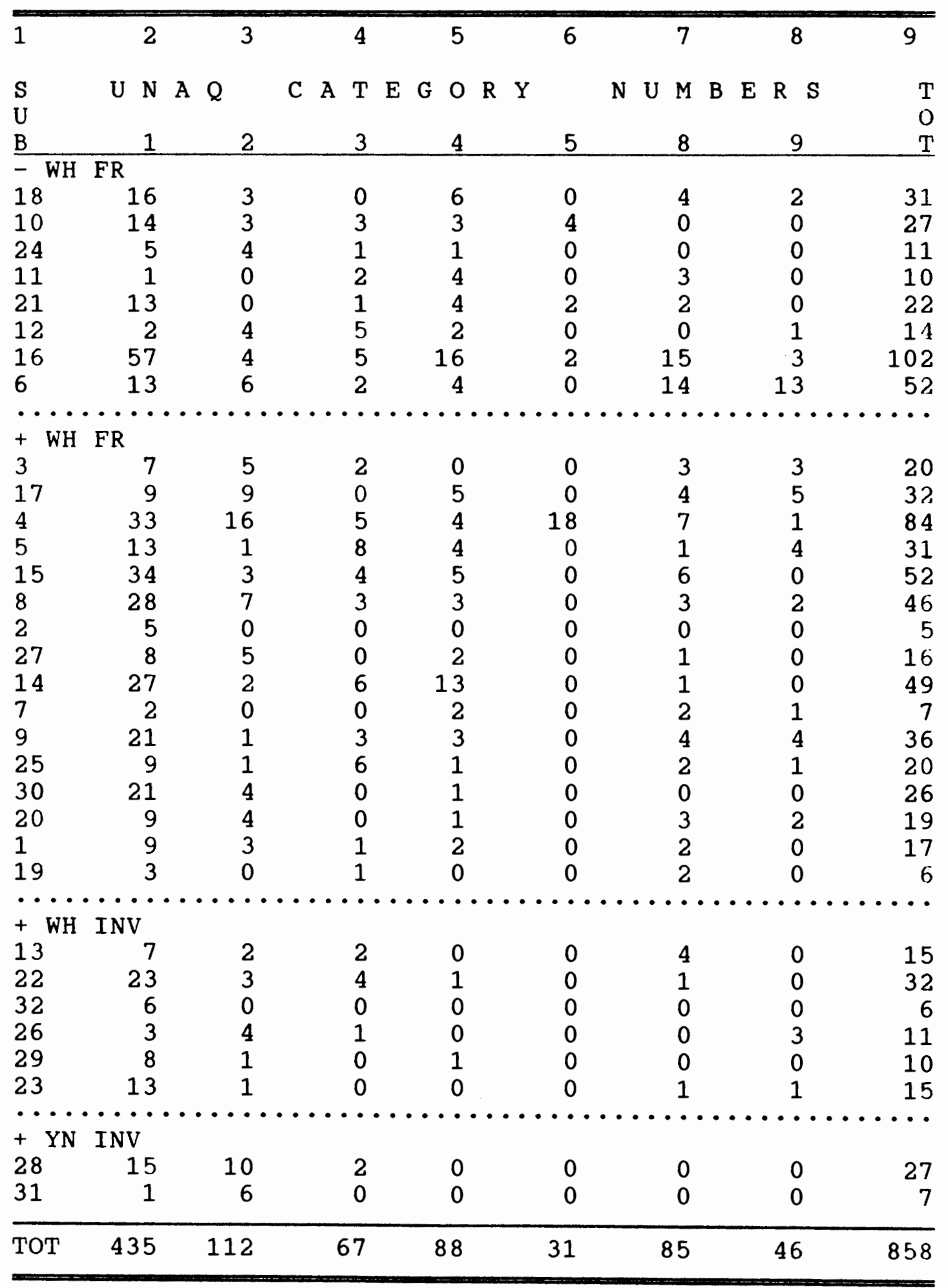


representative of an early stage or strategy of acquisition.) subjects are listed in Table 19 in the same order as in the implicational scaling in Table 14, above, and are divided into their TIU stages by dotted lines, with the lowest level subjects listed first. Thus subjects 18 through 6 are at the lowest TIU stage, - WH fronting, because, according to the 90 percent criterion, they do not yet control WH fronting; subjects 3 through 19 control WH fronting but none of the other constructions on the TIU; subjects 13 through 23 have attained the + WH inversion stage; and subjects 28 and 31 control YN inversion.

The first example of regularity can be seen in UNAQ 1. the category that contains YNQs composed of single words, isolated phrases, or two or more isolated phrases juxtaposed. At 435 total utterances, this category comprises the largest number of utterances of any UNAQ category. When the number of UNAQ 1 utterances for the subjects at each TIU stage are added together and averaged, it becomes evident that subjects at lower stages produce more of these utterances than do subjects at higher stages. These averages are displayed in Table 20, below. The TIU stages across the top of the table proceed from the highest, + YN inversion, in column 1, to the lowest, - wH fronting, in column 5. Subjects were 
assigned to each stage based on the most advanced structure that they controlled according to the 90 percent criterion as shown in the implicational scaling, above.

Table 20

Decreasing Average Number of UNAQ 1 Utterances for each More Advanced stage of the TIU

\begin{tabular}{lcccc}
\hline \multicolumn{1}{c}{ 1 } & 3 & 4 & 5 \\
$\begin{array}{l}\text { TIU } \\
\text { Stage }\end{array}$ & + YN INV & + WH INV & + WH FR & - WH FR \\
\hline $\begin{array}{l}\text { Total No. } \\
\text { of UNAQ 1 } \\
\text { Utterances }\end{array}$ & 16 & 60 & 238 & 121 \\
$\begin{array}{l}\text { No. of } \\
\text { Subjects in } \\
\text { the Stage }\end{array}$ & 2 & 6 & 16 & 8 \\
$\begin{array}{l}\text { Average } \\
\text { No. of } \\
\text { UNAQ } 1\end{array}$ & & & & \\
Utterances & 8 & 10 & 14.8 & 15.1 \\
\hline
\end{tabular}

From the figures in Table 20, it seems that, in general, subjects in lower stages rely more heavily on questioning devices not included in the $Q$ TIU than do subjects at higher stages. Of course, not all utterances from UNAQ 1 are unlike NS utterances, as can be seen in the underlined example here: 
EXAMPLE 6:

TIU D 028-097 Why, why, mmm can, couldn't couldn't 1 028-098 Ah, because of his job?

However, the overwhelming tendency was for the UNAQ 1 utterances of lower level subjects to be predominantly unlike NS utterances while those of higher level subject:3 tended to include more NS-like questions, so the pattern revealed above still seems to imply that subjects at lower stages employ more UNAQ 1 questions.

A similar pattern, but on a larger scale, emerges when all UNAQ categories (except UNAQ 6 and 7) are considered together and contrasted with figures from the TIU categories. With subjects listed in order of their TIU stage as in the implicational scaling, above, Table 21 shows the number of questions in the TIU categories and the total of all UNAQ utterances (excluding 6 and 7 ) for each subject. Column 10 shows each subject's percentage of UNAQ utterances out of all question utterances, from both the TIU and UNAQ categories.

The pattern appears when subjects are considered in groups, demarcated in Table 21 with dotted lines, according to the subjects' most difficult structure controlled on the TIU. The next table, Table 22, compares the total of all TIU utterances from categories A through $F$ with the total of all UNAQ utterances (except 
Table 21

228

Total Number of TIU and UNAQ Utterances, with Percentage of UNAQ Utterances

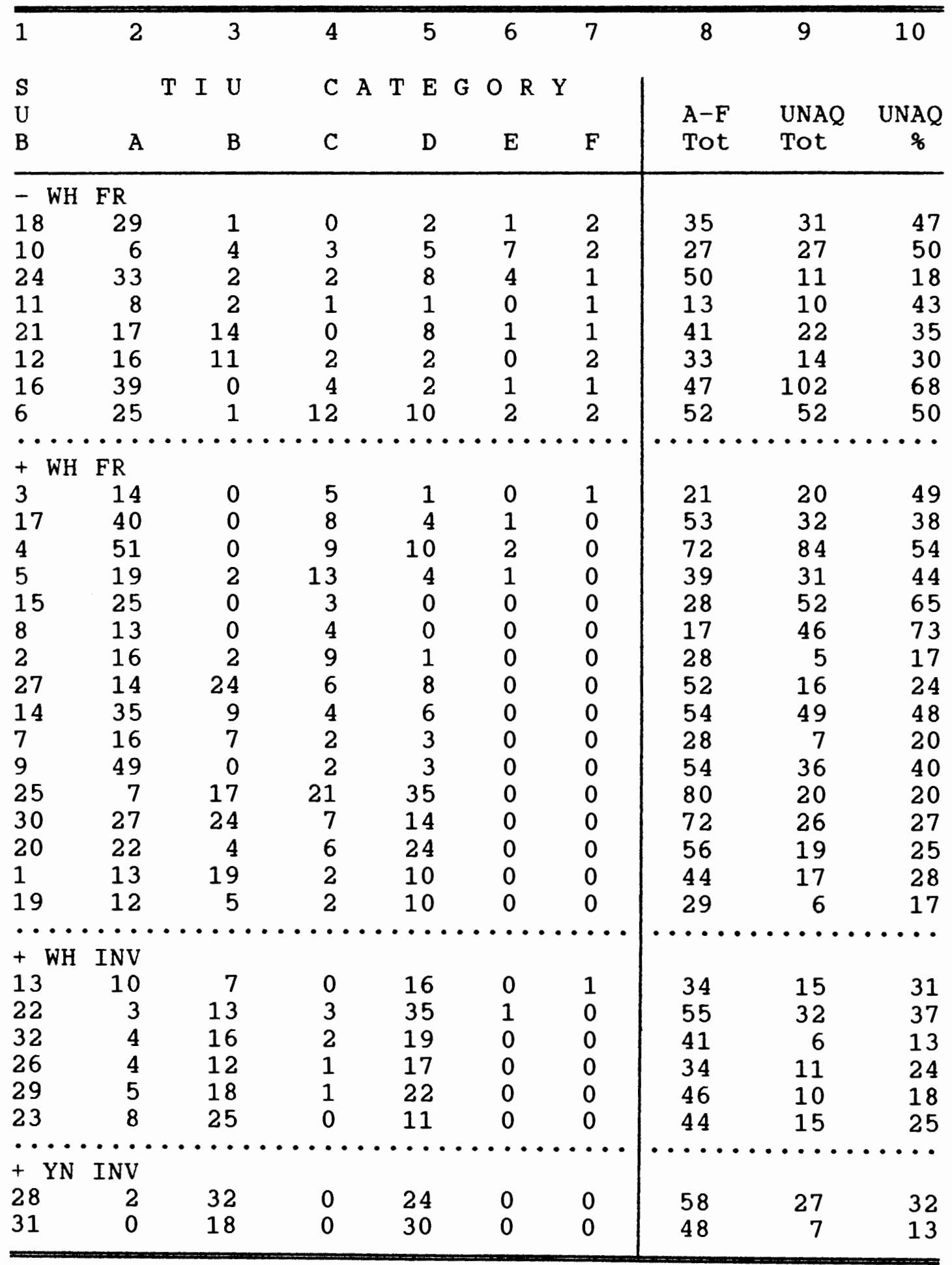


Table 22

Lower Percentage of UNAQ Utterances for each More Advanced stage of the TIU

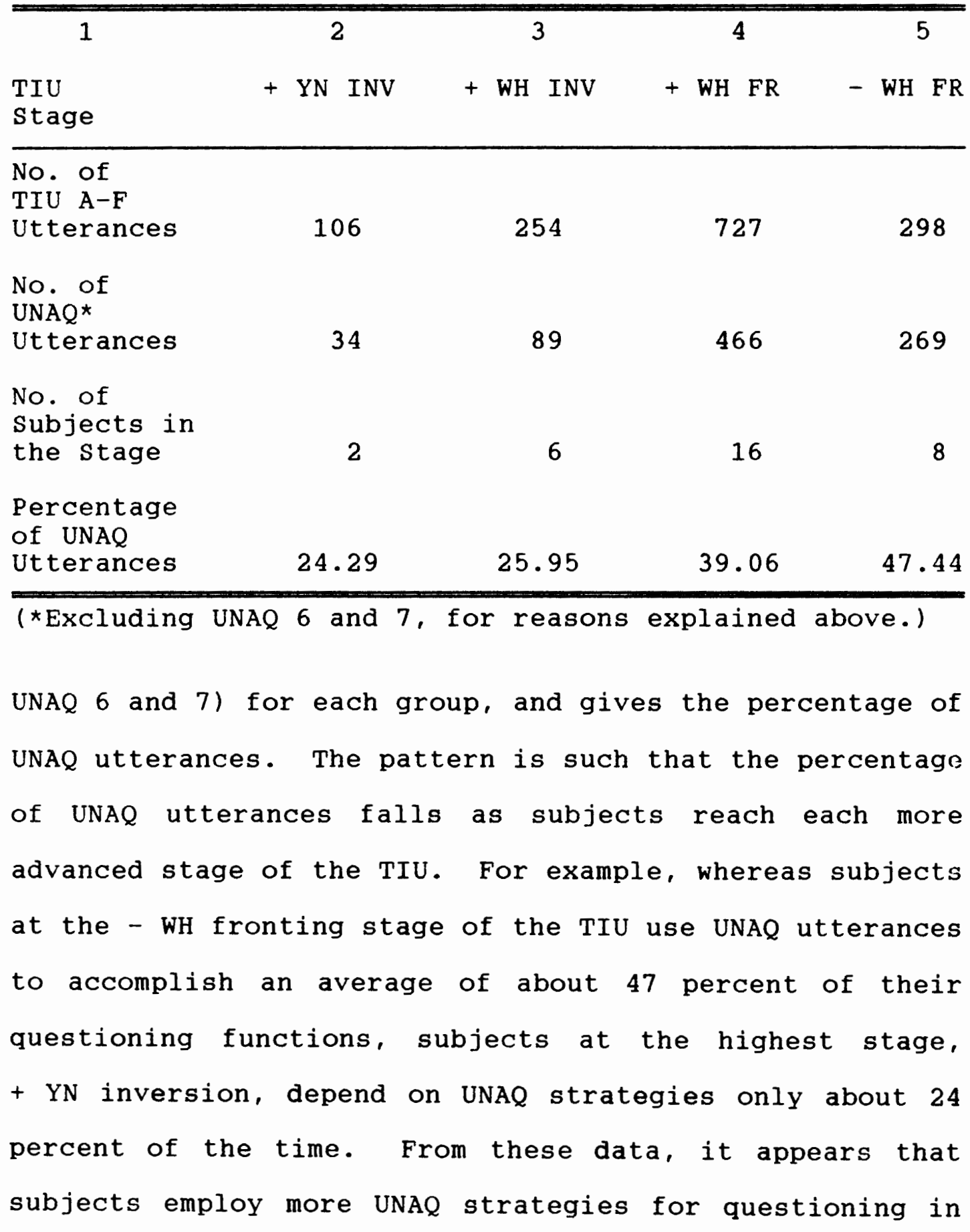


the beginning stages of acquisition, and, as they gain control of the constructions of the TIU, they rely less on the UNAQ strategies and more on the TIU constructions. This suggests that something with regard to stages of interrogative acquisition may be occurring even before the TIU begins to exert its influence, concurrently with the beginning of the TIU's force, or both and then decreasing in significance as the TIU takes control. This dynamic would also be occurring before and/or concurrently with the inversion or choice of auxiliary issues investigated by most question acquisition studies.

Specifically what is taking place as represented by the UNAQ utterances is beyond the scope of this paper to investigate. Whether these patterns will eventually be determined to represent initial stages in question acquisition, or to be questioning strategies that work in addition to the early TIU structures, or to be simply idiosyncratic strategies used by certain subjects, is not presently known.

\section{Incidental Findings: Early Inversion Strategies?}

Among some subjects who comprised the two lower acquisition stages (- WH fronting and + WH fronting) of the TIU, two patterns appeared that may represent early 
attempts at inversion. The patterns are described below, along with possible explanations and interpretations.

Appearing but Uninverted Auxiliary. Eleven subjects who had not yet reached the 90 percent control criterion for WH inversion produced utterances of the pattern, (WH word +) Subject + Aux + Verb + Rest of the Sentence, in situations where no auxiliary would normally be present in the underlying statement and would appear only in the inverted position in questions. Some examples follow, with the WHQs listed before the YNQs:

EXAMPLE 7:

TIU C 006-153 Why Patty is . stole money from bank? EXAMPLE 8:

TIU C 015-094 Why Patty was steal? [Gloss: Why did Patty steal?]

EXAMPLE 9:

TIU C 025-117 Why he did return Oakland?

EXAMPLE 10:

TIU C 025-068 Day before yesterday. mm Why they's scold, they did fight?

EXAMPLE 11:

TIU A 003-048 Tina and John . is control Jim?

EXAMPLE 12:

TIU A 004-150 He is go to Los Angeles?

There were at least 34 such utterances in the data; the uncertainty of the number is due to the fact that some of 
them, such as the underlined portion in Example 13, could alternately be interpreted as containing a progressive form of the verb but with the -ing missing, in which case, the presence of the auxiliary in the statement form would not be unusual.

EXAMPLE 13:

TIU A $\begin{array}{lll}\text { 001-041 She is keep him? } & \begin{array}{c}\text { (Mm-hmm.) } \\ \text { (They're seeing } \\ \text { girlfriend and boyfriend.) }\end{array} & \begin{array}{c}\text { Before- } \\ \text { other-- }\end{array}\end{array}$ It seems possible that such utterances that were not attempts at the progressive form could represent a subject's first attempts at inversion wherein the auxiliary has appeared, but the actual movement of inversion has not succeeded.

A Second Person Pronoun Template for Inversion. Other first attempts at inversion may have been revealed in the inappropriate use of first or second person pronouns by four subjects, none of whom had surpassed the + WH fronting stage of the TIU. The distribution of the 28 questions using first or second person for the subjects involved is shown in Table 23. Most of these questions were coded as UNAQ 5 , but subjects 10 and 21 each produced one such question that was also unfronted, so those were coded into TIU $F$ and are indicated by $a+1$ in the table. In addition, many of the utterances in which first or second person pronouns were used 
inappropriately also contrained NPs referring to third persons, the actual referents of the questions. It should also be pointed out that all utterances actually contained second person pronouns except for the two by subject 16, who used first person.

\section{Table 23}

Type and Distribution of UNAQ 5 Utterances

\begin{tabular}{lccc}
\hline 1 & 2 & 3 & 4 \\
$S$ & $\begin{array}{c}\text { No. of UNAQ } \\
\text { S Utterances }\end{array}$ & $\begin{array}{c}\text { No. with only } \\
\text { ist \& 2nd } \\
\text { Person }\end{array}$ & $\begin{array}{c}\text { No. with combo. } \\
\text { of 1st/2nd } \\
\& \text { 3rd Pers. }\end{array}$ \\
\hline 4 & 18 & 11 & 7 \\
10 & $4+1$ & 3 & $1+1$ \\
16 & 2 & 1 & 1 \\
21 & $2+1$ & 1 & $1+1$ \\
Tot & 28 & 17 & 11 \\
\hline
\end{tabular}

It seems that these subjects were using questions containing first or second person pronouns as memorized, unanalyzed chunks, or as a type of question marker: 12 of the 18 utterances by subject 4 involve the chunk, Do you know, and five of the 28 utterances are How old are you. In both types of questions, the referent for you is not the interviewer, but a character in the story square. The reason for the use of second person in particular is 
probably that ESL students so often hear questions addressed to themselves that they become accustomed to hearing inverted questions with you and learn them as chunks. These unanalyzed chunks can then operate as templates for inversion, as they seem to be doing here. One use of the template seems to be the use of a memorized, second person question without any modification, as in these examples:

EXAMPLE 14:

004-178 Whe- Do you know her? (Um, they don't know each other, but they go to same university.)

EXAMPLE 15:

$$
\begin{aligned}
& \text { 004-174 Uhh? hmm. . . Where do you job? } \\
& \text { (Hm?) Where do you job? (Um, sue is } \\
& \text { student.) }
\end{aligned}
$$

EXAMPLE 16:

$$
\begin{aligned}
& \text { 010-086 How old are you? (Um, Sue is } 20 \\
& \text { years old, no } 21 \text { years old.) }
\end{aligned}
$$

EXAMPLE 17:

021-051 She, ah, sue usually drink Budweiser [D], (mm-hm) mm why . why did you drink California wine more yesterday? (Because she [Sue] was sad.)

The template is also sometimes modified to include NPs referring to the actual referent of the question in addition to the memorized chunk with first or second person pronoun: 
EXAMPLE 18:
5 004-017 Oh. .. Tina issss, Tina . where .. do 3 004-018 Where.. live, live? (Tina?)
oK 004-019 Yes. (She lives in Baltimore.)
EXAMPLE 19:

5

010-037 Oh... Tina, (mm-hm) do you like him?
(Yes, Tina likes her boyfriend.)

EXAMPLE 20:

5

016-203 Tom . I don't know . steal? (Pardon me?)

8

016-204 Tom. Tom car /de/ (mm) /hara/ don't know, I don't, don't know Tom. (Ah, yes, Tom doesn't know about kidnap and Tom doesn't know about stealing, etc.)

EXAMPLE 21:

5

$$
\begin{array}{ll}
\text { 021-028 Two ... Did you . did a }\{\mathrm{J}\} \text { did two } \\
\text { person, do you person friends? (Ah, } \\
\text { no, not friends.) }
\end{array}
$$

In all the above cases involving second person pronouns, the subject managed to produce an inverted question because of the presence of an inappropriate pronoun. In the case of subject 16 , even though inversion is not accomplished, a negative question is produced by using the first person pronoun inappropriately.

Occasionally there is evidence that the subjects use the template as a bridge to begin actually analyzing the memorized chunks to form questions of their own. In the first instance below, subject 21 eventually eliminated the second person pronoun from her final question but did 
not succeed in inverting on her own even though her second person template was inverted. In the other instances, the subjects did succeed in applying the inversion in their templates to their own questions that use the appropriate third person NP or pronoun.

EXAMPLE 22 :

TIU E

$$
\text { 021-026 }
$$
Two, two person relation, relationship, (relationship) what, what do you- ah, what ummm. what two people what relation?

EXAMPLE 23:

TIU D 004-115 Hmm? Where are you, where do they go to date?

EXAMPLE 24:

TIU B 021-059 Taxi . mmm taxi driver umm, . do you have, do taxi driver have. mm a - lot of money?

All these examples suggest that second language learners may employ memorized chunks as templates, as aids in producing the correctly inverted question form, when they first begin to produce analyzed questions on their own, instead of relying solely on unanalyzed chunks.

\section{Incidental Findings: "Verb-final" Questions}

Another structure found in some ILs may reveal a transitional step in question formation between the subjects' SOV NL and the sVo word order of English. Gass (1984) states that basic word order does not transfer 
from NL to TL, giving the example, "Japanese learners do not go through a stage in which they place their verb in sentence-final position, despite the fact that Japanese is a verb-final language" (p. 123). It is probably a fact that Japanese ESL learners as a whole do not go through a verb-final stage. However, a few questions from the data appear to be verb-final, suggesting that, for at least some Japanese ESL learners, a transition from questioning devices not included in the $Q$ TIU (such as those represented by UNAQ 1) to sVo uninverted questions may involve, if not a sov question stage, at least occasional experiments in sov question formation in the TL. The relevant questions from the data are listed here:

EXAMPLE 25:

TIU C 005-082 . ah, why, why guys kid- she, um Patty kidnap?

EXAMPLE 26:

TIU A 009-024 New boyfriend, he is?

EXAMPLE 27 :

TIU A 012-041 OK. mm! . mm This idea mm she knows? EXAMPLE 28:

TIU A 018-020 Peter . different stay? [Gloss: Is Peter staying at a different place?]

EXAMPLE 29:

TIU A 018-033 . . Jim and Peter umm.. Jim and Peter. . each other know? 
Although there are only these very few tokens in the data of the sov type of question above, another IL structure, (WH word + ) Subject $+B E+$ Rest of Sentence + Main Verb, appears to be a possible transition between the sov questions and uninverted svo questions. In questions of this structure, the main verb remains in final position but the svo verb position is marked with the verb $B E$. This structure was produced by eight subjects, with 15 occurrences in the data. Examples are given below:

EXAMPLE 30 :

TIU C 004-138 Why he they are Patty kidnap?

EXAMPLE 31:

TIU C 010-041 Why . Tina mmmm . . is Peter marry?

EXAMPLE 32 :

TIU A 003-070 Oh. . mm Tina.. Tina is him love?

EXAMPLE 33:

TIU A $005-049$ Jim is Tina and Peter together saw?
[Gloss: Did Jim see Tina and Peter
together?]

EXAMPLE 34:

TIU A 006-061 John and Peter is . together work?

EXAMPLE 35:

TIU A 009-057 But last year, Tina is job starting?

EXAMPLE 36:

TIU A 009-063 John is Peter known? 
EXAMPLE 37 :

TIU A 016-088 Oh, Peter is. John kill?

EXAMPLE 38 :

TIU A 018-099 Gang is Patty force? [Gloss: Did the gang force patty?]

Since this study included only subjects whose NL was Japanese, no conclusion can be reached about whether such patterns as the two above are exhibited by all second language learners, by all ESL learners, by all ESL learners with SOV NLs, or only by Japanese ESL learners. However, the pattern seems to represent an initial attempt at approximating TL interrogative word order.

\section{SUMMARY}

This chapter reported the patterns found in the data gathered and categorized as described in chapter III. In general, subjects seemed to perform as predicted by the $Q$ TIU. Under the AEI approach to the data, which required a 90 percent accuracy rate to merit control of a construction, there were no exceptions to the TIU. Under a whole group approach that considered together the data from all subjects, the TIU was also upheld.

However, under the REI perspective of the data, which mandated that each lower, more difficult structure of the TIU occur with a decreasing rate of accuracy in the subjects' utterances, three subjects were exceptions 
to the claim that WH inversion implies WH fronting, and four subjects were exceptions to the claim that YN inversion implies WH inversion. All but one of these exceptions were found to be marginal due to the fact that their aberrations from the hypothesized pattern could be traced to the difference of just one utterance. Possible explanations for the one remaining exception were offered.

The final section of this chapter presented several incidental findings regarding TIU and UNAQ utterances that were apparent in the data.

Further discussions of the results of this study, from the perspectives of limitations, implications, and suggestions for further research, follow in the next chapter. 


\section{CHAPTER V}

\section{SUMMARY AND CONCLUSIONS}

\section{INTRODUCTION}

This final chapter discusses the limitations of this study; the implications of the results of this inquiry for linguistic theory, for SLA research, and for teaching ESL; and avenues for further research. The chapter concludes with a summary of the entire project.

\section{LIMITATIONS}

In general, the limitations of this study originate from four sources: characteristics of the subjects, the type and quantity of data obtained, the methods and techniques employed in the study, and the nature of the universal under study. Each of these is discussed in the ensuing sections.

\section{Limitations Due to Characteristics of the subjects}

\section{Only One Native Language}

All subjects in this study were NSs of Japanese. This happened not by accident or by default, but by design. In a paper laying the framework for testing ILs 
against primary language universals in order to discover whether the same universals constrain both language types, Eckman stipulates that "such tests should consider only certain NL-TL combinations where both the implicans [the implying structure, such as wH inversion] and implicatum [the implied structure, such as wH fronting] are part of the TL and neither is part of the NL" (1984, p. 86). This combination of NL and TL is necessary, says Eckman, so that if the order of the universal obtains in the IL, this fact may be attributable unambiguously to the force of the universal alone, rather than being attributable ambiguously to either the force of the universal or transfer from the NL.

English meets Eckman's (1984) TL requirement by possessing all three structures of the $Q$ TIU. To meet the NL part of the requirement, it was necessary to find a group of ESL speakers whose NL contained none of the $Q$ TIU structures. Finding NLs with neither wH inversion nor YN inversion was a simple matter. However, as the $Q$ TIU indicates, languages of the world most frequently front their question words, and it was difficult to find an available language without a fronting rule. As mentioned in chapter III, of NLs belonging to the potential subject pools available locally, only Japanese could adequately be concluded to meet Eckman's 
requirement. Thus, only Japanese ESL learners were selected to participate in this study.

At first glance, it may seem that this study is making universal claims on the basis of only one language. However, it must be realized that this study was not searching for a universal; it is not claiming that "WH fronting > WH inversion > YN inversion" is a language universal based on its own results from subjects of just one language. On the contrary, "WH fronting > WH inversion > YN inversion" has already been established as a universal on the basis of evidence from many diverse primary languages (Greenberg, 1963a; Ultan, 1978). This study has merely attempted to determine whether this universal for primary languages also applies to ILs and has tested it against the ILs of Japanese ESL learners, which is a legitimate, and, in light of Eckman's (1984) requirement above, even a preferred test.

Nevertheless, in order to know whether ILs in general follow the $Q$ TIU, it would be necessary to additionally test the $Q$ TIU against ILs of subjects with other NLs. Thus, although the participation of subjects of only one $\mathrm{NL}$ is not as severe a limitation as might initially be supposed, the fact remains that the results cannot be generalized to ESL learners of other language backgrounds. 


\section{Formal Classroom Context of Language Learning}

Another characteristic of the subjects that limits this study has to do with the context of language learning. All subjects had studied English as a foreign language in Japan for between four and seven years. English instruction in the typical Japanese school is highly formalized, with limited NS contact. Even those subjects who had been learning English in the Ns context of the United states for some time were enrolled in formal ESL programs. Thus, the results of this study cannot necessarily be generalized to learners of English in an informal or untutored environment.

\section{Other Factors}

Two other limiting elements are related to number and proficiency levels of subjects. Thirty-two subjects participated in this study. This number exceeds the number of subjects in many SLA studies investigating interrogative acquisition or the force of TIUs in IL: Gass (1981) had 18 subjects; Gass (1979) had 17; Eckman et al. (1989) had 13; Eckman (1991) had 11 subjects; Schmidt (1980) had nine; and Eckman (1984) had only one. However, 32 subjects still may not be a large enough sample. The proficiency level of the subjects is also a consideration. The subjects in this study were at an overall lower level than the subjects in the study by 
Eckman et al. (1989). In fact, only two of them reached the 90 percent criterion equated with control of YN inversion. Had the subjects been at higher levels, results might have been different.

\section{Limitations Due to the Type and Quantity of}

\section{Data obtained}

\section{Limited Number of Questions Produced}

The number of questions produced by each subject is the first of two limitations due to the type and quantity of the data obtained in this study. Although the averages of 27 grammatically complete YNQs and almost 16 grammatically complete WHQs per subject may perhaps be adequately representative of the subjects' ILs (Eckman et al., 1989, hoped to obtain 20 of each for each subject), the range in number of each type of question among subjects shows that such adequate representation was probably lacking for some subjects. Subjects produced between ten and 51 complete YNQs and between two and 56 complete WHQs. Thus, the few questions produced by some subjects may not have given an accurate representation of their true ability in question formation. For example, subject 11, who produced only two complete WHQs, inverted one but not the other, an wH inversion rate of 50 percent. But perhaps these two whQs did not adequately 
represent the interrogative portion of her IL. Perhaps if she had produced not two but 20 wHQs, only that one would have been inverted, yielding a wH inversion rate of only five percent. Conversely, perhaps only that one would have been uninverted, yielding a WH inversion rate of 95 percent.

Although the adequacy with which the data represented the subjects' true competence cannot be known, it seems reasonable to assume that the more questions elicited, the higher the degree of adequacy. Table 24, below, shows the number of subjects who produced the given ranges of each question type.

\section{Table 24}

Number of Subjects Producing Specific Ranges of YNQs and WHQS (Subjects $n=32$ )

\begin{tabular}{lcccccccc}
\hline 1 & 2 & 3 & 4 & 5 & 6 & 7 & 8 & 9 \\
$\#$ & $2-5$ & $6-10$ & $11-15$ & $16-20$ & $21-25$ & $26-30$ & $31-40$ & $41+$ \\
of & & & & & & & & \\
Qs & & & & & & & & \\
\hline YN & 0 & 2 & 2 & 7 & 5 & 4 & 8 & 4 \\
Qs & 0 & 2 & & & & & & \\
WH & 7 & 5 & 7 & 3 & 6 & 2 & 1 & 1 \\
QS & 7 & & & & & & \\
\hline \hline
\end{tabular}

The table shows that the possibility of the data inadequately representing a subject's IL more seriously 
affects WHQs than it does YNQs; far fewer subjects produced high numbers of wHQs. In fact, while twothirds, or 21 , of the subjects produced over 20 YNQs, only 10, less than one-third, produced over 20 WHQs.

Eckman et al. (1989) also obtained fewer questions per subject than they had hoped for. They were not able to elicit their goal of 20 YNQs and 20 wHQs from each subject: Three of their 13 subjects produced fewer than 20 YNQs, and nine produced fewer than 20 wHQs, with six WHQs being the lowest number produced. Their problem with limited numbers of questions was slightly less severe than in the present study, probably due, at least in part, to two factors. First, Eckman et al. instructed subjects to first ask YNQs and then instructed them to ask WHQs. Although they then apparently answered whatever questions the subjects asked, whether they were the specified type or not, this instruction as to question type may have prompted their subjects to produce more WHQs than the subjects otherwise might have. The method of giving these instructions to their subjects was not discussed, and, as mentioned in chapter III, such instructions were not given to the subjects of the present study because of the risk of compromising the spontaneity of the data, which was evidenced in the 
skewing impact that such instructions had had on the performance of the first pilot study subject.

The second reason that limited numbers of questions plagued Eckman et al. (1989) to a lesser degree is probably due to the fact that their subjects were, overall, at a higher level of English proficiency than were the subjects in this study. Despite the fact that subjects in the present study tended to demonstrate control of WH inversion before YN inversion, those at the higher (easier) end of the $Q$ TIU tended to produce far fewer WHQ tokens than YNQ tokens. In fact, of the 19 subjects in Table 24, above, who produced 15 or fewer WHQs, 18 were at the first (- WH fronting) or second (+ WH fronting) stages implied by the $Q$ TIU, while only six of the 13 who produced more than 15 WHQs were at the first or second stages. The tendency for subjects still at the high (easy) end of the $Q$ TIU to produce fewer WHQ tokens, coupled with the fact that 24 , or 75 percent, of the subjects were at this end of the $Q$ TIU, probably accounts for the limited number of wHQs obtained from subjects overall.

To the extent that the low numbers of questions produced compromises the accurate representation of the ILs involved, this study is limited. 


\section{The Difference of Just one Data Item}

The second limitation due to the type and quantity of the data obtained relates to the fact that the difference of just one utterance could cause some subjects, who, up until this point, have been considered confirming cases, to become exceptions to the $Q$ TIU.

In Chapter IV, the argument that "just one data item" is "insignificant" was used to neutralize six of the seven exceptions to the $Q$ TIU under the REI approach. In each of these six cases, either the subjects' percentages of WH inversion exceeded their rates of WH fronting, or their rates of $Y N$ inversion were greater than their rates of WH inversion. Both of these patterns were considered to violate the TIU under the REI. In all six cases, however, the difference of just one data item was shown to rectify the violation and transform each exception into a confirming case. This argument that "just one data item" is insignificant was borrowed from Eckman et al. (1989) who also resolve two of their three exceptions in this manner and who claim that since those exceptions differ only insignificantly from the pattern required by the TIU, they are, ultimately, not true exceptions. Thus, in neutralizing exceptions, the "insignificance" of just one data item worked in favor of the TIU, and it is beneficial to the status of the 
hypothesis to maintain that just one data item is, indeed, insignificant.

However, if the argument about the insignificance of just one data item is applied to certain subjects who are not exceptions to the TIU, the argument works against the TIU by changing those conforming subjects into exceptions. An example is subject 12. She had a 50 percent rate of WH inversion and a 41 percent rate of $\mathrm{YN}$ inversion, which confirms the TIU. However, her 50 percent WH inversion rate was based on two inverted WHQs out of a total of four wHQs. If, instead, she had inverted just one less time, her wH inversion rate would have been only 25 percent (one wH inversion out of four WHQs). A 25 percent $\mathrm{WH}$ inversion rate would have been lower than her 41 percent $Y N$ inversion rate, and she would have been an exception rather than a confirming case. In cases such as this, where confirming subjects may become exceptions given the difference of just one data item, it is in the interest of the TIU to maintain that just one data item is, indeed, significant.

Subject 12 has already been given as an example. Her case and all other affected subjects are presented below in Table 25. The left side of the table presents the actual data on each subject. Even though all subjects' data conform to the TIU under the REI approach 
(which specifies that the YN inversion rate must be the lowest, WH inversion must be the middle rate, and wH fronting must be the highest rate), the addition or subtraction of just one hypothetical data item can, at some point in the data, cause each of the subjects in Table 25 to deviate from the REI-required pattern. That vulnerable point in the real data is underlined in any of: columns 2 through 4 . Column 5 gives the ratio of correctly produced utterances to total number of relevant utterances, which produced the percentage in the category that was underlined.

The right side of Table 25 presents a hypothetical situation in which a violation of the $Q$ TIU is shown to be created by the difference of only one utterance. Column 6 presents the ratio from column 5 with the addition or subtraction of just one correctly produced utterance. This represents the "difference of one data item" that Eckman et al. consider to be insignificant (1989, p. 191) but which, in these cases, changes subjects whose data originally confirmed the TIU into exceptions. Columns 7 through 9 repeat the rates of YN inversion, wH inversion, and wH fronting from columns 2 through 4 except that the vulnerable percentage that was underlined in columns 2 through 4 is now an anomalous percentage in the pattern of the TIU and has been marked 
with an asterisk. The resulting patterns of percentages in columns 7 through 9 all violate the TIU pattern of relative frequency, demonstrating that the difference of only one item of data is significant for maintaining these subjects as confirming cases rather than exceptions to the TIU under the REI.

Table 25

Conforming Cases Changed to Exceptions

by the Addition or subtraction of

One Hypothetical Data Item

\begin{tabular}{|c|c|c|c|c|c|c|c|c|}
\hline \multirow[b]{2}{*}{$\begin{array}{l}\text { S } \\
\text { U } \\
\text { B }\end{array}$} & $\begin{array}{l}\text { The } \\
\text { Data } \\
\text { Poss }\end{array}$ & $\begin{array}{l}3 \\
\text { AC } \\
\text { onfor } \\
\text { \& the } \\
\text { ble }\end{array}$ & $\begin{array}{l}\quad 4 \\
\text { ual: } \\
\text { ing } \\
\text { Sour } \\
\text { nconf }\end{array}$ & $\begin{array}{l}\text { e of } \\
\text { ormance }\end{array}$ & \multicolumn{4}{|c|}{$\begin{array}{l}\text { Hypothetical: } \\
\text { A Problem } \\
\text { Created by the Difference } \\
\text { of One Utterance }\end{array}$} \\
\hline & $\begin{array}{l}: Y N \\
I N V\end{array}$ & $\begin{array}{l}\text { \&WH } \\
\text { INV }\end{array}$ & $\begin{array}{r}\% W H \\
\text { FR }\end{array}$ & $\begin{array}{l}\text { Source } \\
\text { of "-" }\end{array}$ & $\begin{array}{l}\text { One utt. } \\
\text { diffrnce }\end{array}$ & $\begin{array}{l}\% Y N \\
\text { INV }\end{array}$ & $\begin{array}{l}\text { \&WH } \\
\text { INV }\end{array}$ & $\begin{array}{r}\text { \&WH } \\
\text { FR }\end{array}$ \\
\hline 11 & 20 & $\underline{50}$ & 80 & $1 / 2$ & $0 / 1$ & 20 & $\star 0$ & 80 \\
\hline 12 & 41 & $\underline{50}$ & 86 & $2 / 4$ & $1 / 4$ & 41 & $\star 25$ & 86 \\
\hline 31 & 100 & $\underline{100}$ & 100 & $30 / 30$ & $29 / 30$ & 100 & *97 & 100 \\
\hline$\ddot{11}$ & $\ddot{20}$ & $\begin{array}{l}50 \\
50\end{array}$ & $\ddot{80}$ & $\cdots \cdots$ & $\cdots \cdots$ & $\ddot{20}$ & $* \ddot{10}$ & 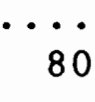 \\
\hline 24 & 6 & $\underline{71}$ & 76 & $10 / 14$ & $11 / 14$ & 6 & $\star 79$ & 76 \\
\hline 23 & 76 & 100 & 100 & $14 / 14$ & $13 / 14$ & 76 & 100 & $\star 93$ \\
\hline 28 & 94 & 100 & $\underline{100}$ & $30 / 30$ & $29 / 30$ & 94 & 100 & $\star 97$ \\
\hline 31 & 100 & 100 & 100 & $31 / 31$ & $30 / 31$ & 100 & 100 & $\star 97$ \\
\hline
\end{tabular}


Two groups of subjects are presented on Table 25, separated by a dotted line. For the first group, the violation of the $Q$ TIU stems from the fact that their rates of $\mathrm{YN}$ inversion exceed their rates of WH inversion when a hypothetical data item is added or subtracted. In the second group, the problem is that wH inversion rates exceed WH fronting rates when the hypothetical data item is added or subtracted. Subjects 11 and 31 appear in both groups.

Table 25 shows that six of the 32 subjects attained their status as confirming cases to the TIU by virtue of only one data item. In other words, if they had produced just one more (or one less) correctly formed utterance in place of one incorrectly formed (or correctly formed), they would have been exceptions to the TIU instead of confirming cases. These six subjects, who could be considered to follow the TIU only marginally, combined with the six exceptions in Chapter IV who differed only marginally from the TIU together form a group of 12 subjects whose data could be considered to be inconclusive with regard to the hypothesis. Regarding the data of 12 of the 32 subjects as inconclusive is definitely a limitation on the earlier claims that there was only one true exception to the TIU. In view of this 
limitation, the data did not support hypothesis as strongly as previously concluded.

This state of affairs is not a limitation unique to this study, however. Indeed, although they make no mention of it, the problem of just one data item affects the study by Eckman et al. (1989) even more profoundly than it affects this study. In Table 26, below, relevant data from Eckman et al. is presented along with the addition or subtraction of one hypothetical data item. The format of Table 26 is exactly the same as that of Table 25, above, with two exceptions, the first of which is that the subjects therein are from Eckman et al. instead of from the present study. The second difference is that three of the five subjects in the second group appear twice because adding or subtracting the one utterance difference at either of two points on the $Q$ TIU results in one of two patterns of percentages that violate the TIU. For each of these subjects, both methods of violation are presented on the table.

As evidenced in Table 26, nine of the 13 subjects in Eckman et al. (1989) can be shown to be only one utterance away from being exceptions to the TIU rather than confirming cases. These nine, together with the two neutralized exceptions to the TIU, mean that, under the argument presented above, the data of 11 of their 13 
subjects are inconclusive with regard to the status of the hypothesis.

\section{Table 26}

Eckman et al. (1989): Conforming Cases Changed to Exceptions by the Addition or Subtraction of One Hypothetical Data Item

\begin{tabular}{|c|c|c|c|c|c|c|c|c|}
\hline \multirow[b]{2}{*}{$\begin{array}{l}S \\
U \\
B\end{array}$} & $\begin{array}{l}\text { The } \\
\text { Dat } \\
\text { Pos: }\end{array}$ & $\begin{array}{c}3 \\
\text { Ac } \\
\text { onfol } \\
\text { o the } \\
\text { ole } 1\end{array}$ & $\begin{array}{c}4 \\
\text { ual: } \\
\text { ing } \\
\text { Sourc } \\
\text { ncon }\end{array}$ & $\begin{array}{l}\text { of } \\
\text { rmance }\end{array}$ & \multicolumn{4}{|c|}{$\begin{array}{l}\qquad \text { Hypothetical: } \\
\text { A Problem } \\
\text { Created by the Difference } \\
\text { of One Utterance }\end{array}$} \\
\hline & $\begin{array}{l}\text { \&YN } \\
\text { INV }\end{array}$ & $\begin{array}{l}\text { \&WH } \\
\text { INV }\end{array}$ & $\begin{array}{r}\text { \&WH } \\
\text { FR }\end{array}$ & $\begin{array}{r}\text { Source } \\
\text { of "_"\% }\end{array}$ & $\begin{array}{l}\text { One utt. } \\
\text { diffrnce }\end{array}$ & $\begin{array}{l}\text { \&YN } \\
\text { INV }\end{array}$ & $\begin{array}{l}\text { \&WH } \\
\text { INV }\end{array}$ & $\begin{array}{r}\text { 8WH } \\
\text { FR }\end{array}$ \\
\hline YK & 51 & 100 & $\underline{100}$ & $6 / 6$ & $5 / 6$ & 51 & 100 & $\star 83$ \\
\hline TM & 83 & 100 & $\underline{100}$ & $14 / 14$ & $13 / 14$ & 83 & 100 & $\star 93$ \\
\hline BG & 86 & 100 & $\underline{100}$ & $22 / 22$ & $21 / 22$ & 86 & 100 & *95 \\
\hline MA & 88 & 100 & $\underline{100}$ & $21 / 21$ & $20 / 21$ & 88 & 100 & *95 \\
\hline ST & 100 & 100 & 100 & $6 / 6$ & $5 / 6$ & 100 & 100 & $\star 83$ \\
\hline $\begin{array}{l}\mathrm{TS} \\
\text { or }\end{array}$ & 67 & $\underline{70}$ & 100 & $7 / 10$ & $6 / 10$ & 67 & $\star 60$ & 100 \\
\hline TS & $\underline{67}$ & 70 & 100 & $10 / 15$ & $11 / 15$ & $\star 73$ & 70 & 100 \\
\hline $\begin{array}{l}\text { RO } \\
\text { or }\end{array}$ & 85 & $\underline{88}$ & 100 & $14 / 16$ & $13 / 16$ & 85 & $\star 81$ & 100 \\
\hline RO & $\underline{85}$ & 88 & 100 & $23 / 27$ & $24 / 27$ & * 89 & 88 & 100 \\
\hline KO & 93 & $\underline{95}$ & 100 & $18 / 19$ & $17 / 19$ & 93 & $\star 89$ & 100 \\
\hline $\begin{array}{l}\text { MH } \\
\text { or }\end{array}$ & 95 & $\underline{95}$ & 100 & $20 / 21$ & $19 / 21$ & 95 & $\star 90$ & 100 \\
\hline MH & $\underline{95}$ & 95 & 100 & $18 / 19$ & $19 / 19$ & $\star 100$ & 95 & 100 \\
\hline ST & 100 & $\underline{100}$ & 100 & $6 / 6$ & $5 / 6$ & 100 & $\star 83$ & 100 \\
\hline
\end{tabular}


This argument that just one data item can transform confirming cases into exceptions is not, however, as strong as it may appear to be, based on the information in Tables 23 and 24, above. First of all, it affects only the REI approach to the data, not the AEI or whole group approaches. Secondly, close examination reveals that three of the six confirming cases-turned-exception in the present study and six of the nine in the study by Eckman et al. (1989) are subjects who have attained 100 percent accuracy in wH fronting and wH inversion. The significance of this fact is that whenever both of these structures have reached 100 percent accuracy, the hypothetical difference of just one less fronted wHQ will always result in a violation of the TIU. For example, even if these subjects had produced 100 inverted WHQs and 100 fronted wHQs, the hypothetical difference of just one less fronted WHQ would result in a lower percentage of Wil fronting than of WH inversion and, thereby, would constitute a hypothetical violation of the TIU. Rather than argue that the next wHQ produced by the subject could have been unfronted, which the "just one data item" argument assumes, it seems more likely, given the perfect rate of fronting thus far, that the subject's next wHQ would also be fronted. From this point of view, once structures have attained 100 percent accuracy, they may 
be considered to be immune from the "just one data item" argument. Thus, the limitation that the difference of just one data item may transform confirming cases into exceptions may not apply to cases where the relevant structures are produced with 100 percent accuracy. Therefore, subjects 23,28 , and 31 in Table 25 may be regarded as fully confirming the $Q$ TIU.

In the three cases in this study where subjects did not reach 100 percent accuracy for wH inversion and wH fronting, a third consideration also weakens the limiting power of "just one data item" problem. All three of these subjects, subjects 11,12 , and 24 , produced fewer than 15 wHQs. In fact, subjects 11 and 12 produced only two and four whQs, respectively. It is quite probable, then, that in these cases the problem caused by "just one data item" difference is compounded or even completely caused by the limited numbers of questions produced. In other words, in these cases, the "Limited Number of Questions Produced" limitation is exacerbating "The Difference of Just One Data Item" limitation. Perhaps if the data had more adequately represented these subjects' ILs by containing a greater number of the questions that they are typically able to form, their percentages of $\mathrm{WH}$ fronting, WH inversion, and $Y N$ inversion would have fallen in patterns that could not have been altered into 
exceptions by the addition or subtraction of one hypothetical data item.

As one final qualification on the limiting power of "the difference of just one data item" stands the contention that if all six of the confirming-casesturned-exception in this study had actually been exceptions to $Q$ TIU because the one data item was real instead of hypothetical, these exceptions could have been resolved just as the other six exceptions in Chapter IV were--with the argument that one data item is not: significant. The conclusion is, then, that the status of the hypothesis is not appreciably compromised even in light of these six confirming-cases-turned-exception. However, the fact that these six cases could be argued to not significantly confirm the hypothesis because they do so by virtue of the difference of only one data item can be construed to be a further limitation on the study.

\section{Limitations Due to Methods and Techniques of the study}

\section{Rules of Categorization}

The rules employed for counting and categorizing subjects' utterances place another limitation on the results of this study. Simply put, other researchers may use different rules resulting in much different outcomes. 
A case in point may be seen in Pienemann et al. (1988). As mentioned in chapter II, in their interpretation of data that they use to support their Multidimensional Model, WHQs are split into two groups: those exhibiting "Pseudo-inversion" and those called "AUX-2nd". WHQs with "Pseudo-inversion" are defined as WHQs with a copula, as in where is the station? WHQs with "AUX-2nd" are those such as, Where has he seen you? Likewise, YNQs are also split into two groups: those characterized by "Do fronting" and those with "Yes/No-Inversion". "Do fronting" includes questions such as, Do he work?, and "Yes/No-Inversion" applies to questions such as, Have he seen it? According to the data of Pienemann et al., acquisition of questions occurs in this order: "Do fronting," "Pseudo-inversion," "Yes/No-Inversion", and "AUX-2nd." An exact fit between their categories and those of the $Q$ TIU cannot be made, but assuming that questions with "Pseudo-inversion" are, as the name implies, not truly inverted, their data seem to indicate that YN inversion precedes WH inversion.

Since the present study is a partial replication of that by Eckman et al. (1989), it would be ideal for the categorization rules employed herein to be the same as theirs. However, as noted in Chapter III, Eckman et al. make only little mention of the rules they used. They do 
not mention their classification of wHQs with copula. Yet it seems reasonable to suppose that since the $Q$ TIU does not distinguish between "Pseudo-inversion" and "real" inversion, Eckman et al. probably did not make such a distinction, either. Based on this likelihood and on the supporting syntactic arguments given in Chapter IV, this study, in direct contrast to pienemann et al. (1988), asserts that inversion is present in wHQs with copula and classifies subjects' utterances accordingly. Were Pienemann et al. to sort the same utterances into the inverted and uninverted groups demanded by the $Q$ TIU, with no "Pseudo-inverted" option available, they would likely classify the inverted WHQs with copula as uninverted WHQs or as UNAQ 6 , and the results would be markedly different from those reported in this paper. In fact, of the 345 WHQs considered in this study to display inversion, 142 would need to be reclassified because they contain copula, and only 18 of the 32 subjects would have produced more than one inverted WHQ.

Other approaches to the categorization of the data may yield similarly disparate results. For example, another researcher may assign more weight to false starts, under the reasonable assumption that they reflect a more spontaneous, unmonitored rule of the subject's IL 
than the final, settled-upon question. In that case, an utterance such as

EXAMPLE 1:

TIU B 019-031 She had, she had, did she have a lot of money?

may be counted as uninverted or as two uninverted tokens and one inverted token instead of as one inverted YNQ as it was in this study, in which false starts were not counted at all.

Similarly, other researchers might categorize as inverted utterances with an auxiliary left in place as well as inverted, such as these EXAMPLE 2:

TIU A 007-043 Does Peter don't like John?

EXAMPLE 3:

TIU A 009-043 Mmm. Jim is good boy - ah - was, uuuum. In the past, is Jim is good boy?

on the premise that they do exhibit some form of inversion. However, in this study, all such utterances were counted as uninverted because inversion has apparently not been mastered.

The rules used for the categorization of utterances, then, make a significant difference in the outcome of the study, and, as such, they constitute a limitation. 


\section{Story Square Method of Elicitation}

Another methodological-related limitation, and one that Eckman et al. (1989) point out, is related to the nature of the story square task used for elicitation of the data. They state, "One might argue that tho experimental conditions under which we elicited the data were biased in favor of the universal" (p. 192, 1989). The bias of which they write stems from the fact that in a situation such as the story square interviews, where subjects' questions were based on pictures and previously given "basic information," many of the YNQs posed might have been for the purpose of confirmation. Since English allows such confirmation-type YNQs to be correctly uninverted in form, the story square task itself might have reduced the number of inversions in YNQs. The inversion-reducing effects of the context might then have been more responsible for the lower percentages of $Y N$ inversion than was the force of the TIU. If the context had been such that confirmation-type YNQs would have been inappropriate, perhaps the subjects' rates of YN inversion would have exceeded their rates of WH inversion, and the data would not have supported the TIU.

To determine whether the context of the task had indeed reduced the rate of YN inversion, Eckman et al. (1989) administered the story square task to NSs of 
English. They found that NSs produced much higher percentages of inverted YNQs than did the NNSs and concluded from this that the reason that their subjects' YN inversion rates were lower than their wH inversion rates was due not to the context of the story square task but to the fact that YN inversion is actually acquired after WH inversion, just as the TIU claims. Since the subjects of the present study were of an overall lower level than the subjects in Eckman et al., it may further be proposed that subjects at such an elementary level of English proficiency would probably not possess the sophistication necessary to have discovered the fact that: uninverted YNQs can be used for confirmation. Furthermore, according to williams (1989), the overwhelming likelihood is that they also would not have been taught that use and form of YNQs. Hence, the limitation of the method of elicitation is probably not a critical one.

\section{The Nature of a Cross-sectional study}

The cross-sectional nature of this study constitutes another limitation since it yielded data from only a frozen moment in time. It is generally assumed that the picture of IL resulting from the cross-sectional performances of subjects at different levels of proficiency approximates, to a high degree, the results 
that would be obtained for any given subject over a long period of time, but this is not necessarily perfectly so. To the degree that this is not true, this study is limited.

\section{The Nature of a Created Tool}

The fact that a created tool was used for elicitation also limits the study. Although every attempt was made to elicit data that were as natural as possible, the unavoidable result of using any tool is a lower degree of authenticity than could ideally be obtained by recording absolutely natural, non-elicited data. To the extent that elicited data differ from purely spontaneous utterances, this study is limited.

\section{Limitation to the Target structure}

The final limitation to be considered relates to the target structure, the interrogative TIU. Even though the data support the constraining power of the $Q$ TIU in IL, this constraining power cannot, therefore, also be claimed for any other TIUs. Although the idea that the $Q$ TIU constrains IL was supported by this study, existing studies need to be consulted and further studies conducted in order to draw conclusions about the influence of TIUs in general upon IL. 


\section{IMPLICATIONS}

The implications of this study for the formation of linguistic theory, for SLA research procedures, and for the teaching of ESL are discussed in the following sections.

\section{Implications for Linguistic Theory}

Since ILs are constrained by universals, as this and other studies show, SLA data should be elevated to a position, on a par with FLA data, where they can be used as a testing ground for other language universals and other aspects of linguistic theory. SLA data should be used to inform linguistic theory instead of only being informed by it.

In the context of studies investigating the influence of TIUs on SLA data, several other researchers voice this implication as well. Rutherford states, "the only fair way to characterize the linguistics/sLA relationship is as a two-way street. That is, both disciplines are, at least potentially, mutually informing and mutually informed" (1993, p. 4).

Similarly, Eckman (1993, p. ix) decries the current situation in which the theoretical field of linguistics unidirectionally informs SLA. He calls for linguistic theory to be altered or abandoned in light of 
disconfirming evidence from SLA and uses as an example exceptions to the Accessibility Hierarchy (AH) for relative clauses (RCs) found by SLA researchers Gass (1979), Hyltenstam (1984), and Pavesi (1986).

Gass campaigns for the same reform, in several articles (Gass, 1984, 1989; Gass \& Schachter, 1989). Her strongest argument may be in an article co-authored with Ard (1980), where they find that first language acquisition data on relative clause formation are strongly influenced by developing cognitive abilities while SLA data more clearly demonstrate constraints of language universals. They conclude,

it may be maintained that second language
acquisition data are less distorted than those
from first language acquisition. Thus,
better correspondence obtains between language
universals and second language acquisition data
than between universals and first language
acquisition data. Hence, second language
acquisition data provide a clearer window for
the investigation and verification of language
universals a dhere is no reason why second
language acquisition must play a subsidiary
role in the development of theoretical
constructs in linguistics. The communication
should not be entirely from theoretical
linguistics and first language acquisition to
second language acquisition. Interesting and
essential information can and should travel in
the opposite direction as well. (Gass \& Ard,
1980, pp.451, 452)

The results of the current study provide additional support for this perspective. 


\section{Implications for SLA Research}

In this study, uncertainty arose in attempting to categorize the subjects' utterances because Eckman et al. (1989), whose study this one attempted to partially replicate, did not explicitly describe the rules that they used in categorizing their subjects' data. An example of particular concern was the way in which they treated wHQs with copula. This uncertainty leads to the call for SLA researchers to more explicitly define the rules that they use for categorizing subjects' data. More explicit definition of rules is vital to insure replicability. It is also necessary in order to insure meaningful results when comparing different studies that examine the same phenomenon. For example, both Pienemann et al. (1988) and Eckman et al. (1989) were concerned with order of question acquisition, and both reached seemingly opposite conclusions, the former that YN inversion precedes $\mathrm{wH}$ inversion, the latter that $\mathrm{wH}_{\mathrm{H}}$ inversion precedes YN inversion. However, since Eckman et al. (1989) did not explicitly define their rules for categorization (in this case, particularly with regard to wHQs with copula), it cannot be decided if the conclusions of the two research efforts were actually contradictory or actually unanimous. Furthermore, this lack of explicitness is not limited to the studies by 
Eckman et al. and by Pienemann et al. While a few of the studies reviewed for this paper did give syntactic descriptions for their various categories (see, for example, Lindholm, 1986, and wode, 1978), most did not. And none of the studies specified methods used for deciding how to match subjects' actual utterances, full of false starts, self-corrections, etc., to the correct category. There exists, therefore, a need for SLA researchers to more explicitly define their methods of analyzing subjects' data.

This study partially meets this need by offering a detailed taxonomy of question types (both TIU Qs and UNAQS) as well as detailed rules on how to recognize a question and how to recognize various question types (unfronted and fronted questions, uninverted and inverted questions, and UNAQs) amidst the "noise" of naturalistic data. Therefore, independent of the contribution of the TIU-related results, this study is a contribution to SLA research in the area of text- or corpus-based linguistics.

\section{Implications for Teaching ESL}

Since this study does not address interrogative pedagogy, no direct implication for teaching ESL may be made. However, the results of this study, especially 
when considered in light of two pedagogically oriented studies by Gass (1982) and by Eckman et al. (1988), may hold indirect or tentative implications for teaching that could be tested in future pedagogical studies. It is in this vein that the following comments on implications should be interpreted.

It is not necessarily an implication of this study that ESL teachers should instruct their students first in WH fronting, if necessary, then in WH inversion, and then in YN inversion even though this may appear to be implied from the results of this study--it seems intuitively reasonable to teach the easier structure first. However, studies by Gass (1982) and by Eckman et al. (1988) would suggest otherwise. In those two studies, the researchers taught the harder structure (on the relative clause TIU hierarchy, the AH) first and found that subjects "automatically" generalized to the correct formation of the easier structures, without specific instruction, once they had learned the harder structure. The researchers' suggestion then, was that ESL instructors should teach the harder structure first, allowing maximal automatic generalization. (Eckman et al., 1988, qualified this recommendation by stipulating that this should be done only if it proved to be more time efficient than teaching the structures from easiest to hardest, a factor that has 
not been researched.) Applying this suggestion to the present study suggests that perhaps ESL students should be taught $Y N$ inversion first, with the result that WH inversion and wH fronting will automatically fill in.

Thus, the possible implication of this study for teaching ESL has two parts, each of which result in converse teaching practices. First, if the assumption of the instructor is that structures should be presented in the order from simplest to most complex, then instruction in $\mathrm{WH}$ inversion should precede instruction in $\mathrm{YN}$ inversion. This is opposite of the progression in several ESL grammar textbooks surveyed, which tend to teach YN inversion followed by WH inversion (Azar, 1992; Chamot, Rainey de Diaz, Baker de Gonzalez, \& Yorkey, 1990; and Elbaum, 1986). Secondly, if it is the teacher's philosophy that instruction should be done in such a way as to maximize the generalization of learning, then instruction in interrogatives need consist only of instruction in $\mathrm{YN}$ inversion. It is doubtful that any ESI, textbooks currently follow this approach; they would seem, intuitively, to be incomplete without explicit instruction in WHQ formation. 


\section{AVENUES FOR FURTHER RESEARCH}

In the relatively unexplored domain where TIUs intersect SLA performance, there remain numerous possibilities for future research. Many of the suggestions included here are variations on the present study that would serve to reconfirm the $Q$ TIU; others concern either question acquisition in general or other TIUs.

\section{Further Research to Reconfirm the $Q$ TIU}

Further inquiry could test the $Q$ TIU against SLA data from subjects with an even greater range of second language proficiency levels. The present study replicated the one of Eckman et al. (1989) to a lesser degree than intended in that its subjects were, overall, at a lower level than theirs, as indicated by the fact that, in this study, no ceiling effect was found that excluded unfronted WHQs from the data as was found in their study. This unanticipated circumstance had the effect of broadening the claims of Eckman et al. (1989) to include lower level subjects, but even the subjects in this study had all been studying English for a minimum of four years. Further study could involve replication at all proficiency levels, with data being gathered from subjects just beginning their study of English, from 
subjects at levels similar to those in this study, and from those at more advanced levels.

Not only could the story square interviews be carried out with subjects from a greater range of proficiency levels, but also the interviews could be done with subjects who are speakers of other NLs. These other NLs could include languages such as Turkish, Korean, and Chinese which, like Japanese, employ none of the question formation strategies specified by the Q TIU, as well as including languages that do employ fronting and inversion, such as German. As previously mentioned, Eckman's (1984) admonishes that studies testing TIUs against SLA data should involve NLs that exhibit none of the TIU structures and TLs that exhibit all of the TIU structures. Although this is a point well taken, it would be interesting to discover whether subjects whose NL includes all the structures of the $Q$ TIU would, in a second language, produce unfronted wHQs, uninverted WHQs, and uninverted YNQS in the order predicted by the TIU, in spite of the presence of fronting and both types of inversion in their NLs.

Replication of this study with TLs other than English (and that also have inversion in YNQs and WHQs) would also be useful in order to insure that the results of this study and that of Eckman et al. (1989) are not 
merely a relic of the particular complexities of English syntax.

Another way of productively varying this study would be by conducting repeat story square sessions later on in the subjects' acquisition time. The results of story Square interviews with the same subjects after they had progressed to higher levels of proficiency would serve to show whether the cross-sectional and longitudinal pictures are equivalent.

Finally, the $Q$ TIU should also be tested using different data-collection procedures: translation, dialog completion, grammaticality judgement, and others.

\section{Further Research on Question Acquisition in General}

\section{Non-TIU Dynamics of Question Acquisition}

The non-TIU dynamics of question acquisition, represented in this study by the utterances placed into the UNAQ (unanalyzable questions) categories, deserve more detailed study. Questions such as the UNAQ utterances should be analyzed to determine whether they exemplify other stages of interrogative acquisition that occur before or concurrently with the $Q$ TIU stages, idiosyncratic questioning strategies, or other processes. In attempting to systematically study such utterances, the results of this study suggest that the subjects 
should be in the very beginning stages of question acquisition, since it was these subjects who produced higher percentages of non-TIU governed questions.

\section{Question Acquisition as a Matrix}

SLA studies of interrogatives typically result in a list of acquisition stages for questions. Though the content of the lists may vary or even appear to be contradictory, the stages are invariably presented in list form, implying that acquisition of questions is a linear process.

However, when the conclusions of many of these studies are observed and compared collectively--such as the apparently conflicting conclusions of Pienemann and Johnston (1987) versus this Q TIU study and the one by Eckman et al. (1989), the conclusions of studies investigating which auxiliaries are inverted first (For instance, Adams, 1978; Cazden et al., 1975; Wode, 1978; and Syamala, 1991), and studies that investigate the order of acquisition of WH words themselves (Felix, 1976; see also Ellis, 1992a; and Wode, 1978)--a very complicated picture begins to emerge. It seems likely that the issue of question acquisition is much more complicated than a simple answer to the question, "Which question construction appears first, second, and third?" Perhaps the idea of trying to find a linear "order of 
acquisition" is off-track. It may be that L2 question acquisition does not happen linearly, even if the linear order is adjusted for the inevitable "backsliding" of a variable IL.

This concept is hinted at by Dulay et al. (1982), who link a learner's tendency to produce some inverted and some uninverted questions to the observation that some auxiliaries (such as is, are, and was) appear early on in learners' speech, while other auxiliaries (such as do and am) appear late. Expanding their idea to include additional variables of question acquisition suggests that perhaps L2 question acquisition is more like a matrix than like a line. Perhaps the $Q$ TIU is the dominant horizontal force, but other factors, such as the relative difficulty of the various auxiliaries, the relative difficulty of the various WH words, tenses, and other grammatical phenomena such as objects of prepositions are vertical forces that interweave themselves between the structures of the TIU and make it appear as if the learner has control of a construction at times but not at other times.

A study intended to sort it all out would need to consider each type of question individually. For example, in questions with do, does wH inversion appear before YN inversion? In questions with does, does WH 
inversion appear before $\mathrm{YN}$ inversion? What about in questions with are or is or can? It would take an enormous amount of question-filled data and probably numerous elicitation sessions with each of many subjects over time, but the results may yield a definitive picture of inversion of interrogatives in SLA.

\section{Further Research on other TIUs}

Further research involving other TIUs is also needed, with both observational and experimental approaches. Given a TIU established cross-linguistically in primary languages, an observational approach would examine SLA data to determine whether they are constrained by the TIU. The present study and most other related studies to date have used this approach, but similar work is still needed. For example, the phonology studies by Eckman (1984, 1991) which involved seven subjects from four different NLs and 11 subjects from three NLs should be replicated with greater numbers of subjects and NLs. Also, the study of the complement hierarchy by Frawley (1981) which involved 20 ESL subjects from five language backgrounds should be replicated with larger groups of subjects from more NLs, with subjects learning second languages that contain all 
three types of complements on the hierarchy, if possible, and with different methods of data collection.

Additionally, the literature could be surveyed to discover whether there exist other TIUs for primary languages, either well-known or newly established, that have not yet been tested against $\mathrm{L} 2$ data.

In addition to inquiries that probe SLA data to determine whether they are constrained by primary language TIUs, studies with a more experimental approach are also needed. Such studies may resemble the $\mathrm{RC} A H$ studies by Gass (1982) and by Eckman et al. (1988) that investigated the effects of teaching the correct formation of the lowest (most difficult) construction of the hierarchy to subjects and found that subjects automatically learned the correct formation for constructions higher on the hierarchy. Other TIUs, including the $Q$ TIU (with beginning level subjects), may be amenable to such experimentation.

\section{SUMMARY OF THE PROJECT}

This thesis was a partial replication of a study by Eckman et al. (1989) that examined SLA data for evidence of influence of a typological implicational universal for interrogatives that constrains primary languages such that inversion in YNQs implies inversion in WHQs which, 
in turn, implies wH fronting. Unlike the study by Eckman et al., however, this one involved more subjects, subjects who were from just one $\mathrm{NL}$ background and who were, over all, at a lower level of English proficiency than theirs. In addition, the instructions given to subjects in the two studies differed in that this study did not attempt to specify which type of questions subjects were to produce. The methods of classifying subjects' utterances may have also differed, albeit unintentionally. This occurred because Eckman et al. did not extensively delineate their methods of categorization. In contrast, this study defines categories and rules of categorization in detail. Further differences between the two studies are that this study reports on UNAQs and considers a whole group approach to the data, neither of which is done by Eckman et al. This study also finds unfronted wHQs in the data, while Eckman et al. did not.

In this study, as in the one by Eckman et al. (1989), data were collected by means of tape-recorded interviews in which each of 32 Japanese-speaking subjects individually attempted to discover the story behind a grid of story square pictures by asking questions of the interviewer. Each interview was then transcribed and the subject's interrogative utterances categorized into one 
of six TIU categories if the utterances had sufficient elements to show the dynamics of the $Q$ TIU or into one of nine UNAQ categories if the utterances were grammatically incomplete or otherwise unanalyzable according to the TIU. Percentages of inverted and uninverted YNQS, inverted and uninverted WHQs, and fronted and unfronted WH words were calculated for each subject and for the group.

It was hypothesized that subjects' control of YN inversion would imply their control of WH inversion which would, in turn, imply their control of wh fronting. Three interpretations of this hypothesis were examined, including an Absolute Existence Interpretation (AEI) in which a 90 percent accuracy rate was equated with "control;" a Relative Existence Interpretation (REI) in which each easier structure of the $Q$ TIU was expected to occur at a greater accuracy rate than the previous, more difficult structure; and a whole group approach where all subjects' results were combined to observe the aggregate patterns of question formation.

In each case, the hypothesis was upheld. Although in the case of the REI there were seven subjects whose results did not follow the hypothesized pattern, six of these diverged only slightly, leaving only one subject a true exception. Several possible explanations for her 
aberrant pattern were discussed. Chief among these was the explanation that the unexpected pattern of percentages may have been produced by a combination of the subject's individual variables and the fact that, in English, YN inversion involves a simpler syntactic procedure than does wH inversion. 


\section{REFERENCES}

Adams, M. (1978). Methodology for examining second language acquisition. In E. Hatch (Ed.), Second language acquisition: A book of readings (pp. 277296). Rowley, MA: Newbury House.

Adjemian, C. (1976). On the nature of interlanguage systems. Language Learning, 26(2), 297-320.

Anderson, R. (Ed.), Second languages: A cross linguistic perspective. Rowley, MA: Newbury House.

Azar, B. S. (1992). Fundamentals of English grammar. Englewood Cliffs, NJ: Regents/Prentice Hall.

Bailey, N., Eisenstein, M., \& Madden, C. (1976). The development of wh-questions in adult second language learners. In J. Fanselow \& R. Crymes (Eds.), on TESOL '76 (pp. 1-9). Washington, DC: TESOL.

Bailey, N., Madden, C., \& Krashen, S. (1974). Is there a "natural sequence" in adult second language learning? Language Learning, 24(2), 235-243.

Bley-Vroman, R. (1983). The comparative fallacy in interlanguage studies: The case of systematicity. Language Learning, 33(1), 1-17.

Bolinger, D. L. (1957). Interrogative structures of American English (the direct question). American Dialect Society publication 28. Alabama: University of Alabama Press.

Brines, V. (1990). Learning yes-no questions under different academic conditions. IRAL, 28(3), 234-247.

Brown, H. D. (Ed.). (1976). Papers in second language acquisition: Proceedings of the Sixth Conference on Applied Linguistics. Ann Arbor, MI: Research Club in Language Learning.

Brown, H. D., Yorio, C. A., \& Crymes, R. H. (Eds.). (1977). On TESOL '77: Teaching and learning English as a second language. Washington, DC: TESOL. 
Brown, R. (1968). The development of wh-questions in child speech. Journal of Verbal Learning and Verbal Behavior, 7, 279-290.

Butterworth, G., \& Hatch, E. (1978). A Spanish-speaking adolescent's acquisition of English syntax. In $E$. Hatch (Ed.), Second language acquisition: $A$ book of readings (pp. 231-245). Rowley, MA: Newbury House.

Cazden, C., Cancino, H., Rosansky, E.,\& Schumann, J. (1975). Second language acquisition sequences in children, adolescents and adults, final report. Washington, DC: National Institute of Education. (ERIC Document Reproduction Services No. ED 121 155)

Celce-Murcia, M. , \& Larsen-Freeman, D. (1983). The grammar book: An ELS/EFL teacher's course. Cambridge, MA: Newbury House.

Chamot, A. U., Rainey de Diaz, I., Baker de Gonzalez, J., \& Yorkey, R. (1990). Intercom 2000, book 2. Boston: Heinle \& Heinle Publishers.

Chen, J. (1986). An investigation of the patterns of learning English interrogative structures by EFL learners in China. (ERIC Document Reproduction Services No. ED 297 572)

Comrie, B. (1989). Language universals and linguistic typology. Chicago: University of Chicago Press.

Cook, V. (1993). Linguistics and second language acquisition. New York: St. Martin's Press.

Dechert, H. W. (Ed.). (1990). Current trends in European second language acquisition research. Clevedon, England: Multilingual Matters, Ltd.

Dieterich, T., \& Vasbinder, A. S. (in press). English grammar: Structure and theme. Ann Arbor, MI: University of Michigan Press.

Dryer, M. S. (1988). Universals of negative position. In M. Hammond, E. Moravcsik, \& J. Wirth (Eds.), Studies in syntactic typology (pp. 93-124). Amsterdam: John Benjamins Publishing Co.

Dulay, H., \& Burt, M. (1973). Should we teach children syntax? Language Learning, 23(2), 245-258. 
Dulay, H., \& Burt, M. (1974). Natural sequences in child second language acquisition. Language Learning, $24(1), 37-53$.

Dulay, H., Burt, M., \& Krashen, S. (1982). Language two. New York: Oxford University Press.

Eckman, F. R. (1977). Markedness and the contrastive analysis hypothesis. Language Learning, 27(2), 315330 .

Eckman, F. R. (1984). Universals, typologies and interlanguage. In W. E. Rutherford (Ed.), Typological studies in language, volume 5, language universals and second language acquisition (pp. 79105). Amsterdam: John Benjamins Publishing Co.

Eckman, F. R. (1985). Some theoretical and pedagogical implications of the markedness differential hypothesis. Studies in Second Language Acquisition, $7,289-307$.

Eckman, F. R. (1991). The structural conformity hypothesis and the acquisition of consonant clusters in the interlanguage of ESL learners. Studies in Second Language Acquisition, 13, 23-41.

Eckman, F. R. (Ed.). (1993). Confluence: Linguistics, L2 acquisition and speech pathology. Amsterdam: John Benjamins Publishing Co.

Eckman, F. R., Bell, L. H., \& Nelson, D. (Eds.). (1984). Universals of second language acquisition. Rowley, MA: Newbury House.

Eckman, F. R., Bell, L. H., \& Nelson, D. (1988). On the generalization of relative clause instruction in the acquisition of English as a second language. Applied Linguistics, 9(1), 1-20.

Eckman, F. R., Moravcsik, E. A., \& Wirth, J. R. (1989). Implicational universals and interrogative structures in the interlanguage of ESL students. Language Learning, 39(2), 173-205.

Elbaum, S. N. (1986). Grammar in context, book 1. USA: Harper Collins Publishers.

Ellis, R. (1986). Understanding second language acquisition. Oxford: Oxford University Press. 
Ellis, R. (1988). Classroom second language development. New York: Prentice Hall.

Ellis, R. (1992a). Can syntax be taught? A study of the effects of formal instruction on the acquisition of WH questions by children. In R. Ellis, second language acquisition and language pedagogy ( $\mathrm{pp}$. 5374). Clevedon, England: Multilingual Matters Ltd.

Ellis, R. (1992b). Second language acquisition and language pedagogy. Clevedon, England: Multilingual Matters Ltd.

Fanselow, J., \& Crymes, R. (1976). On TESOL '76. Washington, DC: TESOL.

Felix, S. (1976). WH-pronouns in first and second language acquisition. Linguistische Berichte, 44, 52-64.

Felix, S. (1981). The effect of formal instruction on second language acquisition. Language Learning, $31(1), 87-112$.

Flynn, S. (1987). A parameter-setting model of L2 acquisition. Boston: D. Reidel Publishing Co.

Flynn, S., \& O'Neil, W. (1988). Introduction. In S. Flynn \& $\mathrm{W}$. O'Neil (Eds.), Linguistic theory in second language acquisition (pp. 1-24). Norwell, MA: Kluwer Academic Publishers.

Frank, M. (1972). Modern English. Englewood Cliffs, NJ: Prentice Hall.

Frawley, w. (1981). The complement hierarchy: Evidence for language universals from L2. Paper presented at the annual meeting of the Linguistic society of America. (ERIC Document Reproduction Services No. ED 210 944)

Gass, S. (1979). Language transfer and universal grammatical relations. Language Learning, 29(2), 327-344.

Gass, S. (1980). An investigation of syntactic transfer in adult second language learners. In $R$. Scarcella $\& \mathrm{~S}$. Krashen (Eds.), Research in second language acquisition (pp. 132-141). Rowley, MA: Newbury House. 
Gass, S. (1982). From theory to practice. In M. Himes \& W. E. Rutherford (Eds.), On TESOL 82 (pp. 129-139). Washington, DC: TESOL.

Gass, S. (1984). A review of interlanguage syntax: Language transfer and language universals. Language Learning, 34(2), 115-131.

Gass, S. (1989). Language universals and second-language acquisition. Language Learning, 39(4), 497-534.

Gass, S., \& Ard, J. (1980). L2 data: Their relevance for language universals. TESOL Quarterly, 14, 443-452.

Gass, S. , \& Ard, J. (1984). Second language acquisition and the ontology of language universals. In W. E. Rutherford (Ed.), Typological studies in language, volume 5, language universals and second language acquisition (pp. 33-68). Amsterdam: John Benjamins Publishing Co.

Gass, S., \& Schachter, J. (Eds.). (1989). Linguistic perspectives on second language acquisition. Cambridge: Cambridge University Press.

Gass, S., \& Selinker, L. (1994). Second language acquisition: An introductory course. Hillsdale, NJ: L. Erlbaum Associates.

Gillis, M., \& Weber, R. (1976). The emergence of sentence modalities in the English of Japanese-speaking children. Language Learning, 26(1), 77-94.

Greenberg, J. H. (1963a). Some universals of grammar with particular reference to the order of meaningful elements. In J. H. Greenberg (Ed.), Universals of language (pp. 306-337). Cambridge, MA: MIT Press.

Greenberg, J. H. (Ed.). (1963b). Universals of language. Cambridge, MA: MIT Press.

Greenberg, J. H. (1969). Language universals: A research frontier. Science, 166, 473-478.

Greenberg, J. H., Ferguson, C. A., \& Moravcsik, E. (Eds.). (1978). Universals of human languages, volume 4, syntax. Stanford, CA: Stanford University Press. 
Gregg, K. R. (1989). Second language acquisition theory: The case for a generative perspective. In S. Gass \& J. Schachter (Eds.), Linguistic perspectives on second language acquisition (pp. 15-40). Cambridge: Cambridge University Press.

Hammond, M., Moravcsik, E.,\& Wirth, J. (Eds.). (1988). Studies in syntactic typology. Amsterdam: John Benjamins Publishing Co.

Hansen, L. (1986). Universals in relative clause acquisition: Evidence from child and adult L1 and L2 learners of Hindi-Urdu. Language Learning, 36(2), 143-158.

Hatch, E. (1974). Second language learning - universals? working Papers on Bilingualism, 3, 1-17.

Hatch, E. (Ed.). (1978). Second language acquisition: A book of readings. Rowley, MA: Newbury House.

Hatch, E., \& Wagner-Gough, J. (1976). Explaining sequence and variation in second language acquisition. In $\mathrm{H}$. D. Brown (Ed.), Papers in second language acquisition: Proceedings of the Sixth Conference on Applied Linguistics (pp. 1-17). Ann Arbor, MI: Research Club in Language Learning.

Hawkins, J. A. (1983). Word order universals. New York: Academic Press.

Hawkins, J. A. (1987). Implicational universals as predictors of language acquisition. Linguistics, $25(3), 453-473$.

Himes, M., \& Rutherford, W. E. (Eds.), On TESOL 82. Washington, DC: TESOL.

Huang, J., \& Hatch, E. (1978). A Chinese child's acquisition of English. In E. Hatch (Ed.), Second language acquisition: $A$ book of readings (pp. 118131). Rowley, MA: Newbury House.

Hyltenstam, K. (1977). Implicational patterns in interlanguage syntax variation. Language Learning, $27(2), 383-411$. 
Hyltenstam, K. (1981). Dynamic change in the acquisition of a second language as exemplified by negation and interrogation. In J. G. Savard \& L. Laforge (Eds.), Actes $d u 5^{e}$ Congres de I'Association Internationale de Linguistique Appliquee (International Association of Applied Linguistics) (pp. 197-194). Quebec: Presses de Universite Laval.

Hyltenstam, K. (1984). The use of typological markedness conditions as predictors in SLA: The case of pronominal copies in relative clauses. In $R$. Anderson (Ed.), Second languages: A cross linguistic perspective (pp. 39-58). Rowley, MA: Newbury House.

Hyltenstam, K. (1987). Markedness, language universals, language typology, and second language acquisition. In C. W. Pfaff (Ed.), First and second language acquisition processes (pp. 55-78). Cambridge, MA: Newbury House.

Hyltenstam, K. (1990). Typological markedness as a research tool in the study of second language acquisition. In H. W. Dechert (Ed.), Current trends in European second language acquisition research (pp. 23-36). Clevedon, England: Multilingual Matters, Ltd.

Ioup, G. \& Kruse, A. (1977). Interference versus structural complexity as a predictor of second language relative clause acquisition. In $H . D$. Brown, C. A. Yorio, \& R. H. Crymes (Eds.), On TESOL 17: Teaching and learning English as a second language (pp. 159-171). Washington, DC: TESOL.

Jakobson, R. (1968). Child language, aphasia and phonological universals. The Hague: Mouton.

Keenan, E. L., \& Comrie, B. (1977). Noun phrase accessibility and universal grammar. Linguistic Inquiry, 8(1), 63-99.

Klima, E. S., \& Bellugi, U. (1966). Syntactic regularities in the speech of children. In J. Lyons \& R. J. Wales, (Eds.), Psycholinguistic papers (pp. 183-208). Edinburgh: Edinburgh University Press.

Knowles, P. L., \& Sasaki, R. A. (1980). Story squares: Fluency in English as a second language. Cambridge, MA: Winthrop Publishers. 
Kwan-Terry, A. (1986). The acquisition of word order in English and Cantonese interrogative sentences: A Singapore case study. RELC Journal, 17(1), 14-39.

Lado, R. (1957). Linguistics across cultures. Ann Arbor, MI: University of Michigan Press.

Larsen-Freeman, D. \& \& Long, M. H. (1991). An introduction to second language acquisition research. New York: Longman.

Lightbown, P., \& Spada, N. (1993). How languages are learned. Oxford: Oxford University Press.

Lindholm, K. (1986). English question use in Spanishspeaking ESL children: Changes with English language proficiency. Los Angeles: UCLA Center for Language education and research. (ERIC Document Reproduction Services No. ED 278 263)

Lyons, J.. \& Wales, R. J. (Eds.). (1966). Psycholinguistic papers. Edinburgh: Edinburgh University Press.

Mazurkewich, I. (1984). Dative questions and markedness. In F. R. Eckman, L. Bell, \& D. Nelson (Eds.), Universals of second language acquisition (pp. 119131). Rowley, MA: Newbury House.

Nunan, D. (Ed.), Applying second language acquisition research. Adelaide, Australia: NCRC.

oller, J., \& Ziahosseiny, S. (1970). The contrastive analysis hypothesis and spelling errors. Language Learning, 20, 183-189.

Pavesi, M. (1986). Markedness, discoursal modes, and relative clause formation in a formal and an informal context. Studies in second Language Acquisition, $8,38-55$.

Pfaff, C. W. (1987). First and second language acquisition processes. Cambridge, MA: Newbury House.

Pienemann, M., \& Johnston, M. (1987). Factors influencing the development of language proficiency. In $D$. Nunan (Ed.), Applying second language acquisition research (pp. 45-142). Adelaide, Australia: NCRC. 
Pienemann, M., Johnston, M., \& Brindley, G. (1988). Constructing an acquisition-based procedure for second language assessment. Studies in second Language Acquisition, 10, 217-243.

Quirk, R., \& Greenbaum, S. (1973). A concise grammar of contemporary English. New York: Harcourt, Brace, Jovanovich.

Quirk, R., Greenbaum, S., Leech, G., \& Svartvik, J . (1985). A Comprehensive grammar of the English language. New York: Longman.

Radford, A. (1981). Transformation syntax: A student's guide to Chomsky's extended standard theory. Cambridge: Cambridge University Press.

Ravem, R. (1974a). The development of wh-questions in first and second language learners. In J. C. Richards (Ed.), Error analysis: Perspectives on second language acquisition (pp. 134-155). London: Longman.

Ravem, R. (1974b). Language acquisition in a second language environment. In J. C. Richards (Ed.), Error analysis: Perspectives on second language acquisition (pp. 124-133). London: Longman.

Ravem, R. (1978). Two Norwegian children's acquisition of English syntax. In E. Hatch (Ed.), Second language acquisition: $A$ book of readings (pp. 148-154). Rowley, MA: Newbury House.

Richards, J. C. (Ed.). (1974). Error analysis: Perspectives on second language acquisition. London: Longman.

Rollins, L. (1988). The accessibility hierarchy as a predictor of formal and informal ESL learners' grammaticality judgments about English relative clauses. Unpublished master's thesis, Portland State University, Portland, Oregon.

Rutherford, W. E. (1984a). Description and explanation in interlanguage syntax: State of the art. Language Learning, 34(3), 127-155. 
Rutherford, W. E. (Ed.). (1984b). Typological studies in language, volume 5, language universals and second language acquisition. Amsterdam: John Benjamins Publishing Co.

Rutherford, W. E. (1993). Linguistics and SLA. In F. R. Eckman (Ed.), Confluence: Linguistics, L2 acquisition and speech pathology (pp. 3-14). Amsterdam: John Benjamins Publishing Co.

Schmidt, M. (1980). Coordinate structures and language universals in interlanguage. Language Learning, 30, $397-416$.

Sadock, J. M., \& Zwicky, A. M. (1985). Speech act distinctions in syntax. In T. Shopen, (Ed.), Language typology and syntactic description, volume 1, clause structure (pp. 155-196). Cambridge: Cambridge University Press.

Savard, J. G., \& Laforge, L. (Eds.). (1981). Actes du $5^{e}$ Congres de I'Association Internationale de Linguistique Appliquee (International Association of Applied Linguistics). Quebec: Presses de Universite Laval.

Scarcella, R., \& Krashen, S. (Eds.). (1980). Research in second language acquisition. Rowley, MA: Newbury House.

Schumann, J., \& Stenson, N. (Eds.). (1974). New frontiers in second language learning. Rowley, MA: Newbury House.

Seliger, H. W. (1984). Processing universals in second language acquisition. In F. R. Eckman, L. H. Bell, $\&$ D. Nelson (Eds.), Universals of second language acquisition (pp. 36-47). Rowley, MA: Newbury House.

Selinker, L. (1969). Language transfer. General Linguistics, 9, 67-92.

Selinker, L. (1972). Interlanguage. In J. Schumann \& N. Stenson (Eds.), New frontiers in second language learning (pp. 114-136). Rowley, MA: Newbury House. Reprinted from IRAL, 10(3). 
Shimada, Y. (1987). The acquisition of English interrogatives by a Japanese speaker. JALT Journal, $8(1), 1-15$. (ERIC Document Reproduction Services No. ED 283398 )

Shopen, T. (Ed.). (1985). Language typology and syntactic description, volume 1, clause structure. Cambridge: Cambridge University Press.

Sobin, N. (1977). Notes on the acquisition of interrogative-word questions. Paper presented at Southwest Areal Languages and Linguistics Workshop. (ERIC Document Reproduction Services No. ED 144377 )

Syamala, V. (1991). Acquisition of English syntax by nonnative speakers: A case study of ESL learning by Malayalee children. Paper presented at the Regional Language Centre Seminar, Singapore. (ERIC Document Reproduction Services No. ED 338 080)

Tang, G. (1991). Do learning environments make a difference? A study on the acquisition of the English interrogative by three types of Cantonese classroom learners. CUHK papers in linguistics, 3, 49-82. (ERIC Document Reproduction Services No. ED $363101)$

Tarallo, F., \& Myhill, J. (1983). Interference and natural language processing in second language acquisition. Language Learning, 33, 55-76.

Tarone, E. (1979). Interlanguage as chameleon. Language Learning, 29, 181-191.

Tarone, E. (1988). Variation in interlanguage. London: Edward Arnold.

Thompson, A., \& Martinet, A. (1991). A practical English grammar. Oxford: Oxford University Press.

Ultan, R. (1978). Some general characteristics of interrogative systems. In J. H. Greenberg et al. (Eds.), Universals of human languages, volume 4, syntax (pp. 211-248). Stanford: Stanford University Press. 
Vander Brook, S., Schlue, K. \& Campbell, C. (1977). Discourse and second language acquisition of yes/no questions. In H. D. Brown, C. A Yorio, \& R. H. Crymes (Eds.), On TESOL '77: Teaching and learning English as a second language (pp. 178-193). Washington, DC: TESOL.

Wagner-Gough, J. (1978). Comparative studies in second language learning. In E. Hatch (Ed.), Second language acquisition: A book of readings (pp. 155171). Rowley, MA: Newbury House.

Wardhaugh, R. (1974). The contrastive analysis hypothesis. In J. Schumann \& N. Stenson (Eds.), New frontiers in second language learning (pp. 11-19). Rowley, MA: Newbury House.

Whitman, R., \& Jackson, K. (1972). The unpredictability of contrastive analysis. Language Learning, 22, 2941 .

Williams, J. (1989). Yes/no questions in ESL textbooks and classrooms. Issues and developments in English and applied linguistics, 4, 149-156.

wode, H. (1978). The L1 vs. L2 acquisition of English interrogation. Working Papers on Bilingualism, 15, $37-57$. 
Appendix A

Acronyms Used in this Thesis 
Appendix $A$

Acronyms Used in this Thesis

\begin{tabular}{|c|c|}
\hline Acronym & Meaning \\
\hline $\mathrm{AEI}$ & $\begin{array}{l}\text { Absolute Existence Interpretation. A way of } \\
\text { interpreting data that sets a certain } \\
\text { percentage as a criterion for ascertaining a } \\
\text { subject's control of a construction. }\end{array}$ \\
\hline $\mathrm{AH}$ & $\begin{array}{l}\text { Accessibility Hierarchy. A universal order, } \\
\text { established cross-linguistically by Keenan and } \\
\text { Comrie (1977), that describes the order of the } \\
\text { relativizability of Noun Phrase (NP) positions } \\
\text { in primary languages. }\end{array}$ \\
\hline $\mathrm{CA}$ & $\begin{array}{l}\text { Contrastive Analysis Hypothesis. A theory that } \\
\text { difficulties in learning a second language } \\
\text { arise as a result of interference or transfer } \\
\text { from one's first language. }\end{array}$ \\
\hline ESL & English as a Second Language. \\
\hline IL & $\begin{array}{l}\text { Interlanguage. The variable but systematic } \\
\text { speech of second language learners. }\end{array}$ \\
\hline L1 & First language, native language. \\
\hline $\mathrm{L} 2$ & Second language. \\
\hline NL & Native language. \\
\hline $\mathrm{N}$ & Noun. \\
\hline NP & Noun phrase. \\
\hline NNS & Non-native speaker. \\
\hline NS & Native speaker. \\
\hline PP & Prepositional phrase. \\
\hline Q TIU & $\begin{array}{l}\text { Typological Implication Universal for } \\
\text { interrogatives. A universal that states that } \\
\text { inversion in YNQs implies inversion in wHQs, } \\
\text { which, in turn, implies wH fronting, written } \\
\text { as: wH fronting, wH inversion) YN inversion. }\end{array}$ \\
\hline
\end{tabular}


Appendix A

Acronyms Used in this Thesis

(continued)

\begin{tabular}{|c|c|}
\hline Acronym & Meaning \\
\hline $\mathrm{RC}$ & Relative Clause. \\
\hline REI & $\begin{array}{l}\text { Relative Existence Interpretation. A way of } \\
\text { interpreting data that deems that each more } \\
\text { difficult structure of an implicational } \\
\text { universal must occur with a lower accuracy rate } \\
\text { than the easier structure preceding it. }\end{array}$ \\
\hline SLA & Second Language Acquisition. \\
\hline SOV & Subject-object-Verb basic word order. \\
\hline SVO & subject-Verb-object basic word order. \\
\hline TIU & $\begin{array}{l}\text { Typological Implication Universal. } \\
\text { typological universal that contains a sequence } \\
\text { of structures that are related in such a way } \\
\text { that the presence of a structure later in the } \\
\text { sequence implies the presence of all the } \\
\text { structures earlier in the sequence. }\end{array}$ \\
\hline TIU Q & $\begin{array}{l}\text { A question that can be analyzable according to } \\
\text { the TIU for interrogatives. }\end{array}$ \\
\hline $\mathrm{TL}$ & Target Language. \\
\hline UG & Chomskyan universals. \\
\hline UNAQ & $\begin{array}{l}\text { A question that is Unanalyzable according to } \\
\text { the TIU for interrogatives. }\end{array}$ \\
\hline VP & Verb phrase. \\
\hline WHQ & $\begin{array}{l}\text { WH Question. A question with a WH word, an } \\
\text { information word question. }\end{array}$ \\
\hline YNQ & $\begin{array}{l}\text { Yes-No Question. A question that seeks an } \\
\text { answer of "Yes" or "no." }\end{array}$ \\
\hline$+1-$ & $\begin{array}{l}\text { The presence or absence of a certain structure } \\
\text { or feature. }\end{array}$ \\
\hline
\end{tabular}


Appendix $B$

Summary of Category Names and Definitions 


\section{Appendix B}

Summary of Category Names and Definitions

\begin{tabular}{|c|c|}
\hline $\begin{array}{l}\text { Category } \\
\text { Name }\end{array}$ & Description \\
\hline UNAQ 1 & YNQs: Single words, isolated phrases. \\
\hline UNAQ 2 & $\begin{array}{l}\text { WHQs: WH word only, wH word + Single } \\
\text { word, wH word }+ \text { isolated phrases. }\end{array}$ \\
\hline UNAQ 3 & WHQs without verb or without subject. \\
\hline UNAQ 4 & YNQs without verb or without subject. \\
\hline UNAQ 5 & $\begin{array}{l}\text { Inappropriate first or second person } \\
\text { pronouns mixed in. }\end{array}$ \\
\hline UNAQ 6 & $\begin{array}{l}\text { Grammatically } \\
\text { unanalyzable due to English-specific } \\
\text { rules. }\end{array}$ \\
\hline UNAQ 7 & $\begin{array}{l}\text { Unanalyzable because of interviewing } \\
\text { problems. }\end{array}$ \\
\hline UNAQ 8 & Miscellaneous unanalyzable. \\
\hline UNAQ 9 & $\begin{array}{l}\text { wH question in intent, but without a wH } \\
\text { word, including echoes. }\end{array}$ \\
\hline$\ddot{T I U A}$ & YN uninverted. \\
\hline TIU B & YN inverted. \\
\hline TIU C & WH fronted, uninverted. \\
\hline TIU D & WH fronted, inverted. \\
\hline TIU Ea & WH unfronted, uninverted. \\
\hline TIU Eb & WH unfronted, inverted. \\
\hline TIU F & WH unfronted with subject or verb missing. \\
\hline
\end{tabular}


Appendix C

Story Squares: Basic Information, Complete stories, and Picture Grids 


\author{
Appendix $C$ \\ Story Squares: Basic Information, \\ Complete stories, and Picture Grids
}

\begin{abstract}
The following "Basic Information" and stories are from the teacher's manual for story Squares: Fluency in English as a Second Language by P. Knowles and R. Sasaki (1980) but have been greatly simplified from their original forms in order to be at a level appropriate for most of the subjects of this study. The "Basic Information" was given to the subject as the interviewer pointed to the appropriate pictures. The information in parentheses was optional; interviewers could give that information if they chose. The complete stories were for the interviewers' information only, so that they could answer the subjects' questions. The subjects did not seo the complete stories.
\end{abstract}

\title{
BASIC INFORMATION: STORY SQUARE 1 - TINA, JIM, PETER, $\underline{\text { JOHN }}$ \\ Box 1: This is Tina. In the past, Tina was a housewife.
}

Box 2: Last year, she got a job at a restaurant. She is a waitress. That's her job.

Box 3: Now she has a boyfriend.

Box 4: This is Jim. In the past, Jim was a high school student. He was a very good student.

Box 5: But last year, he stopped going to school. Now he does not go to school.

Box 6: Now he is a member of a motorcycle gang. He has joined a motorcycle gang.

Box 7: This is Peter. In the past, peter worked at this factory. (The factory is in the city of Baltimore.) He worked here.

Box 8: But last year, he moved to washington, DC. So now he lives in Washington, DC. 
Box 9: In washington, DC, Peter drives a taxi. That's his job. He's a taxi driver.

Box 10: This is John. In the past, John worked at this factory.

Box 11: But last year, there was an explosion at the factory. (The explosion hurt John.)

Box 12: Now John is in the hospital. (Maybe he can come out of the hospital after 3 months.)

COMPLETE STORY: STORY SQUARE 1 - TINA, JIM, PETER, JOHN

Tina and John are married. Jim is their son. They live in Baltimore, which is very near washington, DC. The factory where John works is also in Baltimore. In the past, Peter worked at the same factory as John. Although Peter and John worked at the same factory, they did not know each other well. But they had met each other; they were acquaintances. Peter met Tina when John and Tina came to the company's New Year party. Peter and Tina began seeing each other secretly, behind John's back.

Last year, Peter decided to kill John, so he made an explosion at the factory. The explosion hurt John very badly. John is still in the hospital in Baltimore, and he doesn't know that Peter made the explosion that hurt him. John doesn't know that Peter is Tina's boyfriend.

Peter was fired (lost his job) because the factory's boss thought that peter made the explosion because he wasn't careful. Everyone at the factory thinks the explosion was a careless accident. They don't know that Peter wanted to make the explosion, so Peter was not arrested by the police. After Peter lost his job, he moved to washington, $\mathrm{DC}$ and got a job as a taxi driver. He is dating Tina more openly now, and he's trying to save his money so that he can convince Tina to divorce John and marry him.

Because John was hurt and in the hospital, he couldn't work, so Tina got $a$ job in a restaurant as a waitress. Now Jim's parents are rarely at home--his father is in the hospital and his mother is at her job or with her boyfriend. So there is no one at home to take care of Jim and control or help him. Also, Jim is very angry that his mother has a boyfriend. Because of these 
problems, Jim dropped out of school and joined a motorcycle gang. Jim hates Peter. And he has lost all his respect for his mother. He's also very sad because his father is so sick.

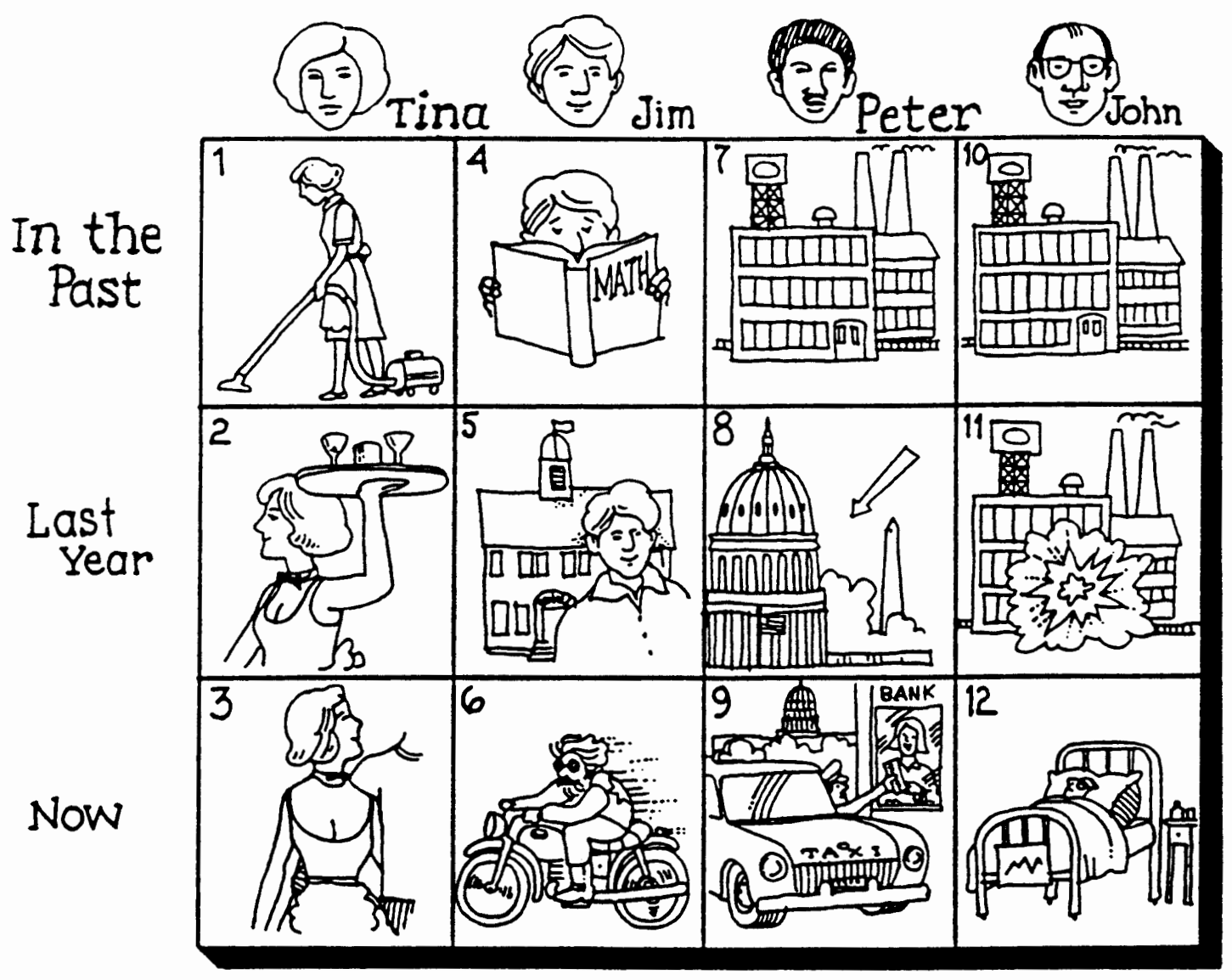

Basic information, story, and pictures adapted from Knowles, P. L. \& Sasaki, R. A. (1980). Story squares: Fluency in English as a second language. Cambridge, MA: Winthrop Publishers. 


\section{BASIC INFORMATION: STORY SQUARE 2 - SUE, PATTY, TOM}

Box 1: This is sue. Sue usually drinks Budweiser beer.

Box 2: But yesterday, sue drank a lot of alcohol. She drank two bottles of California wine, and she drank more alcohol.

Box 3: And now, today, sue is drinking orange juice!

Box 4: This is Patty. Patty is a student at UC. (UC means "University of California.") She is a student at University of California, UC.

Box 5: But yesterday, two bad guys came. The two bad guys kidnapped Patty.

Box 6: Now Patty has a gun, and she is trying to steal money from a bank.

Box 7: This is Tom. He lives in San Francisco. He is a taxi driver. That's his job. He's a taxi driver in San Francisco.

Box 8: Yesterday, Tom drove his taxi from san Francisco to Los Angeles.

Box 9: Now Tom is taking a vacation in Palm springs. Palm Springs is near Los Angeles. Palm Springs is an expensive vacation place. Tom is taking a very expensive vacation in Palm springs.

\section{COMPLETE STORY: STORY SQUARE 2 - SUE, PATTY, TOM}

Sue and Patty are students at UC (University of California). They don't know each other. They live in Berkeley, which is very near san francisco. They each have their own apartments. Tom lives in San Francisco. He's Sue's boyfriend, but sue and Tom don't have a good relationship.

Patty's father is very rich. The bad guys kidnapped Patty because they want money (for political purposes). They think Patty's father will give them a lot of money to get Patty back home again. The bad guys kidnapped 
Patty from her apartment and then they took her to san Francisco. In San Francisco, the bad guys and Patty got into Tom's taxi. The bad guys paid Tom to drive them to Los Angeles. Tom didn't know about the kidnapping. He didn't know the bad guys or Patty.

When they got to Los Angeles, the bad guys paid Tom the taxi fare and gave him a big tip. Tom now has a lot of money, so he decided to take a vacation in Palm Springs, which is an expensive vacation place near Los Angeles. Yesterday evening, Tom telephoned sue from Los Angeles and told her, "I am going to take a great vacation in Palm springs!" sue was very sad when he said that he was going to stay in Palm Springs for vacation without her! She thinks she will miss Tom a lot, and she is also envious of the nice vacation. Last night, after the phone call, Sue drank too much alcohol. This morning she has a very bad headache because of too much alcohol, so she's drinking orange juice.

Patty and the bad guys are at a bank right now. The bad guys want money, so they told Patty, "You must use this gun to steal money from the bank. If you don't steal money, we will kill you!" The bad guys also want the bank workers to see that Patty is alive because if her father knows that Patty is alive, he will send money to the bad guys, to try to make the bad guys let Patty go free. 


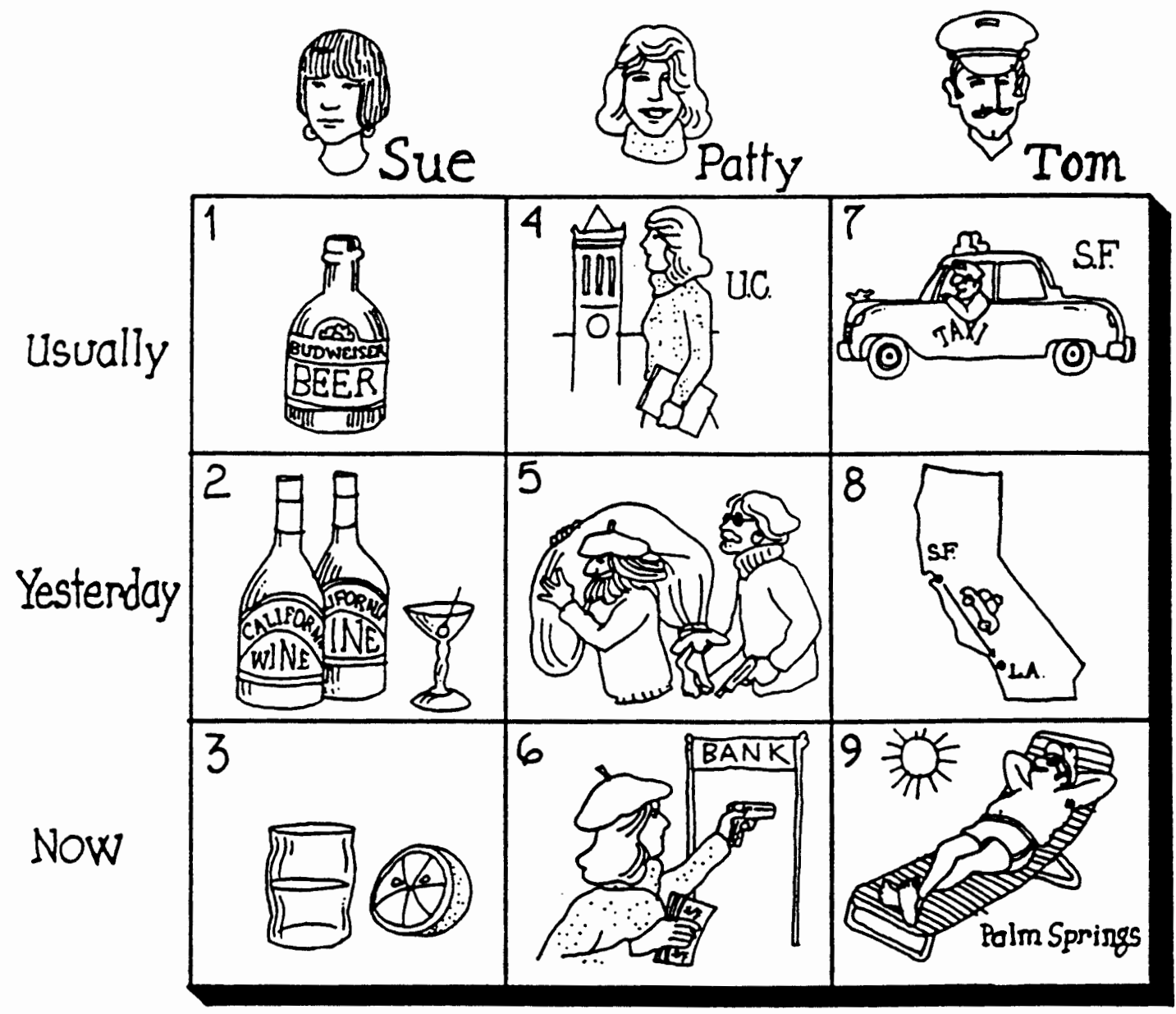

Basic information, story, and pictures adapted from Knowles, P. L. \& Sasaki, R. A. (1980) . Story squares: Fluency in English as a second language. Cambridge, MA: Winthrop Publishers. 

BASIC INFORMATION: STORY SQUARE 3 - PROFESSOR BROWN,
BORIS, CINDY

Box 1: Last week, professor Brown made a very important discovery. The discovery is "Top secret."

Box 2: Now she is reading a letter. The letter makes Professor Brown feel afraid. She is afraid because of the letter, and she doesn't know what to do.

Box 3: Next week she is going to go to an important meeting in Washington, DC.

Box 4: Last week, this man said to Boris, "You must go to America."

Box 5: Now Boris is in America. He is staying at a hotel in Houston, Texas.

Box 6: Next week, Boris may be dead.

Box 7: Last week, somebody paid Cindy a lot of money.

Box 8: Now Cindy has stopped working at her job, and she wants to travel around the world to visit many different countries.

Box 9: Next week, maybe Cindy will be in prison. or maybe she will taking a vacation in China.

COMPLETE STORY: STORY SQUARE 3 - PROFESSOR BROWN,
BORIS, CINDY

Professor Brown is a scientist. She works at the University of Houston, in Houston, Texas. Last week she made a big discovery. The discovery is important for the American government and the American army. Professor Brown talked to the American government about her discovery. The government said, "Shhh! This discovery is very important! It's a 'Top secret' discovery." The government sent policemen to Texas to protect Professor Brown. The policemen will protect Professor Brown until next week. Next week, Professor Brown will go to a 
meeting with American government leaders in washington, DC. At the meeting in Washington, DC, she will tell the government leaders everything about her discovery.

Cindy was Professor Brown's secretary. Last week, Cindy knew that Professor Brown made an important discovery. Cindy didn't understand the discovery, but she knew it was important. Cindy doesn't care about her country, so she telephoned a Russian government leader. She told the Russian leader that Professor Brown had made an important "Top Secret" discovery. When Cindy told the Russian government leader about the Top secret discovery, the Russian government paid a lot of money to Cindy. Now Cindy has a lot of money, so she stopped working. And now she's going to travel around the world.

When the Russians heard about Professor Brown's discovery, Russian government leaders sent Boris to America. Boris is a spy. Boris wants to understand everything about Professor Brown's discovery. Then he will tell the Russian government about the discovery. Then Boris will try to kill Professor Brown before the meeting next week. If Boris kills her, the American government will not have her discovery. Boris is staying at a hotel in Houston and has sent a letter to Professor Brown. The letter says, "You must meet with me secretly to talk about your discovery. If you don't meet with me, I will hurt your family." Professor Brown feels afraid because of the letter.

But the policemen read Boris' letter, and they asked Professor Brown to help them catch Boris. The policemen want Professor Brown to meet with Boris and help them catch him. But Professor Brown is worried about her family. She doesn't know what to do. If she helps the policemen, maybe the policemen will catch Boris. If the policemen catch Boris, Professor Brown and her family will be safe, and Boris may be killed. But if the policemen make a mistake and cannot catch Boris, then Boris will hurt Professor Brown or her family.

of course, because Cindy quit her job, the policemen think that she told the Russian government about the Top Secret discovery. So policemen are looking for Cindy at the airports. If they find her, they will put Cindy in prison. If they can't find her, she will probably be in China next week. 


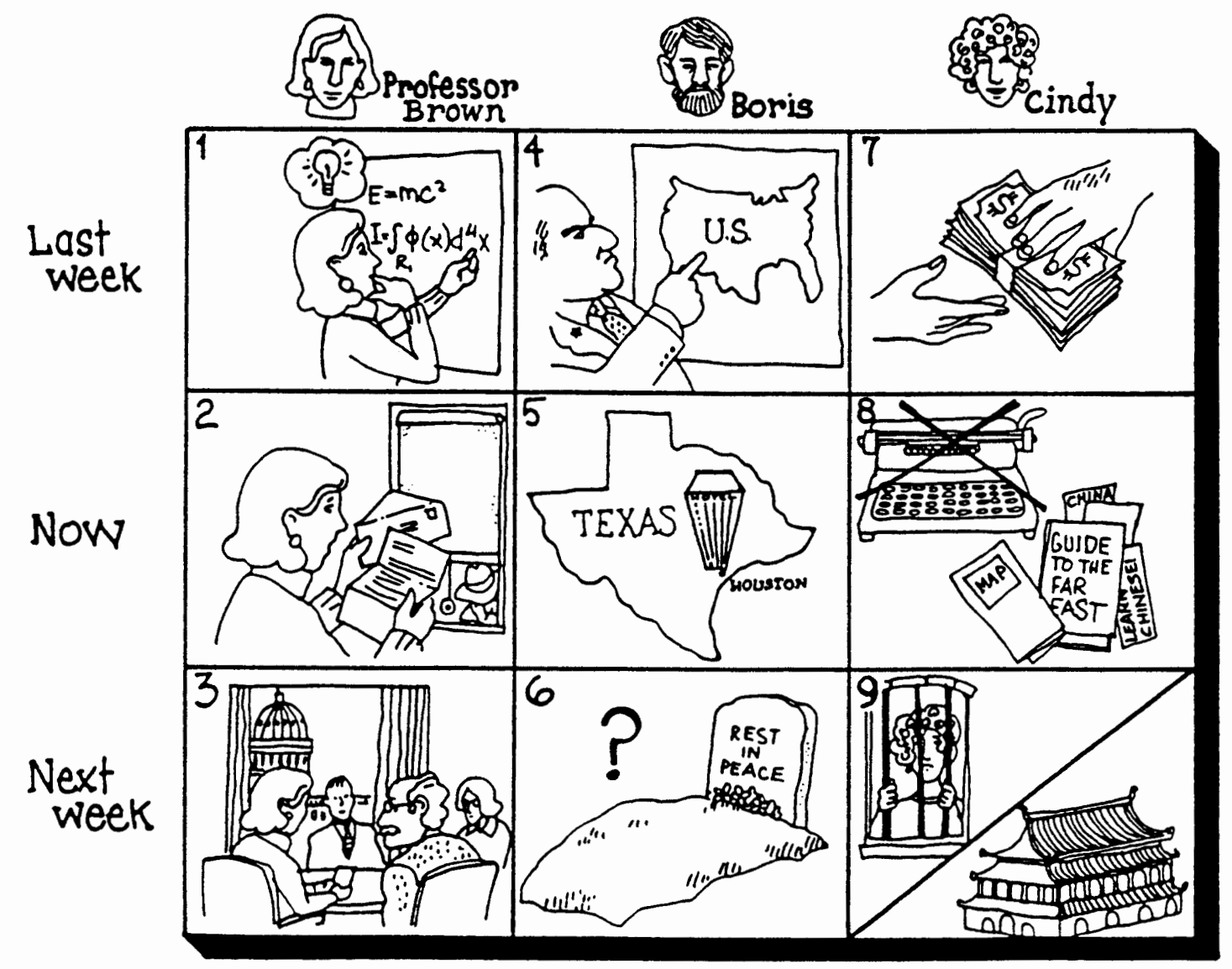

Basic information, story, and pictures adapted from Knowles, P. L. \& Sasaki, R. A. (1980). story squares: Fluency in English as a second language. Cambridge, MA: Winthrop Publishers. 
BASIC INFORMATION: STORY SQUARE 4 -JOHN, MR. PUFF, SAM, TONY

Box 1: Six months ago, John got a job.

Box 2: Last month, someone gave John some important information.

Box 3: Now his boss is telling John, "Congratulations! Good work!" Now John's boss will give him more money for his work. John's boss is giving him a raise. John will have a higher salary.

Box 4: Mr. Puff is the president of Puff Company. Six months ago, Mr. Puff's company's sales were very low. Mr. Puff's company was losing money. Mr. Puff was very worried about his company. Mr. Puff thought, "Maybe my company will go out of business. I don't want my company to go out of business! My company needs to sell more things! My company needs to get more money!"

Box 5: Last month, Mr. Puff's doctor told him to stop smoking.

Box 6: Now the police are taking him to the police office to ask him questions.

Box 7: Six months ago, sam was looking for a job. Then, he got a job.

Box 8: Last month, he was working on a special project at his new job.

Box 9: Now he has lost his job and is looking for a new job again.

Box 10: Six months ago, Tony got a phone call.

Box 11: Last month, Tony was on a news program on television. On the television, Tony talked about some new information. Tony's television report was controversial.

Box 12: Now he's working as a used car salesman. He sells used cars. That's his job. 
COMPLETE STORY: STORY SQUARE 4 - JOHN, MR. PUFF, SAM, TONY

Six months ago, Puff Cigarette Company (was in financial trouble) did not have enough money because the company was not selling enough cigarettes. Many people stopped buying cigarettes because scientists and government leaders said, "Smoking cigarettes is dangerous for your health." Many people stopped buying cigarettes because they wanted good health. Mr. Puff, the company's president, was worried. He did not want Puff Cigarette Company to go out of business. Mr. Puff wanted many people to buy cigarettes. Mr. Puff wanted to help his company.

So, six months ago, Mr. Puff telephoned Tony. Tony is the boss of NRC, a science research company. Mr. Puff paid Tony's company to do some research about smoking cigarettes and health. That's OK because NRC is a research company. But, Mr. Puff knew that smoking is dangerous to health. So he secretly paid more money to Tony. Mr. Puff paid a bribe to Tony. Mr. Puff wants Tony to be dishonest. He wants Tony to tell a lie in the research report and to say that smoking is not dangerous to health, so he secretly paid a bribe to Tony. Tony took the money and told Mr. Puff that his report will say good things about smoking.

Sam is a scientist. Tony hired sam, so sam was working at NRC. Last month, Sam was working on the research about cigarettes and health, but Tony did not tell Sam about Mr. Puff's bribe.

Last month, Tony talked on a television news program. On the news program, Tony said, "Don't worry, smoking is not dangerous to your health. It's oK to smoke!" Tony told a lie. When sam heard Tony's television news report, Sam thought, "Tony is not honest. Tony is telling a lie to everybody. My research said smoking is very dangerous!" So last month, Sam talked to a newspaper reporter, John. John is a new newspaper reporter. John listened to sam's story and understood that Tony told a lie on television. So John wrote a newspaper story about NRC's dishonesty.

When people read John's newspaper story, they understood that NRC told a lie. NOW NRC is out of business because no one wanted a dishonest company to do research. NRC is out of business, so sam doesn't have a job, and he's looking for a job again. Tony found a new job. Now he sells used cars. When the police read John's newspaper story, they thought, "Mr. Puff hired NRC to do research. Maybe Mr. Puff did something dishonest, 
too." So the police are taking Mr. Puff to the police station to ask him questions. John's boss at the newspaper company knows that John's story was true and stopped NRC's lie. So John's boss congratulated John and gave him more money (a raise).

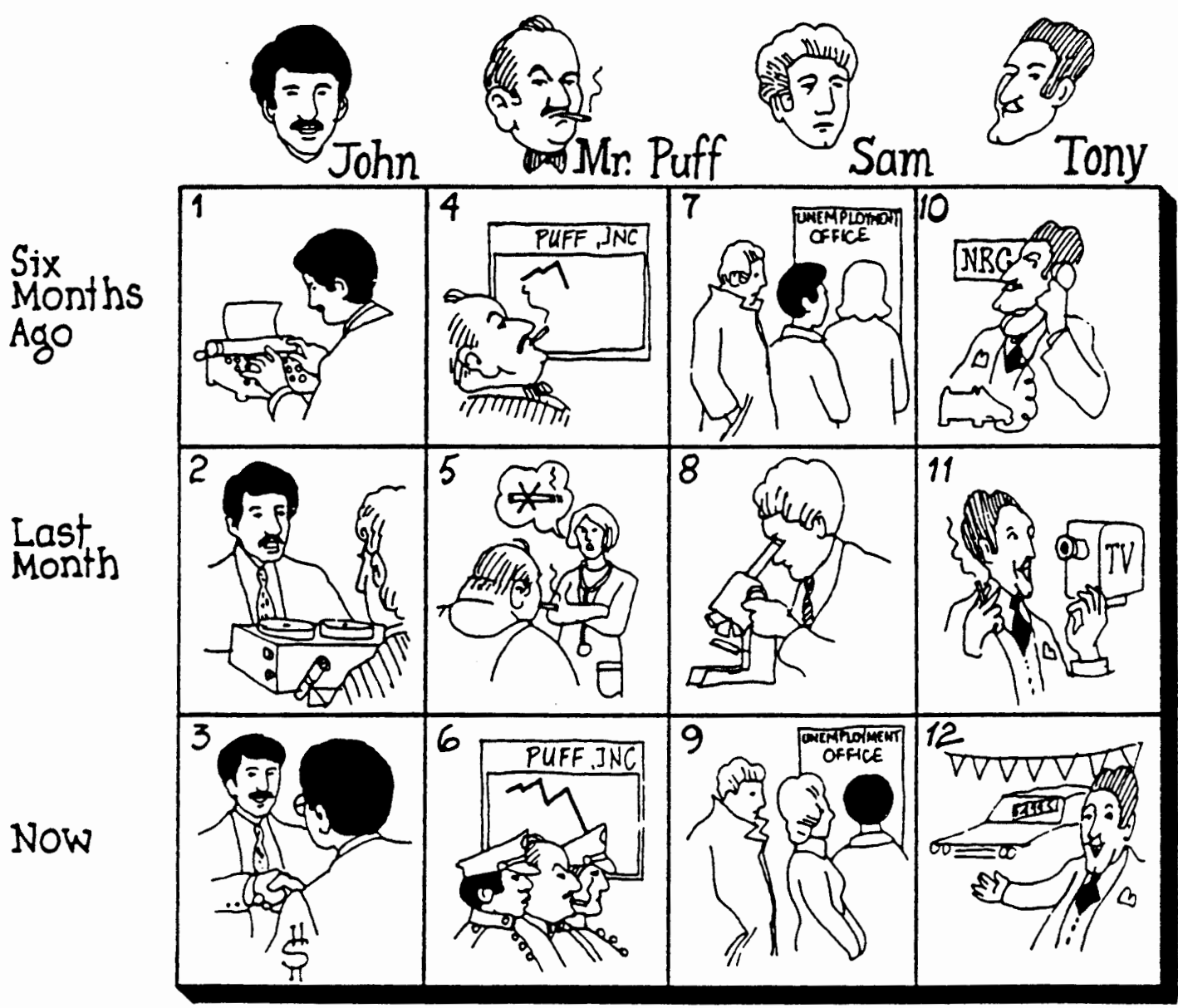

Basic information, story, and pictures adapted from Knowles, P. L. \& Sasaki, R. A. (1980) . story squares: Fluency in English as a second language. Cambridge, MA: Winthrop Publishers. 
BASIC INFORMATION: STORY SQUARE $5-$ KEN, JIMMY CHANG PROFESSOR SMITH, SAM

Box 1: The day before yesterday, Ken gave some flowers to his girlfriend.

Box 2: Yesterday, Ken and his father were fighting.

Box 3: In the middle of the night, Ken woke up and saw an Indian near his door.

Box 4: This morning, Ken is in class.

Box 5: The day before yesterday, Jimmy Chang was visiting Shasta Dam.

Box 6: Yesterday, Jimmy ate dinner at his hotel.

Box 7: In the middle of the night, Jimmy was trying to sleep.

Box 8: This morning, he went to the airport to catch a plane.

Box 9: The day before yesterday, Professor Smith was teaching a class.

Box 10: Yesterday, Professor Smith visited a grave.

Box 11: In the middle of the night, Professor Smith went to the bathroom.

Box 12: This morning, Professor smith is teaching a class.

Box 13: The day before yesterday, Sam was at a business meeting in Portland.

Box 14: Yesterday, he got on a train to go to Oakland, California.

Box 15: In the middle of the night, he was sleeping. Box 16: This morning, he was dead. 
\begin{tabular}{lcccc}
\hline COMPLETE & STORY: & STORY & SQUARE $5-$ KEN, JIMMY CHANG \\
\hline PROFESSOR & SMITH, SAM & &
\end{tabular}

Sam is a successful businessman in Portland. Ken is his son, and Ken is a student at the University of California, in Davis. Ken and his father don't get along. His father wants Ken to become a businessman, too, but Ken wants to become a professor.

The day before yesterday, Sam's company had a business meeting. Sam said to Ken, "You must leave California and come to the business meeting in Portland." Ken came to Portland, but he did not go to the business meeting. He went to visit his girlfriend. Ken's father was very angry because Ken did not go the meeting. They had a big fight. Then sam and Ken got on the train to go to California. Sam was going to another business meeting in Oakland. Ken was going back to university in Davis.

Jimmy Chang is an archery teacher from Hong Kong. Early this morning, he got on the same train in Redding. He got off the train in Oakland. Then he went to san Francisco to catch a plane back to Hong Kong.

Professor Smith teaches Asian history at the University of California, in Davis. The day before yesterday, she taught a class at University of oregon in Eugene. Yesterday, she went to Portland and visited her sister's grave. Then she got on the same train to go back to Davis. This morning, she was teaching class at University of California again. Ken was in her class.

Professor Smith and Jimmy Chang murdered Sam, for revenge. Professor Smith's father worked in Hong Kong, so she and her sister grew up in Hong Kong. The two sisters and Jimmy studied archery together and were good friends. Professor Smith's sister came to America to marry Sam. She had a son, Ken. Then her husband killed her to get her money. The police thought maybe sam killed his wife, but they didn't know for sure.

On the night of Sam's murder, Professor smith dressed in Indian clothes. She and Jimmy killed sam with three arrows, one for Jimmy, one for Professor Smith, and one for her sister. Then Jimmy went back to his room. Professor Smith went near Ken's room and made a lot of noise to wake him up. Then she went to the bathroom, took off the Indian clothes, and threw them out the train window. (Professor Smith used the Indian clothes to make the police confused. Professor Smith does not want the police to think, "Ken killed his father." She made sure to wake ken up so that he saw the "Indian." Then, in court, Ken will say, "I saw an Indian." In court, Professor Smith and Jimmy will also 
say they saw an Indian in the night. The police will think that an Indian killed Sam.)

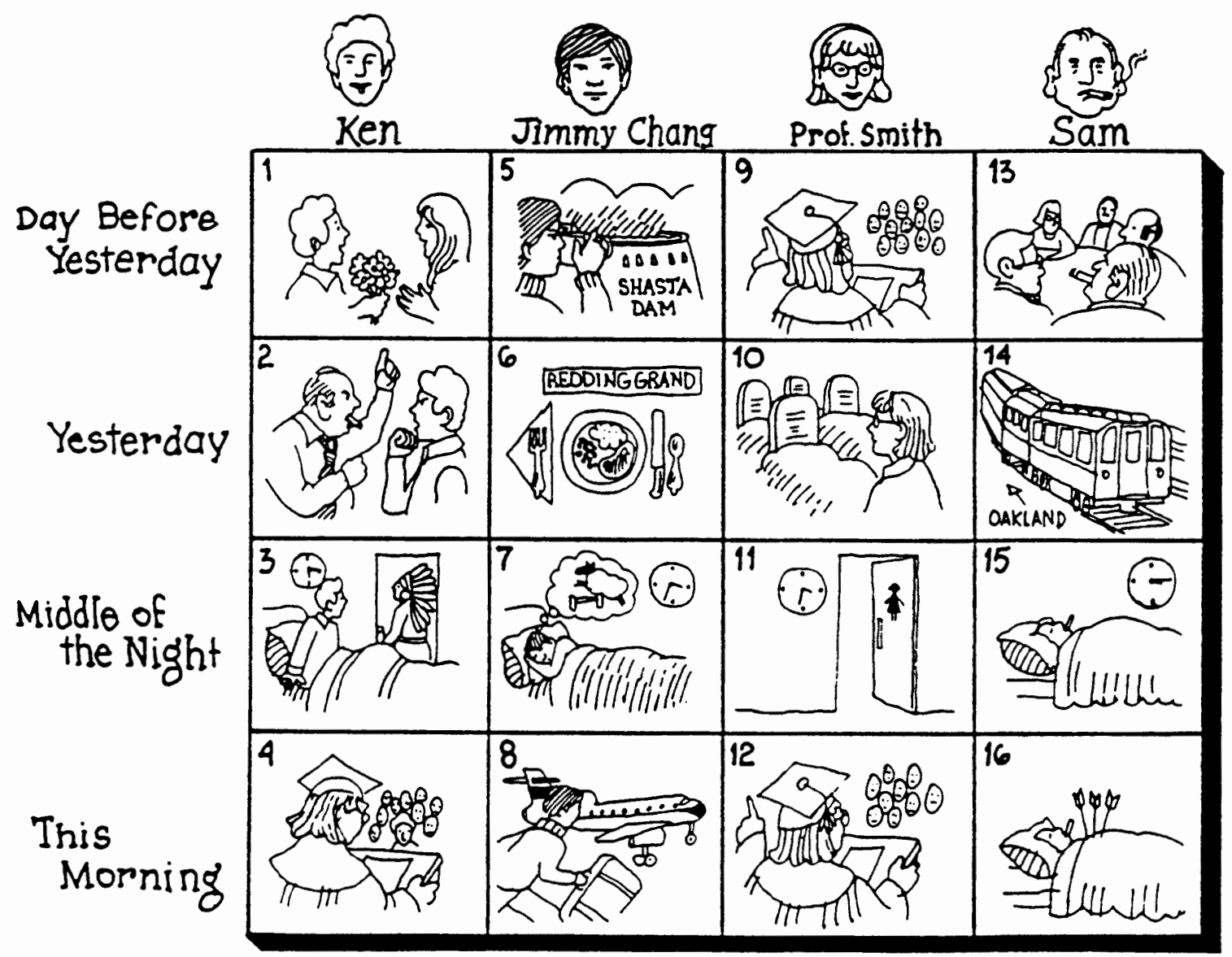




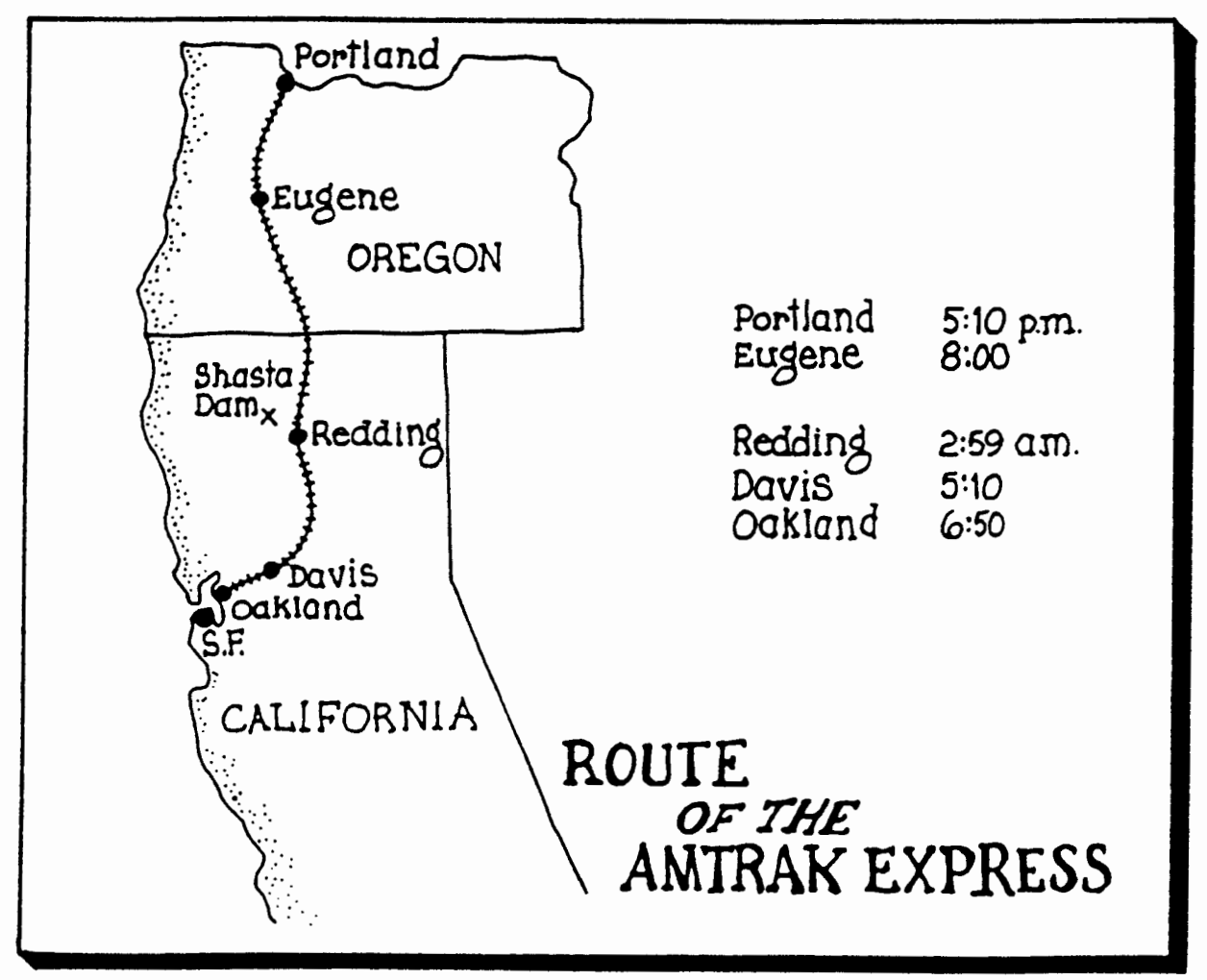

Basic information, story, and pictures adapted from Knowles, P. L. \& Sasaki, R. A. (1980). Story squares: Fluency in English as a second language. Cambridge, MA: Winthrop Publishers. 
Appendix $D$

Story Square Instructions 
Appendix $D$

\title{
story Square Instructions
}

\begin{abstract}
Below are the instructions for interviewers and subjects. These instruction sheets were used by the interviewer to give instructions to each subject during the individual interviews. The actual words spoken to each subject may have varied slightly from the prescribed form below because the interviewers were free to repeat, simplify, or elaborate in order to aid the subjects' comprehension of the instructions. However, such variation was rarely necessary since subjects had all participated in or watched a practice session prior to beginning their individual sessions.
\end{abstract}

INSTRUCTION SHEET: Procedures for the story square puzzles with individual students.

Note: Instructions to the interviewer are in brackets []. Instructions to give to the students are numbered and bolded.

\section{A - SMALL TALK:}

[Don't ask any questions! Avoid asking questions! Try to make your speech to the student be only statements or words. Try to help the student feel comfortable and relaxed. If the student seems nervous, tell her not to worry and to have fun.]

1. Please tell me

your name

about your family

about your host family

about your hobbies

[Offer information about yourself as a model, if needed.]

[Have students talk about one or more of these topics for a very short time. It's not important to talk about all of them. It is important for me to have about 5-10 complete sentences from the student.] 
B -- STORY SQUARE PUZZLES:

[Show student the first Story square pictures. Use vocabulary cards as needed.]

2. I want to talk about these pictures. These are puzzle pictures.

Together all these pictures make one story. OK? There are connections between all the pictures. These pictures make a mystery story.

I want you to try to find the answer to the mystery. So please ask me many questions to understand/discover/solve/find the mystery story. You are the detective! After you ask many questions, maybe 100 questions!!, you will discover the mystery.

3. [Give BASIC INFORMATION here.] (See Appendix C.)

4. OK! Please try to find the connections between the pictures.

Ready? Please ask about the mystery pictures. Try to find the story!

5. [After the student discovers the story] Great! You found the mystery! Ready for another Mystery Picture Puzzle? [OR] Thank you very much! But SHнHнH! It's a secret. Don't tell another student! SECRET!!

\section{C -- INSTRUCTIONS FOR SPECIFIC CASES:}

1. [If the student seems to be really struggling to make "perfect" questions, you could say the following:]

Don't worry about good questions or bad questions or crazy questions. Any question is OK!! I want to know how quickly/fast you can discover the mystery.

2. [If the student needs a hint, don't give example questions!! Give hints such as]

Ask a question about this girl. [OR]

Sue and Tom - friends? brother and sister? married?

[You can also give hints about the information from the story, if needed. Just don't give away the whole story! They need to have plenty of information to ask about!] 
3. [If students ask a question that will give away the whole story right at the beginning, give only part of the answer or tell them,]

That's a very good question! Very important! Remember this question and ask it again later!

4. [If the student didn't speak about 5-10 sentences at the beginning, then, once the story is discovered, instruct the student:]

OK, now tell me about Tina [or any other character].

5. [If the student asks "one-word" or short questions such as, "Married?" "Stopped school?" "Good?" "Boyfriend and girlfriend?" "Why angry?" "Tom's girlfriend?", answer the first few, just so the student doesn't stop asking questions completely. But after that, if possible, tell the student, ]

Good idea, but please make a longer question, not only one word.

6. [I want to try to have at least 10 Yes-No questions and 10 WH-questions, but I don't need equal amounts of both kinds. If you think the student has made about 10 WH-questions, don't give the instructions below at all. However, if the student has been asking only Yes-No questions, show her the "Who, what, which, when, where, why, how" card and say,]

Maybe these words can help you. 
Appendix $E$

The 64 Original "Problem" Categories and their Final Classifications 


\section{Appendix E}

\section{The 64 Original "Problem" Categories and their Final Classifications}

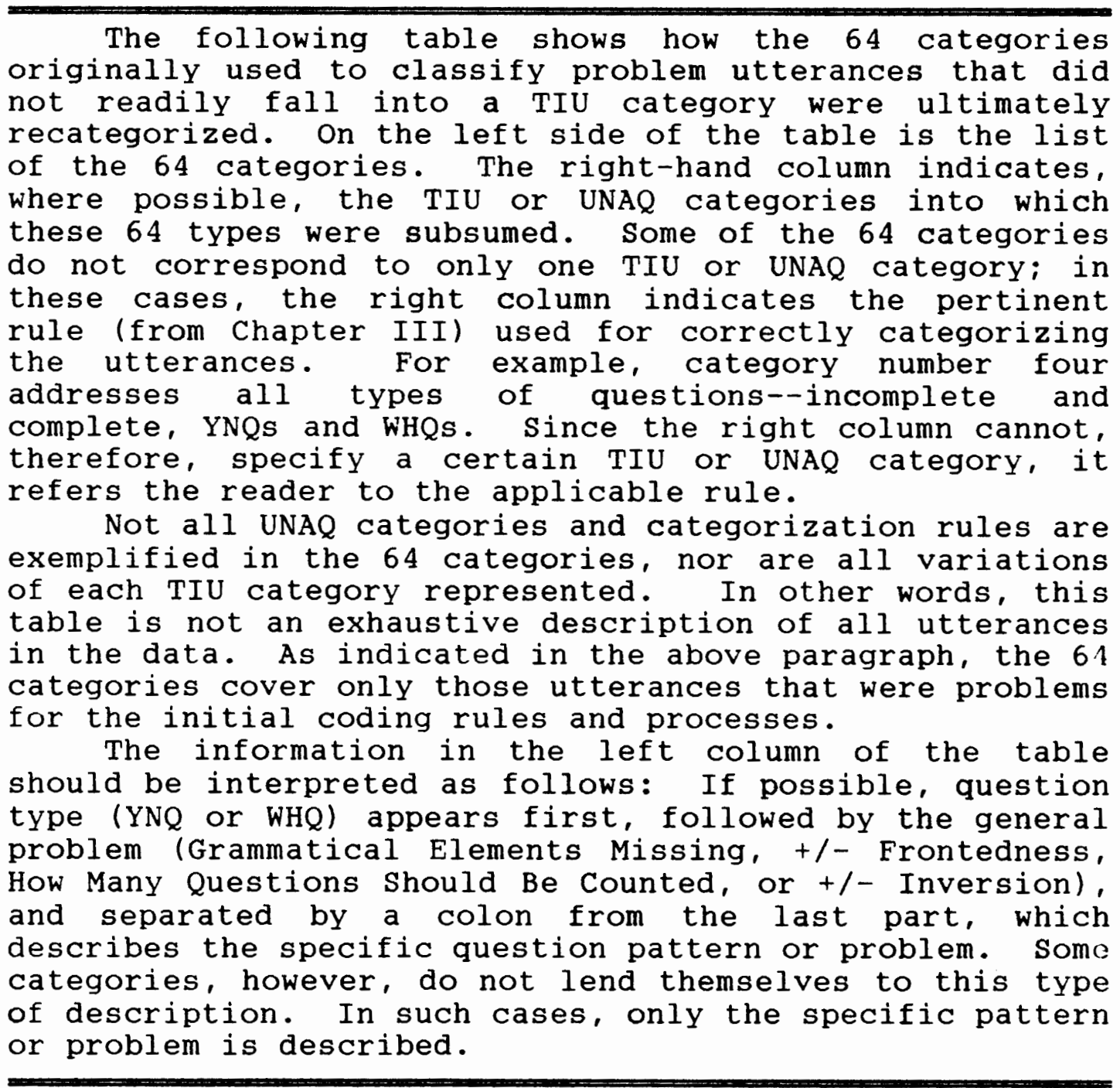


Table E

The 64 Original "Problem" Categories and their Final Classifications

Original 64 "Problem" Categories

Subsuming

Category/Rule

1. YNQ Grammatical Elements

Missing: Echoes of part of

interviewer's previous utterance

2. WHQ +/- Frontedness: Unfronted, controlled and NS-like

3. WHQ Grammatical Elements UNAQ 2

Missing: One word, WH word only

4. How Many Questions should Be

Counted: Repeat same question structure, but with different lexical

items in adjacent utterances

5. Explosion as a verb

\section{TIU A - F \\ see Chapter \\ III, \\ "Additional \\ Considera- \\ tions \\ Concerning \\ Analyzable \\ Questions"}

6. WHQ Grammatical Elements

Missing: Controlled and NS-like

UNAQ 2

(Which state? How about Jim?)

7. YNQ Grammatical Elements

Missing: Noun (N) only

UNAQ 1

8. WHQ +/- Inversion: Uninverted

UNAQ 6

because it is a question about the

subject of the sentence

9. How Many Questions should Be

Counted: False start series with two

Rule 2 or more complete questions 
Table E

The 64 Original "Problem" Categories and their Final Classifications (continued)

\begin{tabular}{|c|c|}
\hline Original 64 "Problem" Categories & $\begin{array}{l}\text { Subsuming } \\
\text { Category/Rule }\end{array}$ \\
\hline $\begin{array}{l}\text { 10. WHQ Grammatical } \\
\text { Missing: No verb }\end{array}$ & UNAQ 3 \\
\hline $\begin{array}{l}\text { 11. YNQ Grammatical Elements } \\
\text { Missing: } N \text { or NP only, not echo }\end{array}$ & UNAQ 1 \\
\hline $\begin{array}{l}\text { Interviewer supplies unknown } \\
\text { vocabulary word to complete subject's } \\
\text { question }\end{array}$ & Rule 5 \\
\hline $\begin{array}{l}\text { 13. WHQ Grammatical } \\
\text { Missing: Missing more than just the } \\
\text { verb }\end{array}$ & UNAQ 2 \\
\hline $\begin{array}{l}\text { 14. YNQ +/- Inversion: Because- } \\
\text { clause question, uninverted as in NS } \\
\text { rules }\end{array}$ & UNAQ 6 \\
\hline $\begin{array}{l}\text { 15. WHQ }+1-\text { Frontedness: Unfronted, } \\
\text { following a Because-clause question } \\
\text { (see } 14, \text { above) (...or why? Only one } \\
\text { instance) }\end{array}$ & UNAQ 2 \\
\hline $\begin{array}{l}\text { 16. Unique, unpatterned questions } \\
\text { not easily categorized, requiring } \\
\text { individual attention later }\end{array}$ & $\begin{array}{l}\text { TIU A }-F \text { or } \\
\text { UNAQ } 1-9\end{array}$ \\
\hline $\begin{array}{l}\text { 17. WHQ Grammatical } \\
\text { Missing: No subject (wH word }+ \text { verb) }\end{array}$ & UNAQ 3 \\
\hline $\begin{array}{l}\text { 18. Second half of an alternative } \\
\text { question }\end{array}$ & UNAQ 1 \\
\hline $\begin{array}{l}\text { 19. How Many Questions should Be } \\
\text { Counted: Repeat almost exactly same } \\
\text { question, with same meaning }\end{array}$ & Rule 1 \\
\hline
\end{tabular}


Table E

The 64 Original "Problem" Categories

and their Final Classifications

(continued)

Original 64 "Problem" Categories

subsuming

Category/Rule

20. How Many Questions should Be
Counted: Difficult to determine
whether the utterance represents a
false start or two separate questions

21. YNQ Grammatical Elements

Missing: Because + PP, NS-like

22. YNQ +/- Inversion: But + uninverted YNQ

Rule 2

23. YNQ +/- Inversion: But + inverted $Y N Q$

24. YNQ +/- Inversion: Uninverted, followed by right?

25. YNQ Grammatical Elements

Missing: PP only, NS-like

26. YNQ +/- Inversion: Auxiliary inverted with verb and left in place

27. WHQ +/- Inversion: Started without inversion, then selfcorrected to be inverted, but without repeating the WH word

28. YNQ uninverted, Angry as a verb

29. YNQ Grammatical Elements

Missing: No subject

30. +/- Inversion: False start, inverted at first, but then self"corrected" to be uninverted

31. WHQ Why Jim angry?

IU A, see

Rule 17

TIU A, see \#5, above

TIU D, see Rule 20

TIU A, see

Rule 15

TIU B, see

Rule 15

UNAQ 6, see

Rule 16

UNAQ 1

UNAQ 4

TIU A or C, see Rule 18

TIU C 
Table E

\section{The 64 Original "Problem" Categories and their Final Classifications \\ (continued)}

Original 64 "Problem" Categories

Subsuming

Category/Rule

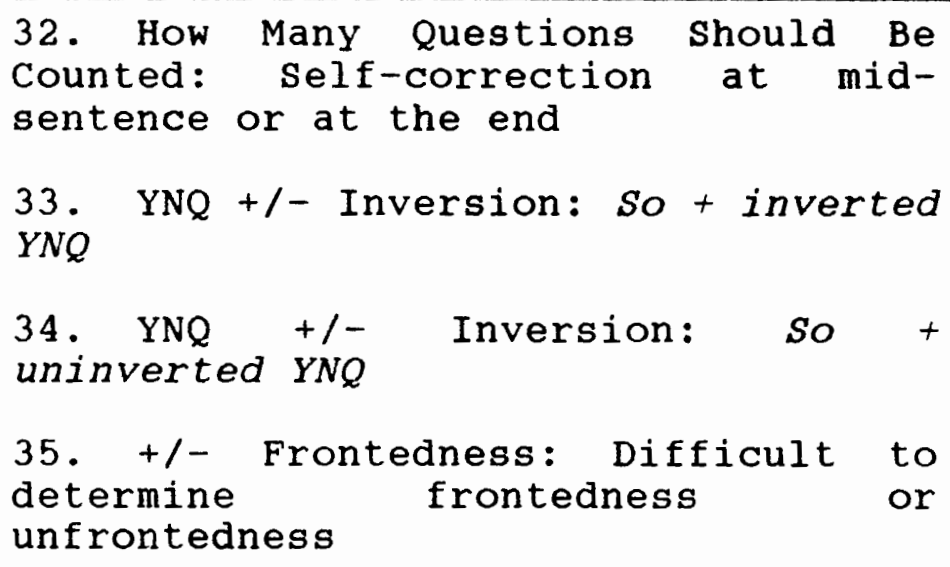

32. How Many Questions should Be Counted: Self-correction at mid33. YNQ + /- Inversion: So + inverted 34. YNQ +/
uninverted YN
35. +1- Fro
determine
unfrontedness

to or
TIU B, see Rule 15

TIU A, see Rule 15

TIU C - F, see Chapter III,

"Unfronted

WH

Utterances"

Rule 5
36. How Many Questions should Be different structure but the same meaning because interviewer said, "Pardon me?"

37. YNQ +/- Inversion: Uninverted, but could be NS-like because of surprise or for clarification

38. YNQ Grammatical Elements Missing: No verb

39. WHQ about the subject of the sentence has an appearing auxiliary

40. Multiple false starts and perhaps no codeable utterances at all
TIU A, see

Rule 15

UNAQ 4

UNAQ 6

If no codeable ut terances at all, UNAQ 8 
Table $E$

\section{The 64 Original "Problem" Categories and their final Classifications (continued)}

Original 64 "Problem" Categories

41. +/- Inversion: Auxiliary is inverted, but there is no main verb

42. Second person pronoun is used inappropriately in question

43. YNQ +/- Inversion: Tag question

44. YNQ Grammatical Elements Missing: One word only, but not a $N$

45. How Many Questions should Be Counted: Repeat same simple question structure nearby, but with a different meaning

46. WHQ +/- Inversion: Auxiliary inverted with verb and left in place

47. YNQ How Many Questions should Be Counted: Subject starts a question, but abandons it without completing it

48. WHQ How Many Questions should Be Counted: Subject starts a question. but abandons it without completing it

49. Angry as a verb

50. Sad as a verb

51. How Many Questions should Be Counted: Repeat same question with same meaning, very nearby
Subsuming

Category/Rule
TIU B or D, see Rule 23

UNAQ 5

UNAQ 6

UNAQ 1

Rule 1

TIU C, see Rule 17

UNAQ 8

UNAQ 8
TIU A $-F$, see \#5, above

TIU A - F, see \#5, above

Rule 1 
Table E

The 64 Original "Problem" Categories

and their Final Classifications

(continued)

Original 64 "Problem" Categories

Subsuming

Category/Rule

52. +/- Inversion: Difficult to determine whether initial auxiliary represents inversion or a false start

53. Question finished after intervening input from interviewer

54. Aberrant word order, difficult to determine correct coding

TIU A - F or

UNAQ 8 , see

Rules $2-4 \&$

18

55. How Many Questions should Be Counted: Question finished with gesture, non-lexical sound, or Japanese

56. How Many Questions Should Be Counted: After interviewer's direction to "make a question"

57. YNQ Grammatical Elements Missing: No subject, no verb

Rule 5

58. Mm?, Ah?, Eh?, etc.

TIU A - F or UNAQ 8

Rule 6

59. WHQ Grammatical

Elements

Missing: No subject or verb

Rule 5

60. Subject reads a question from the dictionary

61. WHQ unfronted, but could also be counted as uninverted

62. Discovery as a verb

TIU A - F, see \#5. above 
Table $E$

The 64 Original "Problem" Categories and their Final Classifications (continued)

Original 64 "Problem" Categories

Subsuming

Category/Rule

63. Connection as a verb

TIU A - F, see \#5, above

64. WHQ unfronted, also with grammatical elements missing or other word order problems

TIU E or, if grammatical elements missing, TIU F 
Appendix $F$

Transcript Conventions and Sample Transcript 


\section{Appendix $F$ \\ Transcript Conventions and sample Transcript}

The transcript of subject 20 was chosen primarily because it had relatively large numbers of YNQs and WHQs, both inverted and uninverted, as well as utterances from most UNAQ categories. Other factors considered in the its choice were that the interview was by the primary interviewer, it was of average length, it involved the two story squares most commonly used, and the subject followed the TIU.

Several types of symbols are used in the transcript. The following table identifies the symbols and explains their significance.

Table F

The Meaning of Transcription symbols

\begin{tabular}{|c|c|}
\hline Symbol & Meaning \\
\hline\{\} & enclosed words are whispered \\
\hline $\begin{array}{l}? \text { (at the end } \\
\text { of a sentence) }\end{array}$ & $\begin{array}{l}\text { question intonation or unmistakable } \\
\text { question in the context of the discourse }\end{array}$ \\
\hline [D] & declarative follows. \\
\hline $1 ? /$ & $\begin{array}{l}\text { word or utterance is not clear enough to } \\
\text { transcribe }\end{array}$ \\
\hline- & $\begin{array}{l}\text { subject or interviewer interrupts } \\
\text { himself/herself }\end{array}$ \\
\hline$? ? \quad ? ?$ & $\begin{array}{l}\text { items enclosed are not clear enough to be } \\
\text { sure of the transcription }\end{array}$ \\
\hline OK (code) & $\begin{array}{l}\text { declarative utterances, transcription } \\
\text { notes, actions, etc., that do not require } \\
\text { a TIU or UNAQ code }\end{array}$ \\
\hline [ ] & $\begin{array}{l}\text { enclosed words are explanations, actions, } \\
\text { transcription notes or other non-verbal } \\
\text { information }\end{array}$ \\
\hline
\end{tabular}


Table $F$

The Meaning of Transcription Symbols (continued)

\begin{tabular}{|c|c|}
\hline Symbol & Meaning \\
\hline $\begin{array}{l}\text { [vocabulary } \\
\text { card] }\end{array}$ & $\begin{array}{l}\text { an English/Japanese vocabulary card with } \\
\text { a pertinent word was placed on the table }\end{array}$ \\
\hline 11 & $\begin{array}{l}\text { enclosed words/utterances are } \\
\text { phonetically transcribed as accurately as } \\
\text { recording allowed }\end{array}$ \\
\hline etc. & $\begin{array}{l}\text { interviewer continued talking about the } \\
\text { preceding topic until the subject } \\
\text { expressed understanding }\end{array}$ \\
\hline 1 & $\begin{array}{l}\text { enclosed words were spoken by the } \\
\text { interviewer }\end{array}$ \\
\hline - & $\begin{array}{l}\text { When immediately following a word, } \\
\text { without an intervening space, a } \\
\text { punctuation mark. } \\
\text { When placed after a word with space } \\
\text { intervening, a pause longer than } \\
\text { subject's normal between-word or between- } \\
\text { sentence pause. Multiple dots indicate } \\
\text { longer pauses. }\end{array}$ \\
\hline $\begin{array}{l}\text { (under- } \\
\text { lining) }\end{array}$ & $\begin{array}{l}\text { When a single conversation turn of the } \\
\text { subject contains multiple utterances, } \\
\text { each requiring separate coding, the } \\
\text { entire turn is copied onto consecutive } \\
\text { lines, with a different utterance } \\
\text { underlined in each line. The underlined } \\
\text { words correspond to the coding to the } \\
\text { left. (This convention holds } \\
\text { invariably in the transcripts. Note that } \\
\text { in the text of the research paper, } \\
\text { however, underlining in example } \\
\text { utterances may also function to simply } \\
\text { point out the part of the } \\
\text { utterance relevant to the applicable } \\
\text { explanation.) }\end{array}$ \\
\hline
\end{tabular}


Further explanatory information about the transcript is listed here:

1. As in all transcripts, interviewer's answers are often abbreviated to include only the basic idea of the answer. This is particularly true of the lowest level subjects because, with all the pauses, repetitions, explanations, gestures, etc., necessary to simplify the information for their comprehension, the interviewer's answers could become quite lengthy. However, when the wording of the interviewer's answer somehow affects the subject's next utterance, or the interviewer inadvertently produced an utterance in question form, the interviewer's answer is transcribed verbatim.

2. As in all transcripts, the initial warm-up prompts by the interviewer were not transcribed and the subject's utterances, though transcribed verbatim, were not numbered until the subject asked the first question.

3. Some line numbers appear more than once, differentiated by letters and with different parts of the utterance underlined. Each underlined part was counted as a separate question. This combination of line numbers and letters resulted from the fact that, in some cases, the initial line numbering did not reflect the multiple and separate questions, which are in the same conversational turn, and it was not possible to change the numbering at the point at which the questions were separated.

4. Numbers, OK, or TIU $X$ at the far left side indicate the coding for the subject's utterance under consideration.

5. Hyphenated numbers in the second column on the left indicate subject number and utterance number. "020-001" represents subject number 20 , utterance number one. 
TRANSCRIPT OF SUBJECT 20

[The following sentences are the subject's responses to the ice-breaker warm-up.]

My name is [Subject states name]. My hobbies are play basketball and listen to the music. (What kind of music?) Pop. My favorite music is oldies, classic. (Classical like Beethoven?) No! Abba. Got to be Real. (I don't know that one. I feel very old because Abba was popular when I was young, etc.)

[Interviewer gives instructions. See Appendix D.]

[Interviewer gives basic information. See Appendix C.]

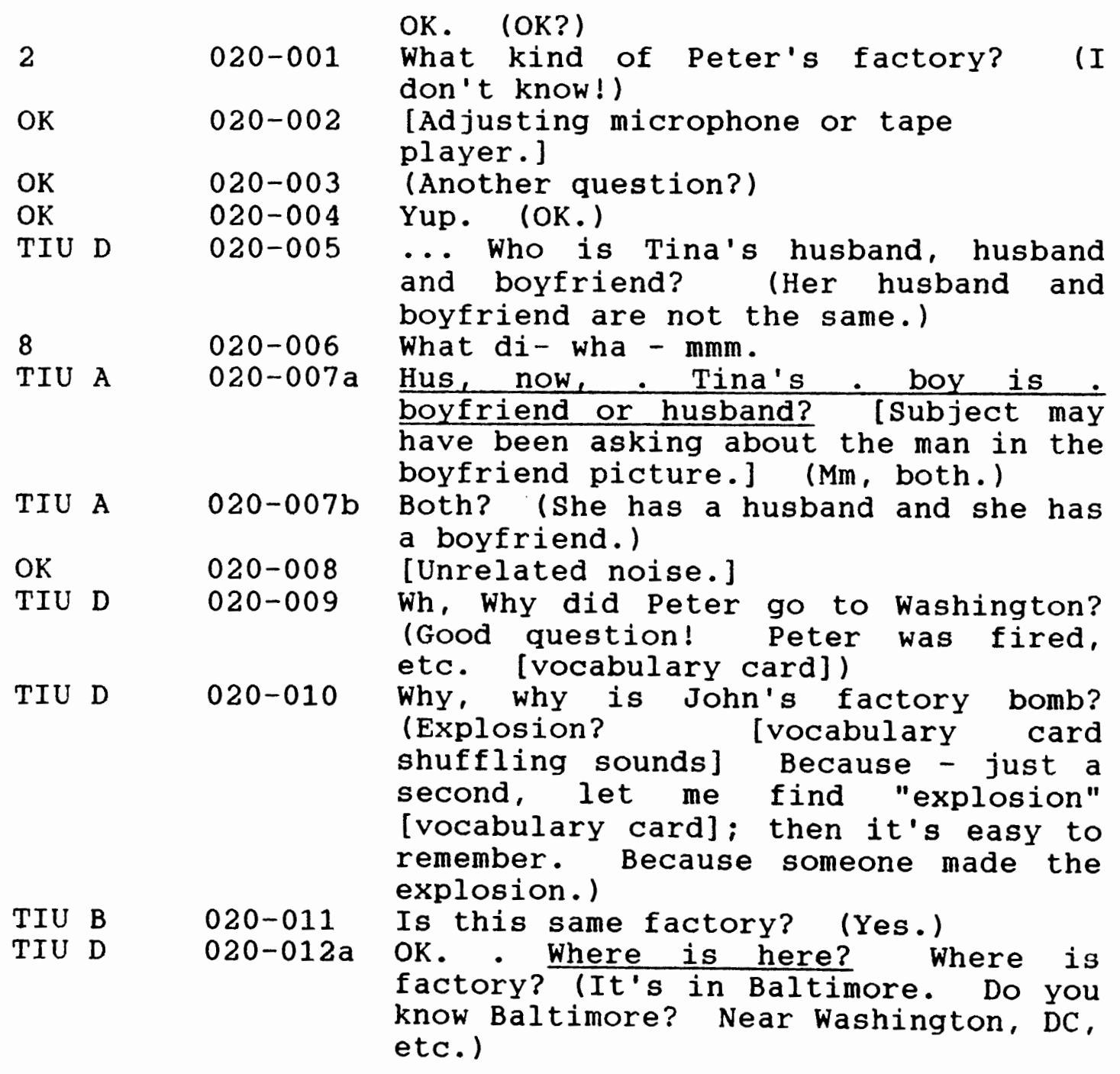




\begin{tabular}{|c|c|c|c|}
\hline IU & D & $020-012 b$ & $\begin{array}{l}\text { OK. Where is here? where is } \\
\text { factory? (It's in Baltimore. Do you } \\
\text { know Baltimore? Near Washington, DC, } \\
\text { etc.) }\end{array}$ \\
\hline IU & A & $020-013 a$ & $\begin{array}{l}\mathrm{mmm} \\
\mathrm{mmm} \text { - Where, where, umm, I- This is housekeeper? mm? } \\
\text { This is, what is this, what? (Hmm?) }\end{array}$ \\
\hline & $\mathrm{D}$ & $020-013 b$ & $\begin{array}{l}\mathrm{mmm} \\
\mathrm{mmm} \text { - Where, where, umm, }- \text { Thina } \\
\text { This is, What is this, what? (Hmm?) }\end{array}$ \\
\hline & D & $020-014$ & $\begin{array}{l}\text { Where is } \text { Tina's, Tina's work, } \\
\text { workplace in the past? (In this } \\
\text { picture? } \\
\text { picture]) }\end{array}$ \\
\hline & & $020-015$ & Yes. (Her house.) \\
\hline & D & & $\begin{array}{l}\text { Where? Where is her house? (In } \\
\text { Baltimore.) }\end{array}$ \\
\hline & A & $020-017$ & $\begin{array}{l}\text { OK } \cdots \text { Tina, Tina likes Peter and } \\
\text { John? (She likes one of them.) }\end{array}$ \\
\hline & D & $020-018$ & $\begin{array}{l}\text { Who is Tina's, who is } \\
\text { like, who is. Tina likes? (Peter!) }\end{array}$ \\
\hline & & $020-019$ & $\begin{array}{l}\text { Peter. } \quad(\mathrm{Mm}-\mathrm{hm} .) \\
\text { OK. }\end{array}$ \\
\hline & D & $20-0$ & $\begin{array}{l}\text { Wh. What, what do you th-, ah, } \\
\text { What do th, what is John think about } \\
\text { Peter? (Mm. John and Peter work } \\
\text { together at the same factory. John } \\
\text { thinks Peter's a nice guy.) }\end{array}$ \\
\hline & D & $020-$ & $\begin{array}{l}\text { Why, why is Jim became motorcycle } \\
\text { gang? (Good question! Because Jim is } \\
\text { angry.) }\end{array}$ \\
\hline & & & Why? [laughter] \\
\hline & D & & $\begin{array}{l}\text { Why is, why is he angry? (He's angry } \\
\text { at his mother.) }\end{array}$ \\
\hline & A & $20-024$ & $\begin{array}{l}\text { Mother. Jim is, ah, Jim is Tina's, } \\
\text { Tina's children? (Yes.) }\end{array}$ \\
\hline & A & $020-025$ & $\begin{array}{l}\text { OK. Mm - um, Peter and John } \cdot \mathrm{mm} \text {. } \\
\text { already go to Tina's /wur/? } \\
\text { Tina's what?) }\end{array}$ \\
\hline & A & $020-026$ & $\begin{array}{l}\text { What. He /wo/ . he, she, she, Tina's } \\
\text { work is waitre - waiter? (Waitress,) } \\
\text { Waitress. So (at a restaurant.) } \\
\text { Restaurant. Ss } \ldots \text { mm . (I - go } \\
\text { ahead) }\end{array}$ \\
\hline & D & $020-027 a$ & $\begin{array}{l}\text { Jim - Who is Jim's father? } \\
\text { Peter is Jim's father? (No.) }\end{array}$ \\
\hline & & $020-027 b$ & $\begin{array}{l}\text { Jim - Who is Jim's father? } \\
\text { Peter is Jim's father? (No.) }\end{array}$ \\
\hline & A & $020-028$ & $\begin{array}{l}\text { Jim - Who is Jim's father? } \\
\text { Peter is Jim's father? (No.) } \\
\text { John? (Yes.) }\end{array}$ \\
\hline
\end{tabular}


OK 020-029 OK. ... (More questions?)

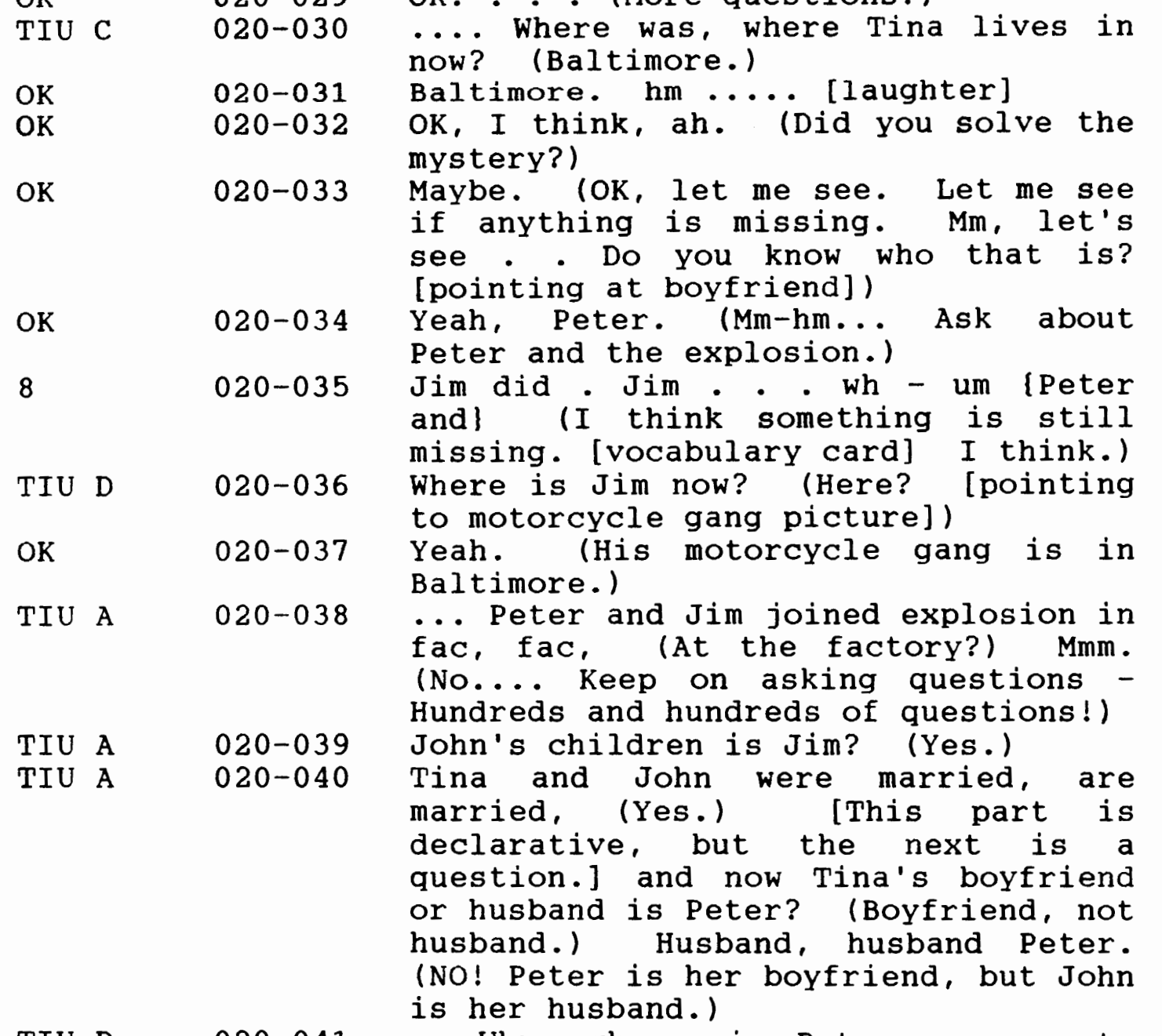

TIU D 020-041 .. Why, why . is Peter . . go to bank? (Ah, um, because he wants to put some money in the bank. He's trying to save money, etc.l

TIU C 020-042 Why, who, why, why - why John's factory explosion? /akura/ why, why - . mm (Explosion?) Yeah. (Because Peter made the explosion. Mm-hm.)

TIU A 020-043 Isss, is Peter. mm Peter is um, professional of bomb?

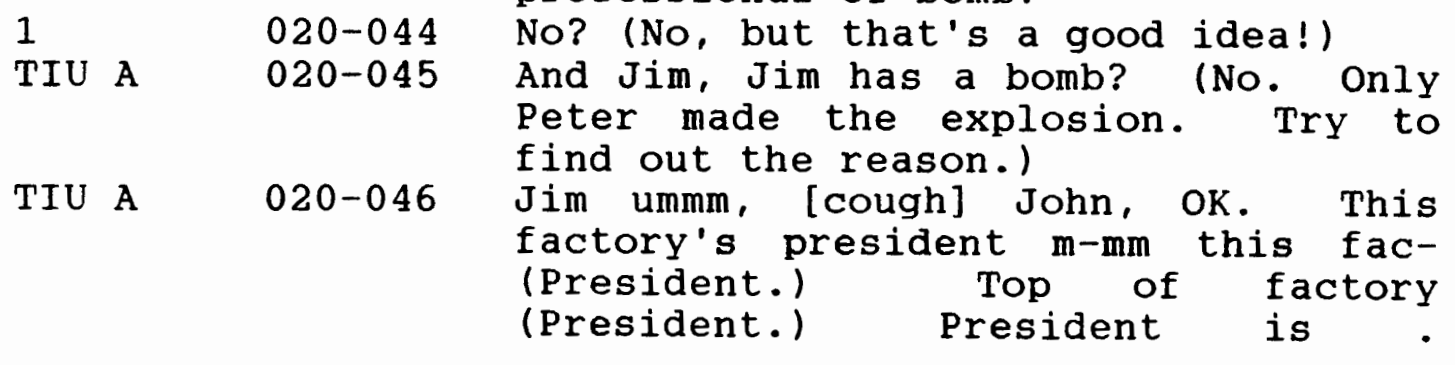




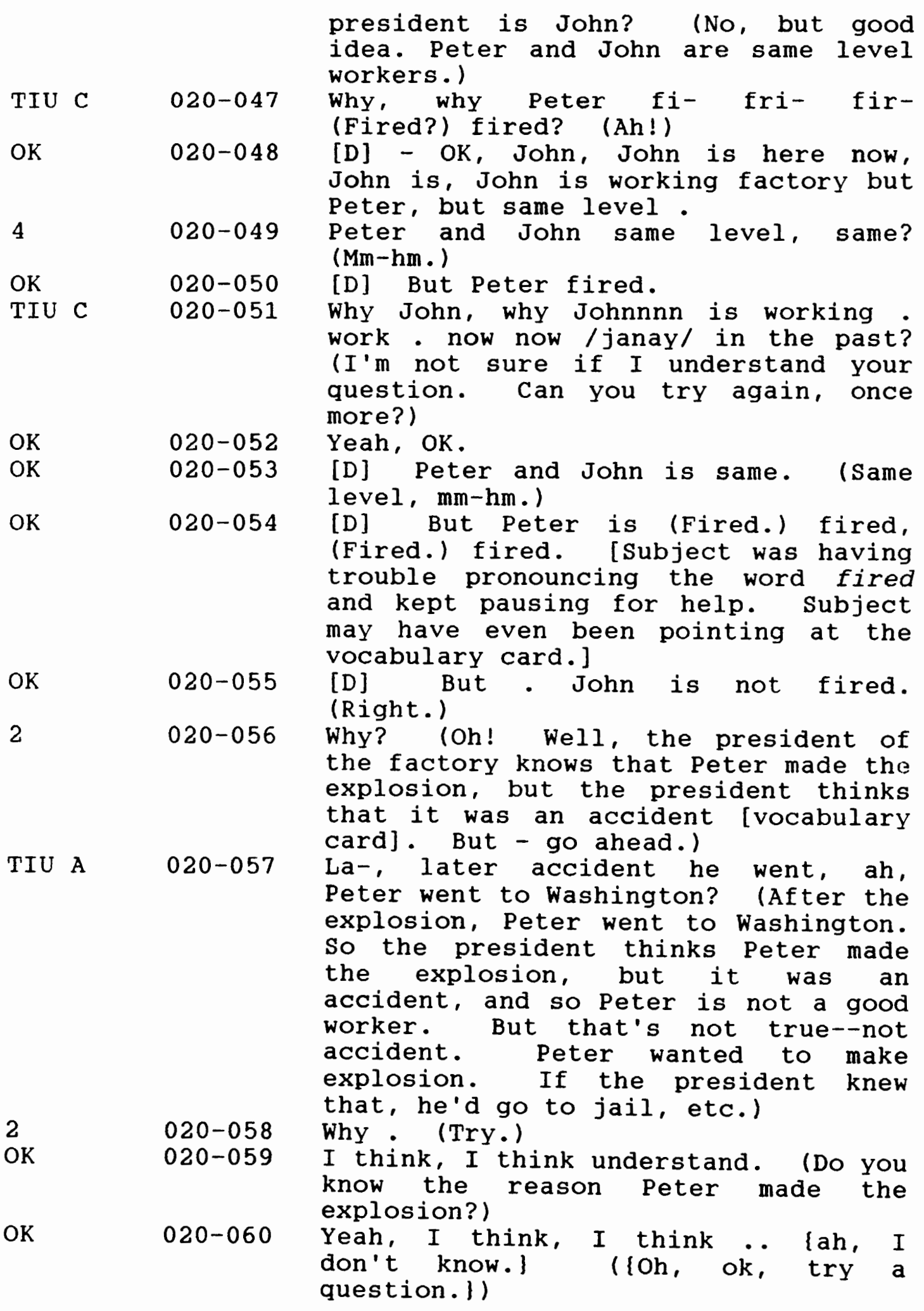


OK

OK

OK

OK

OK

OK

OK

OK

OK

7

8

TIU D 020-072

TIU D $\quad 020-073$

TIU A

TIU A

TIU A

OK
020-061

$020-062$

$020-063$

020-064

020-065

$020-066$

020-067

020-068

020-069

020-070

020-071

020-075

020-076

020-077
20-074
\{OK\} - mm ah, [D] Peter likes Tina, but ah, so, and but Tina is John's ah, Tina is John- oh-oh, John is (Tina is John's wife?) Tina is John's wife.

[D] So Peter and John fight. (Mmm yeah. Peter doesn't like John, but John doesn't know about Tina and Peter.)

[D] OK, OK, . Peter .. Peter want,

Peter want Tina $(\mathrm{Mm}-\mathrm{hm}$.$) , so Peter$ think John, John is . um . Peter think . To marry Tina, Peter think John killed. So Peter (Made the explosion.) made explosion. (Yes, he tried to kill John.) [All this part is declarative.]

(I think you understand.)

Understand. loK, ready for one more?)

[Interviewer gives basic information for second story.]

(Do you know kidnap?) [vocabulary card]

OK. (OK? Many, many questions, please!)

[End of basic information.]

[? is five, five picture. ?? [What the subject said is not at all clear on the tape, but this is what it may have been.]

Patty. Why, . (Don't think a lot, OK? Just speak a lot!) [The subject was trying to puzzle it out without asking many questions.]

Oh, oh OK. Tommmm. . Why, why is sue more drink usual yesterday? (Mm-hm, yesterday she drank a lot because she was sad, etc.l

Why is sue sad? (Because she got a phone call from her boyfriend.)

Tom is Sue's boyfriend? (Yes.)

- Tom, Tom and Sue kidnap. Tom and Sue um kidnapped Patty? (No.)

Tom, Tom did. . Tom kidnapped Patty? (No. Tom did not know about the kidnapping.)

[D]. - Why . I think now sue is very happy so, he drink only orange juice. (Mmmm, please ask a question; no.) 


\begin{tabular}{|c|c|c|c|}
\hline IIU & & $020-078$ & $\begin{array}{l}\text { Why, why why why is is sue drink } \\
\text { umm only orange juice? (Because she } \\
\text { drank too much, and so now she has a } \\
\text { headache, etc.) }\end{array}$ \\
\hline TIU & B & $020-079$ & $\begin{array}{l}\text { Is sue um university student? } \\
\text { (Yeah.) }\end{array}$ \\
\hline 1 & & $020-080$ & $\begin{array}{l}\text { Same, University of California? } \\
\text { (Yes.) }\end{array}$ \\
\hline TIU & A & $020-081$ & $\begin{array}{l}\mathrm{mm} \text { Californ - Los Angeles equal } \\
\text { California? Uh? (Mm, this is } \\
\text { California, all of this is } \\
\text { California, and this city is Los } \\
\text { Angeles. [pointing on map] Mm-hm.) }\end{array}$ \\
\hline IU & $\mathrm{C}$ & $020-082$ & $\begin{array}{l}\text { Sue, Sue and Tom - why, ah, why } \\
\text { mom, Tom have, Tom has a big } \\
\text { money? (Because the customers went }\end{array}$ \\
\hline & & & $\begin{array}{l}\text { from San Francisco to Los Angeles, } \\
\text { very long, etc. And a tip. Do you } \\
\text { know tip? [s: Yes.] So now he has a } \\
\text { lot of money.) }\end{array}$ \\
\hline OK & & $020-083$ & $\begin{array}{l}\text { [This question is repeated below, } \\
\text { verbatim, so is not counted here.]. } \\
\text {. Why, ah, why, why is. why does, } \\
\text { why did Patty d um . (steal?) } \\
\text { steal? [big crackling sound from the } \\
\text { tape recorder] (what happened?) }\end{array}$ \\
\hline 1 & & $020-084$ & $\begin{array}{l}\text { Broken? (I think it's oK. Keer } \\
\text { hoping. oK, pardon me?) }\end{array}$ \\
\hline TIU & D & 020 & $\begin{array}{l}\text { Why did patty steal the money? (The } \\
\text { bad guys forced her to steal it, } \\
\text { etc.) }\end{array}$ \\
\hline IU & A & $020-086$ & $\begin{array}{l}\text { OK. Sue and, sue and Patty ar } \\
\text { friends? }\end{array}$ \\
\hline & & & No? (Sue does not know Patty, etc.) \\
\hline שדת & B & & $\begin{array}{l}\text { And is, is Tom know Patty? (Um, not } \\
\text { before, but Tom met Patty yesterday.) }\end{array}$ \\
\hline 9 & & $020-089$ & $\begin{array}{l}\text { /mæt? / (Hello, how are you, glad } t \\
\text { meet you, etc.) }\end{array}$ \\
\hline & & $020-0$ & $\begin{array}{l}\dot{\text { drives }} \text { Tom's car? } \\
\text { who, who, whoooo wh }\end{array}$ \\
\hline 6 & & $020-090 \mathrm{~b}$ & $\begin{array}{l}\text { Who ride, who ride Tom's taxi? (Good } \\
\text { question. The two bad guys and } \\
\text { Patty.) }\end{array}$ \\
\hline [IU & B & $020-091$ & $\begin{array}{l}\text { OK. But Tom know, is [someone comes } \\
\text { to door and interrupts for a few } \\
\text { seconds.] Tom is, is Tom know bad } \\
\text { guys? (No.) }\end{array}$ \\
\hline & & 020 & $\begin{array}{l}\text { No? (Well, he met them yesterday i } \\
\text { his taxi, but Tom did not know abou } \\
\text { the kidnapping.) }\end{array}$ \\
\hline
\end{tabular}


TIU D 020-093 mm I think $\{O K\} \cdot$. Why, why does she sad yesterday? (Sue?)

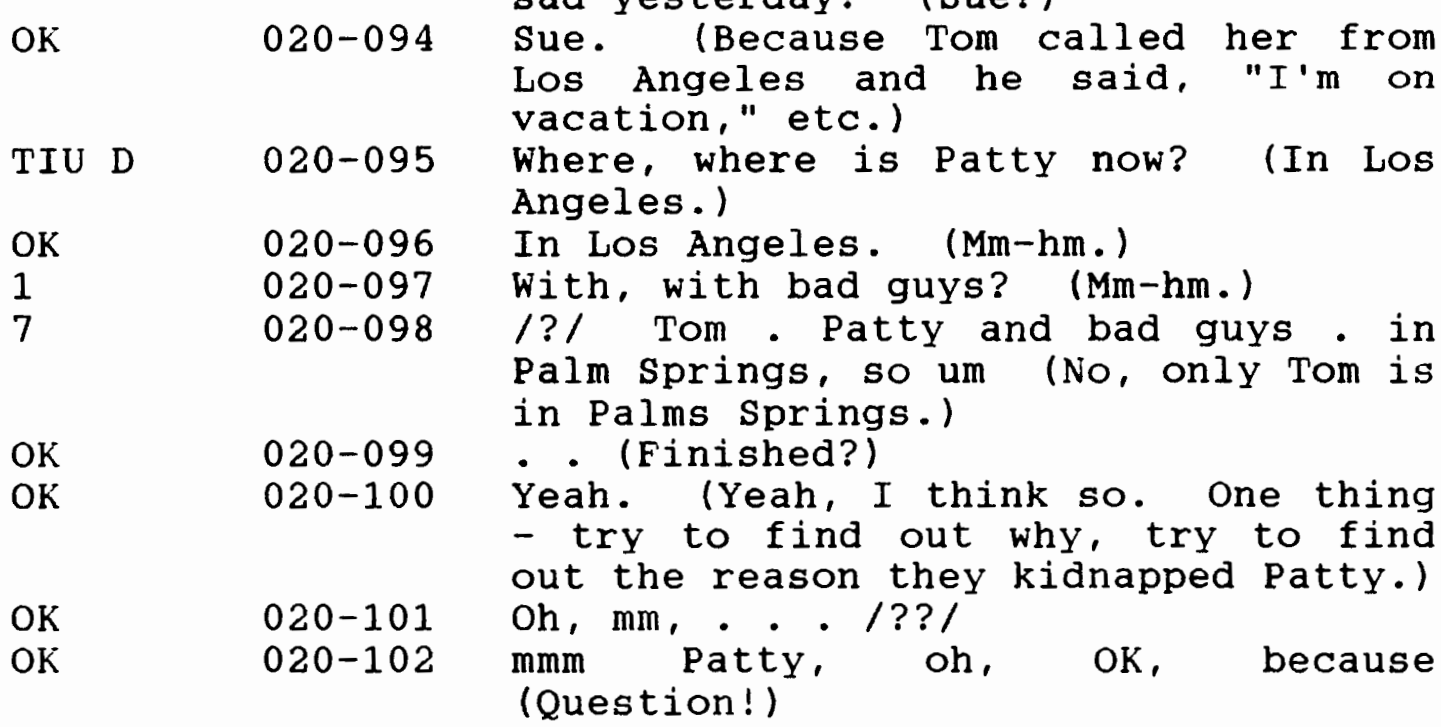

TIU D 020-103 Question. Why. Why is kidnap . Why, why did bad guys, bad guys kidnap Patty? (Because her father is rich, and they wanted ransom money, [vocabulary card] etc.)

TIU A 020-104 Ah. He, Patty, Patty's father is rich? (Mm-hm.)

TIU A 020-105 Umm, but she, bad guys said, he must, he must steal money (Mm-hm.) at bank? (Yes.)

TIU C 020-106 Hm.. [D] Bank's money is not ransom money. Why, why he, why bad guy said you must steal money at bank? (Two reasons - they want a lot of money and they want to show that Patty is alive, etc.l

\begin{tabular}{|c|c|c|}
\hline TIU D & $020-107$ & $\begin{array}{l}\text { Where is Patty's home? (In san } \\
\text { Francisco.) }\end{array}$ \\
\hline TIU & $020-108$ & $\begin{array}{l}\text { So, OK, um, bad guys went to Los } \\
\text { Angeles? (Yes.) }\end{array}$ \\
\hline 1 & $020-109$ & with Patty? (Mm-hm.) \\
\hline TIU D & $020-110$ & Where is bank? (In Los Angeles.) \\
\hline OK & $020-111$ & $\begin{array}{l}\text { I see. (I think you found } \\
\text { everything. Do you understand the }\end{array}$ \\
\hline OK & $020-112$ & $\begin{array}{l}\text { [Subject nods.] } \\
\text { lGood job! }\end{array}$ \\
\hline & & detective. Thank you! etc.) \\
\hline
\end{tabular}

